
EFFECT OF A TEMPERATURE CYCLE ON A ROTATING ELASTIC-PLASTIC SHAFT

A THESIS SUBMITTED TO

THE GRADUATE SCHOOL OF NATURAL AND APPLIED SCIENCES

$\mathrm{OF}$

MIDDLE EAST TECHNICAL UNIVERSITY

BY

ERAY ARSLAN

IN PARTIAL FULFILLMENT OF THE REQUIREMENTS

FOR

THE DEGREE OF DOCTOR OF PHILOSOPHY

IN

ENGINEERING SCIENCES

JANUARY 2010 
Approval of the thesis:

\section{EFFECT OF A TEMPERATURE CYCLE ON A ROTATING ELASTIC-PLASTIC SHAFT}

submitted by ERAY ARSLAN in partial fulfillment of the requirements for the degree of Doctor of Philosophy in Engineering Sciences Department, Middle East Technical University by,

Prof. Dr. Canan Özgen

Dean, Graduate School of Natural and Applied Sciences

Prof. Dr. Turgut Tokdemir

Head of Department, Engineering Sciences

Prof. Dr. Ahmet N. Eraslan

Supervisor, Engineering Sciences Department, METU

\section{Examining Committee Members:}

Prof. Dr. Tülay Özbelge

Chemical Engineering Dept., METU

Prof. Dr. Ahmet N. Eraslan

Engineering Sciences Dept., METU

Prof. Dr. M. Polat Saka

Engineering Sciences Dept., METU

Assoc. Prof. Dr. Zafer Evis

Engineering Sciences Dept., METU

Asst. Prof. Dr. A. Hakan Argeşo

Manufacturing Engineering Dept., Atılım University

Date: January 28, 2010 
I hereby declare that all information in this document has been obtained and presented in accordance with academic rules and ethical conduct. I also declare that, as required by these rules and conduct, I have fully cited and referenced all material and results that are not original to this work.

Name, Last Name: ERAY ARSLAN

Signature 


\begin{abstract}
EFFECT OF A TEMPERATURE CYCLE ON A ROTATING ELASTIC-PLASTIC SHAFT
\end{abstract}

\author{
Arslan, Eray \\ Ph.D., Department of Engineering Sciences \\ Supervisor : Prof. Dr. Ahmet N. Eraslan
}

January 2010, 161 pages

The stress distribution in a rotating solid shaft with temperature dependent yield stress subject to a temperature cycle is investigated. It is presumed that the shaft is in a state of generalized plane strain and obeys Tresca's yield criterion and the flow rule associated with it. By the temperature cycle it is meant that the surface temperature of the shaft is increased to a limiting value, it is held at this temperature for a while, and then slowly decreased at the same rate to the reference temperature. The isothermal shaft is rotated up to around elastic limit rotation speed and then the temperature cycle is applied to the surface of the shaft. Even in an initially purely elastic shaft, two plastic regions with different forms of the yield condition emerge simultaneously at the centre and expand into the elastic region. However, the expansion of the plastic zone ceases soon thereafter, and an unloaded region spreads into the plastic core. It is shown that the stress distribution is altered significantly by the temperature cycle, hence also leading to non-zero residual stresses at stand-still.

Keywords: Rotating shaft, temperature cycle, elastoplasticity, Tresca's criterion 


\title{
ÖZ
}

\section{SICAKLIK ÇEVRIMIINİN DÖNEN ELASTİK-PLASTİK MİL ÜZERİNDEKİ ETKİİ}

\author{
Arslan, Eray \\ Doktora, Mühendislik Bilimleri Bölümü \\ Tez Yöneticisi : Prof. Dr. Ahmet N. Eraslan
}

Ocak 2010, 161 sayfa

Sıcaklık çevrimi uygulanan, sıcaklığa bağlı akma gerilmesine sahip malzemeden yapılmış dönen bir mildeki gerilim dağılımı incelenmiştir. Düzlem şekil değiştirme koşulu ve mil malzemesinin Tresca akma kriteri ve ilgili akma kuralına uygun olduğu varsayılmaktadır. Sıcaklık çevrimi, milin yüzey sıcaklığının bir limit değerine kadar artırılması, bu sıcaklıkta bir süre tutulması ve referans sıcaklığına aynı oranda azaltılması olarak tanımlanmıştır. İzotermal mil elastik limit dönme hızı civarına kadar döndürülmekte ve daha sonra milin dış yüzeyine sıcaklık çevrimi uygulanmaktadır. Bu durumda, başlangıçta tamamiyle elastik davranan milin merkezinde farklı akma koşullarına sahip iki plastik bölge aynı anda ortaya çıkmakta ve bu plastik bölgeler elastik bölgeye doğru genişlemektedir. Fakat bir süre sonra plastik bölgenin genişlemesi sona ermekte ve boşaltma bölgesi (unloading region) plastik merkeze doğru yayılmaktadır. Sonuç olarak mildeki gerilim dă̆glımı, sıcaklık çevrimiyle önemli ölçüde değişmekte ve bu da milde artık gerilmelerin (residual stresses) oluşmasına sebep olmaktadır.

Anahtar Kelimeler: Dönen mil, sıcaklık çevrimi, elastoplastisite, Tresca akma kriteri 
To My Family and Prof. Werner Mack 


\section{ACKNOWLEDGMENTS}

I wish to express my deepest gratitude to my advisor Prof. Dr. Ahmet N. Eraslan and Prof. Dr. Werner Mack (Vienna University of Technology, Austria) for their guidance, advice, criticism, and insight throughout this study.

I am also indebted to Prof. Dr. Udo Gamer (Vienna University of Technology, Austria) for many helpful discussions.

I owe special thanks to my advisory committee members Prof. Dr. M. Polat Saka and Prof. Dr. Tülay Özbelge and examining committee members Assoc. Prof. Dr. Zafer Evis and Asst. Prof. Dr. A. Hakan Argeşo for their remarkable suggestions and comments.

I would also like to thank Prof. Dr. M. Ruşen Geçit for his helpful advices and guidance.

I wish to extend my thanks to my roommate Baran Aydın for his useful discussions and friendship, and to Academic Writing Center of METU for their collaborative effort at the grammatical supervision of the study.

Finally, the biggest thanks go to my parents, my brothers and the most special person in my life Pelin Yüksel for their endless love, patience, support and encouragement.

This study was financially supported by the State Planning Organization (DPT) Grant No: BAP-08-11-DPT2002K120510. 


\section{TABLE OF CONTENTS}

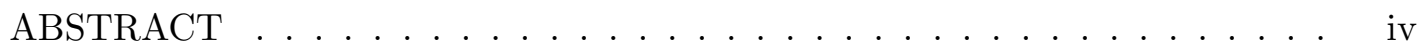

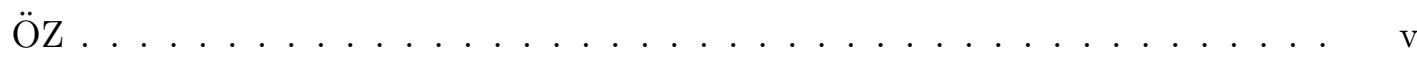

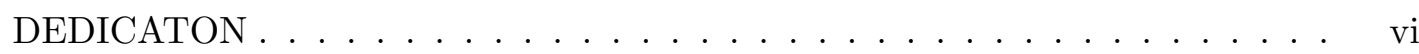

ACKNOWLEDGMENTS ............................... vii

TABLE OF CONTENTS . . . . . . . . . . . . . . . . . viii

LIST OF TABLES . . . . . . . . . . . . . . . . . . . x xi

LIST OF FIGURES . . . . . . . . . . . . . . . . . . . . . xii

CHAPTERS

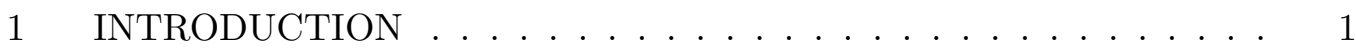

$1.1 \quad$ General Aspects . . . . . . . . . . . . . . . . . . . 1

$1.2 \quad$ Related Literature . . . . . . . . . . . . . . . . . 1

1.2.1 Rotating Cylindrical Elements without Thermal Loading ..................... 2

1.2.2 Cylindrical Elements under Thermal Load . . . . . . 4

1.2.3 Rotating Cylindrical Elements under Thermal Load . 6

$1.3 \quad$ Scope of the Present Work . . . . . . . . . . . . . . 7

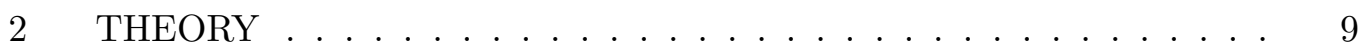

2.1 The Stress-Strain Relation _. . . . . . . . . . . . . 9

$2.2 \quad$ Criteria of Yielding . . . . . . . . . . . . . . 11

2.2.1 Von Mises' Yield Criterion . . . . . . . . . . . 11

2.2.2 Tresca's Yield Criterion _............ 11

$2.3 \quad$ Flow Rule Associated with Yield Criteria . . . . . . . . . . . 13

2.3.1 Flow Rule Associated with Tresca Yield Function . . 15 
3 STATEMENT OF THE PROBLEM AND TEMPERATURE FIELD . 17

$3.1 \quad$ Statement of the Problem . . . . . . . . . . . . . 17

$3.2 \quad$ Temperature Field . . . . . . . . . . . . . . . . . . 18

4 BASIC EQUATIONS AND ANALYTICAL SOLUTIONS OF ELASTIC AND PLASTIC REGIONS . . . . . . . . . . . . . . . 22

$4.1 \quad$ Basic Equations . . . . . . . . . . . . . . . 22

$4.2 \quad$ Elastic Region . . . . . . . . . . . . . . . . 23

$4.3 \quad$ Plastic (Edge Regime) Region I . . . . . . . . . . . . . 26

$4.4 \quad$ Plastic (Side Regime) Region II _ . . . . . . . . . . . . . . 29

$4.5 \quad$ Predeformed Elastic Region _... . . . . . . . . . . . . 34

5 EVOLUTION OF STRESSES DURING TEMPERATURE CYCLE . 37

$5.1 \quad$ Purely Elastic State . . . . . . . . . . . . . . . . 37

$5.2 \quad$ Elastic-Plastic State . . . . . . . . . . . . . . . 38

$5.3 \quad$ Unloaded State . . . . . . . . . . . . . . . . . . . 40

6 RESULTS AND DISCUSSION . . . . . . . . . . . . . 43

$6.1 \quad$ Non-Dimensional and Normalized Quantities . . . . . . . . . 43

$6.2 \quad$ Numerical Results . . . . . . . . . . . . . . . . . . . . . 44

$6.3 \quad$ Summary and Discussion . . . . . . . . . . . . . . . 111

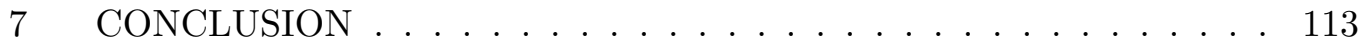

REFERENCES . . . . . . . . . . . . . . . . . . . . . . 114

APPENDICES

A DESCRIPTION OF FORTRAN CODES . . . . . . . . . . . . 119

B FORTRAN CODES OF PURELY ELASTIC STATE . . . . . . . . 123

B.1 MAIN PROGRAM: PURELY ELASTIC STATE . . . . . 123

B.2 SUBROUTINE: TEMPERATURE DISTRIBUTION $\ldots \ldots$.

B.3 FUNCTION: TEMPERATURE . . . . . . . . . . . . . 128

B.4 FUNCTION: TEMPERATURE INTEGRAL $1 \ldots \ldots$

B.5 FUNCTION: SERIES $1 \ldots \ldots \ldots \ldots$

B.6 FUNCTION: SERIES $2 \ldots \ldots \ldots \ldots \ldots$ 
C FORTRAN CODES OF ELASTIC-PLASTIC STATE . . . . . . . . . . . 134

C.1 MAIN PROGRAM: ELASTIC-PLASTIC STATE . . . . . . . . 134

C.2 SUBROUTINE: NLNEQN . . . . . . . . . . . . . . . . . . . . 140

C.3 SUBROUTINE: PLASTIC REGION I . . . . . . . . . . . . . . 144

C.4 SUBROUTINE: PLASTIC REGION II. . . . . . . . . . . . . . . 145

C.5 SUBROUTINE: ELASTIC REGION . . . . . . . . . . . . . 147

C.6 FUNCTION: TEMPERATURE INTEGRAL $2 \ldots \ldots \ldots \ldots$

C.7 FUNCTION: SERIES $3 \ldots \ldots$. . . . . . . . . . . . . . . . 150

C.8 FUNCTION: HYPERGEOMETRIC FUNCTION . . . . . . . . 152

D FORTRAN CODES OF UNLOADED STATE . . . . . . . . . . . . . . . . 154

D.1 MAIN PROGRAM: UNLOADED STATE . . . . . . . . . . . . . 154

D.2 DATA FILE: PERMANENT PLASTIC STRAINS . . . . . . . . 159

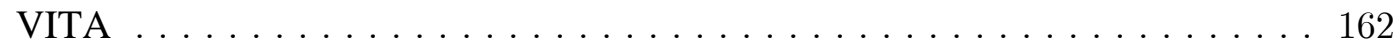




\section{LIST OF TABLES}

\section{TABLES}

Table 6.1 Calculated constants of $\bar{C}_{2}$ and $\bar{\epsilon}_{0}$ at different rotations speeds in purely elastic state . . . . . . . . . . . . . . . . . 46

Table 6.2 Calculated constants of $\bar{C}_{2}$ and $\bar{\epsilon}_{0}$ versus time in purely elastic state 58

Table 6.3 Calculated constants in elastic-plastic state at different time values . $\quad 67$

Table 6.4 Calculated constants in unloaded state at different time values until the end of the temperature cycle . . . . . . . . . . . 86

Table 6.5 Calculated constants in unloaded state at different time values after

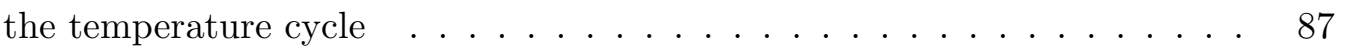

Table 6.6 Differences in response variables between the beginning and the end

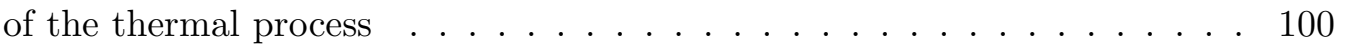

Table D.1 Permanent plastic strains at $\tau \geq 1.7882 \ldots \ldots \ldots \ldots$ 


\section{LIST OF FIGURES}

\section{FIGURES}

Figure 1.1 Categories of the studies in the literature . . . . . . . . . . . 2

Figure 2.1 Stress-strain Diagram . . . . . . . . . . . . . . . . . . . . . . . . 10

Figure 2.2 Tresca's hexagon with yielding conditions on three-dimensional principal stress space . . . . . . . . . . . . . . . . . . . 12

Figure 3.1 Sketch of the rotating solid shaft subjected to temperature cycle . . 18

Figure 3.2 Prescribed surface temperature of the shaft $\ldots \ldots \ldots$

Figure 3.3 Description of surface temperature with linear function . . . . . . . 20

Figure 6.1 Prescribed surface temperature of the shaft $(x=1) \ldots \ldots$

Figure 6.2 Transient temperature field at $\tau \leq 1.2 \ldots \ldots \ldots$. . . . . . . 47

Figure 6.3 Transient temperature field at $1.2 \leq \tau \leq 1.5 \ldots \ldots \ldots$. . . . . 48

Figure 6.4 Transient temperature field at $1.5 \leq \tau \leq 2.7 \ldots \ldots$. . . . . . 49

Figure 6.5 Transient temperature field at $2.7 \leq \tau \leq 3.0 \ldots \ldots \ldots$. . . . 50

Figure 6.6 Transient temperature field at $3.0 \leq \tau \leq 3.6 \ldots \ldots \ldots$. . . . . 51

Figure 6.7 Change of temperature difference between outer surface and the center of the shaft with time . . . . . . . . . . . . . 52

Figure 6.8 Radial stress distribution in the shaft with increasing rotation speed 53

Figure 6.9 Circumferential stress distribution in the shaft with increasing rota-

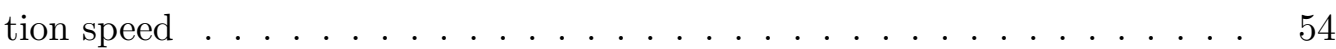

Figure 6.10 Axial stress distribution in the shaft with increasing rotation speed $\quad 55$

Figure 6.11 Radial displacement distribution in the shaft with increasing rotation

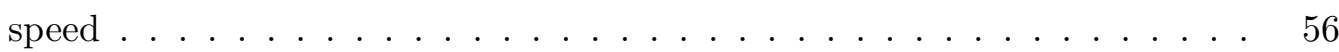


Figure 6.12 Stresses and radial displacement distributions in purely elastic state

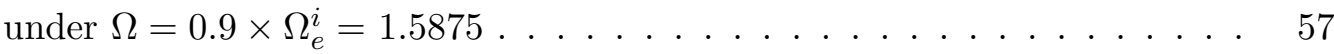

Figure 6.13 Ratio of equivalent and yield stresses at different time until plastic

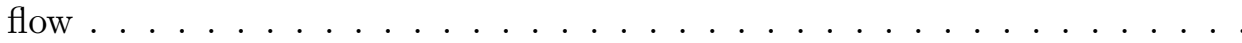

Figure 6.14 Change of ratio of equivalent and yield stresses with time until plastic flow at the center . . . . . . . . . . . . . . 60

Figure 6.15 Radial stress distribution at different time steps in purely elastic state 61 Figure 6.16 Circumferential stress distribution at different time steps in purely elastic state . . . . . . . . . . . . . . . . . . .

Figure 6.17 Axial stress distribution at different time steps in purely elastic state 63

Figure 6.18 Radial displacement distribution at different time steps in purely

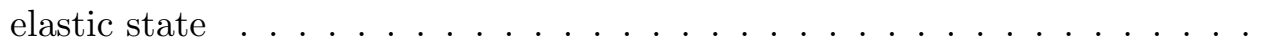

Figure 6.19 Stresses and radial displacement distributions in purely elastic state

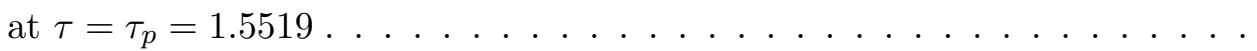

Figure 6.20 Evolutions of plastic tangential strain component with time at $x=0$ and $x=x_{1} \ldots \ldots \ldots \ldots \ldots \ldots \ldots \ldots \ldots \ldots \ldots \ldots \ldots \ldots \ldots \ldots$

Figure 6.21 Evolutions of derivative of plastic tangential strain with time at

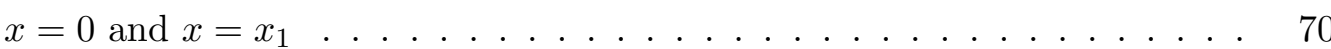

Figure 6.22 Evolution of interface radius $x_{2}$ with time $\ldots \ldots \ldots 71$

Figure 6.23 Evolution of derivative of $x_{2}$ with respect to time $\ldots \ldots \ldots 72$

Figure 6.24 Stresses and radial displacement distributions in elastic-plastic state

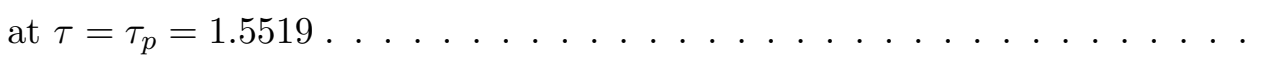

Figure 6.25 Stresses and radial displacement distributions in elastic-plastic state

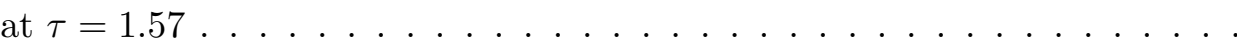

Figure 6.26 Stresses and radial displacement distributions in elastic-plastic state

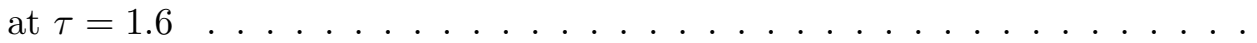

Figure 6.27 Stresses and radial displacement distributions in elastic-plastic state

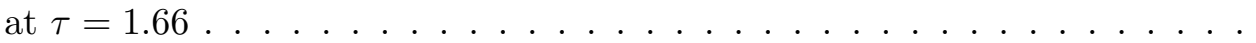

Figure 6.28 Stresses and radial displacement distributions in elastic-plastic state

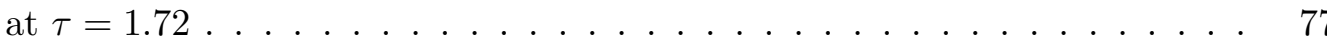


Figure 6.29 Stresses and radial displacement distributions in elastic-plastic state

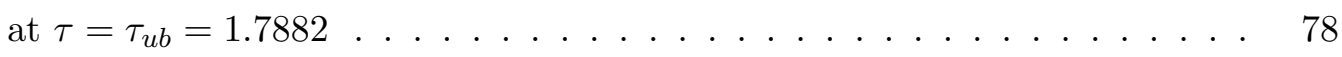

Figure 6.30 Plastic strain distributions in elastic-plastic state at $\tau=1.57 \ldots \quad . \quad 79$

Figure 6.31 Plastic strain distributions in elastic-plastic state at $\tau=1.6 \quad \ldots \quad 80$

Figure 6.32 Plastic strain distributions in elastic-plastic state at $\tau=1.66 \ldots \quad$. . 81

Figure 6.33 Plastic strain distributions in elastic-plastic state at $\tau=1.72 \ldots . \quad 82$

Figure 6.34 Plastic strain distributions in elastic-plastic state at $\tau=\tau_{u b}=1.788283$

Figure 6.35 Evolution of plastic regions with time . . . . . . . . . . . . . . 84

Figure 6.36 Evolution of the ratio of equivalent and yield stresses with time for three different radii after assumed sudden unloading $\ldots \ldots . . . . .85$

Figure 6.37 Stresses and radial displacement distributions in unloaded state at

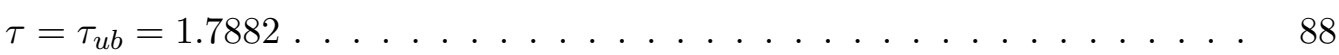

Figure 6.38 Stresses and radial displacement distributions in unloaded state at

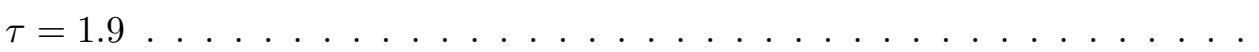

Figure 6.39 Stresses and radial displacement distributions in unloaded state at

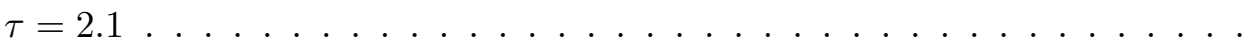

Figure 6.40 Stresses and radial displacement distributions in unloaded state at

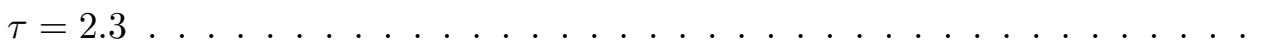

Figure 6.41 Stresses and radial displacement distributions in unloaded state at $\tau=2.5 \ldots \ldots \ldots \ldots \ldots \ldots \ldots \ldots \ldots \ldots \ldots \ldots \ldots \ldots \ldots \ldots \ldots$

Figure 6.42 Stresses and radial displacement distributions in unloaded state at $\tau=2.7 \ldots \ldots \ldots \ldots \ldots \ldots \ldots \ldots \ldots \ldots \ldots \ldots \ldots \ldots \ldots \ldots \ldots$

Figure 6.43 Stresses and radial displacement distributions in unloaded state at $\tau=3.0 \ldots \ldots . \cdots$

Figure 6.44 Stresses and radial displacement distributions in unloaded state at

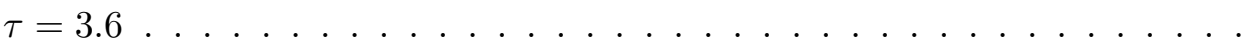

Figure 6.45 Stresses and radial displacement distributions in unloaded state at

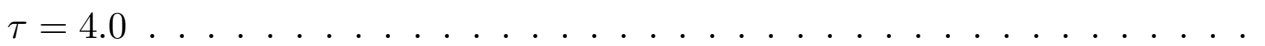

Figure 6.46 Stresses and radial displacement distributions in unloaded state at

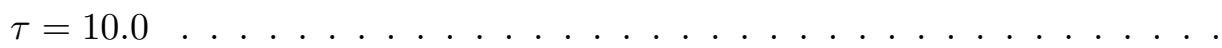


Figure 6.47 Stresses and radial displacement distributions in unloaded state at

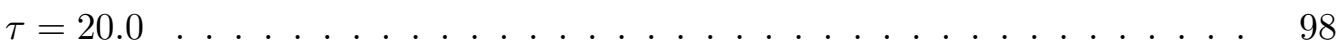

Figure 6.48 Evolution of the radial stress at the center of the shaft . . . . . . 99

Figure 6.49 Evolution of the tangential stress on the outer surface of the shaft . 102

Figure 6.50 Evolution of the axial stress at the center of the shaft . . . . . . . 103

Figure 6.51 Evolution of the axial stress on the outer surface of the shaft . . . . 104

Figure 6.52 Evolution of the radial displacement on the outer surface of the shaft 105

Figure 6.53 Ratio of equivalent and yield stresses at different time in the unloaded state . . . . . . . . . . . . . . . . . 106

Figure 6.54 Change of ratio of equivalent and yield stresses at the center with time in the unloaded state . . . . . . . . . . . . . . . . 107

Figure 6.55 Approximate residual stress distribution at stand-still $(\Omega=0)$ after cooling . . . . . . . . . . . . . . . . . . . 108

Figure 6.56 Stress field in the rotating shaft mapped onto the deviatoric plane of the principal stress space (sketch) at $(a) \tau=\tau_{p}$, (b) $\tau_{p}<\tau<\tau_{u b},(c)$ $\tau=\tau_{u b},(d) \tau>\tau_{u b} \ldots \ldots \ldots \ldots \ldots$. . . . . . . . . . . . . . . . . . . .

Figure 6.57 Evolution of elastic, plastic and predeformed elastic regions on the cross section of the shaft at different times . . . . . . . . . . . 110 


\section{CHAPTER 1}

\section{INTRODUCTION}

\section{$1.1 \quad$ General Aspects}

Rotating shafts are commonly used in most of the engineering applications to transmit power [1]-[3]. In some cases, such shafts are also exposed to nonuniform heating [4]. Hence, it is of engineering interest to an economical design of rotating transmission shafts. Due to the trend to utilize the material up to its limits, the deformation behavior of rotating shafts must carefully be analyzed in elastic and elastic-plastic ranges.

Rotating shafts that exhibit purely elastic behavior may undergo plastic deformation when subjected to an inhomogeneous temperature field. This is caused by the additional stress due to the temperature gradient and by softening of the material due to transient heating [5]. The latter effect may cause plasticization even for homogeneous heating. Indeed, rotating elastic-plastic cylindrical elements that are also subjected to thermal loads have received attention in the literature $[2]-[5]$.

\subsection{Related Literature}

Investigations on this topic in the literature can be classified into three categories (See Figure 1.1). The studies that are related to the elastic and elastic-plastic behavior of rotating cylindrical elements constitute the first category. The second category includes the studies concerned with analysis of cylindrical elements which are subjected to merely thermal loading. The works that represent the solution for cylindrical ele- 
ments under mechanical and thermal loads together form the third category.

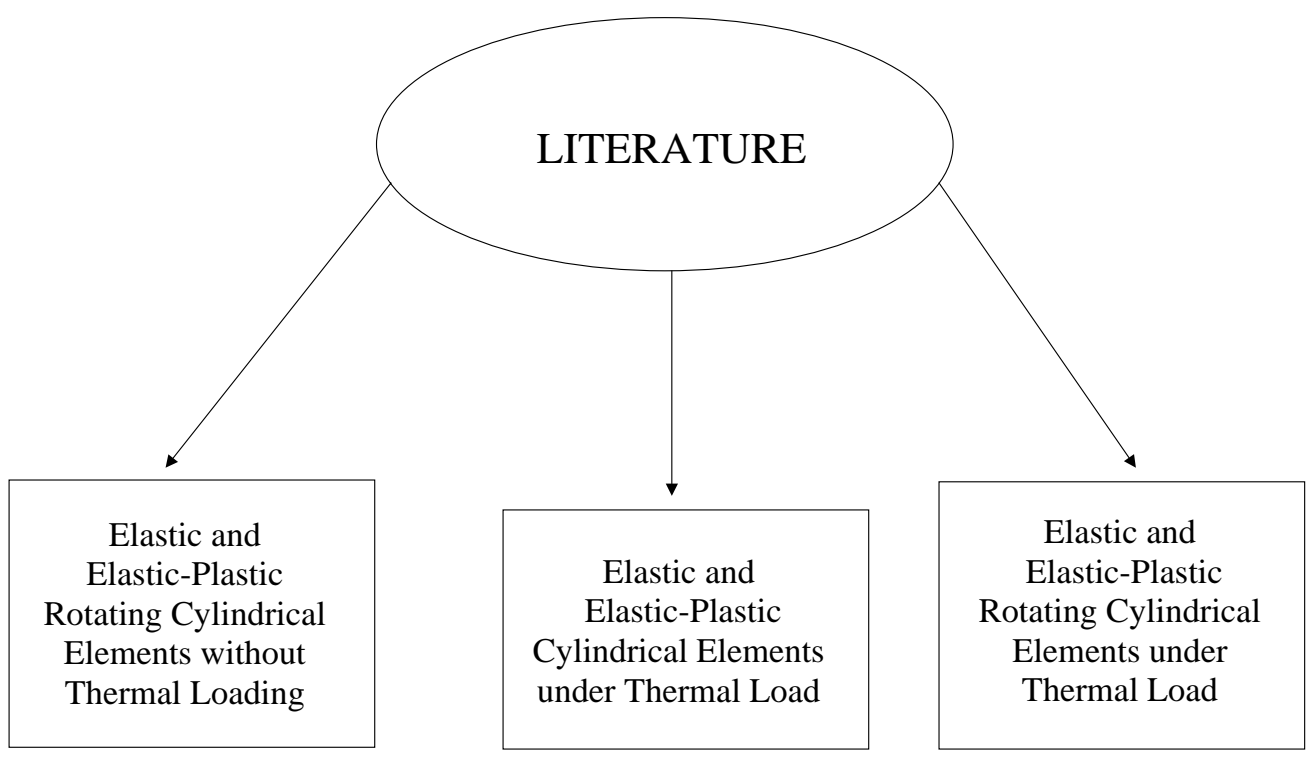

Figure 1.1: Categories of the studies in the literature

\subsubsection{Rotating Cylindrical Elements without Thermal Loading}

A comprehensive treatment of the rotating cylindrical elements in the elastic state of stress was presented by Timoshenko and Goodier [1]. They derived basic equations for the rotating solid and hollow disk problems, and obtained a solution for purely elastic state. In 1950, the deformation behavior beyond the elastic limits for rotating perfectly plastic cylinders was firstly treated by Nadai [6]. He considered that only one plastic region, which is an edge regime of Tresca's hexagon in principal stress space, emerges at the center of the cylinder at elastic limit rotation speed. He obtained stresses for this region. However, he did not calculate radial displacement component and did not check the kinematical continuity at the interface of the elastic and plastic regions. Hence, in the solution, it was not noticed that the compatibility requirements are not satisfied. Davis and Conelly [7] solved the rotating fully plastic strain hardening solid and hollow shaft problems in 1959. Similar to Nadai's solution, they assumed that 
yielding occurs at the center of the rotating solid shaft with only one plastic region. In 1962, Hodge and Balaban [8] tried to solve the problem that was described by Nadai with more general conditions. However, plastic behavior in their work was based on the same plastic regime with Nadai. Lenard and Haddow [9] obtained instability speed for rotating solid cylinders. However, they also adopted same and wrong point of view as Nadai for plastic flow.

The common mistake that was made in the studies above was detected and corrected by Gamer and Sayir [10] in 1984. In their remarkable study, they explored that when yielding starts at the center of the rotating solid shaft in an edge regime of Tresca's hexagon in principal stress space, another plastic region in a side regime emerges simultaneously and these two regions spread together into the elastic region with the increasing rotation speed. With this solution, the necessary continuity requirement of the displacement field that fails in the Nadai's work was assured. Although all plastic and elastic regions were derived analytically in this investigation, more details concerning the latter process were presented by Gamer, Mack and Varga [11]. An analytical solution to the rotating elastic-perfectly plastic solid shaft with axially unconstrained ends was derived by Mack [12] in 1991. On the other hand, the residual stresses in a rotating elastic-perfectly plastic solid shaft with fixed ends, which means that the long tube is constrained at both ends in the axial direction with rigid plates, were obtained by Lindner and Mack in another work [13].

Gamer and Lance [14] obtained stresses and radial displacement in rotating linearly hardening hollow shaft with fixed ends in 1983. Mack [15] treated the problem of rotating elastoplastic hollow shaft with free ends in 1991. In his another study [16], he investigated the unloading and the secondary flow in a rotating elastic-plastic hollow cylinder.

Some studies related with the rotating strain hardening disks, where the plane stress state is assumed inversely to the shafts, are given below. Guven [17] obtained an exact solution for the rotating elastoplastic hyperbolic disk that is mounted on a rigid solid shaft. Eraslan and Orcan [18] solved the same problem analytically for the exponential concave profiles of a solid disk. Eraslan and Argeso [19] developed a computational model for rotating nonlinearly hardening solid disk of variable thickness. Eraslan [20] 
then obtained an analytical solution to lineraly hardening and a numerical solution to nonlinearly hardening rotating disks with an elliptical thickness profile.

The exact solutions for the elastic-plastic deformations of a rotating linearly strain hardening solid shaft were firstly obtained by Eraslan [21] in 2003. One year later, Eraslan [22] developed a computational model for rotating elastoplastic nonlinearly strain hardening shafts. Another computational study was performed for estimating residual stresses and secondary plastic flow limits in rotating nonlinearly hardening shafts by Eraslan and Mack [23] in 2005.

In 1999, Horgan and Chan [24] studied the deformations of a rotating linearly elastic disk and shaft made of Functionally Graded Material (FGM). FGMs are nonhomogeneous but isotropic materials. In their composition, physical properties vary throughout the material. In Horgan and Chan's analytical study, modulus of elasticity varies with the radial coordinate and this variation depends on a power law. However, the modulus of elasticity becomes zero at the center based on nonlinear power function of the radial coordinate. This result is physically unrealistic. Hence, Eraslan and Akis [25] used exponential and parabolic functions of the radial coordinate describing the modulus of elasticity which then becomes non-zero and they obtained a closed form solution for the rotating functionally graded solid shaft and disk at the elastic range and the onset of the yield. The same authors developed an analytical model for functionally graded hollow shaft with fixed and free ends in [26]. In 2006, the problem of rotating functionally graded perfectly plastic hollow shafts was solved by the same authors [27]. Then, the perfectly plastic FGM hollow shafts for free ends was solved by Eraslan and Arslan [28] and for fixed ends by Akis and Eraslan [29] in 2007.

\subsubsection{Cylindrical Elements under Thermal Load}

Whenever temperature difference exists between any sections of a cylindrical element, stresses and displacement are set in the material whose boundaries are constrained or not. The magnitudes of the response variables depend on either the magnitude of temperature difference if it is in the steady-state or temperature variation with time if it is in unsteady-state [30]. On the other hand, different combinations of the heat treatment on different geometries cause interesting and unpredictable stress state 
combinations. Therefore, heat treatment of the metals has been a popular subject for the most investigators. The studies, which are directly related to the current one and may draw the attention of interested readers, are introduced below.

One of the oldest solutions to the thermal stress problem was presented by Dahl [30] in 1924. Dahl investigated stress distribution in thick and thin walled hollow cylinders, which is subjected to steady-state temperature distribution. Another old study in heat-treated elastic and perfectly plastic shafts was presented by Weiner and Huddleston [31] in 1959. Boley and Weiner [4] also presented expressions of the stresses and displacement in an elastic disk and a shaft, which are subjected to steady-state temperature gradient. Timoshenko and Goodier [1] and Johnson and Mellor [32] also reviewed the elastic solution of the problem. In 1960, Landau and Zwicky [33] solved the problem of elastic-perfectly plastic solid shaft with transient temperature distribution under the condition of temperature-dependent yield stress. In 1968, Mendelson [34] formulated a predeformed elastic region, which emerges after unloading and includes permanent plastic strains, for a solid shaft with radial temperature distribution.

In 1974, Chu [35] obtained a solution for a thermoelastoplastic strain hardening hollow shaft subjected to transient thermal load. Perzyna and Sawczuk [36] extensively reviewed the thermally induced deformation of the elastoplastic cylindrical elements. Then, Ishikawa [37] obtained an elastic-plastic solution for a solid shaft subjected to rapid surface heating and cooling.

In 1988, Mack and Gamer [38] investigated the thermal stresses that remain in the non-rotating elastic-plastic cylindrical elements after the unloading. In their study, transient heating was applied to the material and the derivation of predeformed elastic region was presented. They suggested that the exact unloading occurs all of a sudden in the deformed part of the material. They then compared the results of the exact and approximated unloading and concluded that the error of approximated sudden unloading is negligibly small. In a later work, Jahanian and Sabbaghian [39] obtained the residual stresses in an elastoplastic linearly hardening hollow shaft subjected to rapid cooling of the surface.

Moreover, the centrally heat-generating solid or composite shafts problem whose elastic solutions were obtained by Valentin and Carey [40], Citakoglu [41] and Citakoglu 
and Eren [42] has a special importance for the nuclear investigations. Analytical solutions of the elastic-perfectly plastic deformation of a centrally and slowly heated solid shaft with fixed ends by Orcan and Gamer [43], and with free ends by Orcan [44]. Gulgec and Orcan investigated the elastic-plastic deformation of a heat generating hollow shaft with fixed ends in [45] and with free ends in [46] under the assumption of a linear dependence of the yield stress on the temperature. In a following study, thermal stresses for the same problem but in an elastic-perfectly plastic hollow shaft with temperature dependent mechanical and thermal properties were obtained by Orcan and Eraslan [47]. Thereafter, Eraslan [48] obtained an exact solution to thermally induced elastic-plastic stress distributions in nonuniform heat generating composite tubes with axially fixed ends in 2003.

A closed form solution of a linearly hardening solid shaft subjected to nonuniform steady-state thermal load and convective boundary condition were obtained by Eraslan and Orcan [49]. In another study, Eraslan and Argeso [50] developed a computational model to estimate elastic-plastic stress states considering temperature-dependent physical properties for nonlinearly hardening cylindrical materials. This study was detailed in the same authors' another work [51] and the problem was solved with different assumptions.

\subsubsection{Rotating Cylindrical Elements under Thermal Load}

In one of the oldest studies that presents a solution for elastic rotating solid disk with a steady-state temperature gradient was obtained by Mendelson [34] in 1968. In a later work, Alujevic et al. [52] discussed the onset of yielding of a rotating hyperbolic annular disk for a given steady-state temperature distribution. In another study, Alujevic et al. [53] obtained numerical results for the previous work [52]. In 1998, Parmaksizoglu and Guven [54] studied the combined influence of nonuniform steadystate heating and rotation in a linearly hardening disk which is mounted on a rigid shaft in the fully plastic state.

Tarn [55] obtained an exact solution for the elastic functionally graded anisotropic hollow and solid circular cylinders, which are subjected to the thermal loads and rotation. An elastic-plastic analysis of a rotating shrink fit was obtained by Mack and Plöchl in 
[56] and Mack et al. in [57]. In 2003, Eraslan and Akis [58] analyzed the elastic-plastic stress distribution in a rotating linearly and nonlinearly hardening hollow thin disk which is mounted on a rigid shaft subjected to a steady-state temperature gradient.

In a later work, Eraslan, Arslan and Mack [59] obtained an exact solution for the distribution of stresses and displacement in a rotating linearly hardening elastic-plastic hollow shaft with free ends subject to a positive steady-state temperature gradient. In a recent study, Arslan, Mack and Eraslan [60] completed the investigations on such types of hollow shafts by considering a heated inner surface. Analytical solution for the distribution of the stresses and radial displacement in a linearly hardening elasticplastic hollow shaft subjected to the increasing angular speed and a negative radial temperature gradient was presented.

\subsection{Scope of the Present Work}

The literature review above indicates that an analogous investigation for a rotating solid shaft which is subjected to unsteady thermal load has not been conducted. Therefore, in the present study, a rotating solid cylinder with free surface is subjected to a temperature cycle. The temperature cycle is structured as follows: The surface temperature of the shaft is increased slowly and linearly with time up to a certain maximum temperature value. Then, it remains constant at this temperature for some time. Finally, it is decreased linearly to its reference temperature with time. In the problem, the elastic shaft is initially rotated up to a certain rotation speed, which is less than the elastic limit rotation speed for the isothermal shaft. Then the speed is held constant and the heating cycle described above is applied. It is assumed that the shaft is not axially constrained. Under presupposing circular symmetry and generalized plane strain, the problem is amenable to an analytical treatment. The material is presumed to be elastic-plastic and to obey Tresca's yield criterion and its associated flow rule. Furthermore, the yield stress decreases linearly with temperature. The treatment is restricted to small deformations. Then, a certain type of elastoplastic behavior is found to be typical. That is, at the axis of the shaft two plastic regions emerge, simultaneously. The image points of the inner plastic region lie on an edge and the ones of the other plastic region lie on an adjacent side of the Tresca's hexagon as 
in other cylinder problems [10]. In time, these two plastic regions move into the outer zone of the shaft. After a certain time, the plastic zone does not expand any more, and elastic unloading occurs at the plastic-elastic border before the fully plastic state is obtained. Thereafter, the predeformed elastic region spreads rapidly into the plastic zone. The distribution of the stresses, radial displacement and plastic strains are calculated and displayed for elastic region, two plastic regions, and predeformed elastic region at different times. The residual stresses after stand-still are also calculated and presented. 


\section{CHAPTER 2}

\section{THEORY}

\subsection{The Stress-Strain Relation}

The most common and simplest experiment, as well as the most important, is the tensile test to determine the stress-strain relationship of a material [34]. In this experiment, increasing tensile load $P$ is applied to the specimen of the material. Then the nominal stress which is defined by

$$
\sigma_{n}=\frac{P}{A_{0}}
$$

where $A_{0}$ is the original cross sectional area of the specimen, is calculated. Measuring the length $L$ of the specimen, the engineering strain given by

$$
\epsilon=\frac{L-L_{0}}{L_{0}}
$$

in which $L_{0}$ is the original length, is determined and the stress-strain diagram is drawn. A typical stress-strain diagram of a ductile material is shown in Figure 2.1. In this figure, the linear portion of the curve extends up to proportional limit $\sigma_{p}$. Until this limit, the slope of the line gives modulus of elasticity $E$ and Hooke's law is valid there:

$$
\sigma_{n}=E \epsilon
$$

Between proportional limit and yield stress, $\sigma_{y}$, the material still behaves elastic although stress-strain relationship is not constant. Additionally, difference between proportional limit and yield stress is very small for most ductile materials. Hence, it is considered that they coincide with each other. 
For $\sigma_{y}<\sigma<\sigma_{u}$, where $\sigma_{u}$ is the ultimate stress, the material behaves plastically. In this region, the strain increases at a greater rate as load is increased beyond the yield stress. However, the specimen will not deform further unless the load is increased. Hence, this region is called strain hardening region. For the stresses larger than ultimate stress, necking region, which is not recommended amount of loading for any engineering point of view, governs on the material. This region eventuates with the becoming unstable neck and the rupturing specimen when stress becomes equal to failure stress $\sigma_{f}[61]$.

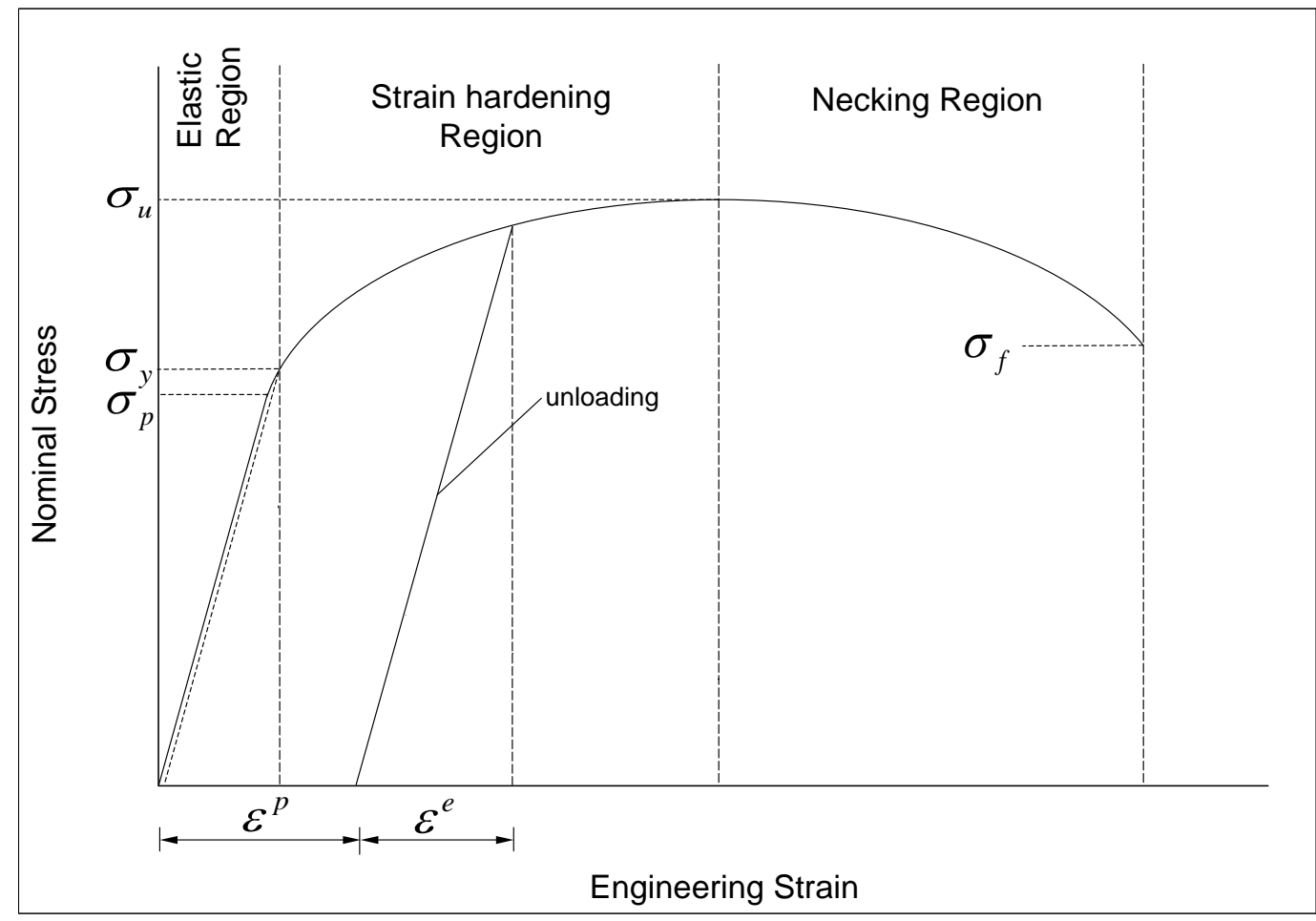

Figure 2.1: Stress-strain Diagram

In the elastic region, when unloading starts, material returns to its original shape. However, if the load is removed at any point in strain hardening region, unloading will take place along a line which is parallel to the elastic line as shown in Figure 2.1. As load is completely removed, elastic strain, i.e., $\epsilon^{e}$, is recovered but the permanent plastic strain, i.e., $\epsilon^{p}$, remains. Hence the total strain can be considered as summation of these two strain components [34]

$$
\epsilon=\epsilon^{e}+\epsilon^{p}
$$




\subsection{Criteria of Yielding}

A law defining the limit of elasticity under any possible combination of stresses is called a criterion of yielding [62]. As seen in Figure 2.1, for the stresses being larger than $\sigma_{y}$, behavior of the material is described by using any yielding criterion. Plastic yielding may depend on the magnitude of the three principal applied stresses, but not on their directions, since the isotropic case is assumed. Numerous criteria have been proposed for the yielding of solids, i.e. Maximum stress theory, maximum strain theory, Von Mises' criterion, Tresca's criterion, etc. Among these, Von Mises' yield criterion and Tresca's yield criterion are reasonably simple mathematically and accurate enough to be highly useful for the initial yield of isotropic materials.

\subsubsection{Von Mises' Yield Criterion}

The criterion, which is also known as distortion energy theory, is attributed to Von Mises [63]. In this theory, failure by yielding occurs at any coordinate of the material when the distortion energy per unit volume in a state of combined stress becomes equal to that associated with yielding in a simple tension test [3]. In other words, when the second deviatoric stress invariant reaches a specified value, yielding emerges. The principal stress, for $\sigma_{1}>\sigma_{2}>\sigma_{3}$, form of the Von Mises' yield criterion in simple tension is

$$
\left(\sigma_{1}-\sigma_{2}\right)^{2}+\left(\sigma_{2}-\sigma_{3}\right)^{2}+\left(\sigma_{1}-\sigma_{3}\right)^{2}=2 \sigma_{y}^{2}
$$

where $\sigma_{y}$ denotes the yield stress. As seen in Eq. (2.5), only the differences of the principal stresses involved. Therefore, yielding condition is not influenced by any additional amount to the each stress [3].

Von Mises' yield criterion finds considerable experimental support in situations involving ductile materials. Consequently, it is in common use in design [3].

\subsubsection{Tresca's Yield Criterion}

Tresca's yield criterion which is also called as maximum shear theory was firstly suggested by Tresca [64]. In this work, he concludes that yielding occurs when the 
maximum shear stress in the material equals maximum shear stress at yielding in a simple tension test. In other words, the maximum shear stress is equal to half of difference between maximum and minimum principal stresses. Hence, for the prescribed principal stresses, $\sigma_{1}>\sigma_{2}>\sigma_{3}$, Tresca's yield condition is

$$
\pm \frac{1}{2}\left(\sigma_{1}-\sigma_{3}\right)=\tau_{\max } .
$$

In the simple tension, the maximum shear stress at yielding point is half of the yield stress, $\sigma_{y} / 2$. Therefore, Tresca's criterion claims that yielding emerges when any of the following conditions is reached [34]

$$
\begin{aligned}
\sigma_{1}-\sigma_{3} & = \pm \sigma_{y} \\
\sigma_{1}-\sigma_{2} & = \pm \sigma_{y} \\
\sigma_{2}-\sigma_{3} & = \pm \sigma_{y} .
\end{aligned}
$$

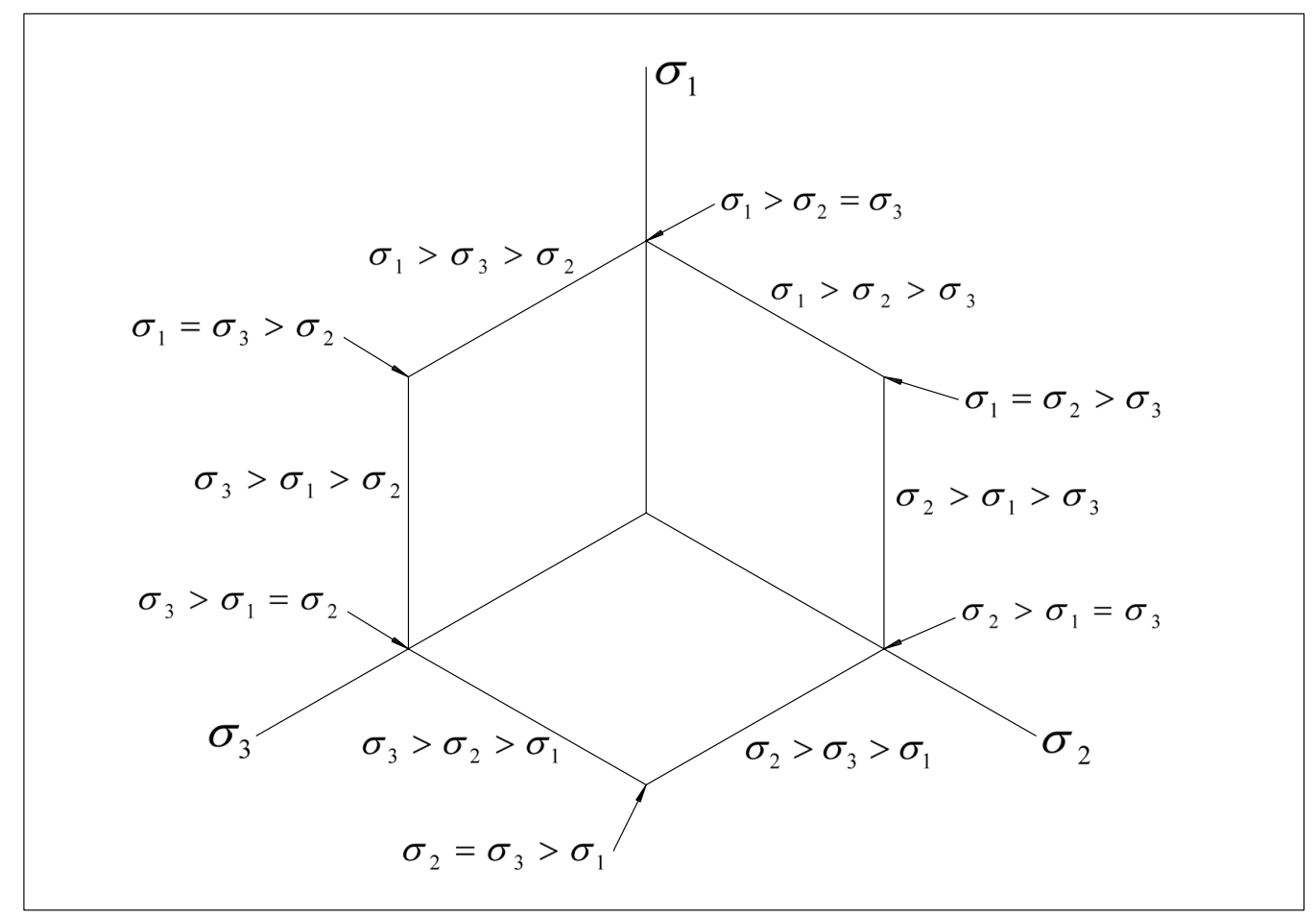

Figure 2.2: Tresca's hexagon with yielding conditions on three-dimensional principal stress space

In Figure 2.2, Tresca's yield criterion is presented as a regular hexagon in the deviatoric plane of the three-dimensional principal stress space [15]. The boundary of the 
hexagon marks the onset of yielding and the points outside of the hexagon represents a yielded state [3]. On this hexagon, each side and edge represent different type of yielding conditions. At the edge regimes of the Tresca's hexagon, two of principal stresses are equal to each other. On the other hand, there exists an inequality between principal stresses on the side regimes. For example, for the principal stresses space $\sigma_{1}>\sigma_{3}>\sigma_{2}$ (see the side regime in Figure 2.2), Tresca yielding condition reads $\sigma_{1}-\sigma_{2}=\sigma_{y}$. For the principal stress space $\sigma_{1}=\sigma_{3}>\sigma_{2}$ (edge regime in Tresca's hexagon), yielding conditions become $\sigma_{1}-\sigma_{2}=\sigma_{y}$ and $\sigma_{3}-\sigma_{2}=\sigma_{y}$. Similarly, yielding conditions of remaining side and edge regimes of the Tresca's hexagon may be obtained.

Tresca's yield criterion has a good agreement with experimental results for ductile materials and the theory offers an additional advantage in its ease of applications [3]. The criterion is mostly chosen for the theoretical treatment of the yielding problem since it generally makes a closed form solution possible.

\subsection{Flow Rule Associated with Yield Criteria}

The flow rule is the necessary kinematic assumption for the plastic deformation. It gives the ratio of the plastic strain increment tensor $d \epsilon_{i j}^{p}$ and it also defines the direction of the plastic strain increment vector in the strain space [65]. To obtain the plastic flow equations, the first approach to plastic strain-stress was suggested by Saint-Venant [66]. He proposed that the principal axes of the strain increment, but not total strain, coincides with the axes of the principal stress. A general relationship between the ratios of the components of strain increment and the stress was firstly suggested by Levy [67] and then independently by Von Mises [63]. Hence, equations given below are called Levy-Mises equations.

$$
\frac{d \epsilon_{x x}}{S_{x x}}=\frac{d \epsilon_{y y}}{S_{y y}}=\frac{d \epsilon_{z z}}{S_{z z}}=\frac{d \epsilon_{x y}}{S_{x y}}=\frac{d \epsilon_{x z}}{S_{x z}}=\frac{d \epsilon_{y z}}{S_{y z}}=d \lambda,
$$

or more compactly,

$$
d \epsilon_{i j}=S_{i j} d \lambda
$$


where $S_{i j}(i, j: x, y, z)$ is the stress deviator tensor and $d \lambda$ is a positive scalar factor of proportionality and non-zero only when plastic deformation occurs [65]. However, these equations are only for the rigid materials in which elastic strains are zero because total strain increments equalized to plastic strain increments. Hence, the extension of the Levy-Mises equation to allow for the elastic strains was carried out by Prandtl [68]. Then, Reuss [69] suggested the plastic strain increments $d \epsilon_{i j}^{p}$ related to the deviatoric stress components by the Prandtl-Reuss equations

$$
\frac{d \epsilon_{x x}^{p}}{S_{x x}}=\frac{d \epsilon_{y y}^{p}}{S_{y y}}=\frac{d \epsilon_{z z}^{p}}{S_{z z}}=\frac{d \epsilon_{x y}^{p}}{S_{x y}}=\frac{d \epsilon_{x z}^{p}}{S_{x z}}=\frac{d \epsilon_{y z}^{p}}{S_{y z}}=d \lambda,
$$

or

$$
d \epsilon_{i j}^{p}=S_{i j} d \lambda
$$

These equations prove that the principal axes of stress and plastic strain-increment coincide for isotropic materials [62].

To express a general stress-strain relation, a loading function $f\left(\sigma_{i j}\right)$ is assumed. According to this assumption, plastic deformation forms only for $f\left(\sigma_{i j}\right)=k$ and $d f>0$, where $k$ depends on the stress state and the strain history. Additionally, the increase in the plastic strain is a linear function of the increase in stress.

The condition that $d f=0$ is satisfied by assuming that

$$
d \epsilon_{i j}^{p}=G_{i j} d f
$$

in which $G_{i j}$ is a symmetric tensor which are supposed to be functions of the stress components and possibly of the previous strain history [62]. For the case of zero plastic volume change, assumption of $G_{i j}=0$ leads to

$$
G_{i j}=h \frac{\partial g}{\partial \sigma_{i j}}
$$

where $g$ and $h$ are general function of stress and strain flow [62]. Substituting Eq. (2.15) into Eq. (2.14) gives

$$
d \epsilon_{i j}^{p}=h \frac{\partial g}{\partial \sigma_{i j}} d f
$$


This equation is firstly obtained by Melan [70]. When the yield function and the plastic potential function coincide, $f=g$, following relation is obtained (see Hill [62])

$$
d \epsilon_{i j}^{p}=\frac{\partial f}{\partial \sigma_{i j}} d \lambda
$$

These relations show that plastic flow develops along the normal to the flow surface $\partial f / \partial \sigma_{i j}$. Eq. (2.17) is known as associated flow rule with the yield condition since the plastic flow is associated with the yield criterion. Furthermore, plastic flow can be expressed in terms of several yield functions as following

$$
d \epsilon_{i j}^{p}=\frac{\partial f_{1}}{\partial \sigma_{i j}} d \lambda_{1}+\frac{\partial f_{2}}{\partial \sigma_{i j}} d \lambda_{2}+\ldots+\frac{\partial f_{n}}{\partial \sigma_{i j}} d \lambda_{n} .
$$

\subsubsection{Flow Rule Associated with Tresca Yield Function}

If the Tresca yield function is taken as the plastic potential, the flow rule associated with it can be expressed in the light of Section 2.3. By supposing that the ordering in magnitude of the principal stresses is $\sigma_{1}>\sigma_{2}>\sigma_{3}$ (a side region of Tresca's hexagon in principal stress space as seen in Figure 2.2), the corresponding yield function takes the form

$$
f=F\left(\sigma_{i j}\right)-2 k=\sigma_{1}-\sigma_{3}-2 k=0,
$$

where $k$ is the yield value [65]. By substituting the yield function into the associated flow rule Eq. (2.17), the principal plastic strain increments, $d \epsilon_{1}^{p}, d \epsilon_{2}^{p}, d \epsilon_{3}^{p}$, are obtained as follows:

$$
\begin{aligned}
d \epsilon_{1}^{p} & =\frac{\partial f}{\partial \sigma_{1}} d \lambda=d \lambda, \\
d \epsilon_{2}^{p} & =\frac{\partial f}{\partial \sigma_{2}} d \lambda=0, \\
d \epsilon_{3}^{p} & =\frac{\partial f}{\partial \sigma_{3}} d \lambda=-d \lambda .
\end{aligned}
$$

Similar results can be obtained for the other five possible combinations in algebraic orders of magnitude of the principal stresses. These are on the side regime of Tresca's hexagon in principal space. Furthermore, the increments of plastic strains are parallel to each other and perpendicular to the side of the hexagon (see Chen and Han [65]).

On the other hand, an example to edge regime of Tresca's hexagon (see Figure 2.2) may be $\sigma_{1}>\sigma_{2}=\sigma_{3}$ in principal stress space. In this more involved case, shear slip may occur along either of two possible maximum shear planes which are [65] 
i) $\sigma_{\max }=\sigma_{1}, \sigma_{\min }=\sigma_{2}$. Therefore

$$
\begin{aligned}
d \epsilon_{1}^{p} & =d \lambda_{1}, \\
d \epsilon_{2}^{p} & =-d \lambda_{1}, \\
d \epsilon_{3}^{p} & =0,
\end{aligned}
$$

where $d \lambda_{1} \geq 0$.

ii) $\sigma_{\max }=\sigma_{1}, \sigma_{\min }=\sigma_{3}$. Therefore

$$
\begin{aligned}
& d \epsilon_{1}^{p}=d \lambda_{2}, \\
& d \epsilon_{2}^{p}=0, \\
& d \epsilon_{3}^{p}=-d \lambda_{2},
\end{aligned}
$$

where for $d \lambda_{2} \geq 0$. In this case, it is assumed that the resulting plastic strain increment vector is a linear combination of the two increments (see Eq. (2.18))

$$
\begin{aligned}
d \epsilon_{1}^{p} & =d \lambda_{1}+d \lambda_{2}, \\
d \epsilon_{2}^{p} & =-d \lambda_{1}, \\
d \epsilon_{3}^{p} & =-d \lambda_{2} .
\end{aligned}
$$

Similary, for remaining five edges of the Tresca's hexagon, the associated flow rules with Tresca's yield criterion may be obtained. 


\section{CHAPTER 3}

\section{STATEMENT OF THE PROBLEM AND TEMPERATURE FIELD}

\subsection{Statement of the Problem}

Consider a rotating solid shaft cross section of which is shown in Figure 3.1. The shaft is subjected to temperature cycle. In formulation, cylindrical polar coordinates, i.e. $r$ is radial, $\theta$ is circumferential, and $z$ is axial directions, are considered. Notation of Timoshenko and Goodier [1] is followed. Hence, $\sigma_{i}$ and $\epsilon_{i}$ denote a normal stress and a normal strain component $(i: r, \theta, z)$, respectively, $u$ is the radial component of the displacement vector, $\rho$ is the mass density of the shaft material, and $\omega$ is constant angular speed of rotation. The subject of the investigation is a rotating elastic-perfectly plastic solid shaft with outer radius $b$ with stress free cylindrical surface (see Figure 3.1) [12]

$$
r=b: \quad \sigma_{r}=0 .
$$

Another mechanical boundary condition is that axial force $F_{z}$ on any cross-section vanishes since the ends of the shaft are free [12]

$$
F_{z}=2 \pi \int_{0}^{b} \sigma_{z} r d r=0
$$

For completeness, it is stated that the radial displacement component has to comply with the condition (see [12])

$$
u(0)=0,
$$

since shaft is solid. A state of generalized plane strain, i. e.

$$
\epsilon_{z}=\epsilon_{0}=\text { Constant }
$$


where the axial strain $\epsilon_{0}$ depends on the angular speed and the temperature field, is considered. Additionally, infinitesimal deformations are presumed. Since end effects are ignored and cylindrical symmetry is presumed, the principal directions of stress and strain are the radial, circumferential and axial directions [11]. As already mentioned, the material is assumed to obey Tresca's yield criterion and the associated flow rule with it [32], [65]. For a linear temperature dependence the yield stress, $\sigma_{t h}$, reads

$$
\sigma_{t h}=\sigma_{0}(1-\beta T)
$$

where $\sigma_{0}$ denotes the uniaxial yield limit at reference temperature and $\beta$ the temperature dependence parameter of the material [45], [56]. $T$, which will be examined in the Section 3.2, means the difference of absolute and reference temperatures.

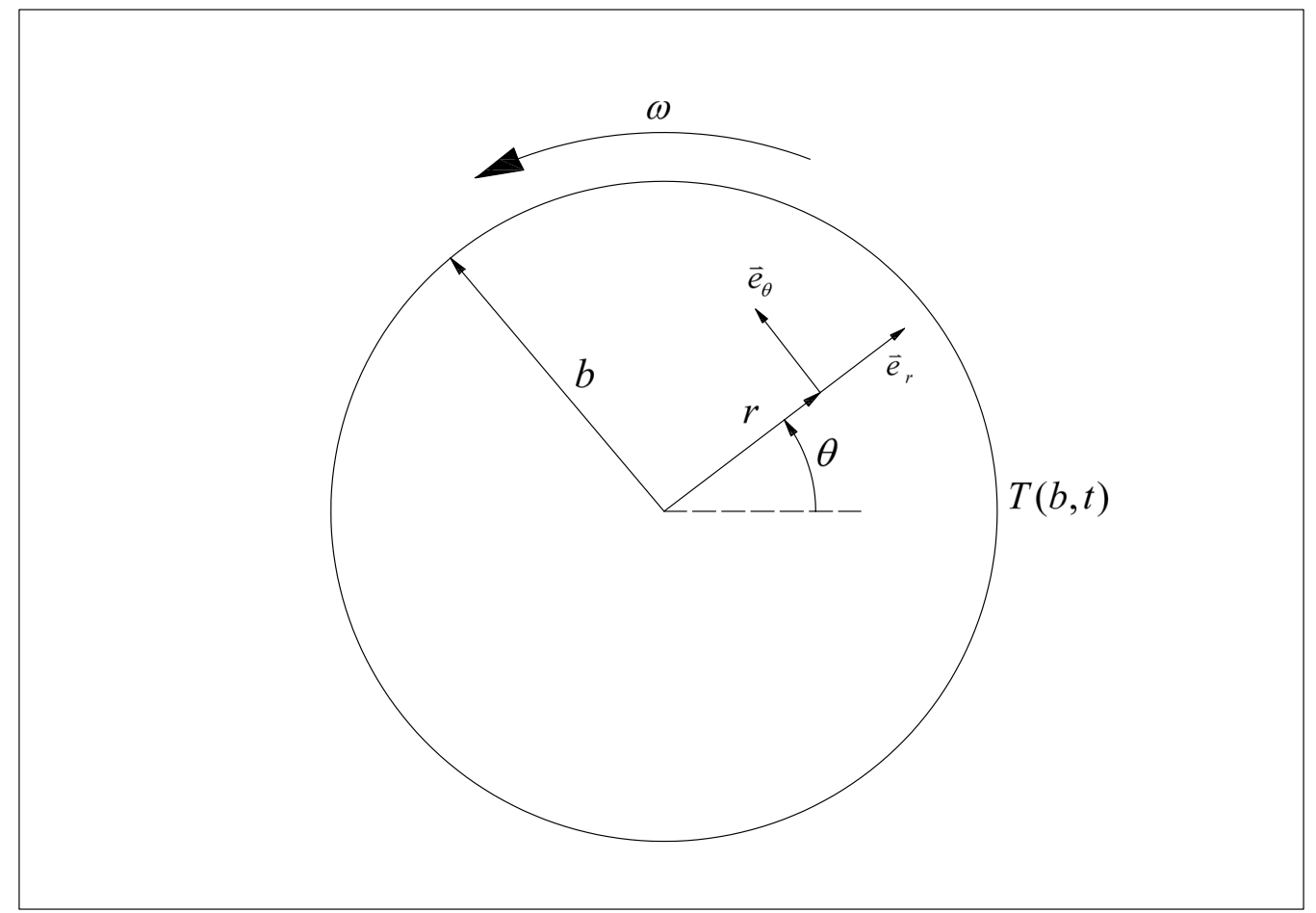

Figure 3.1: Sketch of the rotating solid shaft subjected to temperature cycle

\section{$3.2 \quad$ Temperature Field}

Temperature cycle that is applied to outer surface of the shaft is sketched in Figure 3.2. As seen in the figure, the temperature at the surface of the shaft is increased 
linearly and slowly up to maximum temperature value $T_{m}$ in time $t_{t}$. Then, it is held constant throughout $t=t_{c}$. Finally, it is decreased linearly at the same rate to the reference temperature until $t=2 t_{t}+t_{c}$. For $t>2 t_{t}+t_{c}$, surface temperature remains at the reference temperature value.

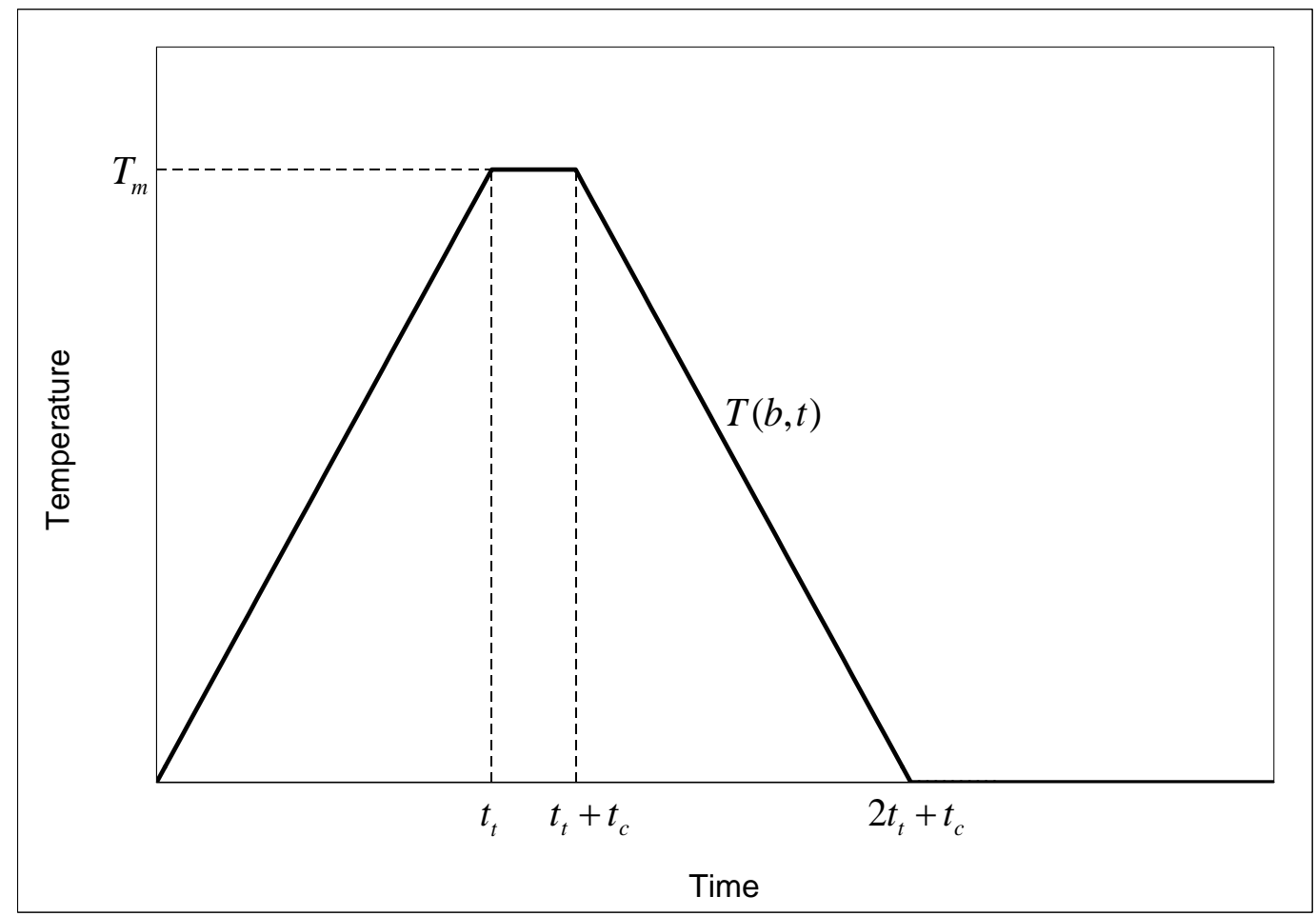

Figure 3.2: Prescribed surface temperature of the shaft

To model this temperature cycle, the surface temperature of the shaft is prescribed as a sectionally linear function of time [56]. Thus, the heat conduction problem is described by the following differential equation:

$$
\frac{\kappa}{r} \frac{\partial}{\partial r}\left[r \frac{\partial T(r, t)}{\partial r}\right]=\frac{\partial T(r, t)}{\partial t}
$$

in which $\kappa$ denotes the thermal diffusivity, subject to the initial condition

$$
T(r, 0)=0 \text { for } 0 \leq r \leq b,
$$


and to the boundary condition (see Figure 3.2 )

$$
T(b, t)=\left\{\begin{array}{ll}
\left(T_{m} / t_{t}\right) t & \text { for } 0<t \leq t_{t} \\
T_{m} & \text { for } t_{t}<t \leq t_{t}+t_{c} \\
T_{m}-\left(T_{m} / t_{t}\right)\left(t-t_{t}-t_{c}\right) & \text { for } t_{t}+t_{c}<t \leq 2 t_{t}+t_{c} \\
0 & \text { for } t>2 t_{t}+t_{c}
\end{array} .\right.
$$

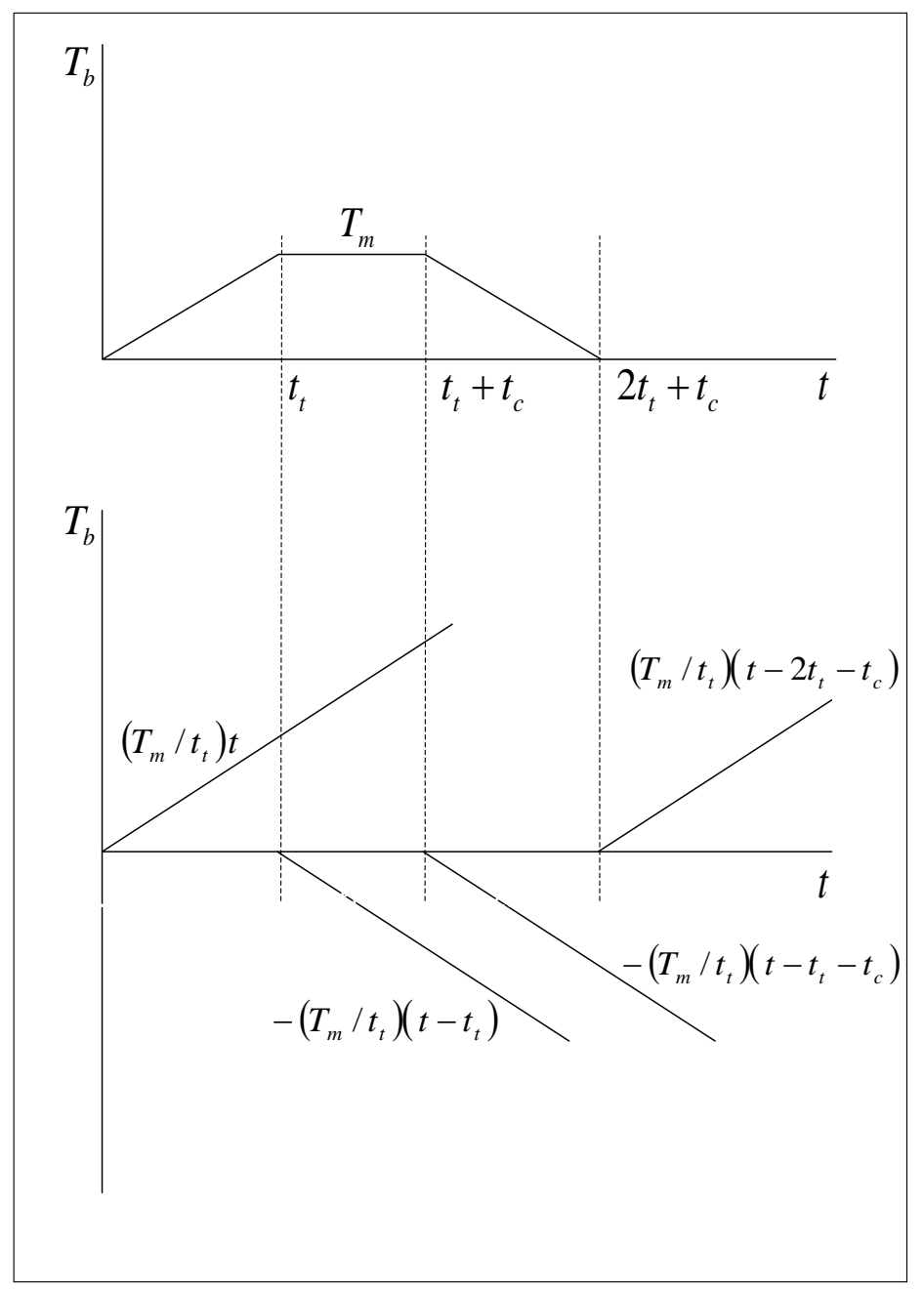

Figure 3.3: Description of surface temperature with linear function

Solution of the heat conduction equation has been obtained in [71] for zero initial temperature (Eq. (3.7)) and the surface temperature of $T(b, t)=\left(T_{m} / t_{t}\right) t$ as following

$$
\bar{T}(r, t)=\frac{T_{m}}{t_{t}}\left[\left(t-\frac{b^{2}-r^{2}}{4 \kappa}\right)+\frac{2}{\kappa b} \sum_{n=1}^{\infty} e^{-\kappa \gamma_{n}^{2} t} \frac{J_{0}\left(r \gamma_{n}\right)}{\gamma_{n}^{3} J_{1}\left(b \gamma_{n}\right)}\right],
$$

where $J_{0}$ and $J_{1}$ indicate Bessel functions of the first kind of order zero and one, 
respectively, and the $\gamma_{n}$ are the positive roots of

$$
J_{0}(b \gamma)=0
$$

This solution is valid for time interval $0<t \leq t_{t}$ since boundary condition in this interval is $T(b, t)=\left(T_{m} / t_{t}\right) t$. In order to find the solution for the range of $t>t_{t}$, different linear functions are defined as shown in the Figure 3.3. By superposition of these linear functions, the boundary condition for each time interval in Eq. (3.8) can be obtained.

Hence, the solution of heat conduction problem (3.9) can be adapted for all time intervals as

$$
T(r, t)=\left\{\begin{array}{ll}
\bar{T}(r, t) & \text { for } \quad 0<t \leq t_{t} \\
\bar{T}(r, t)-\bar{T}\left(r, t-t_{t}\right) & \text { for } \quad t_{t}<t \leq t_{t}+t_{c} \\
\bar{T}(r, t)-\bar{T}\left(r, t-t_{t}\right)-\bar{T}\left(r, t-t_{t}-t_{c}\right) & \text { for } \quad t_{t}+t_{c}<t \leq 2 t_{t}+t_{c} \\
\bar{T}(r, t)-\bar{T}\left(r, t-t_{t}\right)-\bar{T}\left(r, t-t_{t}-t_{c}\right) & \\
+\bar{T}\left(r, t-2 t_{t}-t_{c}\right) & \text { for } \quad t>2 t_{t}+t_{c}
\end{array} .\right.
$$




\section{CHAPTER 4}

\section{BASIC EQUATIONS AND ANALYTICAL SOLUTIONS OF ELASTIC AND PLASTIC REGIONS}

\subsection{Basic Equations}

Equation of motion that is derived by using Newton's second law, is the primary equation that is used for the mathematical derivation of elastic and plastic regions. General form of equation of motion in radial direction is as derived in [1]

$$
\frac{\partial \sigma_{r}}{\partial r}+\frac{1}{r} \frac{\partial \tau_{r \theta}}{\partial \theta}+\frac{\sigma_{r}-\sigma_{\theta}}{r}+R=0
$$

where $\tau_{r \theta}$ is shear stress and $R$ is component of body force. In this problem, the shear stress $\tau_{r \theta}$ vanishes because of the symmetry [1]. Hence, terms of $\partial \tau_{r \theta} / \partial \theta$ drops in Eq. (4.1). Additionally, the body force $R$ is described with neglecting weight of the shaft as

$$
R=\rho \omega^{2} r+\rho \frac{\partial^{2} u}{\partial t^{2}}
$$

where $\rho$ is mass per unit volume of the material and $\omega$ is constant angular rotation speed of the shaft [1], [4]. In this equation, the first term, $\rho \omega^{2} r$, is an inertia force that occurs because of rotation [1]. The second term, i.e. $\rho\left(\partial^{2} u / \partial t^{2}\right)$, is another inertia term that is formed due to thermally induced wave phenomena. In case of sudden temperature change in a material, such as quenching of a hot shaft, this term has a significant effect on the body force. On the other hand, if the temperature is altered slowly in time, this inertia force does not influence the material [4]. Hence, the second term in the body force drops in this study, $\rho \frac{\partial^{2} u}{\partial t^{2}}=0$, since the temperature cycle (in Figure 3.2) is applied to the surface of the shaft slowly. Therefore, for constant angular speed, in the absence of thermally induced wave phenomena, neglecting weight 
of the shaft and in case of cylindrical symmetry, the equation of motion for the radial direction in Eq. (4.1) takes the form

$$
\left(r \sigma_{r}\right)^{\prime}-\sigma_{\theta}=-\rho \omega^{2} r^{2}
$$

In this equation, a prime denotes differentiation with respect to $r$ as radial and circumferential stresses are independent of circumferential direction $\theta$.

Since the treatment is restricted to small deformations, radial and circumferential strain components are described with the following geometric relations in case of cylindrical symmetry as

$$
\epsilon_{r}=u^{\prime}, \quad \epsilon_{\theta}=\frac{u}{r}
$$

Another basic relation is Generalized Hooke's law [4], which follows as

$$
\begin{aligned}
\epsilon_{r} & =\frac{1}{2(1+\nu) G}\left[\sigma_{r}-\nu\left(\sigma_{\theta}+\sigma_{z}\right)\right]+\epsilon_{r}^{p}+\alpha T, \\
\epsilon_{\theta} & =\frac{1}{2(1+\nu) G}\left[\sigma_{\theta}-\nu\left(\sigma_{r}+\sigma_{z}\right)\right]+\epsilon_{\theta}^{p}+\alpha T, \\
\epsilon_{z} & =\epsilon_{0}=\frac{1}{2(1+\nu) G}\left[\sigma_{z}-\nu\left(\sigma_{r}+\sigma_{\theta}\right)\right]+\epsilon_{z}^{p}+\alpha T,
\end{aligned}
$$

where $\nu$ denotes Poison's ratio, $G$ is modulus of rigidity, $\epsilon_{i}^{p}$ are plastic strain components and $\alpha$ is the coefficient of thermal expansion in material [56], [59]. It is presumed that the strains are additively composed of elastic, plastic and thermal parts in these equations.

\subsection{Elastic Region}

In the elastic deformation, Eqs. $(4.5 \mathrm{a}-4.5 \mathrm{c})$ are recovered by setting $\epsilon_{i}^{p}=0$. Axial stress is determined in terms of radial and circumferential stresses from Hooke's law $(4.5 \mathrm{c})$ in a state of generalized plane strain (Eq. (3.4)) as

$$
\sigma_{z}=\nu\left(\sigma_{r}+\sigma_{\theta}\right)+2 G(1+\nu)\left[\epsilon_{0}-\alpha T(r, t)\right]
$$

On the one hand, by making use of geometric relations (4.4) and Hooke's law in radial and circumferential directions (4.5a) and (4.5b), following stress components are derived in terms of radial displacement and its derivative with help of Eq. (4.6) 


$$
\begin{aligned}
\sigma_{r} & =\frac{2 G}{r(1-2 \nu)}\left[\nu u+r(1-\nu) u^{\prime}+r \nu \epsilon_{0}-r \alpha(1+\nu) T(r, t)\right], \\
\sigma_{\theta} & =\frac{2 G}{r(1-2 \nu)}\left[(1-\nu) u+r \nu u^{\prime}+r \nu \epsilon_{0}-r \alpha(1+\nu) T(r, t)\right] .
\end{aligned}
$$

Inserting the stresses in Eqs. (4.7) and (4.8) into the equation of motion (4.3), one obtains the nonhomogenous Euler equation for radial displacement

$$
r^{2} \frac{d^{2} u}{d r^{2}}+r \frac{d u}{d r}-u=-\frac{r^{2}}{(1-\nu)}\left[\frac{1-2 \nu}{2 G} \rho \omega^{2} r-\alpha(1+\nu) T^{\prime}(r, t)\right] .
$$

Solution of homogeneous part of this equation is obtained effortlessly as

$$
u_{h}=\frac{C_{1}}{r}+C_{2} r
$$

in which $C_{1}$ and $C_{2}$ are arbitrary integration constants. The particular solution of the problem is integrated by the method of variation of parameters since the equation is suitable to the form of

$$
\frac{d^{2} u}{d r^{2}}+\frac{1}{r} \frac{d u}{d r}-\frac{u}{r^{2}}=F(r)
$$

as given in [72]. In this method, particular solution of the equation is obtained by using

$$
u_{p}(r)=Y_{1}(r) u_{1}(r)+Y_{2}(r) u_{2}(r)
$$

where $Y_{1}(r)$ and $Y_{2}(r)$ are defined by using homogeneous solution of the problem (4.10) as

$$
\begin{aligned}
& Y_{1}(r)=\frac{1}{r}, \\
& Y_{2}(r)=r,
\end{aligned}
$$

and

$$
\begin{aligned}
& u_{1}(r)=-\int \frac{Y_{2}(r) F(r)}{W(r)} d r, \\
& u_{2}(r)=\int \frac{Y_{1}(r) F(r)}{W(r)} d r,
\end{aligned}
$$

in which Wronskian of the system is obtained by using

$$
W(r)=Y_{1}(r) \frac{d Y_{2}(r)}{d r}-\frac{d Y_{1}(r)}{d r} Y_{2}(r)
$$




$$
W(r)=\frac{2}{r} .
$$

and $F(r)$ is the non-homogeneous part of the equation as

$$
F(r)=-\frac{1}{(1-\nu)}\left[\frac{1-2 \nu}{2 G} \rho \omega^{2} r-\alpha(1+\nu) T^{\prime}(r, t)\right] .
$$

Hence, particular solution is integrated as

$$
u_{p}=-\frac{(1-2 \nu) \rho \omega^{2} r^{3}}{16 G(1-\nu)}+\frac{\alpha(1+\nu)}{r(1-\nu)} \int_{0}^{r} T(\xi, t) \xi d \xi
$$

The integral involved in this equation can be evaluated analytically. The result is

$$
\int_{0}^{r} \bar{T}(\xi, t) \xi d \xi=\frac{T_{m}}{t_{t}}\left[\left(t-\frac{b^{2}}{4 \kappa}+\frac{r^{2}}{8 \kappa}\right) \frac{r^{2}}{2}+\frac{2}{\kappa b} \sum_{n=1}^{\infty} e^{-\kappa \gamma_{n}^{2} t} \frac{r J_{1}\left(r \gamma_{n}\right)}{\gamma_{n}^{4} J_{1}\left(b \gamma_{n}\right)}\right] .
$$

For the general solution of the Eq. (4.9),

$$
u=u_{h}+u_{p}
$$

is used. The result is

$$
u=\frac{C_{1}}{r}+C_{2} r-\frac{(1-2 \nu) \rho \omega^{2} r^{3}}{16 G(1-\nu)}+\frac{\alpha(1+\nu)}{r(1-\nu)} \int_{0}^{r} T(\xi, t) \xi d \xi
$$

From Eqs. (4.7) and (4.8), radial and circumferential stress components are derived as

$$
\begin{aligned}
\sigma_{r}= & -\frac{2 G C_{1}}{r^{2}}+\frac{2 G}{1-2 \nu}\left(C_{2}+\nu \epsilon_{0}\right)-\frac{1}{8(1-\nu)}\left[(3-2 \nu) \rho \omega^{2} r^{2}\right. \\
& \left.+\frac{16 G \alpha(1+\nu)}{r^{2}} \int_{0}^{r} T(\xi, t) \xi d \xi\right], \\
\sigma_{\theta}= & \frac{2 G C_{1}}{r^{2}}+\frac{2 G}{1-2 \nu}\left(C_{2}+\nu \epsilon_{0}\right)-\frac{1}{8(1-\nu)}\left\{(1+2 \nu) \rho \omega^{2} r^{2}\right. \\
& \left.+\frac{16 G \alpha(1+\nu)}{r^{2}}\left[r^{2} T(r, t)-\int_{0}^{r} T(\xi, t) \xi d \xi\right]\right\} .
\end{aligned}
$$

Then, substituting these stresses into Eq. (4.6) gives

$$
\sigma_{z}=\frac{2 G}{1-2 \nu}\left[2 \nu C_{2}+(1-\nu) \epsilon_{0}\right]-\frac{1}{2(1-\nu)}\left[\nu \rho \omega^{2} r^{2}+4 G \alpha(1+\nu) T(r, t)\right]
$$


The solution presented here is in agreement with those in [12],[44],[45]. On the other hand, it should be mentioned that as $r \rightarrow 0$ (at the center of the shaft) the terms containing the temperature $T(r, t)$ are finite in all equations in consistence with the physics of the problem. In this context, following integrals that are located in the equations are calculated in the limiting case by L'Hopital's Rule to prevent computational singularity $[4]$

$$
\begin{aligned}
\lim _{r \rightarrow 0}\left[\frac{1}{r} \int_{0}^{r} T(\xi, t) \xi d \xi\right] & =\lim _{r \rightarrow 0} r T(r, t)=0, \\
\lim _{r \rightarrow 0}\left[\frac{1}{r^{2}} \int_{0}^{r} T(\xi, t) \xi d \xi\right] & =\lim _{r \rightarrow 0} \frac{r T(r, t)}{2 r}=\frac{T(0, t)}{2} .
\end{aligned}
$$

Finally, axial force is determined by assuming the elastic region is bounded in $\delta \leq r \leq$ $\lambda$ with help of Eq. (4.25)

$$
\begin{aligned}
F_{z}^{e}= & 2 \pi \int_{\delta}^{\lambda} \sigma_{z} r d r=2 \pi\left\{\frac{G\left(\lambda^{2}-\delta^{2}\right)}{1-2 \nu}\left[2 \nu C_{2}+(1-\nu) \epsilon_{0}\right]\right. \\
& \left.-\frac{1}{8(1-\nu)}\left[\left(\lambda^{4}-\delta^{4}\right) \nu \rho \omega^{2}+16 G \alpha(1+\nu) \int_{\delta}^{\lambda} T(\xi, t) \xi d \xi\right]\right\},
\end{aligned}
$$

to make use of condition (3.2) for further calculations.

\subsection{Plastic (Edge Regime) Region I}

In the plastic region I, the stress state is in an edge regime of Tresca's hexagon in the principal stress space with the inequality of $\sigma_{r}=\sigma_{\theta}>\sigma_{z}$. Hence, Tresca's yield condition leads to

$$
\sigma_{\theta}-\sigma_{z}=\sigma_{t h}, \quad \sigma_{r}-\sigma_{z}=\sigma_{t h},
$$

where $\sigma_{t h}$ is the yield stress and as defined in Eq. (3.5). Accordingly, for this plastic region, Tresca's yielding functions are described as

$$
\begin{aligned}
& f_{1}=\sigma_{\theta}-\sigma_{z}-\sigma_{t h}=0 \\
& f_{2}=\sigma_{r}-\sigma_{z}-\sigma_{t h}=0 .
\end{aligned}
$$

The flow rule associated with the yielding condition reads

$$
d \epsilon_{i}^{p}=\sum_{j=1}^{2} \frac{\partial f_{j}}{\partial \sigma_{i}} d \lambda_{j},
$$


where the subscript $i$ denotes a principal direction and $d \lambda_{j}$ is a positive scalar factor of proportionality [65]. Hence, for this plastic region, plastic strain increments are

$$
\begin{aligned}
d \epsilon_{r}^{p} & =\frac{\partial f_{1}}{\partial \sigma_{r}} d \lambda_{1}+\frac{\partial f_{2}}{\partial \sigma_{r}} d \lambda_{2}=d \lambda_{2}, \\
d \epsilon_{\theta}^{p} & =\frac{\partial f_{1}}{\partial \sigma_{\theta}} d \lambda_{1}+\frac{\partial f_{2}}{\partial \sigma_{\theta}} d \lambda_{2}=d \lambda_{1}, \\
d \epsilon_{z}^{p} & =\frac{\partial f_{1}}{\partial \sigma_{z}} d \lambda_{1}+\frac{\partial f_{2}}{\partial \sigma_{z}} d \lambda_{2}=-d \lambda_{1}-d \lambda_{2} .
\end{aligned}
$$

Furthermore in case of a monotonically increasing load parameters, the radial and circumferential plastic strains are positive $\left(\epsilon_{r}^{p}>0\right.$ and $\left.\epsilon_{\theta}^{p}>0\right)$, and axial plastic strain is the negative sum of the other two directions due to the plastic incompressibility

$$
\epsilon_{z}^{p}=-\left(\epsilon_{r}^{p}+\epsilon_{\theta}^{p}\right)
$$

According to the yield condition (4.29), circumferential and axial stresses can be expressed in term of radial stress as

$$
\begin{aligned}
\sigma_{\theta} & =\sigma_{r}, \\
\sigma_{z} & =\sigma_{r}-\sigma_{t h} .
\end{aligned}
$$

Inserting Eq. (4.37) into the equation of motion (4.3) gives

$$
r \sigma_{r}^{\prime}+\rho \omega^{2} r^{2}=0
$$

Integration of this equation leads to

$$
\sigma_{r}=C_{3}-\frac{1}{2} \rho \omega^{2} r^{2}
$$

where $C_{3}$ is an integration constant. It should be also kept in mind that $\sigma_{\theta}=\sigma_{r}$. In order to find out axial stress component, Eqs. (3.5) and (4.38) are combined:

$$
\sigma_{z}=C_{3}-\frac{1}{2} \rho \omega^{2} r^{2}-\sigma_{0}[1-\beta T(r, t)]
$$

By taking into account plane strain assumption (3.4) and geometric relations (4.4), summation of strains can be displayed as (see [73])

$$
\epsilon_{r}+\epsilon_{\theta}+\epsilon_{z}=u^{\prime}+\frac{u}{r}+\epsilon_{0}
$$

Here, each strain can be written in terms of stresses and plastic strains by using Hooke's law (4.5). Furthermore, summation of the plastic strains equals zero because 
of plastic incompressibility (4.36). Hence, only stress terms remain in the equation. This equation and additionally Eqs. (4.37), (4.40) and (4.41) are used to derive first order linear differential equation for radial displacement:

$$
\begin{aligned}
u^{\prime}+\frac{u}{r}= & \frac{1}{4 G(1+\nu)}\left\{(1-2 \nu)\left(6 C_{3}-2 \sigma_{0}-3 \rho \omega^{2} r^{2}\right)\right. \\
& \left.+2\left[6 G \alpha(1+\nu)+\beta(1-2 \nu) \sigma_{0}\right] T(r, t)\right\}-\epsilon_{0} .
\end{aligned}
$$

This equation is in the form of linear Bernoulli equation [72] as

$$
u^{\prime}+p(r) u=q(r)
$$

with the solution of

$$
u=\frac{1}{a(r)} \int a(r) q(r) d r+\frac{C}{a(r)},
$$

where $C$ is a constant and $a(r)$ is defined as

$$
a(r)=e^{\int p(r) d r}
$$

In Eq. (4.43)

$$
\begin{aligned}
p(r)= & \frac{1}{r}, \\
a(r)= & r, \\
q(r)= & \frac{1}{4 G(1+\nu)}\left\{(1-2 \nu)\left(6 C_{3}-2 \sigma_{0}-3 \rho \omega^{2} r^{2}\right)\right. \\
& \left.+2\left[6 G \alpha(1+\nu)+\beta(1-2 \nu) \sigma_{0}\right] T(r, t)\right\}-\epsilon_{0} .
\end{aligned}
$$

The general solution is adapted as

$$
\begin{aligned}
u= & \frac{C_{4}}{r}-\frac{\epsilon_{0} r}{2}+\frac{1}{4 G r(1+\nu)}\left\{\frac{(1-2 \nu) r^{2}}{4}\left(12 C_{3}-4 \sigma_{0}-3 \rho \omega^{2} r^{2}\right)\right. \\
& \left.+2\left[6 G \alpha(1+\nu)+\beta(1-2 \nu) \sigma_{0}\right] \int_{0}^{r} T(\xi, t) \xi d \xi\right\},
\end{aligned}
$$

in which $C_{4}$ is fourth integration constant of the problem. The integral here has been evaluated before and given in Eq. (4.20). The plastic parts of the strains are found as the differences of the total strains and their elastic and thermal parts together with Eqs. (4.4), (4.37), (4.40), (4.41) and (4.50) as

$$
\begin{aligned}
\epsilon_{r}^{p}= & -\frac{C_{4}}{r^{2}}-\frac{\epsilon_{0}}{2}+\frac{1}{16 G(1+\nu)}\left\{(1-2 \nu)\left(4 C_{3}-5 \rho \omega^{2} r^{2}\right)-4 \sigma_{0}\right. \\
& -\frac{8\left[6 G \alpha(1+\nu)+\beta(1-2 \nu) \sigma_{0}\right]}{r^{2}} \int_{0}^{r} T(\xi, t) \xi d \xi \\
& \left.+8\left[4 G \alpha(1+\nu)+\beta(1-\nu) \sigma_{0}\right] T(r, t)\right\},
\end{aligned}
$$




$$
\begin{aligned}
& \epsilon_{\theta}^{p}= \frac{C_{4}}{r^{2}}-\frac{\epsilon_{0}}{2}+\frac{1}{16 G(1+\nu)}\left\{(1-2 \nu)\left(4 C_{3}+\rho \omega^{2} r^{2}\right)-4 \sigma_{0}\right. \\
&+\frac{8\left[6 G \alpha(1+\nu)+\beta(1-2 \nu) \sigma_{0}\right]}{r^{2}} \int_{0}^{r} T(\xi, t) \xi d \xi \\
&\left.-8\left[2 G \alpha(1+\nu)-\beta \nu \sigma_{0}\right] T(r, t)\right\}, \\
& \epsilon_{z}^{p}=\frac{(1-2 \nu)\left(\rho \omega^{2} r^{2}-2 C_{3}\right)+2 \sigma_{0}}{4 G(1+\nu)}+\epsilon_{0}-\left[\alpha+\frac{\beta \sigma_{0}}{2 G(1+\nu)}\right] T(r, t) .
\end{aligned}
$$

The axial force integral for the plastic region I is calculated with the help of Eq. (4.41)

as

$$
\begin{aligned}
F_{z}^{P I}= & 2 \pi \int_{\delta}^{\lambda} \sigma_{z} r d r=2 \pi\left\{\frac{\left(\lambda^{2}-\delta^{2}\right)}{2}\left[C_{3}-\sigma_{0}-\frac{\left(\lambda^{2}+\delta^{2}\right) \rho \omega^{2}}{4}\right]\right. \\
& \left.+\beta \sigma_{0} \int_{\delta}^{\lambda} T(\xi, t) \xi d \xi .\right\} .
\end{aligned}
$$

Here, it should be noted that all expressions that are derived in this region for $T(r, t)=$ 0 , recovers the equations given in [12].

\subsection{Plastic (Side Regime) Region II}

Governing equation for this region is obtained by a procedure similar to the one outlined in [21] as following. In plastic region II, the principal stresses satisfy $\sigma_{\theta}>$ $\sigma_{r}>\sigma_{z}$. The stress image points are on a side regime of Tresca's hexagon in principal stress space. At this point, the yield condition takes the form

$$
\sigma_{\theta}-\sigma_{z}=\sigma_{t h}
$$

Accordingly, for this plastic region Tresca's yielding function is described by

$$
f_{1}=\sigma_{\theta}-\sigma_{z}-\sigma_{t h}=0
$$

By making use of Eq. (4.32) plastic strain increments become

$$
\begin{aligned}
d \epsilon_{r}^{p} & =\frac{\partial f_{1}}{\partial \sigma_{r}} d \lambda_{1}=0, \\
d \epsilon_{\theta}^{p} & =\frac{\partial f_{1}}{\partial \sigma_{\theta}} d \lambda_{1}=d \lambda_{1}, \\
d \epsilon_{z}^{p} & =\frac{\partial f_{1}}{\partial \sigma_{z}} d \lambda_{1}=-d \lambda_{1} .
\end{aligned}
$$

and plastic strains satisfy $\epsilon_{r}^{p}=0, \epsilon_{\theta}^{p}>0$, and $\epsilon_{z}^{p}<0$. In the absence of plastic 
predeformation, the associated flow rule becomes

$$
\begin{aligned}
\epsilon_{r}^{p} & =0, \\
\epsilon_{\theta}^{p} & =-\epsilon_{z}^{p} .
\end{aligned}
$$

Hence, the radial strain consists of an elastic and thermal parts only:

$$
\epsilon_{r}=\frac{1}{2(1+\nu) G}\left[\sigma_{r}-\nu\left(\sigma_{\theta}+\sigma_{z}\right)\right]+\alpha T .
$$

Here and further, axial stress is eliminated by using

$$
\sigma_{z}=\sigma_{\theta}-\sigma_{t h}
$$

that is obtained from yield condition (4.55). Thus, axial plastic strain component may be expressed by using Eqs. (4.5c) and (3.5) as

$$
\epsilon_{z}^{p}=\epsilon_{0}+\frac{\nu \sigma_{r}-(1-\nu) \sigma_{\theta}+\sigma_{0}(1-\beta T)}{2 G(1+\nu)}-\alpha T
$$

By using Eq. (4.64) circumferential strain leads to

$$
\epsilon_{\theta}=-\epsilon_{0}-\frac{1}{G(1+\nu)}\left\{\nu \sigma_{r}-(1-\nu)\left[\sigma_{\theta}-\frac{\sigma_{0}}{2}(1-\beta T)\right]\right\}+2 \alpha T
$$

Then Eqs. (4.62) and (4.65) are substituted into geometric relations (4.4) to get

$$
\begin{gathered}
\sigma_{r}=\frac{2 G}{(1-2 \nu) r}\left[\nu\left(u+\epsilon_{0} r\right)+(1-\nu) u^{\prime} r-\alpha(1+\nu) r T(r, t)\right], \\
\sigma_{\theta}=\frac{1}{2(1-2 \nu)}\left\{2 G\left(\frac{u}{r}+2 \nu u^{\prime}+\epsilon_{0}\right)+(1-2 \nu) \sigma_{0}\right. \\
\left.-\left[4 G \alpha(1+\nu)+\beta(1-2 \nu) \sigma_{0}\right] T(r, t)\right\} .
\end{gathered}
$$

Inserting these equations into Eq. (4.3) field equation for plastic region II is obtained:

$$
\begin{aligned}
r^{2} u^{\prime \prime}+r u^{\prime}-\frac{u}{2(1-\nu)}= & \frac{r}{4 G(1-\nu)}\left[(1-2 \nu)\left(2 G \epsilon_{0}+\sigma_{0}-2 \rho \omega^{2} r^{2}\right)\right. \\
& -\beta(1-2 \nu) \sigma_{0} T(r, t)+4 G \alpha(1+\nu) \\
& \left.\times r T^{\prime}(r, t)\right]
\end{aligned}
$$

Solution of homogeneous part of field equation is

$$
u_{h}=C_{5} r^{M}+\frac{C_{6}}{r^{M}},
$$


where $C_{5}$ and $C_{6}$ are arbitrary integration constants and

$$
M=\sqrt{\frac{1}{2(1-\nu)}} .
$$

For the particular solution, method of Variation of parameter is used as defined in the elastic region. For $Y_{1}(r)=r^{M}$, and $Y_{2}(r)=1 / r^{M}$, Wronksian is calculated by using Eq. (4.16) as

$$
W(r)=\frac{-2 M}{r}
$$

In Eq. (4.68), it is visible that

$$
\begin{aligned}
F(r)= & \frac{1}{r^{2}}\left\{\frac { r } { 4 G ( 1 - \nu ) } \left[(1-2 \nu)\left(2 G \epsilon_{0}+\sigma_{0}-2 \rho \omega^{2} r^{2}\right)\right.\right. \\
& \left.\left.-\beta(1-2 \nu) \sigma_{0} T(r, t)+4 G \alpha(1+\nu) r T^{\prime}(r, t)\right]\right\} .
\end{aligned}
$$

By using Eqs. (4.12) and (4.15) particular solution is compiled as

$$
\begin{aligned}
u_{p}= & \epsilon_{0} r-\frac{(1-2 \nu) \rho \omega^{2} r^{3}}{G(17-18 \nu)}+\frac{\sigma_{0}}{2 G}\left\{r-\frac{\beta(1-2 \nu)}{4 M(1-\nu)}\left[r^{M} \int_{0}^{r} T(\xi, t) \xi^{-M} d \xi\right.\right. \\
& \left.\left.-r^{-M} \int_{0}^{r} T(\xi, t) \xi^{M} d \xi\right]\right\}+\frac{\alpha(1+\nu)}{2 M(1-\nu)}\left[r^{M} \int_{0}^{r} \frac{\partial T(\xi, t)}{\partial \xi} \xi^{1-M} d \xi\right. \\
& \left.-r^{-M} \int_{0}^{r} \frac{\partial T(\xi, t)}{\partial \xi} \xi^{1+M} d \xi\right]
\end{aligned}
$$

Integration by parts is applied to get rid of derivatives of temperature in the integrals and following solutions are obtained

$$
\begin{aligned}
& \int_{0}^{r} \frac{\partial T(\xi, t)}{\partial \xi} \xi^{1-M} d \xi=r^{1-M} T(r, t)-(1-M) \int_{0}^{r} T(\xi, t) \xi^{-M} d \xi \\
& \int_{0}^{r} \frac{\partial T(\xi, t)}{\partial \xi} \xi^{1+M} d \xi=r^{1+M} T(r, t)-(1+M) \int_{0}^{r} T(\xi, t) \xi^{M} d \xi
\end{aligned}
$$

The integrals in Eqs. (4.74) and (4.75) are amenable to analytical treatment. The results are

$$
\begin{aligned}
\int_{0}^{r} \bar{T}(\xi, t) \xi^{M} d \xi= & \frac{T_{m}}{t_{t}}\left\{\frac{r^{1+M}\left[(1+M) r^{2}-(3+M)\left(b^{2}-4 \kappa t\right)\right]}{4 \kappa(1+M)(3+M)}\right. \\
& \left.+\frac{2}{\kappa b(1+M)} \sum_{n=1}^{\infty} e^{-\kappa \gamma_{n}^{2} t} \frac{r^{1+M} F_{H}\left(a_{1}, a_{2}, a_{3} ; z\right)}{\gamma_{n}^{3} J_{1}\left(b \gamma_{n}\right)}\right\}
\end{aligned}
$$

where $F_{H}\left(a_{1}, a_{2}, a_{3} ; z\right)$ is a hypergeometric function and is described as

$$
\begin{aligned}
F_{H}\left(a_{1}, a_{2}, a_{3} ; z\right)= & 1+\frac{a_{1}}{a_{2} a_{3}} z+\frac{a_{1}\left(1+a_{1}\right)}{2 a_{2}\left(1+a_{2}\right) a_{3}\left(1+a_{3}\right)} z^{2} \\
& +\frac{a_{1}\left(1+a_{1}\right)\left(2+a_{1}\right)}{6 a_{2}\left(1+a_{2}\right)\left(2+a_{2}\right) a_{3}\left(1+a_{3}\right)\left(2+a_{3}\right)} z^{3}+\cdots
\end{aligned}
$$


and where

$$
\begin{aligned}
a_{1} & =\frac{1}{2}+\frac{M}{2}, \\
a_{2} & =1, \\
a_{3} & =\frac{3}{2}+\frac{M}{2}, \\
z & =-\frac{1}{4} r^{2} \gamma_{n}^{2} .
\end{aligned}
$$

and

$$
\begin{aligned}
\int_{0}^{r} \bar{T}(\xi, t) \xi^{-M} d \xi= & \frac{T_{m}}{t_{t}}\left\{\frac{r^{1-M}\left[(1-M) r^{2}-(3-M)\left(b^{2}-4 \kappa t\right)\right]}{4 \kappa(1-M)(3-M)}\right. \\
& \left.+\frac{2}{\kappa b(1-M)} \sum_{n=1}^{\infty} e^{-\kappa \gamma_{n}^{2} t} \frac{r^{1-M} F_{H}\left(a_{1}, a_{2}, a_{3} ; z\right)}{\gamma_{n}^{3} J_{1}\left(b \gamma_{n}\right)}\right\},
\end{aligned}
$$

where $F_{H}\left(a_{1}, a_{2}, a_{3} ; z\right)$ is same as in Eq. (4.77) and

$$
\begin{aligned}
a_{1} & =\frac{1}{2}-\frac{M}{2}, \\
a_{2} & =1, \\
a_{3} & =\frac{3}{2}-\frac{M}{2}, \\
z & =-\frac{1}{4} r^{2} \gamma_{n}^{2} .
\end{aligned}
$$

After some simplification and with Eq. (4.21), radial displacement is acquired as

$$
\begin{aligned}
u= & C_{5} r^{M}+\frac{C_{6}}{r^{M}}+r\left(\epsilon_{0}+\frac{\sigma_{0}}{2 G}\right)-\frac{(1-2 \nu) \rho \omega^{2} r^{3}}{G(17-18 \nu)} \\
& +\frac{1}{8 G M(1-\nu)}\left\{\frac{4 G \alpha(1+M)(1+\nu)+\beta(1-2 \nu) \sigma_{0}}{r^{M}} \int_{0}^{r} T(\xi, t) \xi^{M} d \xi\right. \\
& \left.-r^{M}\left[4 G \alpha(1-M)(1+\nu)+\beta(1-2 \nu) \sigma_{0}\right] \int_{0}^{r} T(\xi, t) \xi^{-M} d \xi\right\} .
\end{aligned}
$$

Substituting radial displacement and its radial derivative into Eqs. (4.66) and (4.67) gives radial and circumferential stresses

$$
\begin{aligned}
\sigma_{r}= & \frac{2 G}{(1-2 \nu) r}\left\{C_{5}[M(1-\nu)+\nu] r^{M}-C_{6}[M(1-\nu)-\nu] r^{-M}+(1+\nu) \epsilon_{0} r\right. \\
& \left.+\frac{\sigma_{0} r}{2 G}\right\}-\frac{2(3-2 \nu) \rho \omega^{2} r^{2}}{17-18 \nu}-\frac{1}{4 M(1-\nu)(1-2 \nu) r}\{[M(1-\nu)+\nu] \\
& \times\left[4 G \alpha(1-M)(1+\nu)+\beta(1-2 \nu) \sigma_{0}\right] r^{M} \int_{0}^{r} T(\xi, t) \xi^{-M} d \xi \\
& +\frac{[M(1-\nu)-\nu]\left[4 G \alpha(1+M)(1+\nu)+\beta(1-2 \nu) \sigma_{0}\right]}{r^{M}} \\
& \left.\times \int_{0}^{r} T(\xi, t) \xi^{M} d \xi\right\},
\end{aligned}
$$




$$
\begin{aligned}
\sigma_{\theta}= & \frac{G}{(1-2 \nu) r}\left[C_{5}(1+2 M \nu) r^{M}+C_{6}(1-2 M \nu) r^{-M}+2(1+\nu) \epsilon_{0} r\right. \\
& \left.+\frac{\sigma_{0} r}{G}\right]-\frac{(1+6 \nu) \rho \omega^{2} r^{2}}{17-18 \nu}-\frac{1}{8 M(1-\nu)(1-2 \nu) r}\{(1+2 M \nu) \\
& \times\left[4 G \alpha(1-M)(1+\nu)+\beta(1-2 \nu) \sigma_{0}\right] r^{M} \int_{0}^{r} T(\xi, t) \xi^{-M} d \xi \\
& \left.-\frac{(1-2 M \nu)\left[4 G \alpha(1+M)(1+\nu)+\beta(1-2 \nu) \sigma_{0}\right]}{r^{M}} \int_{0}^{r} T(\xi, t) \xi^{M} d \xi\right\} \\
& -\frac{4 G \alpha(1+\nu)+\beta(1-\nu) \sigma_{0}}{2(1-\nu)} T(r, t) .
\end{aligned}
$$

Axial stress component is obtained by making use of Eq. (4.63) as

$$
\begin{aligned}
\sigma_{z}= & \frac{G}{(1-2 \nu) r}\left[C_{5}(1+2 M \nu) r^{M}+C_{6}(1-2 M \nu) r^{-M}+2(1+\nu) \epsilon_{0} r\right. \\
& \left.+\frac{2 \nu \sigma_{0} r}{G}\right]-\frac{(1+6 \nu) \rho \omega^{2} r^{2}}{17-18 \nu}-\frac{1}{8 M(1-\nu)(1-2 \nu) r}\{(1+2 M \nu) \\
& \times\left[4 G \alpha(1-M)(1+\nu)+\beta(1-2 \nu) \sigma_{0}\right] r^{M} \int_{0}^{r} T(\xi, t) \xi^{-M} d \xi \\
& \left.-\frac{(1-2 M \nu)\left[4 G \alpha(1+M)(1+\nu)+\beta(1-2 \nu) \sigma_{0}\right]}{r^{M}} \int_{0}^{r} T(\xi, t) \xi^{M} d \xi\right\} \\
& -\frac{4 G \alpha(1+\nu)-\beta(1-\nu) \sigma_{0}}{2(1-\nu)} T(r, t) .
\end{aligned}
$$

Finally, axial and circumferential plastic strains are derived with the help of Eqs. (4.61) and (4.64) as

$$
\begin{aligned}
\epsilon_{z}^{p}= & -\epsilon_{\theta}^{p}=-\frac{1}{2 r}\left(C_{5} r^{M}+\frac{C_{6}}{r^{M}}\right)+\frac{(1-2 \nu) \rho \omega^{2} r^{2}}{2 G(17-18 \nu)} \\
& +\frac{1}{16 G M(1-\nu) r}\left\{\left[4 G \alpha(1-M)(1+\nu)+\beta(1-2 \nu) \sigma_{0}\right] r^{M}\right. \\
& \times \int_{0}^{r} T(\xi, t) \xi^{-M} d \xi-\frac{\left[4 G \alpha(1+M)(1+\nu)+\beta(1-2 \nu) \sigma_{0}\right]}{r^{M}} \\
& \left.\times \int_{0}^{r} T(\xi, t) \xi^{M} d \xi\right\}-\frac{\beta \sigma_{0}}{4 G} T(r, t) .
\end{aligned}
$$

Axial force integral is more complicated than those of previous regions because of the necessity for evaluation of double integrals that are obtained by using Eq. (3.2). 
Method of integration by parts helps to transform double integrals into single ones as

$$
\begin{aligned}
\int_{\delta}^{\lambda} r^{-M}\left(\int_{0}^{r} T(\xi, t) \xi^{M} d \xi\right) d r= & \frac{\lambda^{1-M}}{1-M} \int_{0}^{\lambda} T(\xi, t) \xi^{M} d \xi \\
& -\frac{\delta^{1-M}}{1-M} \int_{0}^{\delta} T(\xi, t) \xi^{M} d \xi \\
& -\frac{1}{1-M} \int_{\delta}^{\lambda} T(\xi, t) \xi d \xi \\
\int_{\delta}^{\lambda} r^{M}\left(\int_{0}^{r} T(\xi, t) \xi^{-M} d \xi\right) d r= & \frac{\lambda^{1+M}}{1+M} \int_{0}^{\lambda} T(\xi, t) \xi^{-M} d \xi \\
& -\frac{\delta^{1+M}}{1+M} \int_{0}^{\delta} T(\xi, t) \xi^{-M} d \xi \\
& -\frac{1}{1+M} \int_{\delta}^{\lambda} T(\xi, t) \xi d \xi
\end{aligned}
$$

With the help of these integrations and after some simplifications, axial force integral for plastic region II is calculated as

$$
\begin{aligned}
F_{z}^{P I I}= & 2 \pi\left\{\frac { 1 } { 1 - 2 \nu } \left\{\frac{\left(\lambda^{1+M}-\delta^{1+M}\right)(1+2 M \nu) G C_{5}}{1+M}\right.\right. \\
& \left.+\frac{\left(\lambda^{1-M}-\delta^{1-M}\right)(1-2 M \nu) G C_{6}}{1-M}+\left(\lambda^{2}-\delta^{2}\right)\left[(1+\nu) G \epsilon_{0}+\nu \sigma_{0}\right]\right\} \\
& -\frac{\left(\lambda^{4}-\delta^{4}\right)(1+6 \nu) \rho \omega^{2}}{4(17-18 \nu)}-\frac{S_{1}}{1+M}\left[\lambda^{1+M} \int_{0}^{\lambda} T(\xi, t) \xi^{-M} d \xi\right. \\
& \left.-\delta^{1+M} \int_{0}^{\delta} T(\xi, t) \xi^{-M} d \xi\right]+\frac{S_{2}}{1-M}\left[\lambda^{1-M} \int_{0}^{\lambda} T(\xi, t) \xi^{M} d \xi\right. \\
& \left.-\delta^{1-M} \int_{0}^{\delta} T(\xi, t) \xi^{M} d \xi\right]+\left(\frac{S_{1}}{1+M}-\frac{S_{2}}{1-M}-S_{3}\right) \\
& \left.\times \int_{\delta}^{\lambda} T(\xi, t) \xi d \xi\right\},
\end{aligned}
$$

in which

$$
\begin{aligned}
S_{1} & =\frac{(1+2 M \nu)\left[4(1-M)(1+\nu) G \alpha+(1-2 \nu) \sigma_{0} \beta\right]}{8 M(1-\nu)(1-2 \nu)}, \\
S_{2} & =\frac{(1-2 M \nu)\left[4(1+M)(1+\nu) G \alpha+(1-2 \nu) \sigma_{0} \beta\right]}{8 M(1-\nu)(1-2 \nu)}, \\
S_{3} & =\frac{4(1+\nu) G \alpha-(1-\nu) \sigma_{0} \beta}{2(1-\nu)} .
\end{aligned}
$$

\subsection{Predeformed Elastic Region}

Predeformed elastic region is an elastic region that includes permanent plastic deformations, which have been occured in elastic-plastic state. It becomes valid after 
the unloading starts. Formulation of this region is identical with the elastic region. However, permanent plastic strains, i.e., $\epsilon_{i}^{p r}$, are included in this region [16]. In formulation, by using plastic incompressibility

$$
\epsilon_{z}^{p r}=-\left(\epsilon_{r}^{p r}+\epsilon_{\theta}^{p r}\right)
$$

and with help of Hooke's law in axial direction (4.5c), axial stress is obtained as

$$
\sigma_{z}=\nu\left(\sigma_{r}+\sigma_{\theta}\right)+2 G(1+\nu)\left[\epsilon_{0}+\epsilon_{r}^{p r}+\epsilon_{\theta}^{p r}-\alpha T(r, t)\right] .
$$

Substituting this expression into Eqs. (4.5a) and (4.5b) and using Eq. (4.4) gives

$$
\begin{aligned}
\sigma_{r}= & \frac{2 G}{r(1-2 \nu)}\left\{\nu u+r(1-\nu) u^{\prime}+r\left[(1-2 \nu) \epsilon_{r}^{p r}-\nu \epsilon_{0}\right]\right. \\
& -r \alpha(1+\nu) T(r, t)\}, \\
\sigma_{\theta}= & \frac{2 G}{r(1-2 \nu)}\left\{(1-\nu) u+r \nu u^{\prime}-r\left[(1-2 \nu) \epsilon_{\theta}^{p r}-\nu \epsilon_{0}\right]\right. \\
& -r \alpha(1+\nu) T(r, t)\} .
\end{aligned}
$$

Inserting these stress expressions into equation of motion, Eq. (4.3), gives governing differential equation for displacement

$$
\begin{aligned}
r^{2} \frac{d^{2} u}{d r^{2}}+r \frac{d u}{d r}-u= & -\frac{(1-2 \nu) \rho \omega^{2} r^{3}}{2 G(1-\nu)}+\frac{r}{1-\nu}\left\{(1-2 \nu)\left(\epsilon_{r}^{p r}+r \epsilon_{r}^{p r \prime}-\epsilon_{\theta}^{p r}\right)\right. \\
& \left.+r \alpha(1+\nu) T^{\prime}(r, t)\right\}
\end{aligned}
$$

which assures the solution

$$
\begin{aligned}
u= & \frac{C_{1}^{*}}{r}+C_{2}^{*} r-\frac{(1-2 \nu) \rho \omega^{2} r^{3}}{16 G(1-\nu)}+\frac{(1-2 \nu)}{2(1-\nu)}\left[r \int_{0}^{r} \frac{\epsilon_{r}^{p r}-\epsilon_{\theta}^{p r}}{\xi} d \xi\right. \\
& \left.+\frac{1}{r} \int_{0}^{r} \xi\left(\epsilon_{r}^{p r}+\epsilon_{\theta}^{p r}\right) d \xi\right]+\frac{\alpha(1+\nu)}{r(1-\nu)} \int_{0}^{r} T(\xi, t) \xi d \xi,
\end{aligned}
$$

where $C_{1}^{*}$ and $C_{2}^{*}$ are new integration constants. The stresses are obtained as (compare with [16])

$$
\begin{aligned}
\sigma_{r}= & -\frac{2 G C_{1}^{*}}{r^{2}}+\frac{2 G}{1-2 \nu}\left(C_{2}^{*}+\nu \epsilon_{0}\right)-\frac{1}{8(1-\nu)}\left\{(3-2 \nu) \rho \omega^{2} r^{2}\right. \\
& -8 G\left[\int_{0}^{r} \frac{\epsilon_{r}^{p r}-\epsilon_{\theta}^{p r}}{\xi} d \xi-\frac{1-2 \nu}{r^{2}} \int_{0}^{r} \xi\left(\epsilon_{r}^{p r}+\epsilon_{\theta}^{p r}\right) d \xi\right] \\
& \left.+\frac{16 G \alpha(1+\nu)}{r^{2}} \int_{0}^{r} T(\xi, t) \xi d \xi\right\} \\
\sigma_{\theta}= & \frac{2 G C_{1}^{*}}{r^{2}}+\frac{2 G}{1-2 \nu}\left(C_{2}^{*}+\nu \epsilon_{0}\right)-\frac{1}{8(1-\nu)}\left\{(1+2 \nu) \rho \omega^{2} r^{2}+8 G\left[-2 \nu \epsilon_{r}^{p r}\right.\right. \\
& \left.+2(1-\nu) \epsilon_{\theta}^{p r}-\int_{0}^{r} \frac{\epsilon_{r}^{p r}-\epsilon_{\theta}^{p r}}{\xi} d \xi-\frac{1-2 \nu}{r^{2}} \int_{0}^{r} \xi\left(\epsilon_{r}^{p r}+\epsilon_{\theta}^{p r}\right) d \xi\right] \\
& \left.+\frac{16 G \alpha(1+\nu)}{r^{2}}\left[r^{2} T(r, t)-\int_{0}^{r} T(\xi, t) \xi d \xi\right]\right\}
\end{aligned}
$$




$$
\begin{aligned}
\sigma_{z}= & \frac{2 G}{1-2 \nu}\left[2 \nu C_{2}^{*}+(1-\nu) \epsilon_{0}\right]-\frac{1}{2(1-\nu)}\left[\nu \rho \omega^{2} r^{2}+4 G \alpha(1+\nu) T(r, t)\right] \\
& +\frac{2 G}{1-\nu}\left[\epsilon_{r}^{p r}+(1-\nu) \epsilon_{\theta}^{p r}+\nu \int_{0}^{r} \frac{\epsilon_{r}^{p r}-\epsilon_{\theta}^{p r}}{\xi} d \xi\right]
\end{aligned}
$$

These equations include some integrals such as $\frac{1}{r^{2}} \int_{0}^{r} f(\xi) d \xi$ and $\frac{1}{r} \int_{0}^{r} f(\xi) d \xi$. These integrals are not singular at $r=0$. By taking limit as $r \rightarrow 0$ and using L'Hopital's rule, it can easily be shown that

$$
\begin{gathered}
\lim _{r \rightarrow 0} \frac{1}{r} \int_{0}^{r} \xi\left(\epsilon_{r}^{p r}+\epsilon_{\theta}^{p r}\right) d \xi=0, \\
\lim _{r \rightarrow 0} \frac{1}{r^{2}} \int_{0}^{r} \xi\left(\epsilon_{r}^{p r}+\epsilon_{\theta}^{p r}\right) d \xi=\frac{\epsilon_{r}^{p r}+\epsilon_{\theta}^{p r}}{2} .
\end{gathered}
$$

Addition to these limiting cases, Eqs. (4.26) and (4.27) are valid in this region as well. Force integral for this region will be determined in the range $0 \leq r \leq b$ which is used in unloaded state:

$$
\begin{aligned}
F_{z}^{p d e}= & 2 \pi \int_{0}^{b} \sigma_{z} r d r=2 \pi\left\{\frac{b^{2} G\left[2 \nu C_{2}^{*}+(1-\nu) \epsilon_{0}\right]}{(1-2 \nu)}\right. \\
& -\frac{b^{4} \nu \rho \omega^{2}+16 G \alpha(1+\nu) \int_{0}^{b} T(\xi, t) \xi d \xi}{8(1-\nu)} \\
& +\frac{2 G}{1-\nu}\left\{\nu\left[\frac{b^{2}}{2} \int_{0}^{b} \frac{\epsilon_{r}^{p r}-\epsilon_{\theta}^{p r}}{\xi} d \xi-\frac{1}{2} \int_{0}^{b} \xi\left(\epsilon_{r}^{p r}-\epsilon_{\theta}^{p r}\right) d \xi\right]\right. \\
& \left.\left.+\int_{0}^{b} \xi \epsilon_{r}^{p r} d \xi+(1-\nu) \int_{0}^{b} \xi \epsilon_{\theta}^{p r} d \xi\right\}\right\}
\end{aligned}
$$




\section{CHAPTER 5}

\section{EVOLUTION OF STRESSES DURING TEMPERATURE CYCLE}

\subsection{Purely Elastic State}

Initially, the entire shaft is in a purely elastic state. Hence, the distribution of displacement and stresses are described by Eqs. (4.22-4.25). These equations contain three unknowns $C_{1}, C_{2}$, and $\epsilon_{0}$ that have to be determined. With the help of boundary conditions (3.1-3.3), it is possible to obtain analytical expressions for these unknowns. From condition (3.3) there follows immediately

$$
C_{1}=0,
$$

to assure that the mechanical variables are finite at the center. Simultaneous solution of Eqs. (4.23) and (4.28) with substitution of $\delta=0$ and $\lambda=b$ reveals that

$$
\begin{gathered}
C_{2}=\frac{1}{(1-\nu)}\left[\frac{(3-5 \nu) \rho \omega^{2} b^{2}}{16 G(1+\nu)}+\frac{\alpha(1-3 \nu)}{b^{2}} \int_{0}^{b} r T(r, t) d r\right], \\
\epsilon_{0}=-\frac{\nu \rho \omega^{2} b^{2}}{4 G(1+\nu)}+\frac{2 \alpha}{b^{2}} \int_{0}^{b} r T(r, t) d r .
\end{gathered}
$$

Since prior to the temperature cycle the shaft is at the reference temperature, it is subjected only to mechanical load that is caused by rotation. In increasing rotation speed, solutions show (as given in [12]) that yielding commences at the center of the shaft as soon as

$$
\left.\left(\sigma_{\theta}-\sigma_{z}\right)\right|_{r=0}=\left.\left(\sigma_{r}-\sigma_{z}\right)\right|_{r=0}=\sigma_{0} .
$$

By using this equality, the elastic limit rotation speed for isothermal shaft is obtained

$$
\omega_{e}^{i}=\sqrt{\frac{8 \sigma_{0}(1-\nu)}{(3-4 \nu) \rho b^{2}}},
$$


where superscript $i$ denotes the isothermal case. This result is in agreement with that in [12]. As described in the Introduction Chapter, shaft is rotated up to a certain angular speed smaller than $\omega_{e}^{i}$. Thereafter, this rotation speed is kept constant and then the temperature cycle is applied to the surface of the shaft. During merely rotation, and at the beginning of the thermal loading, shaft will behave elastically. Partially plastic behavior will be observed in the later stages of the thermal loading.

\subsection{Elastic-Plastic State}

Plastic flow starts at the center of the shaft in the course of the temperature cycle. At time $t=t_{p}$, the condition $\sigma_{\theta}-\sigma_{z}=\sigma_{r}-\sigma_{z}=\sigma_{t h}$ is reached at the center of the shaft due to thermal softening of the material, as a result of which plastic deformation begins. Plastic region I and plastic region II emerge simultaneously and spread into the shaft. Therefrom, the shaft consists of plastic region $\mathrm{I}$ in the range of $0 \leq r \leq r_{1}$, plastic region II in $r_{1} \leq r \leq r_{2}$, and an elastic region in $r_{2} \leq r \leq b$ with $r_{1}$ being border radius separating two plastic regions and $r_{2}$ is the one between plastic region II and elastic region. Hence, the solution of this problem necessitates the evaluation of 9 unknowns: $C_{1}, C_{2}$ (from elastic region), $C_{3}, C_{4}$ (from plastic region I), $C_{5}, C_{6}$ (from plastic region II), axial strain $\epsilon_{0}$, border radii $r_{1}$ and $r_{2}$. In order to determine these unknowns, boundary conditions and interface conditions are used. Quite generally, at any border radius ten conditions of continuity can be formulated, in principle: the three principal stresses, the radial displacement, elastic parts and plastic parts of the strains (as well as their thermal parts, of course) are continuous throughout the shaft. However, the continuity of three properly chosen quantities e.g. of $\sigma_{r}, \sigma_{t h}$ and $u$ implies the continuity of all the other ones [11]. Nine nonredundant boundary and interface conditions to evaluate unknowns are:

$$
\begin{gathered}
u^{p I}(0)=0, \\
\sigma_{r}^{e}(b)=0, \\
\sigma_{r}^{p I}\left(r_{1}\right)=\sigma_{r}^{p I I}\left(r_{1}\right), \\
u^{p I}\left(r_{1}\right)=u^{p I I}\left(r_{1}\right), \\
\sigma_{r}^{p I I}\left(r_{1}\right)-\sigma_{z}^{p I I}\left(r_{1}\right)=\sigma_{t h}\left(r_{1}\right),
\end{gathered}
$$




$$
\begin{gathered}
\sigma_{r}^{p I I}\left(r_{2}\right)=\sigma_{r}^{e}\left(r_{2}\right) \\
u^{p I I}\left(r_{2}\right)=u^{e}\left(r_{2}\right) \\
\sigma_{\theta}^{e}\left(r_{2}\right)-\sigma_{z}^{e}\left(r_{2}\right)=\sigma_{t h}\left(r_{2}\right) \\
\int_{0}^{r_{1}} \sigma_{z}^{p I} r d r+\int_{r_{1}}^{r_{2}} \sigma_{z}^{p I I} r d r+\int_{r_{2}}^{b} \sigma_{z}^{e} r d r=0
\end{gathered}
$$

where the superscript $e$ denotes elastic region, $p I$ is plastic region $\mathrm{I}$, and $p I I$ is plastic region II. The condition (5.14) is easily assembled with the help of already calculated integrals in Eqs. (4.54), (4.94) and (4.28) by accordingly adjusting limits of the integrals. By using conditions (5.6-5.8) and (5.11-5.13), the constants of integration, $C_{i}(i=1-6)$, can be expressed in terms of the interface radii $r_{1}, r_{2}$ and the axial strain $\epsilon_{0}$ since the equations are linear in constants of integration:

$$
\begin{aligned}
C_{1}= & \frac{r_{2}^{2} b^{2}}{2\left[(1-2 \nu) r_{2}^{2}+b^{2}\right] G}\left\{\frac{(1-2 \nu)\left[r_{2}^{2}-(3-2 \nu) b^{2}\right] \rho \omega^{2}}{8(1-\nu)}+2(1+\nu) G \epsilon_{0}\right. \\
+ & \sigma_{0}\left[1-\beta T\left(r_{2}, t\right)\right]-\frac{2 G \alpha(1+\nu)}{(1-\nu) r_{2}^{2} b^{2}}\left[(1-2 \nu) r_{2}^{2} \int_{0}^{b} \xi T(\xi, t) d \xi\right. \\
+ & \left.\left.b^{2} \int_{0}^{r_{2}} \xi T(\xi, t) d \xi\right]\right\} \\
C_{2}= & \frac{1-2 \nu}{2\left[(1-2 \nu) r_{2}^{2}+b^{2}\right] G}\left\{\frac{\left[(1-2 \nu) r_{2}^{4}+(3-2 \nu) b^{4}\right] \rho \omega^{2}}{8(1-\nu)}\right. \\
& +2\left(r_{2}^{2}-\frac{b^{2} \nu}{1-2 \nu}\right) G \epsilon_{0}+r_{2}^{2} \sigma_{0}\left[1-\beta T\left(r_{2}, t\right)\right]+\frac{2 G \alpha(1+\nu)}{1-\nu} \\
& \left.\times\left[\int_{0}^{b} \xi T(\xi, t) d \xi-\int_{0}^{r_{2}} \xi T(\xi, t) d \xi\right]\right\} \\
C_{3}= & \frac{2 G}{1-}\left\{C_{5} r_{1}^{-1+M}[M(1-\nu)+\nu]-C_{6} r_{1}^{-1-M}[M(1-\nu)-\nu]\right. \\
& \left.+(1+\nu) \epsilon_{0}+\frac{\sigma_{0}}{2 G}\right\}+\frac{5(1-2 \nu) \rho \omega^{2} r_{1}^{2}}{2(17-18 \nu)} \frac{1}{4 M(1-\nu)(1-2 \nu)} \\
& \times\left\{r_{1}^{-1+M}[M(1-\nu)+\nu]\left[4 G \alpha(1-M)(1+\nu)+\beta(1-2 \nu) \sigma_{0}\right]\right. \\
& \times \int_{0}^{r_{1}} \xi^{-M} T(\xi, t) d \xi+r_{1}^{-1-M}[M(1-\nu)-\nu] \\
& \left.\times\left[4 G \alpha(1+M)(1+\nu)+\beta(1-2 \nu) \sigma_{0}\right] \int_{0}^{r_{1}} \xi^{M} T(\xi, t) d \xi\right\} \\
& \\
& \\
& \\
& \\
&
\end{aligned}
$$




$$
\begin{aligned}
C_{5}= & \frac{r_{2}^{-M}}{2 M}\left[-\frac{C_{1}(1-M)}{r_{2}}+(1+M) r_{2}\left(C_{2}-\frac{\sigma_{0}}{2 G}-\epsilon_{0}\right)\right. \\
& \left.-\frac{(3+M)(1-2 \nu)^{2} \rho \omega^{2} r_{2}^{3}}{16(1-\nu)(17-18 \nu) G}\right]-\frac{\alpha(1-M)(1+\nu)}{2 M(1-\nu)}\left\{r_{2}^{-1-M} \int_{0}^{r_{2}} \xi T(\xi, t) d \xi\right. \\
& \left.-\left[1+\frac{\beta(1-2 \nu) \sigma_{0}}{4 G \alpha(1-M)(1+\nu)}\right] \int_{0}^{r_{2}} \xi^{-M} T(\xi, t) d \xi\right\}, \\
C_{6}= & \frac{r_{2}^{M}}{2 M}\left[\frac{C_{1}(1+M)}{r_{2}}-(1-M) r_{2}\left(C_{2}-\frac{\sigma_{0}}{2 G}-\epsilon_{0}\right)\right. \\
& \left.+\frac{(3-M)(1-2 \nu)^{2} \rho \omega^{2} r_{2}^{3}}{16(1-\nu)(17-18 \nu) G}\right]+\frac{\alpha(1+M)(1+\nu)}{2 M(1-\nu)}\left\{r_{2}^{-1+M} \int_{0}^{r_{2}} \xi T(\xi, t) d \xi\right. \\
& \left.-\left[1+\frac{\beta(1-2 \nu) \sigma_{0}}{4 G \alpha(1+M)(1+\nu)}\right] \int_{0}^{r_{2}} \xi^{M} T(\xi, t) d \xi\right\}
\end{aligned}
$$

To determine remaining unknowns, $r_{1}, r_{2}$ and $\epsilon_{0}$, the nonlinear algebraic equations (5.9), (5.10) and (5.14) are solved for these unknowns by iteration. This state of stress is valid throughout the shaft until the beginning of the unloaded state.

\subsection{Unloaded State}

With increasing time, the expansion of the plastic zones becomes slower. In case that the shaft does not turn out fully plastic (which should be avoided in any case from the engineering point of view), its expansion ceases at time $t=t_{u b}$ when the second plastic region and elastic region border radius $r_{2}$ attains a stationary value. Thereafter, a predeformed elastic region begins to spread inwards rapidly, first into plastic region II then into plastic region I and to the center. The basic criterion for unloaded state at some radius $r$ at time $t_{u}(r)$ is (see [56])

$$
\left.\frac{\partial \epsilon_{\theta}^{p}(r, t)}{\partial t}\right|_{t=t_{u}(r)}=0
$$

where $\epsilon_{\theta}^{p}$ is described according to Eq. (4.91). Inversion of the function $t_{u}(r)$ yields $r_{u}(t)$, i.e., the time dependence of the interface radius separating the plastic and the unloaded regions. Since the plastic strains at a fixed radius are frozen with the onset of unloading at this radius, the permanent plastic strains then are given by

$$
\epsilon_{i}^{p}(r)=\epsilon_{i}^{p r}(r)=\epsilon_{i}^{p}\left[r, t_{u}(r)\right]
$$


However, the calculation of $r_{u}(t)$ from Eq. (5.21) and of the permanent plastic strains according to Eq. (5.22) is not an easy task, since the latter enters the equations which one needs for the calculation of the stresses, which in turn, influence the plastic strain distribution. Hence, one obtains a nonlinear, coupled system of algebraic and differential equations. In the related plane stress problem [74] such a system was treated iteratively by a time-discretization of the equation analogous to Eq. (5.21), and in [56] a quite concise treatment based on a universal expression for the displacement field was possible. A necessary prerequisite for this universal expression is the absence of plastic flow in the axial direction, which however in the present case does occur. On the other hand, in contrast to [74], the axial strain has to be found with the help of condition (3.2), too, which represents an additional coupling between the unknowns. Hence, a rigorous treatment of the unloading process could be performed in finite time steps requiring a very complex algorithm only, the achievable accuracy of which - in view of the fast unloading process - remains an open question. Therefore, unloading is treated in an approximate way by assuming sudden unloading in the entire plastic core at time $t_{u b}$, at which the expansion of the plastic zone ends. Thus, in the final stage the permanent plastic strains in Eqs. (4.103-4.106) are given by $\epsilon_{i}^{p}(r)=\epsilon_{i}^{p r}(r)=\epsilon_{i}^{p}\left(r, t_{u b}\right)$, and the entire shaft behaves elastically again. This approximation was discussed in detail in [38], where also an estimate for the occurring error was suggested: after the assumption of sudden unloading the equivalent stress $\sigma_{y}$, i.e., the difference of the extremal principal stresses according to Tresca's yield condition (which for a short interval of time exceeds the yield stress, thus slightly violating the yield condition), is calculated and compared with the yield stress. For a small difference of equivalent stress $\sigma_{y}$ and yield stress $\sigma_{t h}$, only a small error is to be expected; as it is shown in the next Chapter, this is the case for the present problem.

In this state, shaft behaves elastically in all radius of the shaft. However it should be noted that in the range of $0<r<r_{2}^{u}$ predeformed elastic region governs and in the rest of the radial direction $\left(r_{2}^{u}<r<b\right)$ only elastic region is the one where $r_{2}^{u}$ is the radius of interface between plastic region II and elastic region at $t=t_{u b}$. Hence, for whole shaft, formulation of the predeformed elastic region can be taken into account with considering $\epsilon_{i}^{p r}(r)=\epsilon_{i}^{p I}\left(r, t_{u b}\right)$ in $0<r<r_{1}^{u}, \epsilon_{i}^{p r}(r)=\epsilon_{i}^{p I I}\left(r, t_{u b}\right)$ in $r_{1}^{u}<r<r_{2}^{u}$, and $\epsilon_{i}^{p r}(r)=0$ in $r_{2}^{u}<r<b$ in which $r_{1}^{u}$ is the interface radius between 
plastic regions I and II at $t=t_{u b}$. Therefrom, to evaluate unknown constants, i.e., $C_{1}^{*}$, $C_{2}^{*}$ and $\epsilon_{0}$, Eqs. (3.1-3.3) are used and following analytical expressions are obtained:

$$
\begin{gathered}
C_{1}^{*}=0, \\
C_{2}^{*}=\frac{1}{2(1-\nu) b^{2}}\left[\frac{(3-5 \nu) \rho \omega^{2} b^{4}}{8 G(1+\nu)}-(1-2 \nu) b^{2} \int_{0}^{b} \frac{\epsilon_{r}^{p r}-\epsilon_{\theta}^{p r}}{\xi} d \xi\right. \\
\left.+\int_{0}^{b} \xi\left(\epsilon_{r}^{p r}+\epsilon_{\theta}^{p r}\right) d \xi+2 \alpha(1-3 \nu) \int_{0}^{b} \xi T(\xi, t) d \xi\right], \\
\epsilon_{0}=-\frac{\nu \rho \omega^{2} b^{2}}{4 G(1+\nu)}-\frac{2}{b^{2}} \int_{0}^{b} \xi\left(\epsilon_{r}^{p r}+\epsilon_{\theta}^{p r}\right) d \xi+\frac{2 \alpha}{b^{2}} \int_{0}^{b} \xi T(\xi, t) d \xi .
\end{gathered}
$$




\section{CHAPTER 6}

\section{RESULTS AND DISCUSSION}

\subsection{Non-Dimensional and Normalized Quantities}

For the presentation of numerical results, it is customary to use formal non-dimensional and normalized parameters. They are listed below.

$$
\begin{aligned}
& \text { radial coordinate }: x=\frac{r}{b}, \\
& \text { time : } \tau=\frac{\kappa t}{b^{2}}, \\
& \text { rotation speed : } \Omega^{2}=\frac{\rho \omega^{2} b^{2}}{\sigma_{0}}, \\
& \text { temperature dependence parameter }: \beta^{*}=\beta T_{m}, \\
& \text { temperature }: T^{*}=\frac{T}{T_{m}}, \\
& \text { stress }: \bar{\sigma}_{i}=\frac{\sigma_{i}}{\sigma_{0}}, \\
& \text { displacement }: \bar{u}=\frac{u G}{b \sigma_{0}}, \\
& \text { strain }: \bar{\epsilon}_{i}=\frac{\epsilon_{i} G}{\sigma_{0}} .
\end{aligned}
$$

In addition, as a measure for the maximum surface temperature during the transient heating, the parameter $q$ is introduced. It is defined as

$$
q=\frac{\alpha T_{m} G}{\sigma_{0}} .
$$

If the governing equations are rewritten in terms of these non-dimensional and normalized variables, dimensionless forms of integration constants are obtained. They 
are:

$$
\begin{aligned}
& \bar{C}_{1}=\frac{C_{1} G}{b^{2} \sigma_{0}}, \\
& \bar{C}_{2}=\frac{C_{2} G}{\sigma_{0}}, \\
& \bar{C}_{3}=\frac{C_{3}}{\sigma_{0}}, \\
& \bar{C}_{4}=\frac{C_{4} G}{b^{2} \sigma_{0}} \\
& \bar{C}_{5}=\frac{C_{5} b^{-1+M} G}{\sigma_{0}}, \\
& \bar{C}_{6}=\frac{C_{6} b^{-1-M} G}{\sigma_{0}} .
\end{aligned}
$$

Note that the term used in Eq. (3.10) may be normalized as

$$
\bar{\gamma}_{n}=b \gamma_{n} .
$$

Finally, by using Eq. (5.5), non-dimensional elastic limit rotation speed is expressed as

$$
\Omega_{e}^{i}=\frac{2 \sqrt{2(1-\nu)}}{\sqrt{3-4 \nu}} .
$$

\subsection{Numerical Results}

Numerical results are obtained by the calculation of unknown constants, analytical and numerical integrals and Bessel and hypergeometric functions in purely elastic, elastic-plastic and unloaded states. These calculations are performed by executing Fortran programs. Description of these programs are given in Appendix A and the program codes are presented in Appendices B-D.

The temperature cycle introduced in Figure 3.2 is plotted in Figure 6.1 for the nondimensional time parameters $\tau_{t}=1.2$ and $\tau_{c}=0.3$. As seen in the figure, the outer surface is heated until $\tau=\tau_{t}=1.2$. Hence, the outer surface temperature reaches maximum surface temperature and it is kept constant at that one until $\tau=\tau_{t}+\tau_{c}=$ 1.5. Then, cooling starts and it ends at $\tau=2 \tau_{t}+\tau_{c}=2.7$. Therefore, the surface temperature drops back to the reference temperature and it remains there for $\tau \geq 2.7$.

The evolution of the temperature field with time for the described temperature cycle is shown in Figures 6.2-6.6. The temperature field throughout the radial coordinate of 


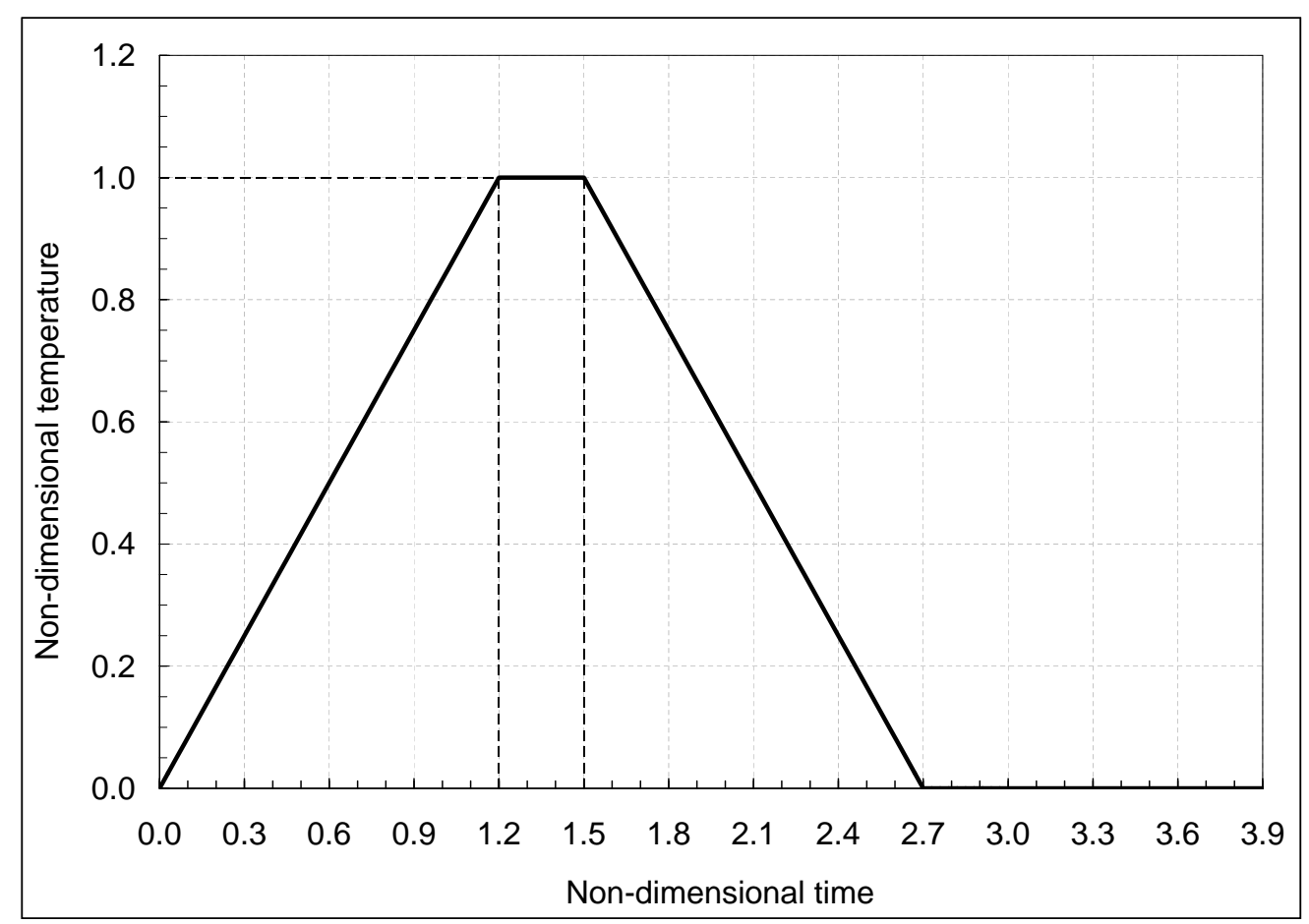

Figure 6.1: Prescribed surface temperature of the shaft $(x=1)$

the shaft during heating $\tau \leq 1.2$ (see Figure 6.1) at different times is shown in Figure 6.2. In this heating region, a positive temperature gradient is observed between the outer surface and the center of the shaft. Figure 6.3 shows the evolution of temperature field in the time interval $1.2 \leq \tau \leq 1.5$. One observes that only after the onset of cooling at $\tau=1.5$ does the temperature in the inner parts of the shaft reach its maximum. Additionally, it should be noted that at $\tau=1.5$, the temperature distribution is very close to isothermal case as difference of temperature between center and outer surface temperatures is very small.

In the Figure 6.4, temperature distribution in the shaft at the cooling time interval, i.e., $1.5 \leq \tau \leq 2.7$, is presented. At the end of this time period, temperature cycle is completed and the outer surface temperature returns to the reference temperature. After this moment, the outer surface stays at the reference temperature and hence isothermal shaft behavior is obtained eventually. Figures 6.5 and 6.6 put on view the evolution of the temperature field for $\tau>2.7$. With increasing time, the entire shaft cools down and an isothermal behavior is observed. Figure 6.6 is given in a small scale 
to emphasize the cases when the whole shaft gets closer to the isothermal case.

During heating, the temperature difference between the outer surface and the center of the shaft changes. This situation is depicted in Figure 6.7. This figure is useful to explain the behavior of the thermal loading. For example; positive temperature gradient is observed until $\tau=1.5$, but then negative temperature gradient emerges for $\tau>1.5$. The effect of these two types of thermal loading on the behavior of the deformation is expected to be different.

Table 6.1: Calculated constants of $\bar{C}_{2}$ and $\bar{\epsilon}_{0}$ at different rotations speeds in purely elastic state

\begin{tabular}{|l|c|c|}
\hline Rotation Speed $(\Omega)$ & $\bar{C}_{2}$ & $\bar{\epsilon}_{0}$ \\
\hline $0.4410\left(0.25 \times \Omega_{e}^{i}\right)$ & $2.003205 \times 10^{-2}$ & $-1.121795 \times 10^{-2}$ \\
\hline $0.8819\left(0.5 \times \Omega_{e}^{i}\right)$ & $8.012821 \times 10^{-2}$ & $-4.487180 \times 10^{-2}$ \\
\hline $1.3229\left(0.75 \times \Omega_{e}^{i}\right)$ & 0.180289 & -0.100962 \\
\hline $1.5875\left(0.9 \times \Omega_{e}^{i}\right)$ & 0.259615 & -0.145385 \\
\hline
\end{tabular}

As mentioned earlier, before the temperature cycle is applied, the shaft is rotated up to a certain rotation speed, which is below the elastic limit for isothermal case $\Omega_{e}^{i}$. In this investigation, the maximum rotation speed is selected as $90 \%$ of elastic limit rotation speed for isothermal shaft. By choosing $\nu=0.3$, the maximum rotation speed is calculated as 1.5875 with help of Eq. (6.8). Other parameter values for the selected material are $q=0.6$ and $\beta^{*}=0.2$. Change of stresses and displacement distributions with increasing rotation speed for $\Omega \leq 1.5875$ are plotted in Figures $6.8-6.11$. It should be noted that the shaft is only under centrifugal force because of rotation and it has not been subjected to any thermal load yet. In Figure 6.8, radial stress, in Figure 6.9 circumferential stress, in Figure 6.10 axial stress and in Figure 6.11 radial displacement distributions are plotted for different rotation speeds. For these speeds, unknown constants are calculated by using Eqs. (5.2) and (5.3) and given in table 6.1. Finally, $\Omega=0.9 \times \Omega_{e}^{i}=1.5875$ is selected as maximum rotation speed in this study and distributions of stresses, displacement and ratio of equivalent stress and yield stress $\bar{\sigma}_{y} / \bar{\sigma}_{t h}$ under this rotation speed are also plotted in Figure 6.12. As seen in the figure, the ratio of $\bar{\sigma}_{y} / \bar{\sigma}_{t h}$ is less than 1 since yielding does not occur yet. 


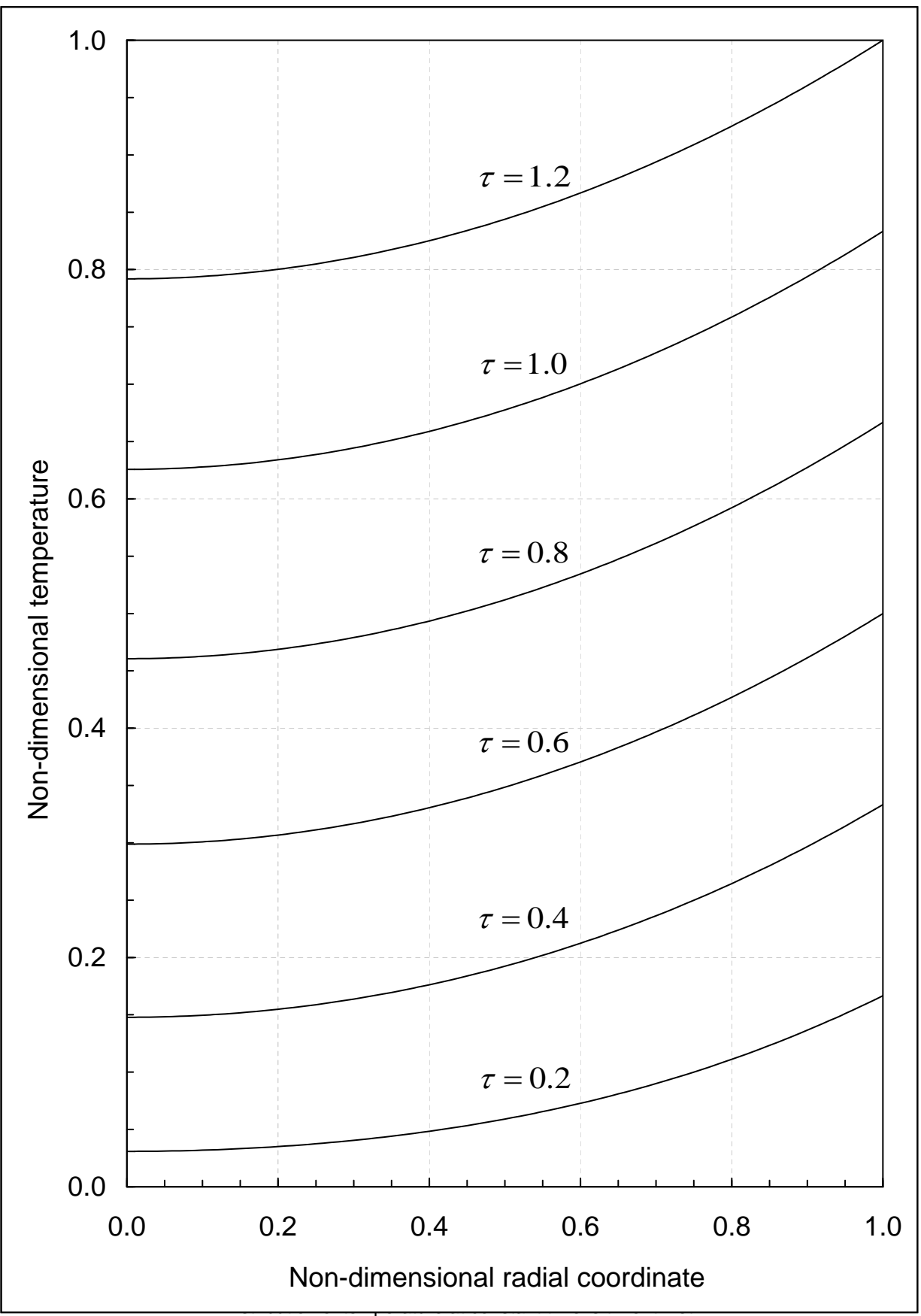

Figure 6.2: Transient temperature field at $\tau \leq 1.2$ 


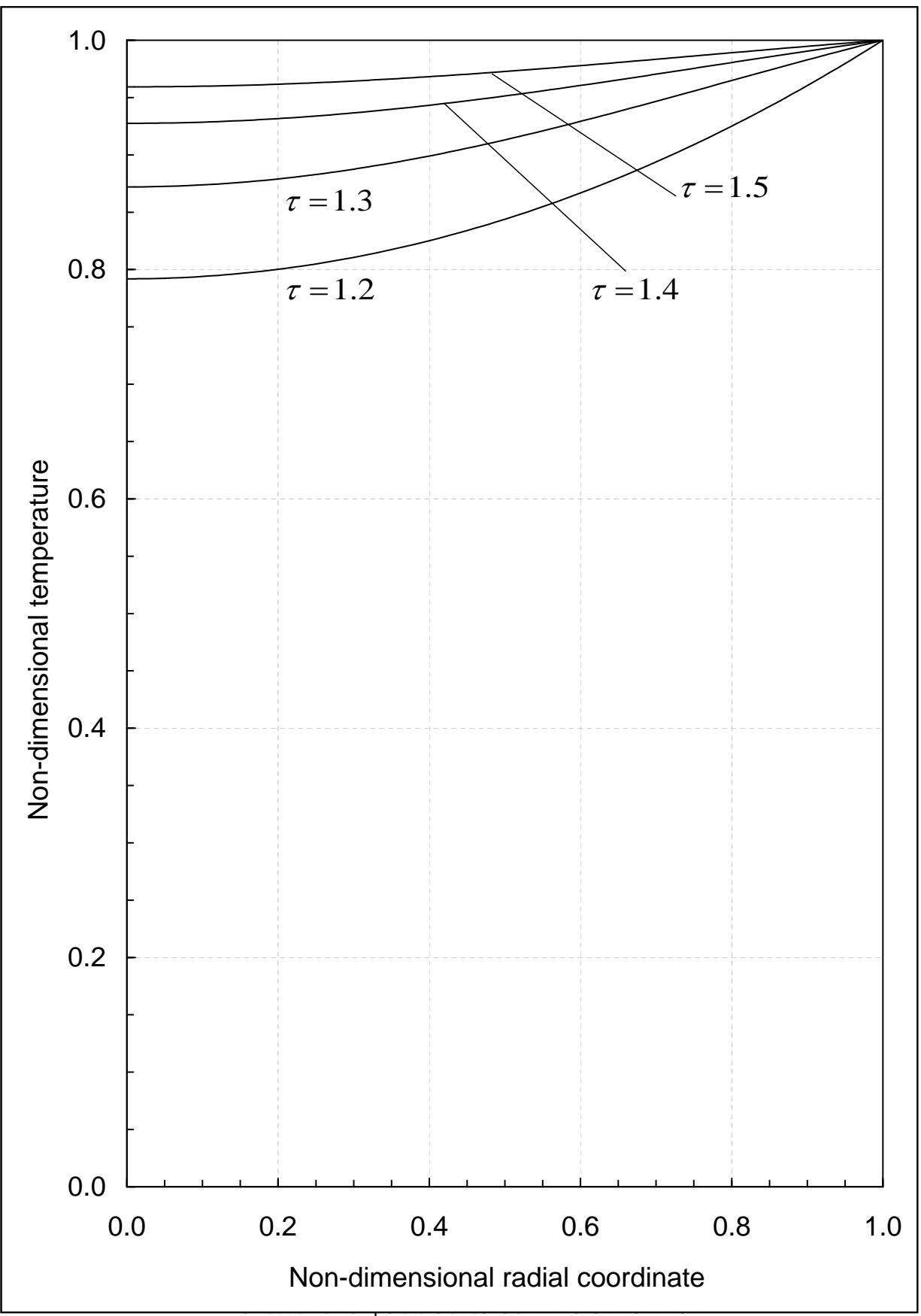

Figure 6.3: Transient temperature field at $1.2 \leq \tau \leq 1.5$ 


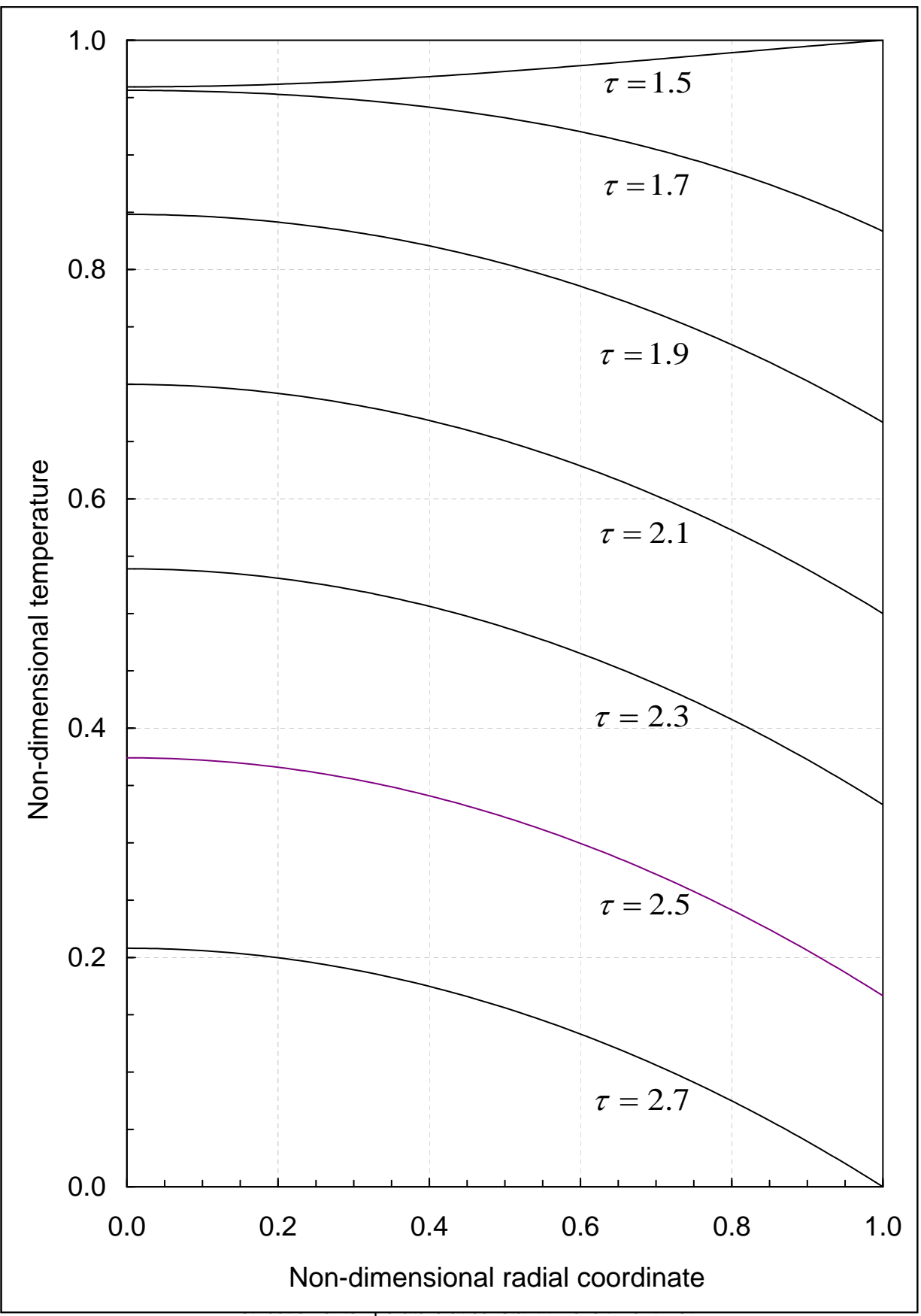

Figure 6.4: Transient temperature field at $1.5 \leq \tau \leq 2.7$ 


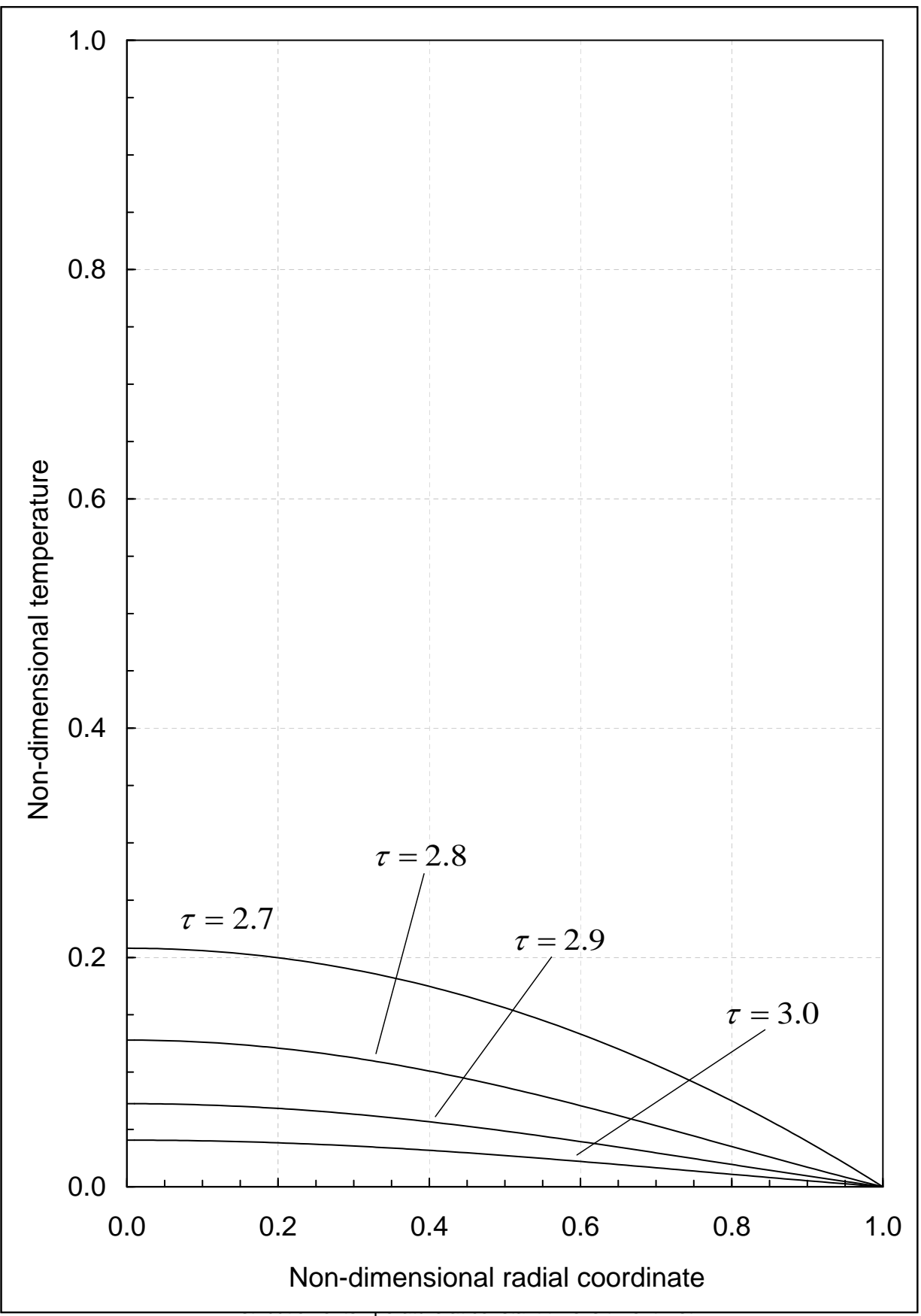

Figure 6.5: Transient temperature field at $2.7 \leq \tau \leq 3.0$ 


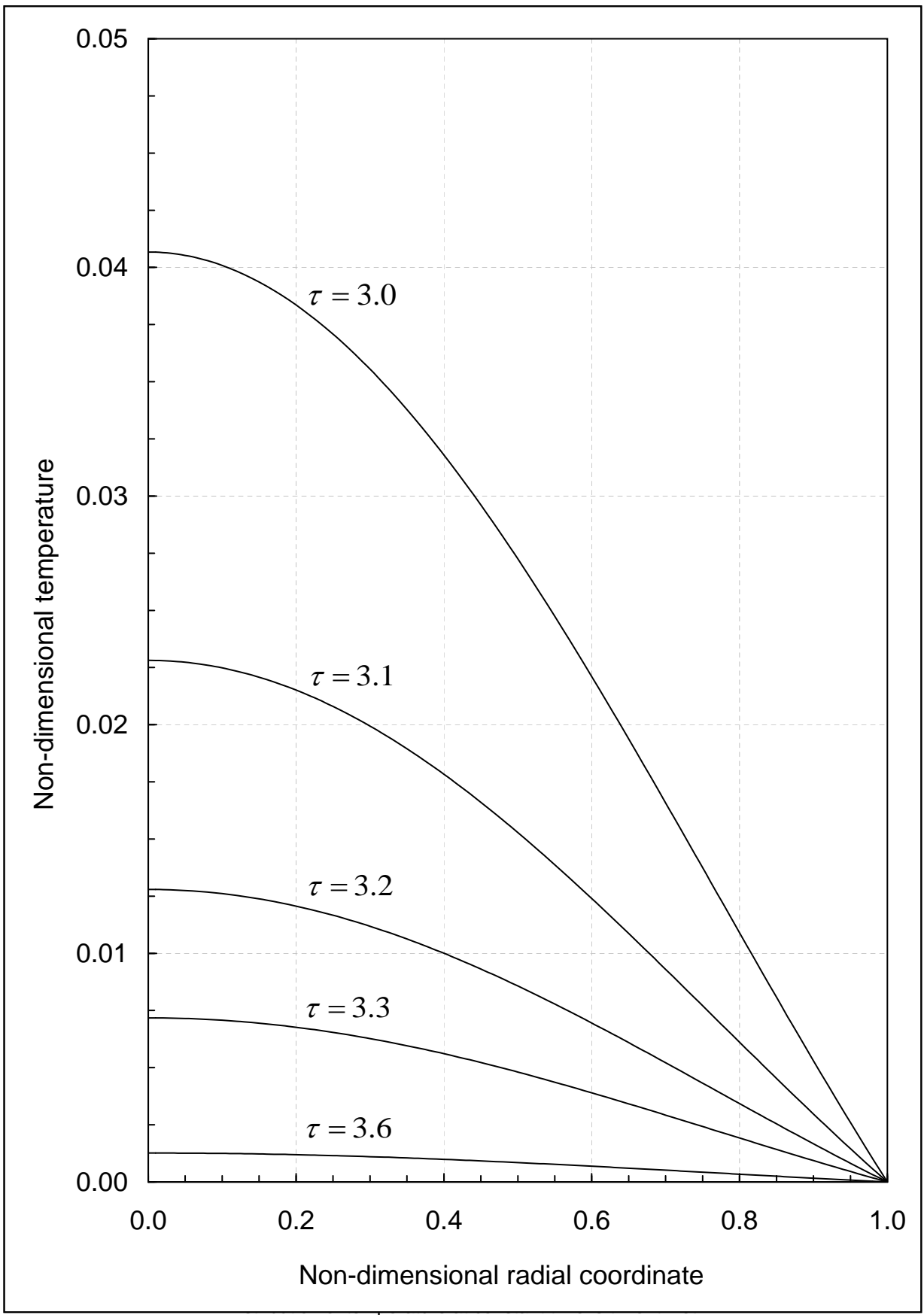

Figure 6.6: Transient temperature field at $3.0 \leq \tau \leq 3.6$ 


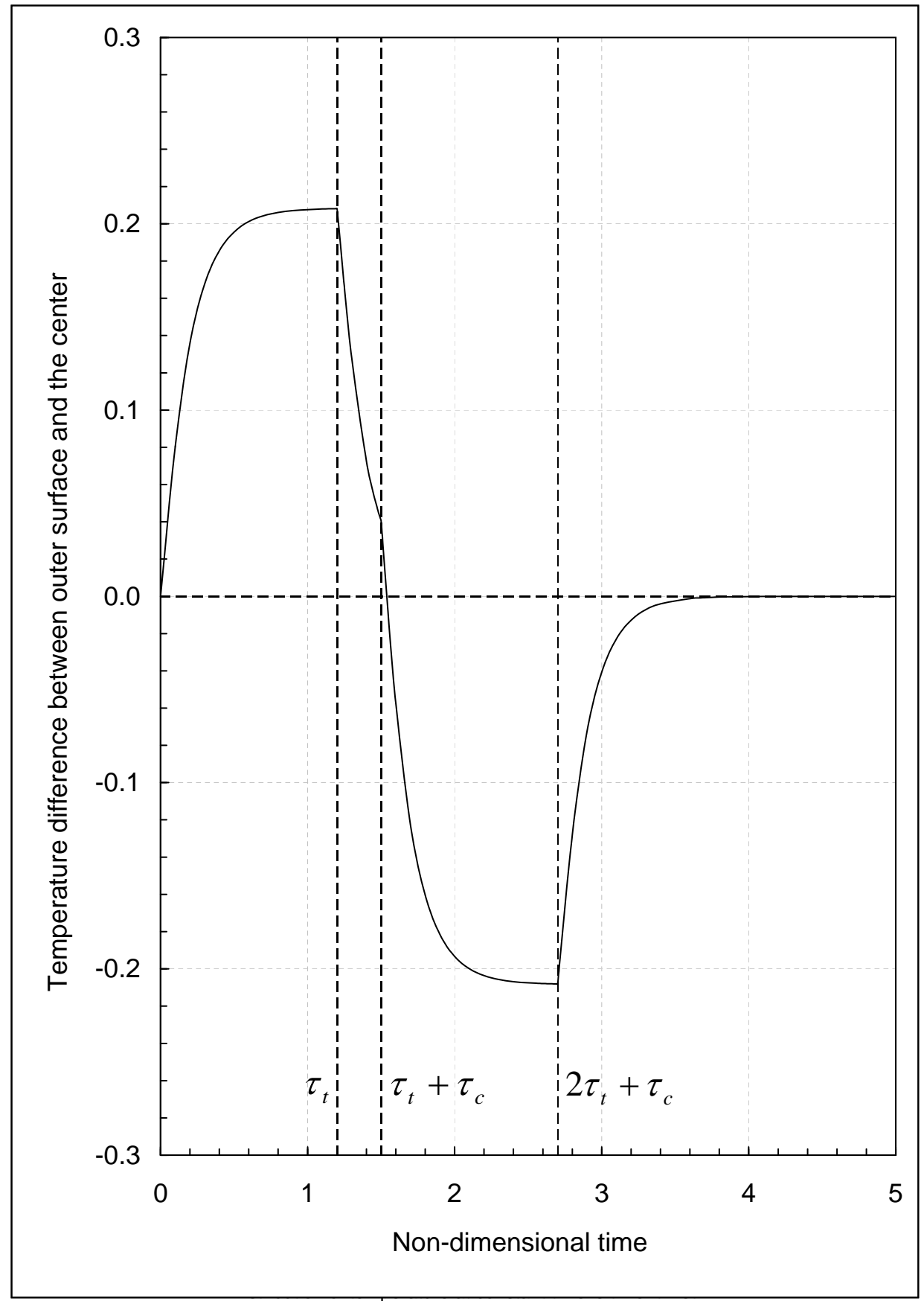

Figure 6.7: Change of temperature difference between outer surface and the center of the shaft with time 


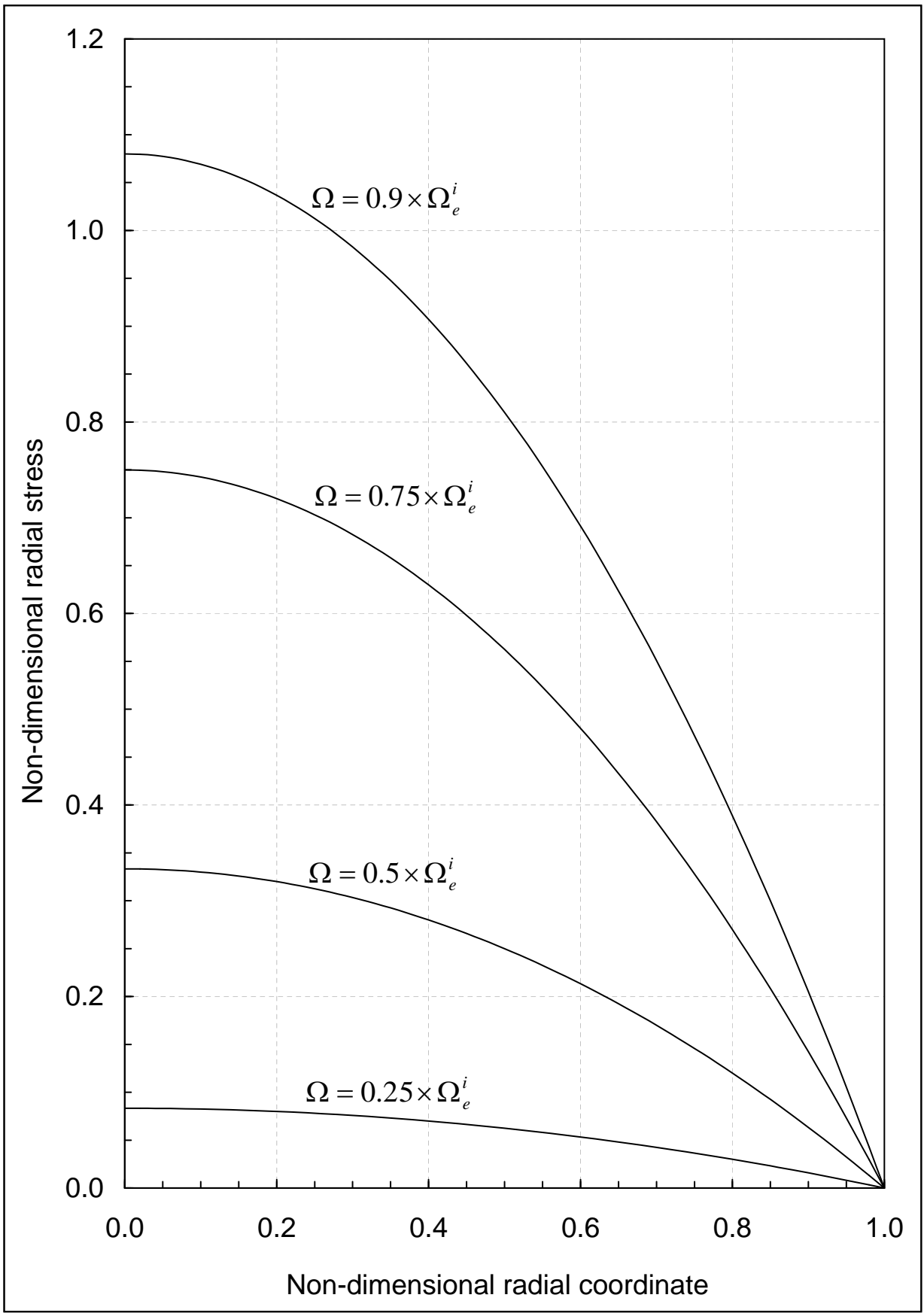

Figure 6.8: Radial stress distribution in the shaft with increasing rotation speed 


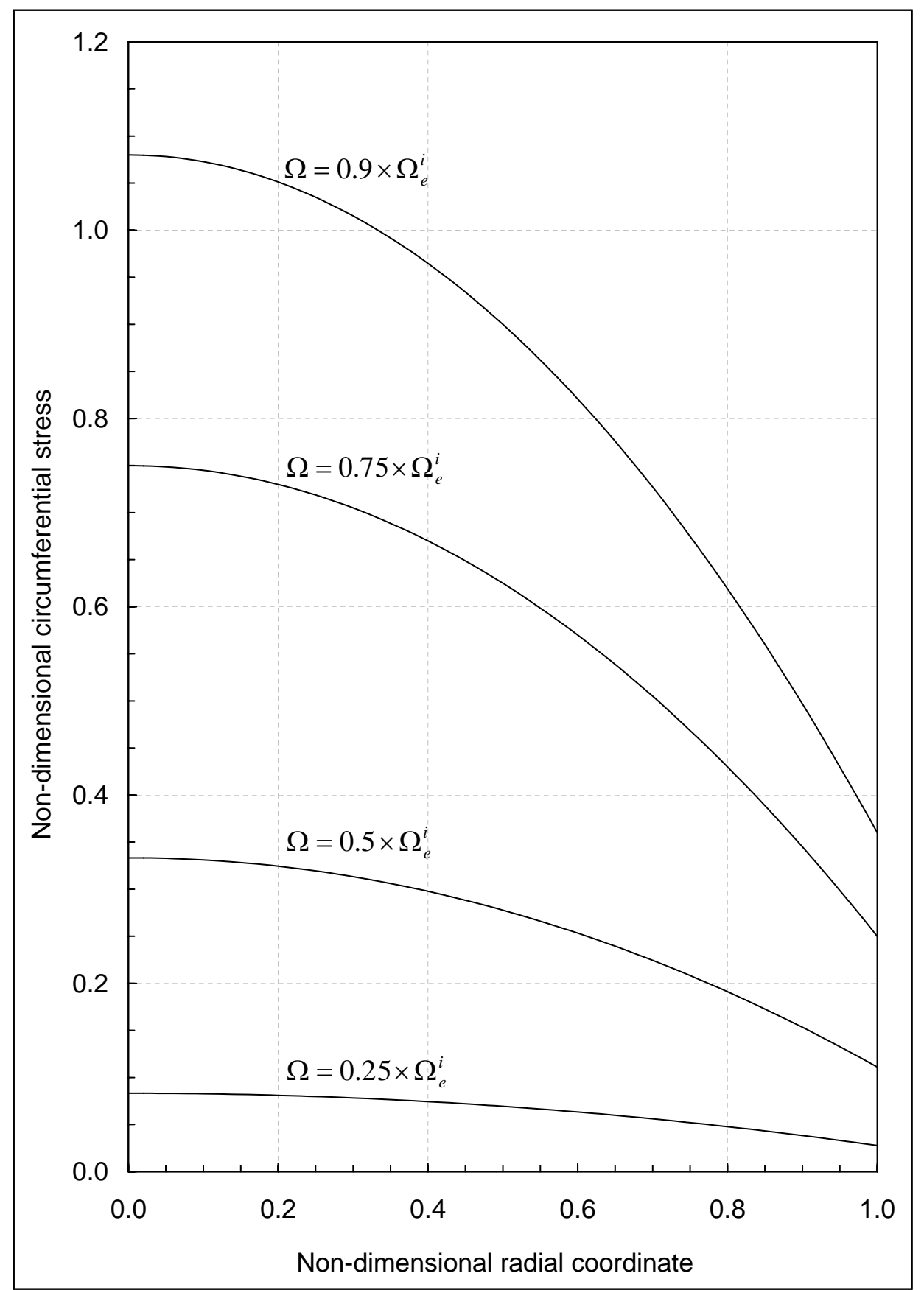

Figure 6.9: Circumferential stress distribution in the shaft with increasing rotation speed 


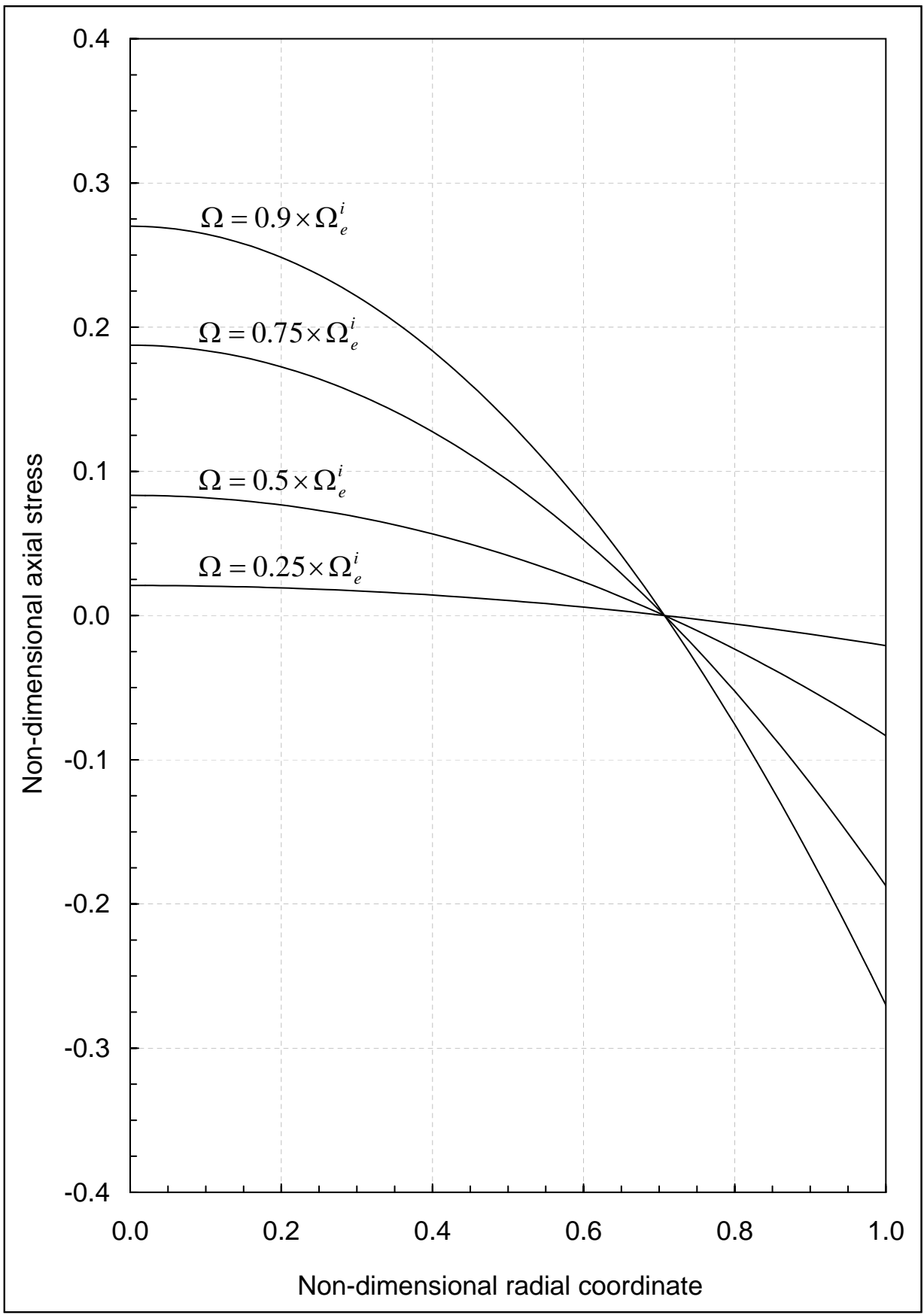

Figure 6.10: Axial stress distribution in the shaft with increasing rotation speed 


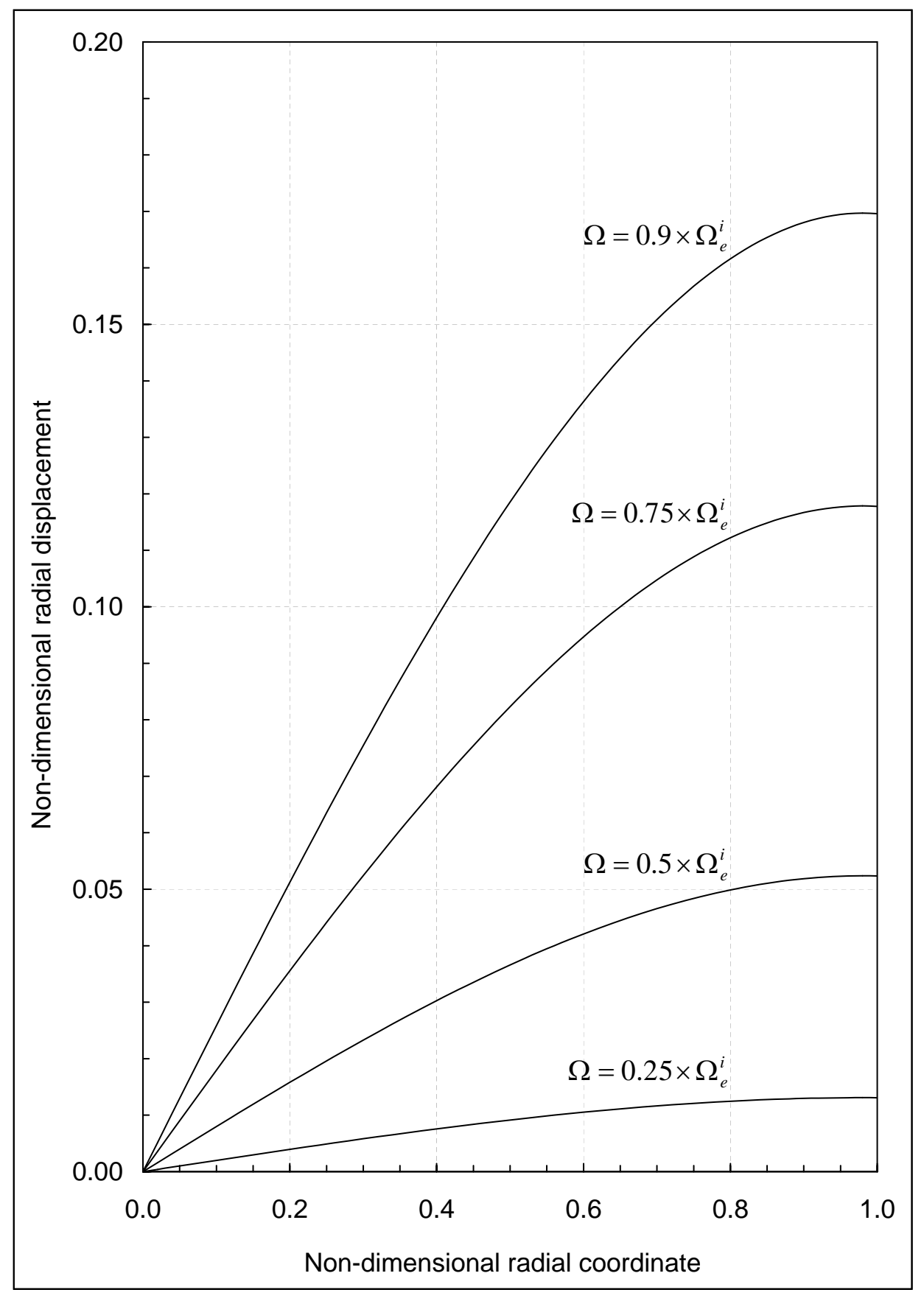

Figure 6.11: Radial displacement distribution in the shaft with increasing rotation speed 


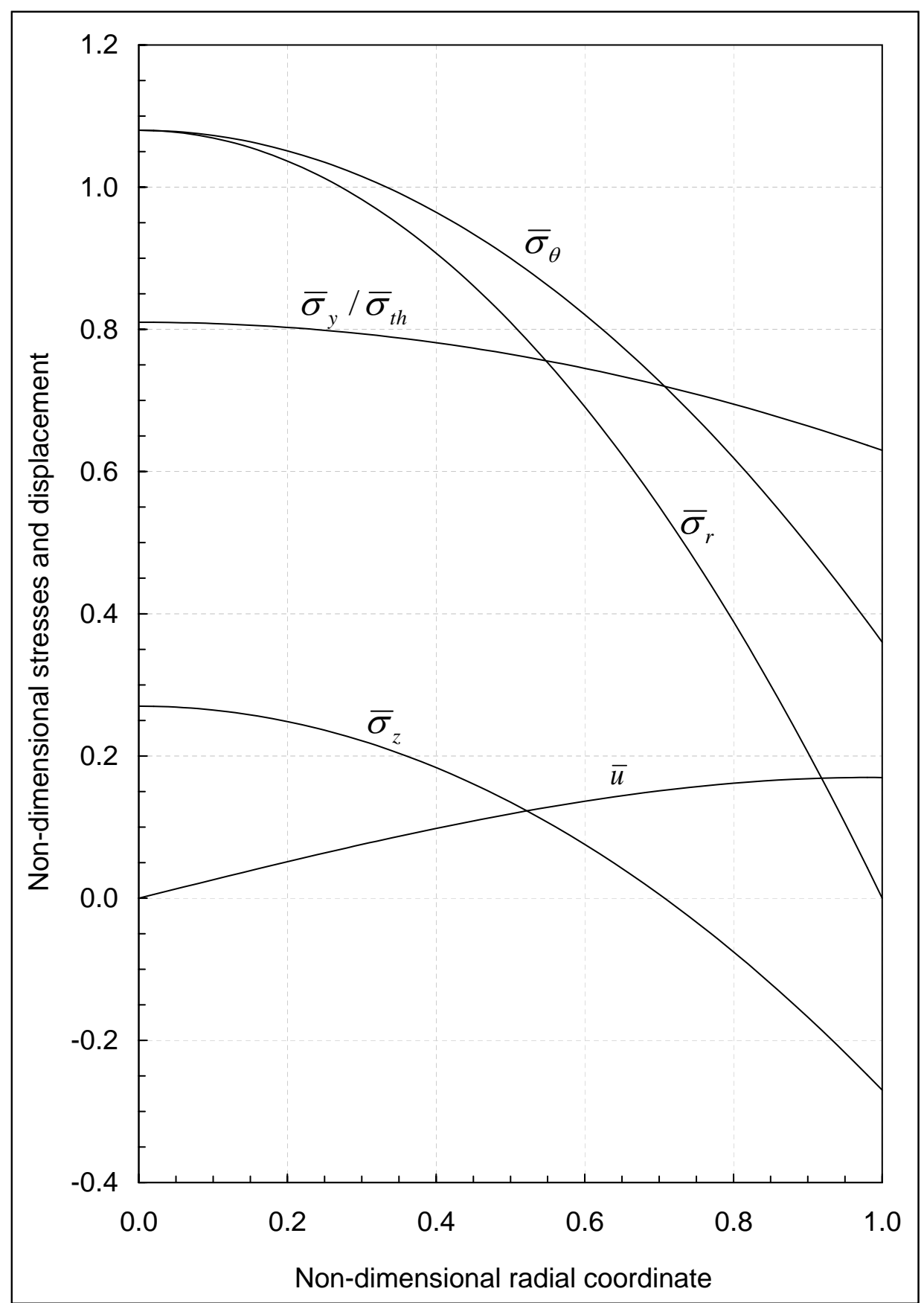

Figure 6.12: Stresses and radial displacement distributions in purely elastic state under $\Omega=0.9 \times \Omega_{e}^{i}=1.5875$ 
In the following calculations, rotation speed is fixed at $\Omega=0.9 \times \Omega_{e}^{i}=1.5875$ and temperature cycle, which is described in Figure 6.1, is started to be applied. The next step is to find the yielding time and the location where it initially starts. For this reason, time is slowly increased in the temperature cycle and it is searched whether the condition of $\sigma_{y}=\sigma_{t h}$ is reached. In Figure 6.13, distribution of $\bar{\sigma}_{y} / \bar{\sigma}_{t h}$ along the radial direction at different times is presented. As seen in the figure, at $\tau=0$, which is the beginning of the temperature cycle, this ratio is less than 1 . As time passes, the ratio decreases until around $\tau=0.37$. Then the ratio starts to increase dramatically. When time reaches to $\tau=\tau_{p}=1.5519$, which is shortly after the beginning of the cooling time $\left(\tau=\tau_{t}+\tau_{c}=1.5\right), \bar{\sigma}_{y} / \bar{\sigma}_{t h}$ becomes equal to 1 at $x=0$. It is observed that the center of the shaft is a critical location for yielding. The evolution of the ratio $\bar{\sigma}_{y} / \bar{\sigma}_{t h}$ with time at $x=0$ is plotted in Figure 6.14. As seen in this figure, the ratio decreases in the early stages until around $\tau=0.37$ as observed in Figure 6.13. One observes that only after the onset of cooling at $\tau=1.5$ the temperature of the inner parts of the shaft reaches its maximum. The corresponding reduction of the yield stress $\sigma_{t h}$ leads to plasticization, which starts at the center. Hence, the last two figures prove that plastic deformation emerges firstly at $\tau=\tau_{p}=1.5519$ and on $x=0$.

Table 6.2: Calculated constants of $\bar{C}_{2}$ and $\bar{\epsilon}_{0}$ versus time in purely elastic state

\begin{tabular}{|c|c|c|}
\hline Time $(\tau)$ & $\bar{C}_{2}$ & $\bar{\epsilon}_{0}$ \\
\hline 0.3 & 0.266619 & $-4.733532 \times 10^{-2}$ \\
\hline 1.2 & 0.298012 & 0.392173 \\
\hline 1.35 & 0.300679 & 0.429501 \\
\hline 1.5 & 0.301720 & 0.444076 \\
\hline $1.5519\left(\tau_{p}\right)$ & 0.301329 & 0.438607 \\
\hline
\end{tabular}

Elastic stresses and displacement for different time values prior to yielding $(\tau<$ 1.5519) are calculated after the determination of the corresponding integration constants. These constants are presented in table 6.2. In Figures from 6.15 to 6.18, radial stress, circumferential stress, axial stress and radial displacement distributions at different time steps in $\tau<1.5519$ are presented, respectively. Finally, distributions of stresses and radial displacement at $\tau=\tau_{p}=1.5519$ is shown all together in Figure 6.19. It should be noted again that this figure is drawn at a time when yielding starts. Hence, formulation of elastic-plastic state is used for $\tau>1.5519$ until unloaded state. 


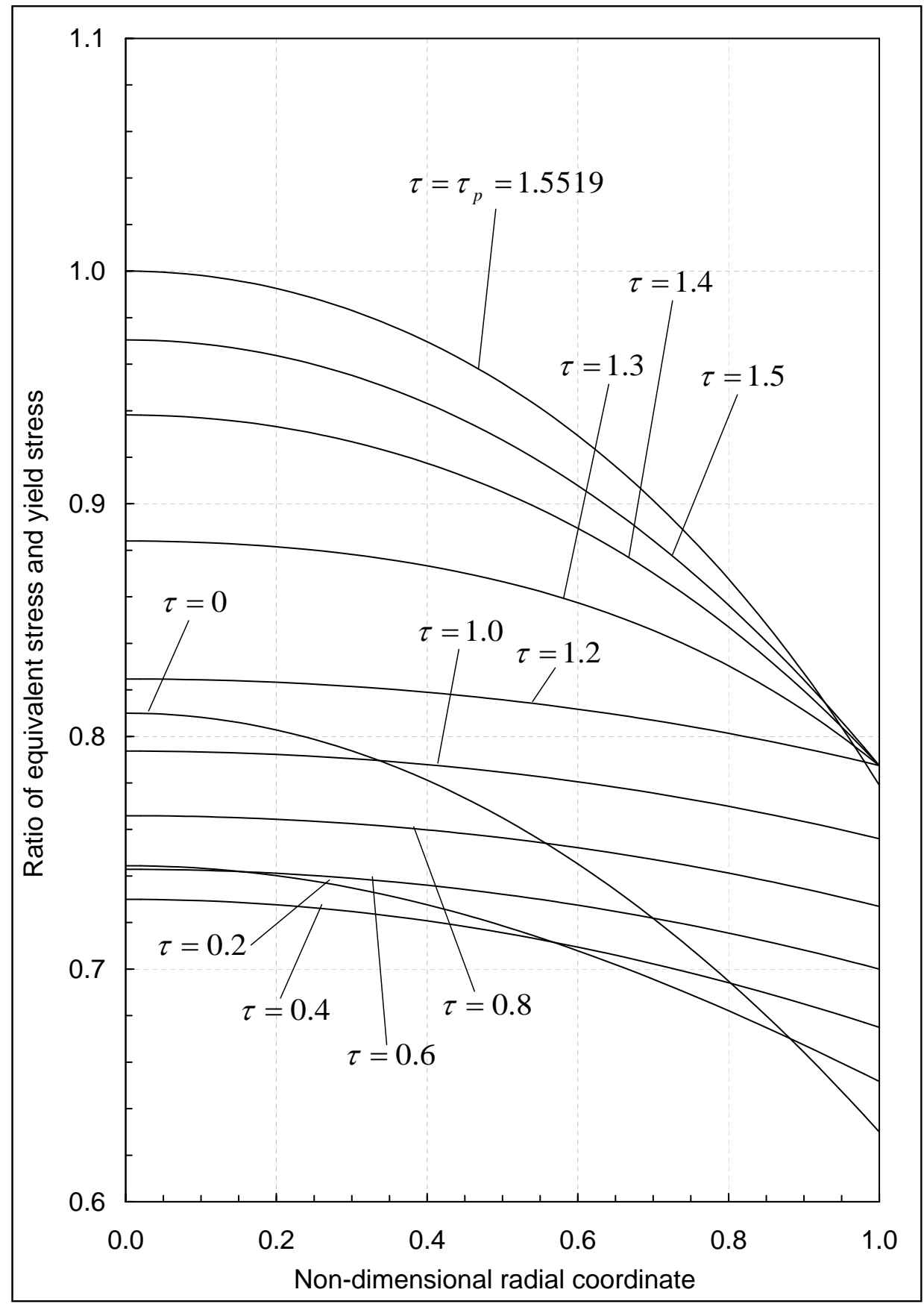

Figure 6.13: Ratio of equivalent and yield stresses at different time until plastic flow 


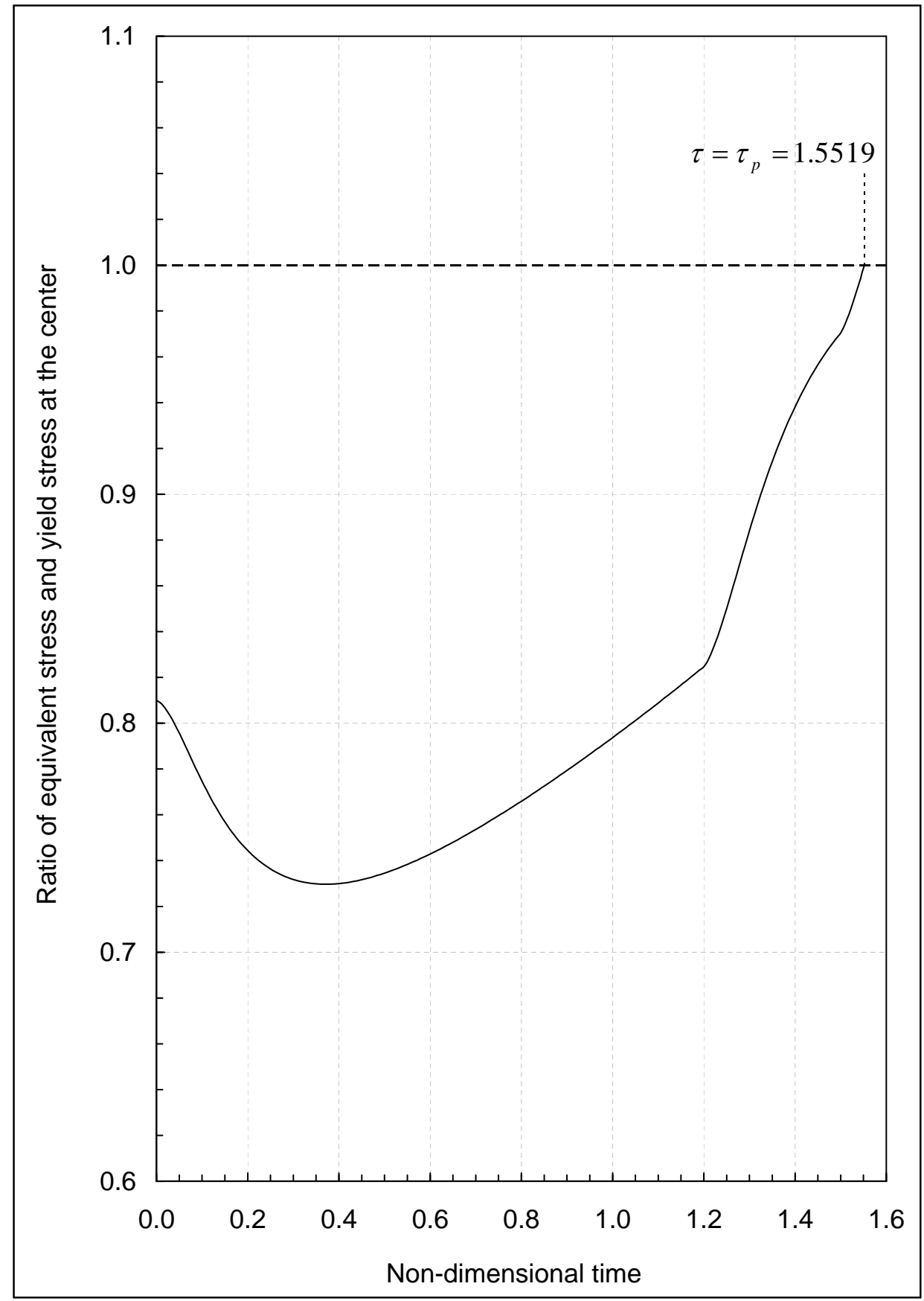

Figure 6.14: Change of ratio of equivalent and yield stresses with time until plastic flow at the center 


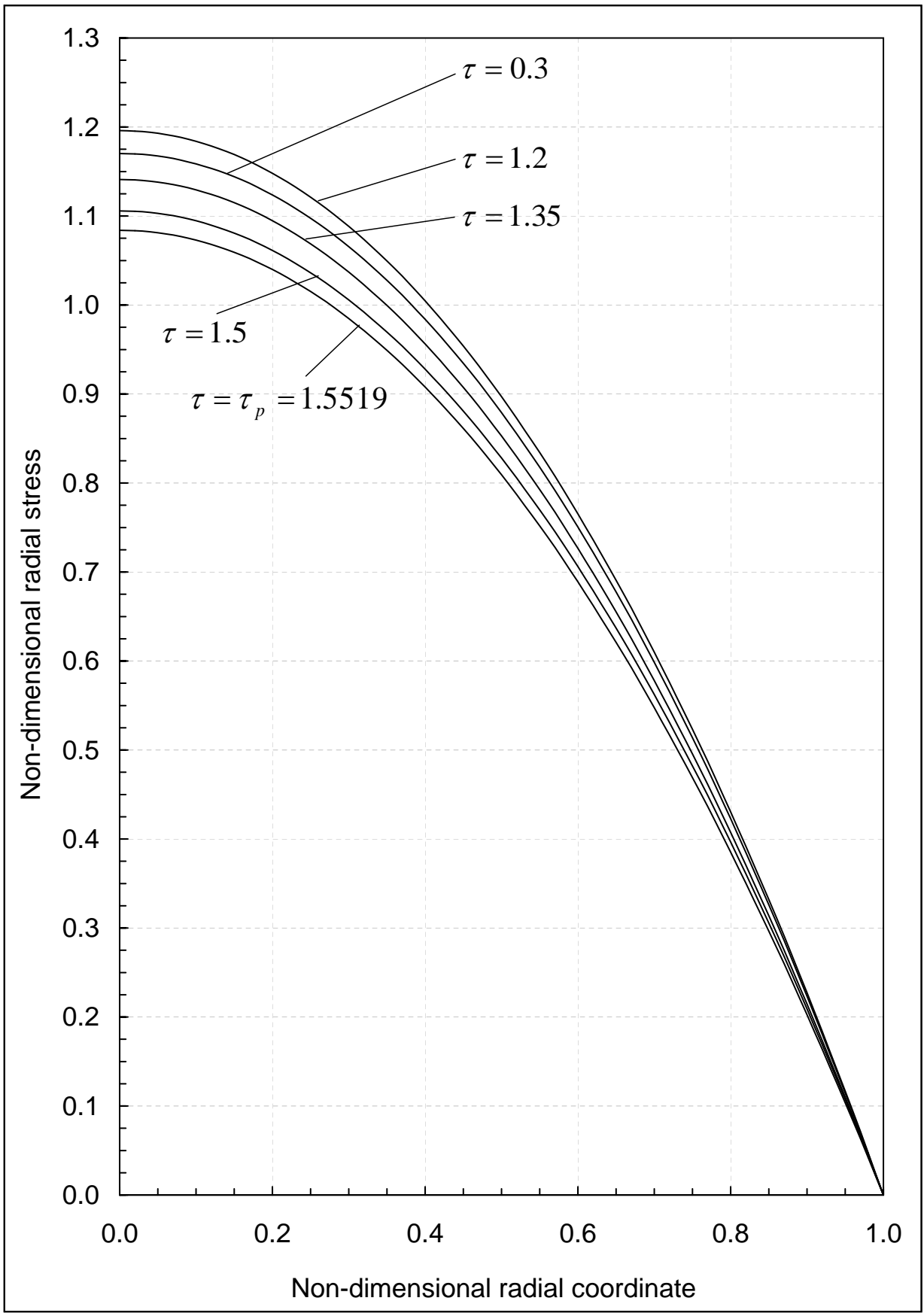

Figure 6.15: Radial stress distribution at different time steps in purely elastic state 


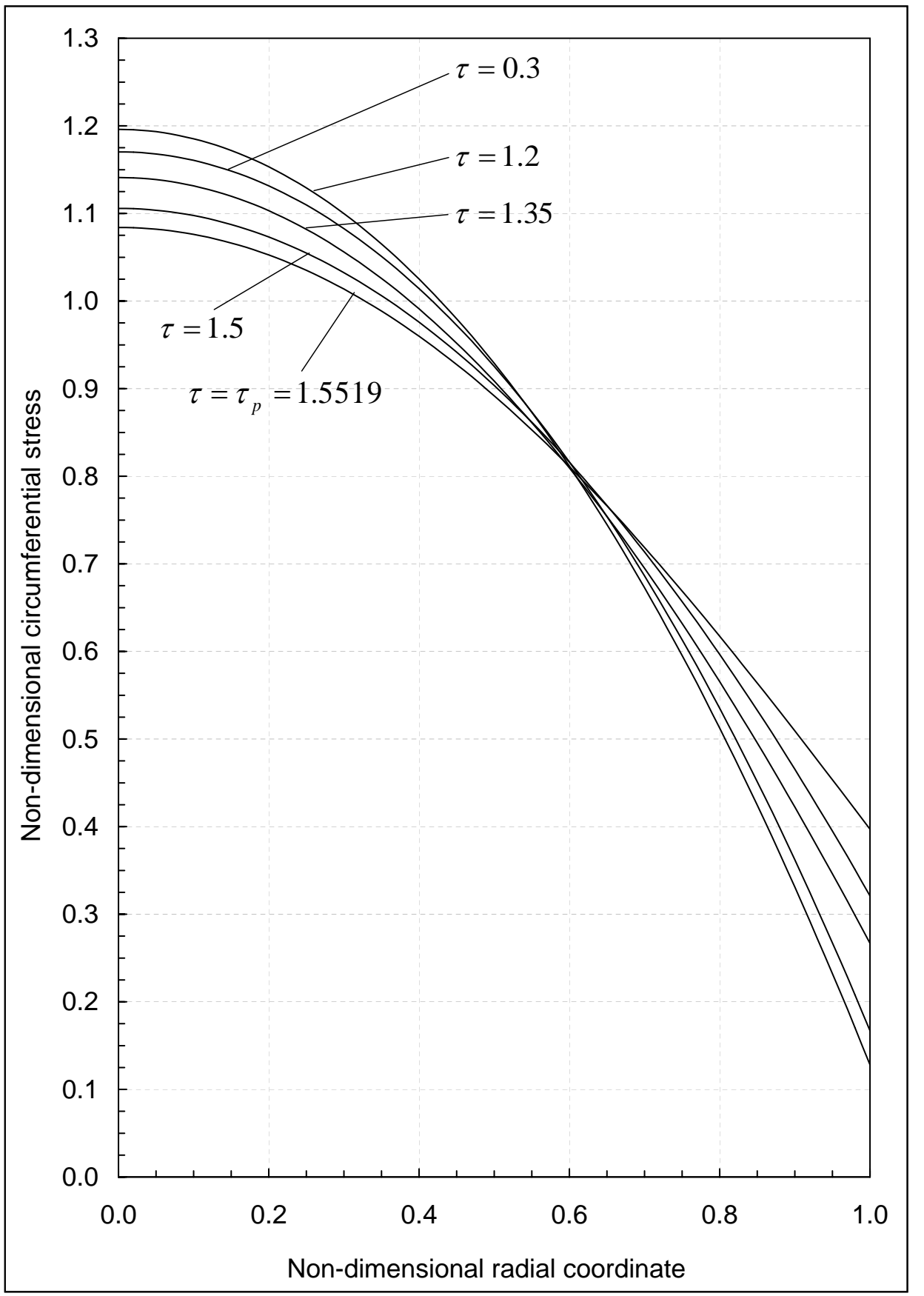

Figure 6.16: Circumferential stress distribution at different time steps in purely elastic state 


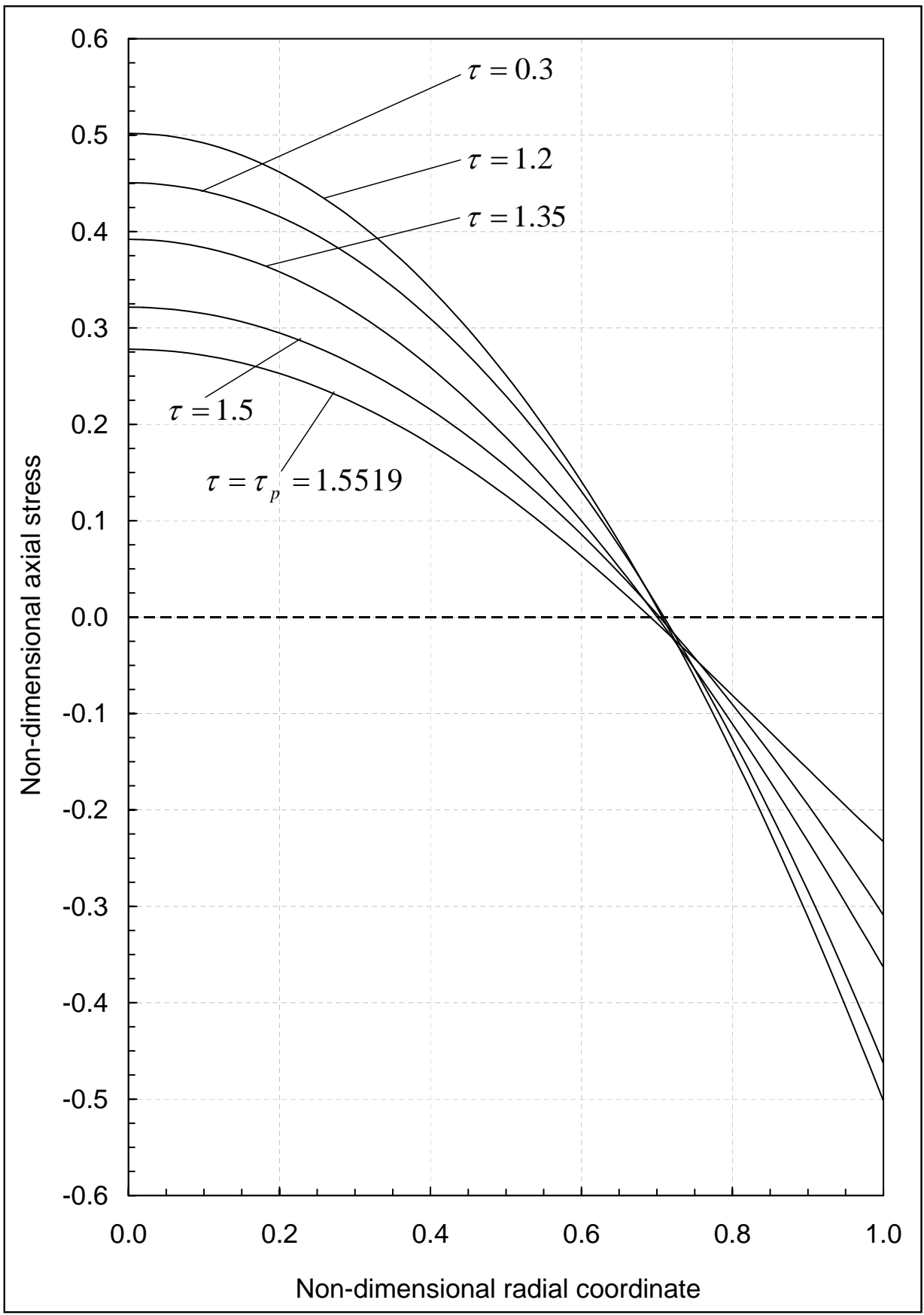

Figure 6.17: Axial stress distribution at different time steps in purely elastic state 


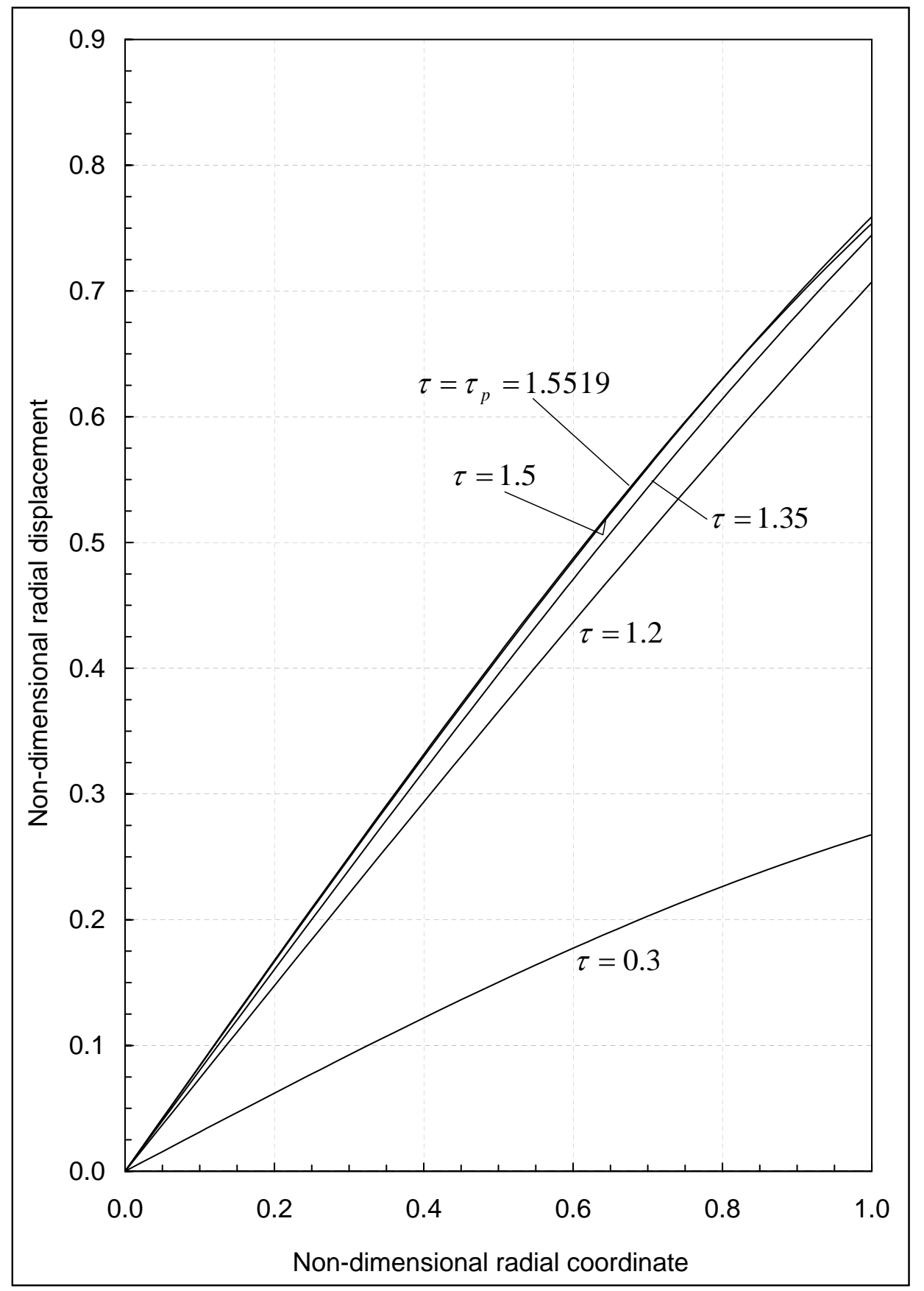

Figure 6.18: Radial displacement distribution at different time steps in purely elastic state 


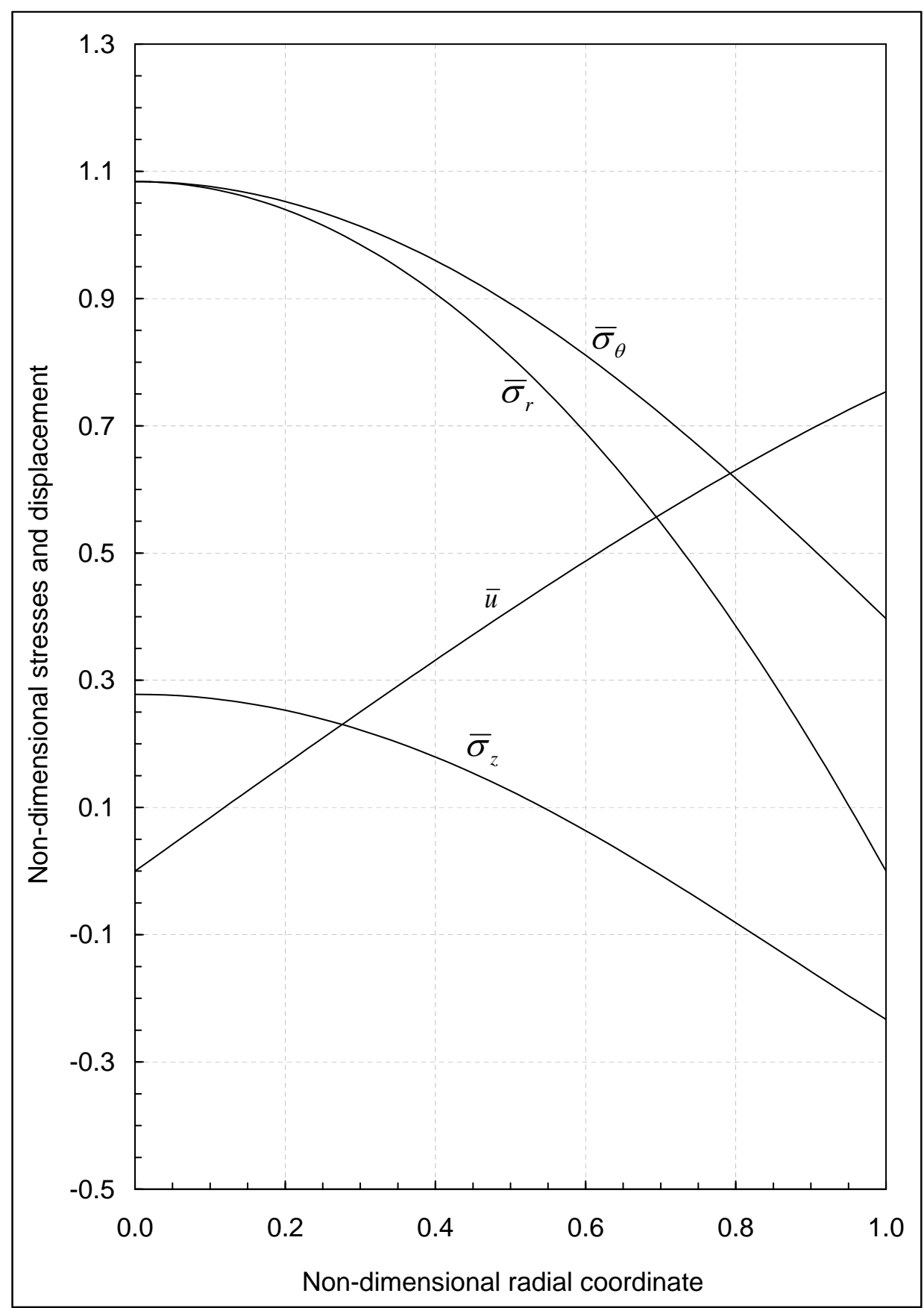

Figure 6.19: Stresses and radial displacement distributions in purely elastic state at $\tau=\tau_{p}=1.5519$ 
As stated earlier, elastic-plastic state of stress is confined in the time interval $\tau_{p}<$ $\tau<\tau_{u b}$ with onset of plasticization time $\tau_{p}$ and unloading bounding time $\tau_{u b}$ being critical time intervals to be determined. In order to determine $\tau_{u b}$, the condition that is described in Eq. (5.21) is used. Evolution of plastic circumferential strain component with respect to time is observed. In the shaft, there are three critical locations where unloading may commence. These are center of the shaft $x=0$, interface radius between two plastic regions $x=x_{1}$, and interface radius between plastic region II and elastic region $x=x_{2}$. Here, it should be noted that $x_{1}$ and $x_{2}$ are functions of time. Evolutions of plastic circumferential strain component at $x=0$ and $x=x_{1}(\tau)$ are plotted in Figure 6.20. Additionally, derivative of plastic circumferential strain with respect to time is calculated by using forward difference as

$$
\frac{d \epsilon_{\theta}^{p}}{d \tau}=\frac{\epsilon_{\theta}^{p}(\tau+\Delta \tau)-\epsilon_{\theta}^{p}(\tau)}{\Delta \tau},
$$

and plotted in Figure 6.21 using time increments of $\Delta \tau=0.005$. As seen in these two figures, plastic circumferential strain component increase first, then rate of the increase slows down with time. For $x=x_{1}$, increase in the strain ceases at $\tau=\left.\tau_{u b}\right|_{x=x_{1}}=$ 1.8454 , i.e., when the condition of (5.21) is satisfied. This time may be considered as a possible starting time of unloaded state according to interface radius between two plastic regions. However, unloading starts at the center at $\tau=\left.\tau_{u b}\right|_{x=0}=1.8469$ as followed in these figures. This shows that $x_{1}$ is more critical radial coordinate than the center of the shaft since unloading emerges earlier. Furthermore, the small time difference of $\tau_{u b}$ between these two points proves that movement of unloading from interface radius $x_{1}$ to the center is very fast.

On the other hand, another critical radial coordinate that is $x=x_{2}$ should be examined for unloading condition. At this interface radius, plastic circumferential strain is always zero because this radial coordinate is adjacent to the elastic region. Hence, it is not possible to investigate the behavior of the plastic strains at this coordinate like at $x=0$ or $x=x_{1}$. However, evolution of interface radius $x_{2}$ with time gives some hints to evaluate the behavior of the plastic strains around there. Evolution of $x_{2}(\tau)$ with time is plotted in Figure 6.22. Additionally, evolution of change in $x_{2}$ with time is obtained by forward difference, which is similar to the Eq. (6.9)

$$
\frac{d x_{2}(\tau)}{d \tau}=\frac{x_{2}(\tau+\Delta \tau)-x_{2}(\tau)}{\Delta \tau},
$$


and plotted in Figure 6.23 by choosing $\Delta \tau=0.002$. These two figures show that when time reaches $\tau=1.7882$, expansion of $x_{2}$ stops all of a sudden. This situation is quite interesting since plastic region always moves into elastic region during loading. Because of the termination in the expansion of plastic region II, plastic strains does not increase at any radial coordinates beyond $x_{2}$. Hence, condition of (5.21) is satisfied at $\tau=1.7882$ and on $x=0.5707$. Furthermore, this time value is earlier than those for $x=0$ and $x=x_{1}$. Thus, we can discuss that unloading emerges at $\tau=\tau_{u b}=1.7882$ on $x=0.5707$ and moves into plastic regions. Therefore, we have obtained the time limits of elastic-plastic state.

Table 6.3: Calculated constants in elastic-plastic state at different time values

\begin{tabular}{|c|c|c|c|c|c|c|}
\hline Time $(\tau)$ & $\bar{C}_{1}$ & $\bar{C}_{2}$ & \multicolumn{2}{|c|}{$\bar{C}_{3}$} & $\overline{C_{4}}$ & $\bar{C}_{5}$ \\
\hline $1.5519\left(\tau_{p}\right)$ & 0 & 0.301329 & \multicolumn{2}{|c|}{1.083954} & 0 & 0 \\
\hline 1.57 & $1.556682 \times 10^{-5}$ & 0.301106 & \multicolumn{2}{|c|}{1.077291} & 0 & $4.246629 \times 10^{-3}$ \\
\hline 1.6 & $9.963254 \times 10^{-5}$ & 0.300789 & \multicolumn{2}{|c|}{1.066483} & 0 & $1.226341 \times 10^{-2}$ \\
\hline 1.66 & $3.467889 \times 10^{-4}$ & 0.300097 & \multicolumn{2}{|c|}{1.047876} & 0 & $2.649257 \times 10^{-2}$ \\
\hline 1.72 & $5.436446 \times 10^{-4}$ & 0.299031 & \multicolumn{2}{|c|}{1.033410} & 0 & $3.590192 \times 10^{-2}$ \\
\hline $1.7882\left(\tau_{u b}\right)$ & $6.473691 \times 10^{-4}$ & 0.297313 & \multicolumn{2}{|c|}{1.020649} & 0 & $4.118450 \times 10^{-2}$ \\
\hline & $\overline{\text { Time }(\tau)}$ & \multicolumn{2}{|l|}{$\overline{C_{6}}$} & \multicolumn{2}{|c|}{$\overline{\bar{\epsilon}} \bar{\epsilon}_{0}$} & \\
\hline & $1.5519\left(\tau_{p}\right)$ & \multicolumn{2}{|l|}{0} & \multicolumn{2}{|c|}{0.438607} & \\
\hline & 1.57 & \multicolumn{2}{|c|}{$1.054304 \times 10^{-6}$} & \multicolumn{2}{|c|}{0.434827} & \\
\hline & 1.6 & \multicolumn{2}{|c|}{$6.492465 \times 10^{-6}$} & \multicolumn{2}{|c|}{0.426867} & \\
\hline & 1.66 & \multicolumn{2}{|c|}{$2.245565 \times 10^{-5}$} & \multicolumn{2}{|c|}{0.406789} & \\
\hline & 1.72 & \multirow{2}{*}{\multicolumn{2}{|c|}{$3.529008 \times 10^{-5}$}} & \multicolumn{2}{|c|}{0.38360} & \\
\hline & $1.7882\left(\tau_{u b}\right)$ & & & \multicolumn{2}{|c|}{0.355186} & \\
\hline
\end{tabular}

Numerical results for the elastic-plastic state in time interval $\tau_{p}<\tau<\tau_{u b}$ are presented in Figures 6.24-6.34. In Figure 6.24, stresses, radial displacement and the ratio of equivalent and yield stresses are plotted at $\tau=\tau_{p}=1.5519$, which is the upper time limit of the purely elastic state and the lower time limit of the elasticplastic state. In the figure, while dots represent the results that are obtained with the formulation of the purely elastic state, solid lines represent those of the elastic-plastic state. As seen in the figure, these two results perfectly fit each other and this verifies that formulations of the both states are correct. Thereafter, time instant is selected as $\tau=1.57, \tau=1.6, \tau=1.66, \tau=1.72$ and $\tau=\tau_{u b}=1.7882$ to plot corresponding distributions of stresses and displacement in Figures 6.25-6.29, respectively. Similarly, 
at these time instants, plastic strains are presented in Figures 6.30-6.34. The plastic strains at $\tau=\tau_{u b}=1.7882$ are permanent plastic strains which will be used in the unloaded state and are also presented in tabular form in Appendix D.2. Additionally, the unknown integration constants that are calculated in elastic-plastic state are given in table 6.3 .

Evolution of the border radii in $\tau_{p}<\tau<\tau_{u b}$ gives enough information about the elastic-plastic behavior of the material under loading. This evolution with all regions and critical time values, i.e., $\tau_{p}$ and $\tau_{u b}$, can be seen in Figure 6.35. This figure shows that, at $\tau=\tau_{p}=1.5519$ plastic regions I and II emerge simultaneously and spread out (compare [12]). Up to $\tau=\tau_{u b}$, the shaft consists of plastic region I at inner part, plastic region II at the middle and elastic region at outer part. However, the expansion of the plastic zone comes soon to an end, and at $\tau=\tau_{u b}=1.7882$ the plastic-elastic border radius $x_{2}$ attains a stationary value as explained with Figures 6.22 and 6.23. At $\tau=\tau_{u b}=1.7882$, plastic strains that are seen in Figure 6.34, are frozen and the quick expansion of an unloaded region is approximated by the assumption of sudden unloading (indicated by the dashed line in Figure 6.35). Here $x_{u}$ separates plastic regions and predeformed elastic region. That is, for $\tau>\tau_{u b}$, the shaft consists of predeformed elastic region, in the range $0 \leq x \leq x_{2}^{u}(=0.5707)$ and elastic region in the range $x_{2}^{u} \leq x \leq 1$, and unloaded state will be valid in the whole shaft.

As discussed above, sudden unloading is approximated in this study. Error between this approximation and exact unloading is negligibly small as shown in [38]. Furthermore, to estimate error thus introduced, Figure 6.36 depicts the ratio of the equivalent stress $\bar{\sigma}_{y}$ and the yield stress $\bar{\sigma}_{t h}$ versus time for three different radii, i.e., $x=0, x=0.1$ and $x=x_{1}\left(\tau_{u b}\right)=0.2324$. One observes that the maximum violation of the yield condition occurs at the center, but it is only about $0.3 \%$. Hence, one reasonably may conclude that the stress distribution thus obtained is a very good approximation of the true stress distribution. 


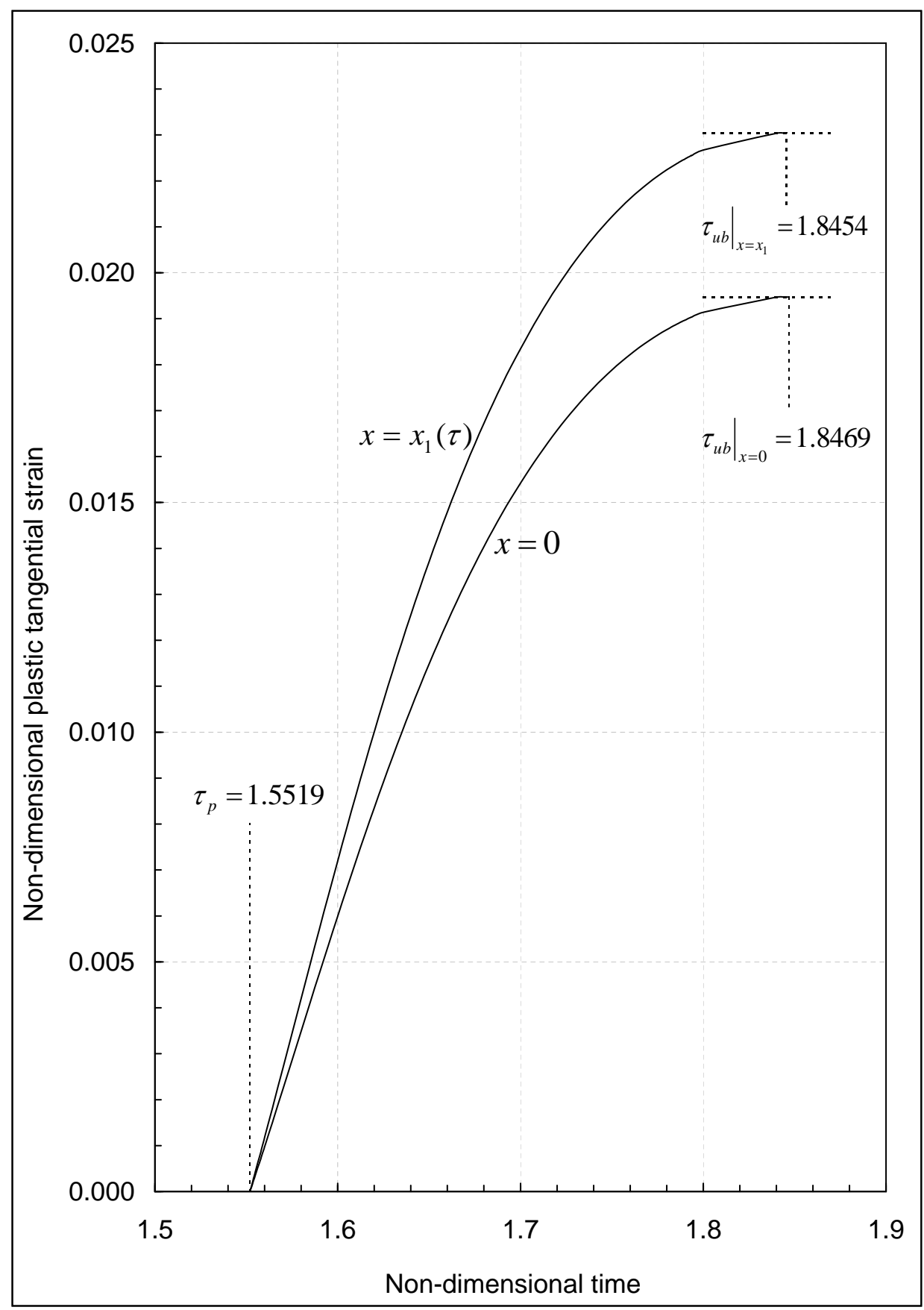

Figure 6.20: Evolutions of plastic tangential strain component with time at $x=0$ and $x=x_{1}$ 


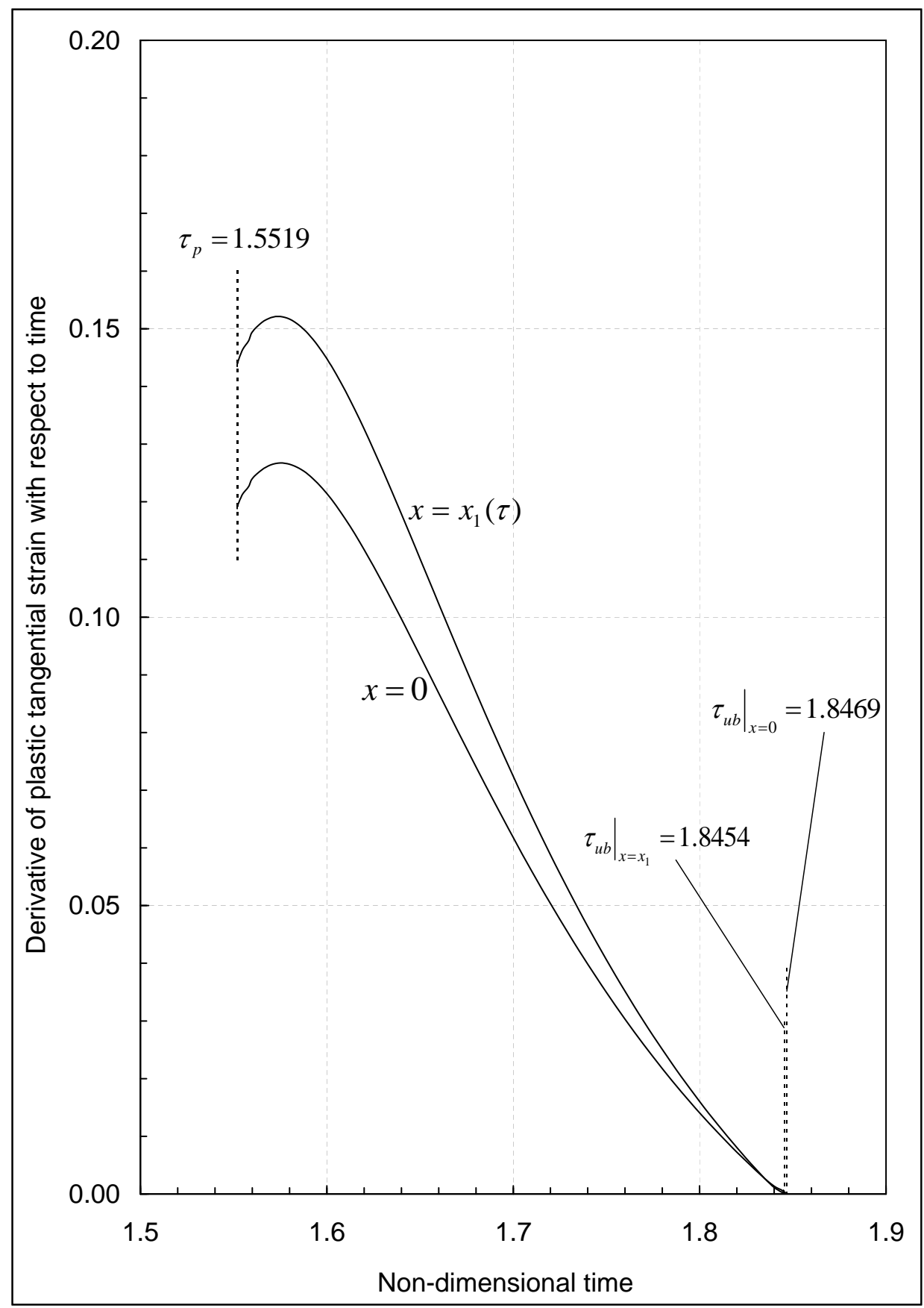

Figure 6.21: Evolutions of derivative of plastic tangential strain with time at $x=0$ and $x=x_{1}$ 


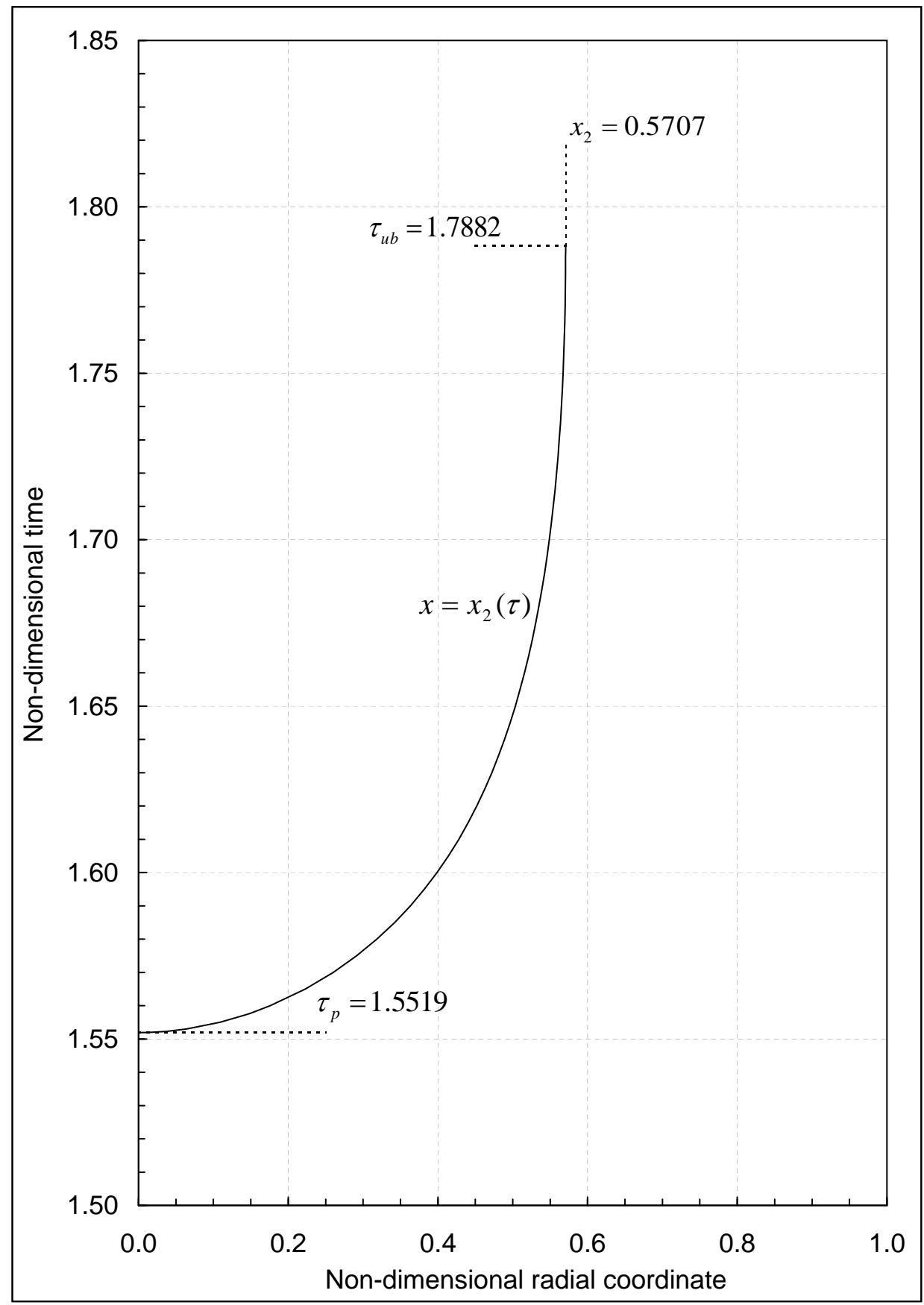

Figure 6.22: Evolution of interface radius $x_{2}$ with time 


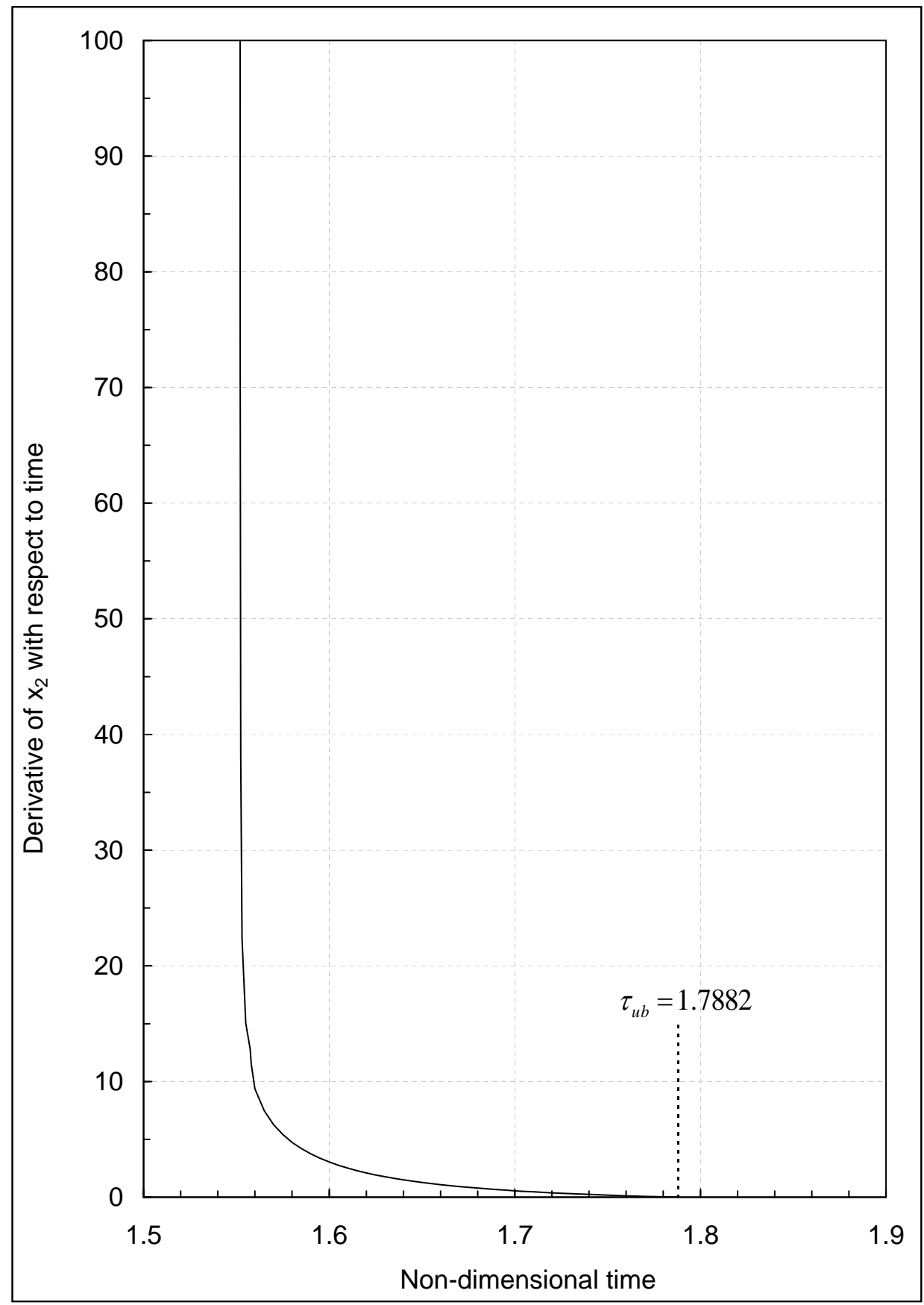

Figure 6.23: Evolution of derivative of $x_{2}$ with respect to time 


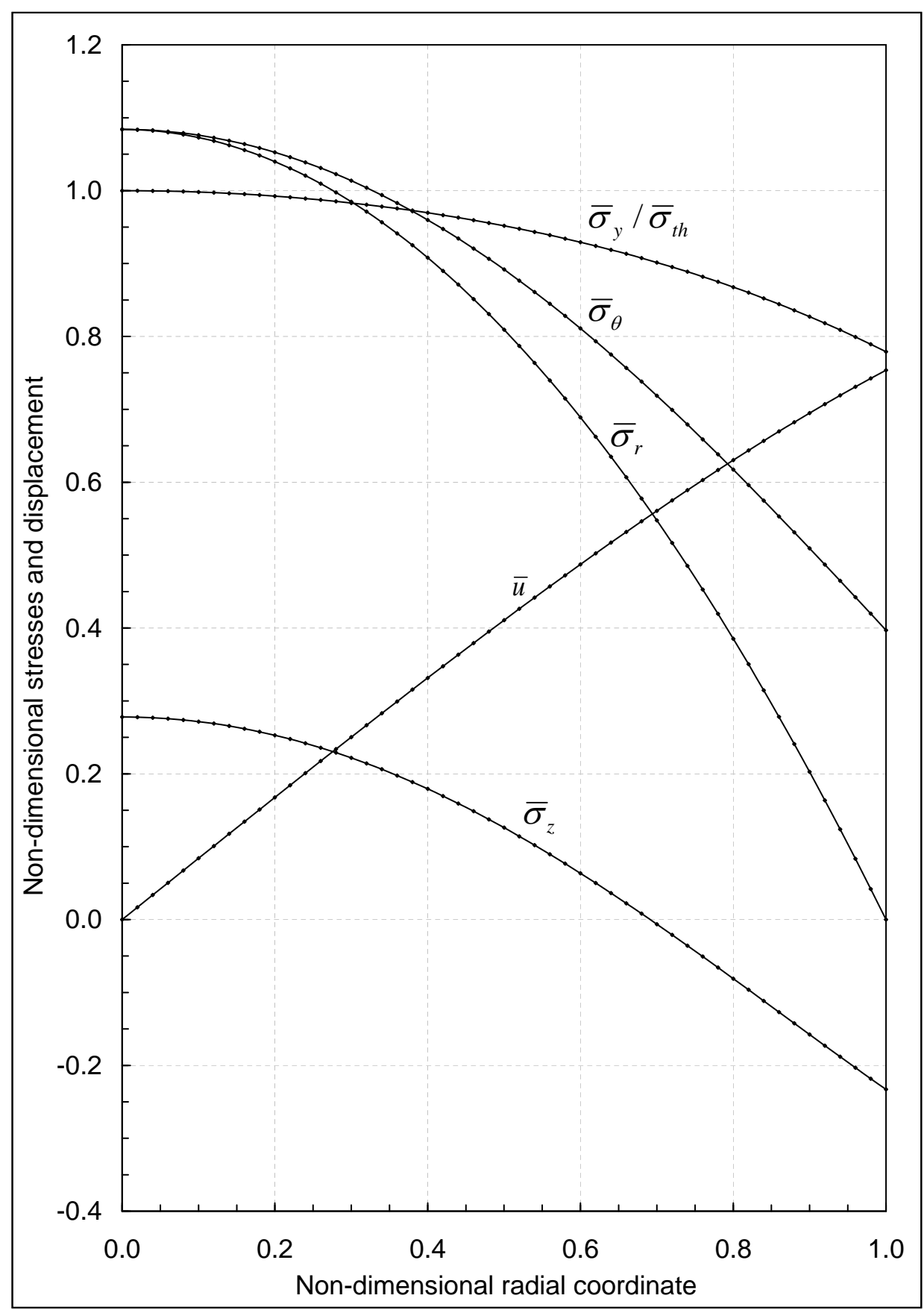

Figure 6.24: Stresses and radial displacement distributions in elastic-plastic state at $\tau=\tau_{p}=1.5519$ 


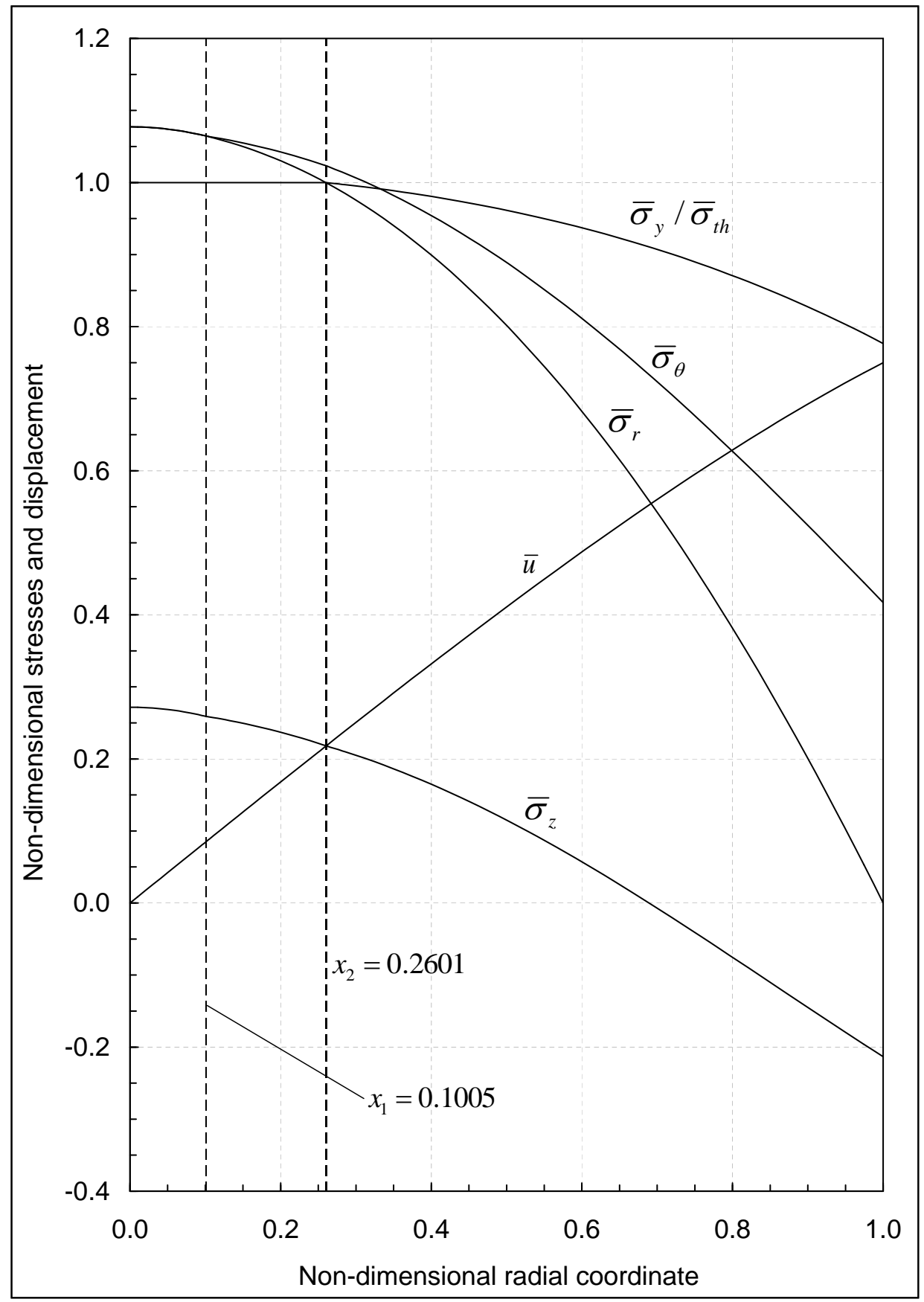

Figure 6.25: Stresses and radial displacement distributions in elastic-plastic state at $\tau=1.57$ 




Figure 6.26: Stresses and radial displacement distributions in elastic-plastic state at $\tau=1.6$ 


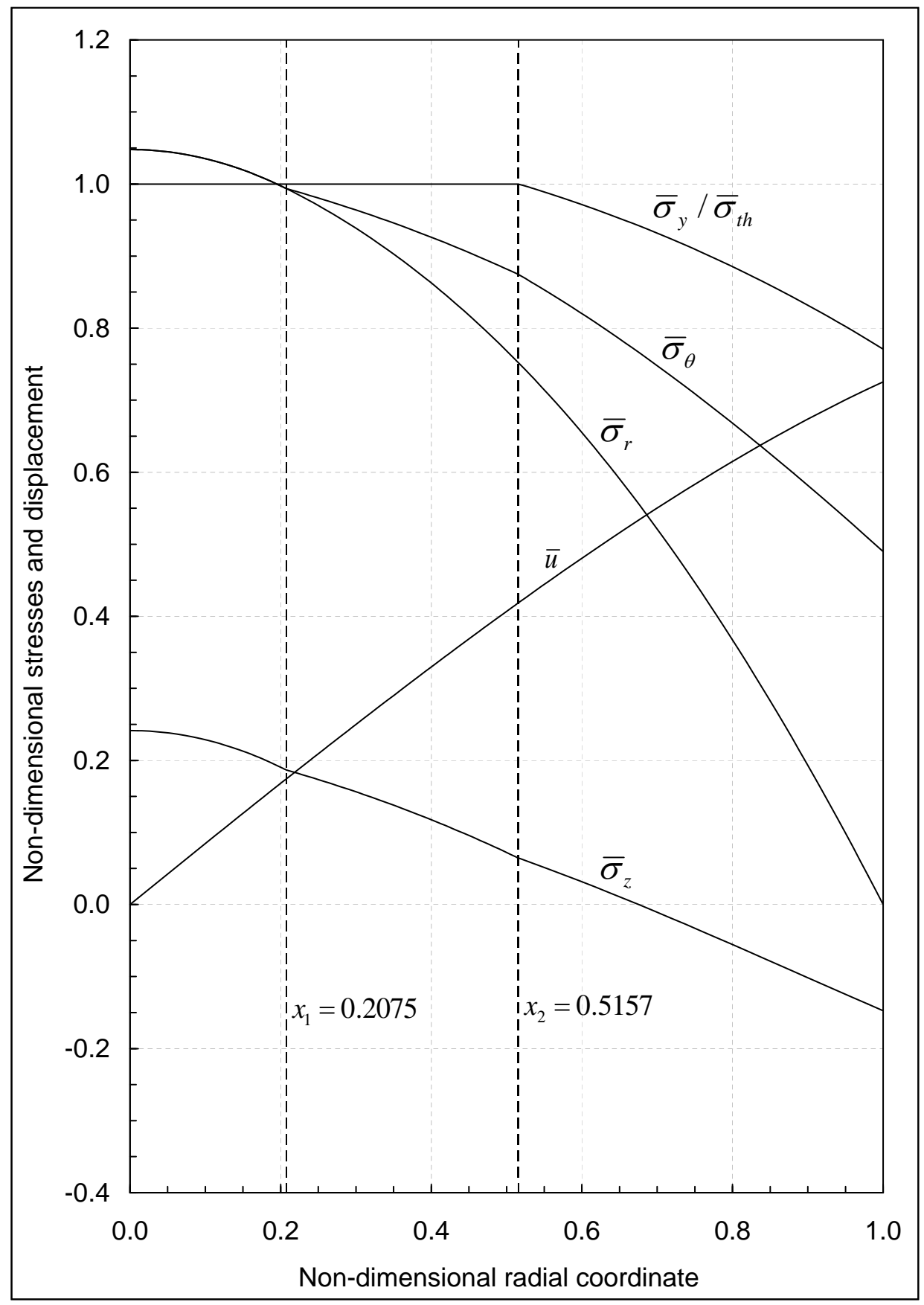

Figure 6.27: Stresses and radial displacement distributions in elastic-plastic state at $\tau=1.66$ 


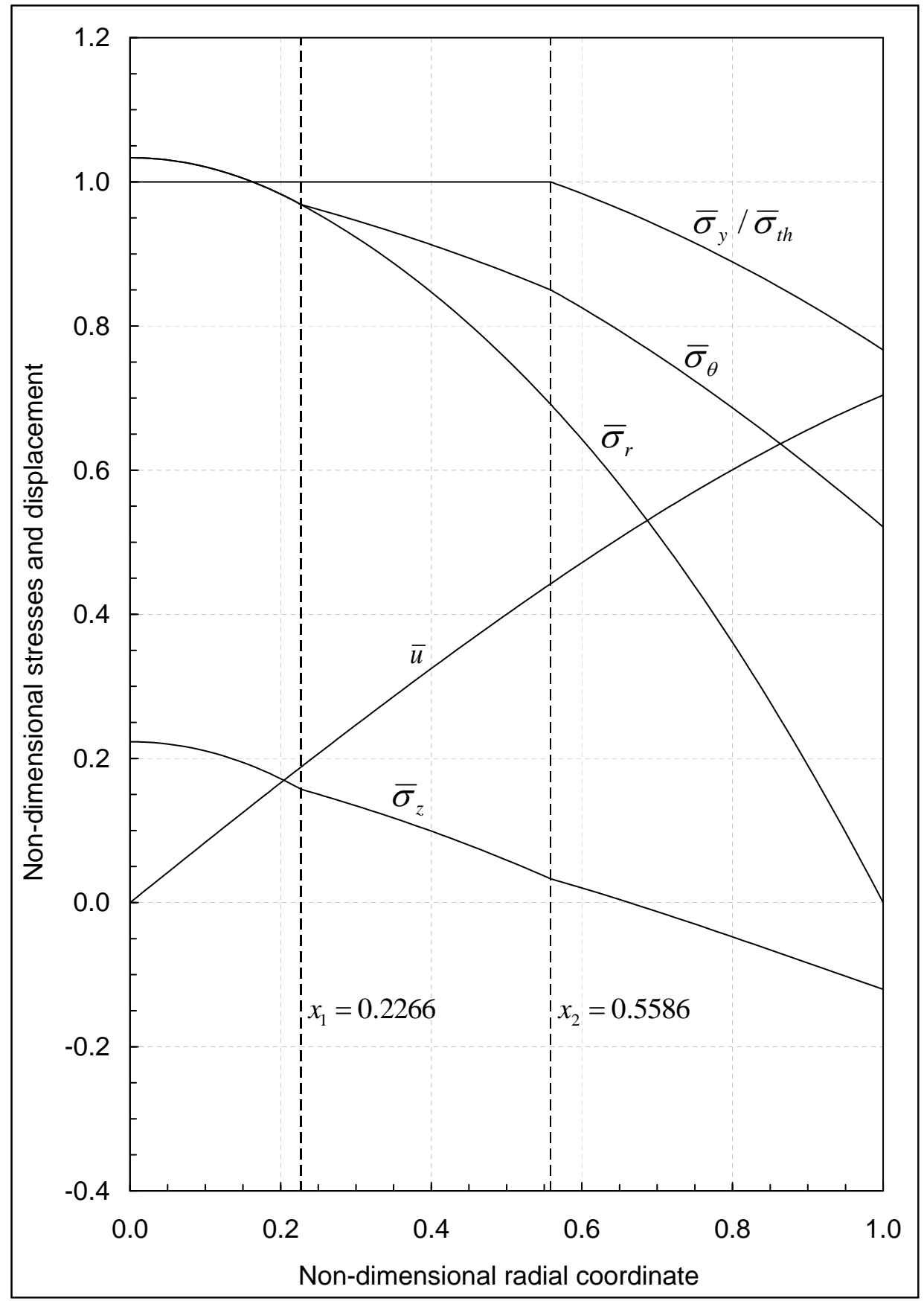

Figure 6.28: Stresses and radial displacement distributions in elastic-plastic state at $\tau=1.72$ 


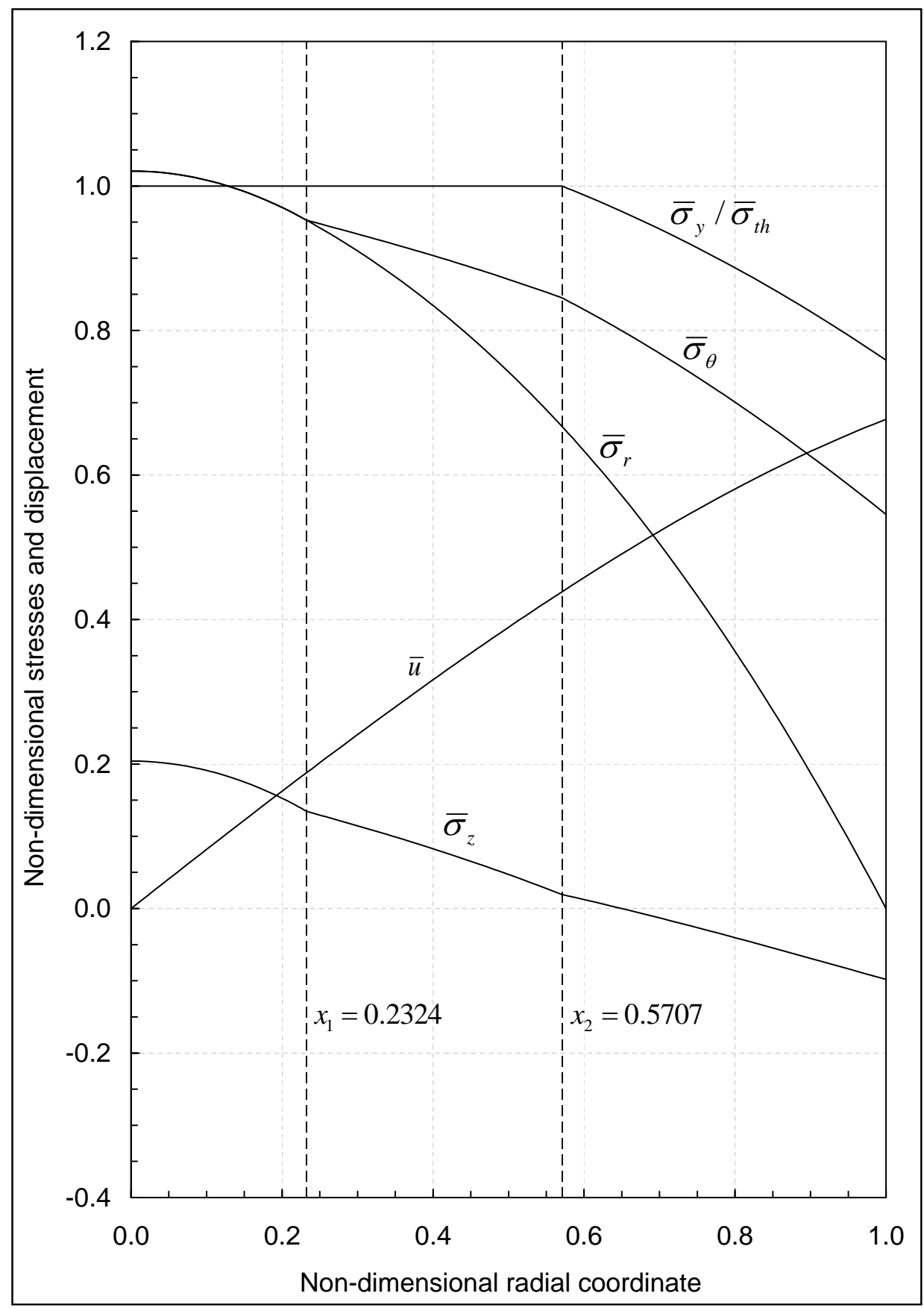

Figure 6.29: Stresses and radial displacement distributions in elastic-plastic state at $\tau=\tau_{u b}=1.7882$ 


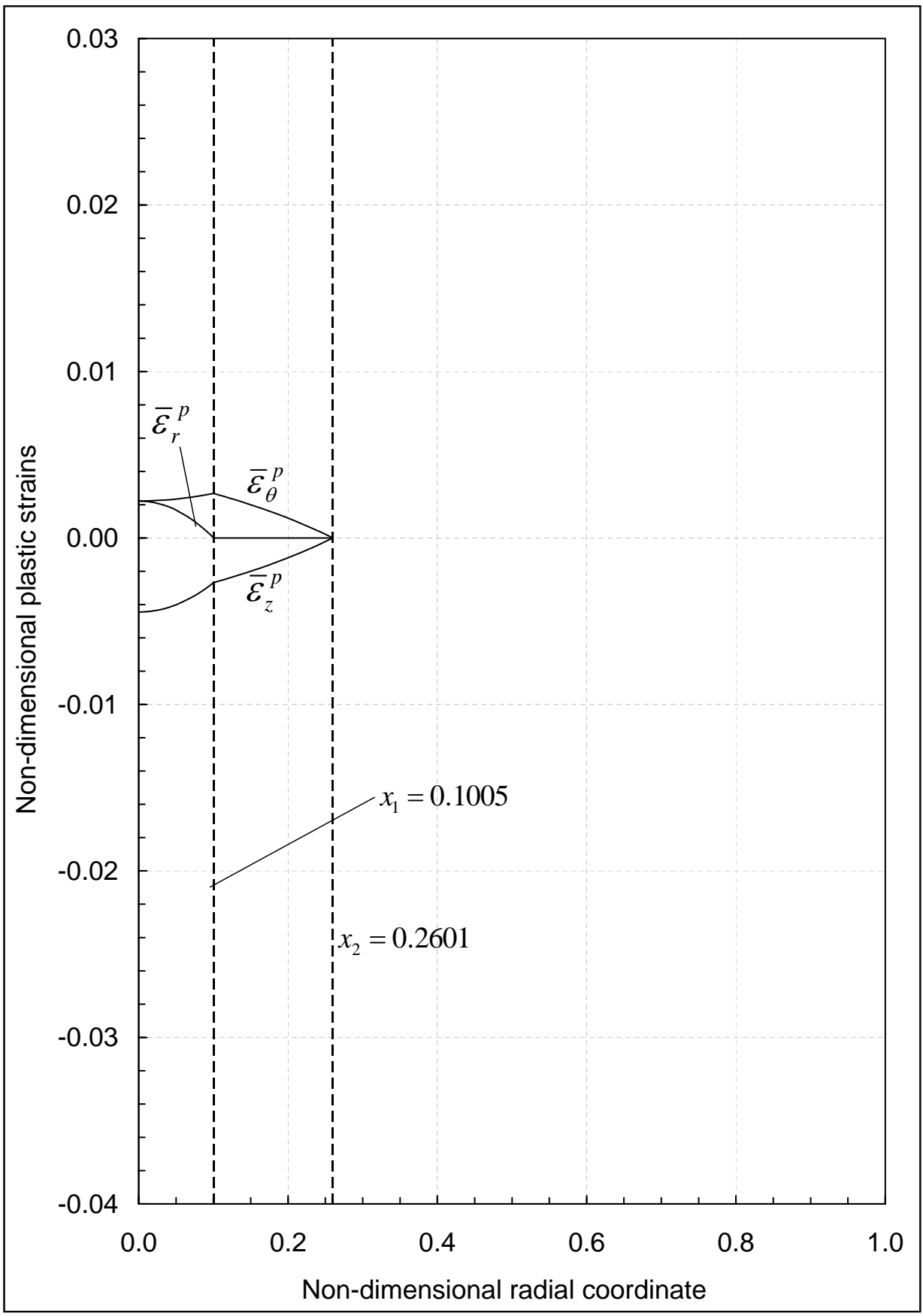

Figure 6.30: Plastic strain distributions in elastic-plastic state at $\tau=1.57$ 


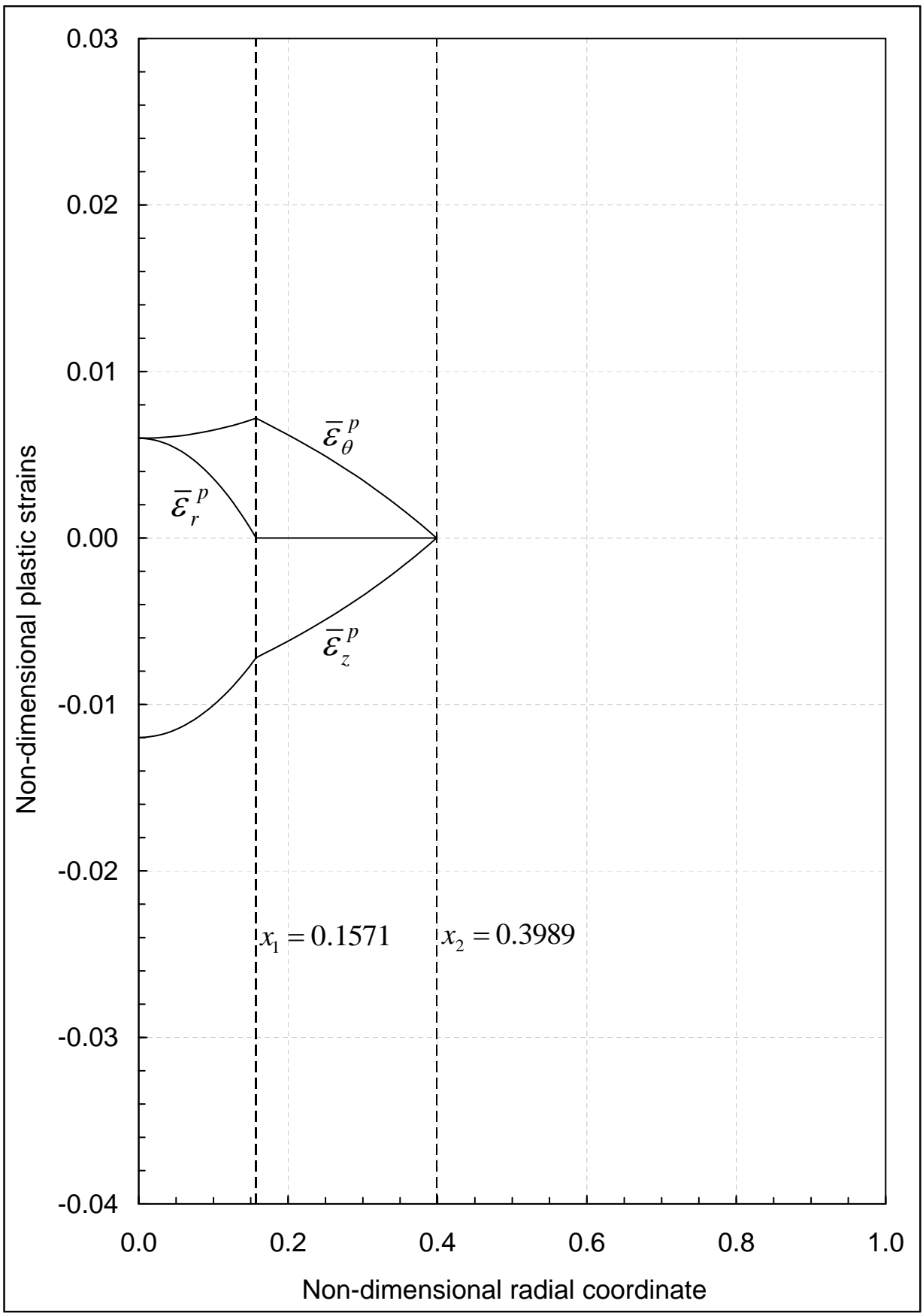

Figure 6.31: Plastic strain distributions in elastic-plastic state at $\tau=1.6$ 


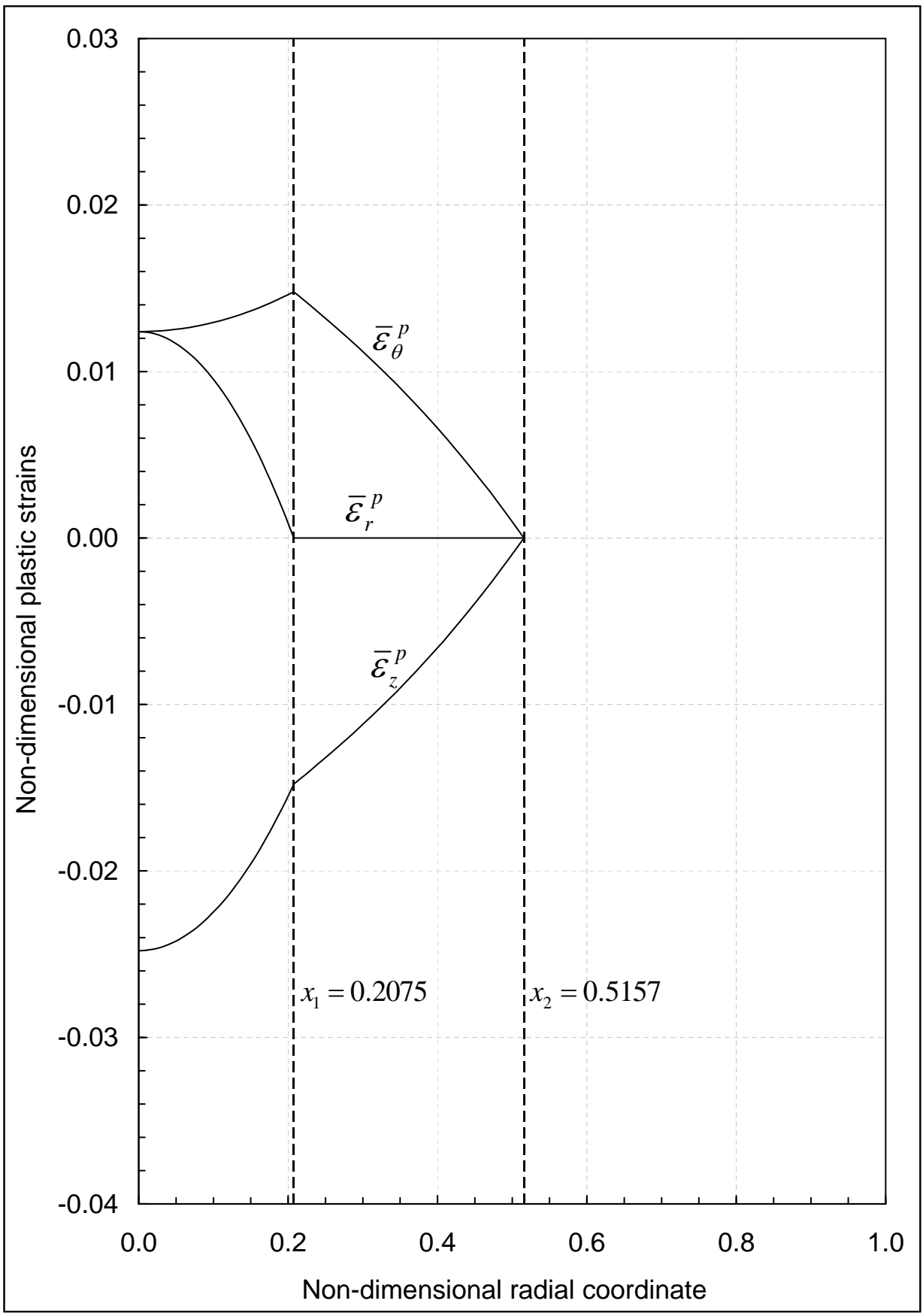

Figure 6.32: Plastic strain distributions in elastic-plastic state at $\tau=1.66$ 


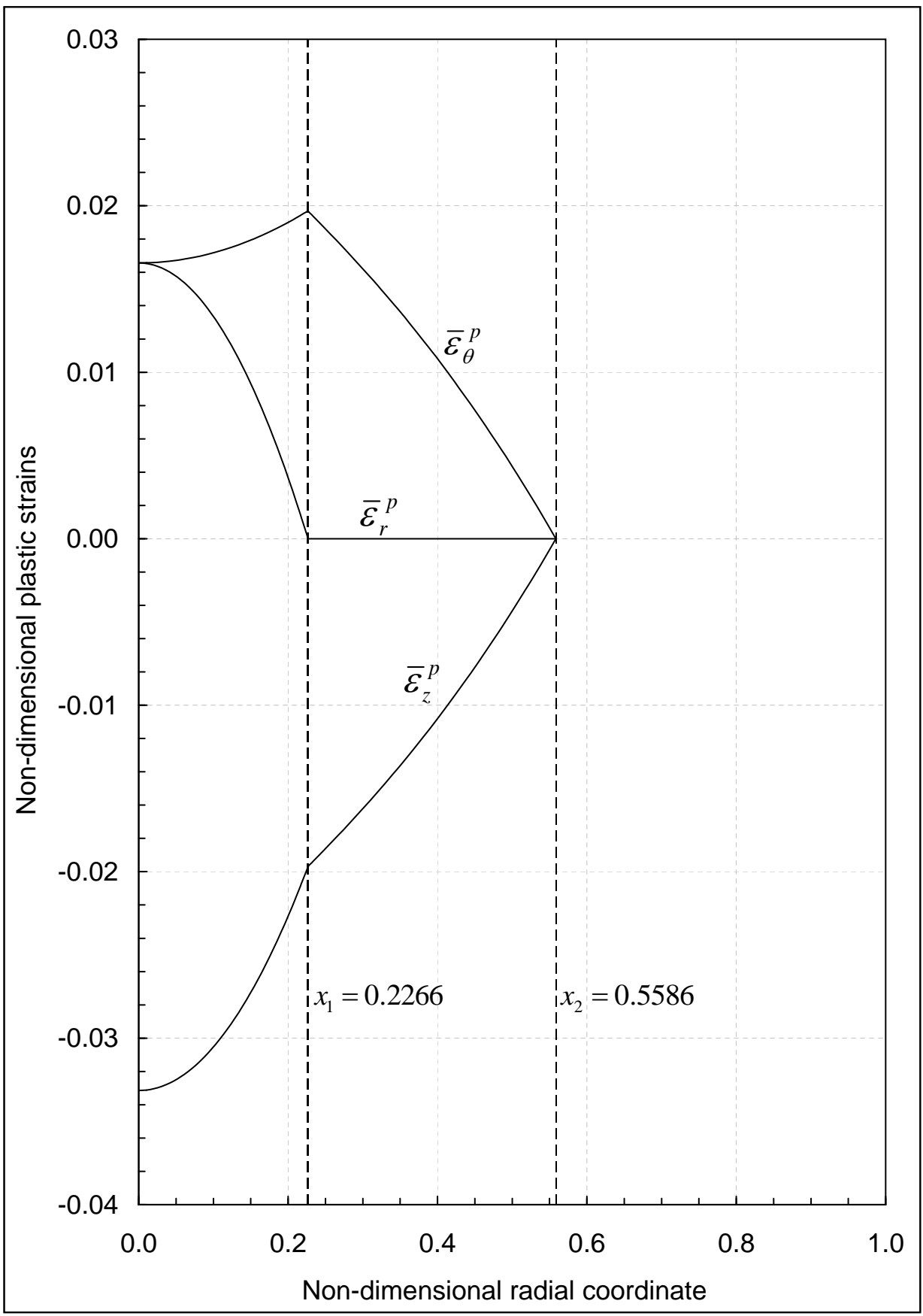

Figure 6.33: Plastic strain distributions in elastic-plastic state at $\tau=1.72$ 


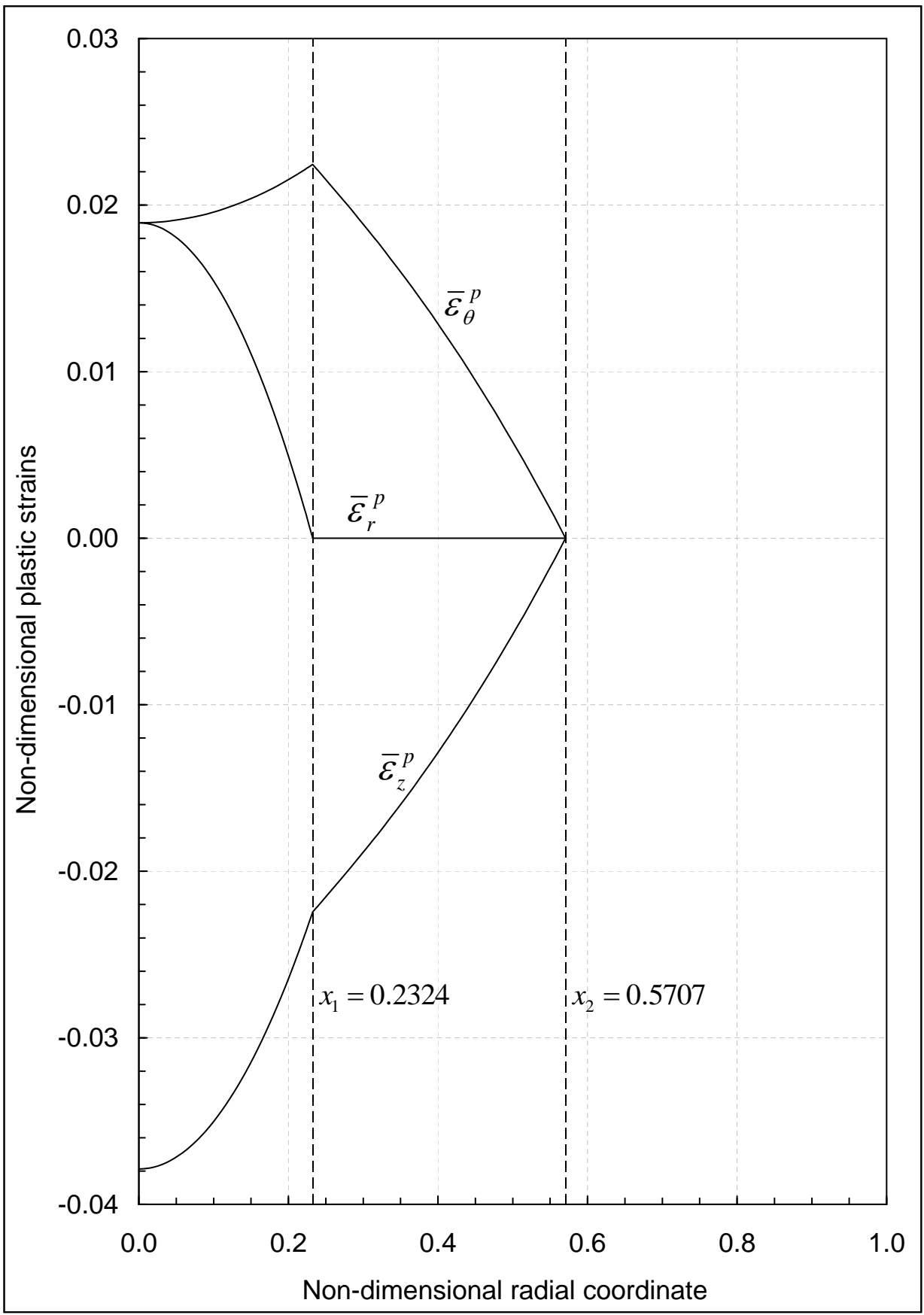

Figure 6.34: Plastic strain distributions in elastic-plastic state at $\tau=\tau_{u b}=1.7882$ 


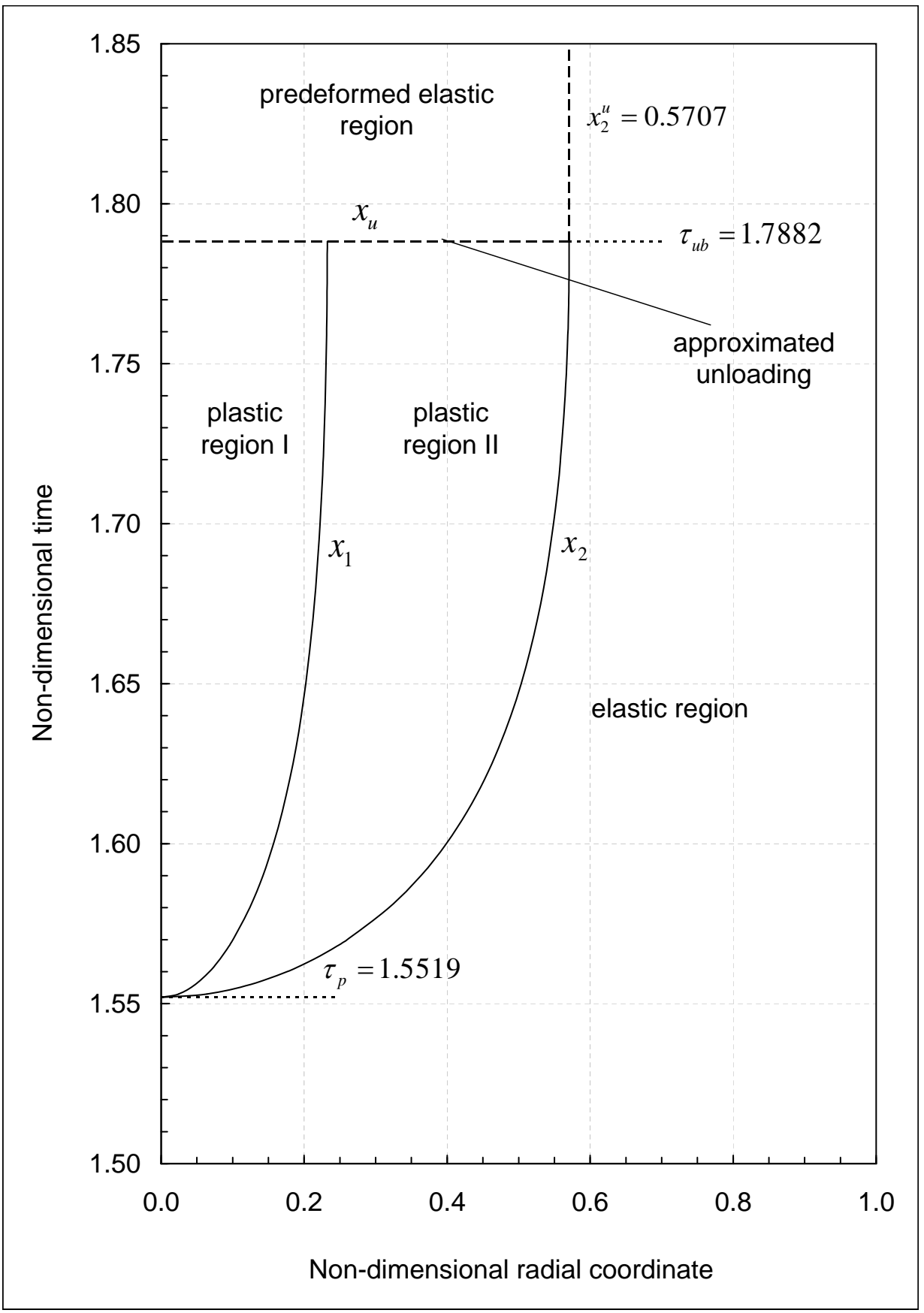

Figure 6.35: Evolution of plastic regions with time 


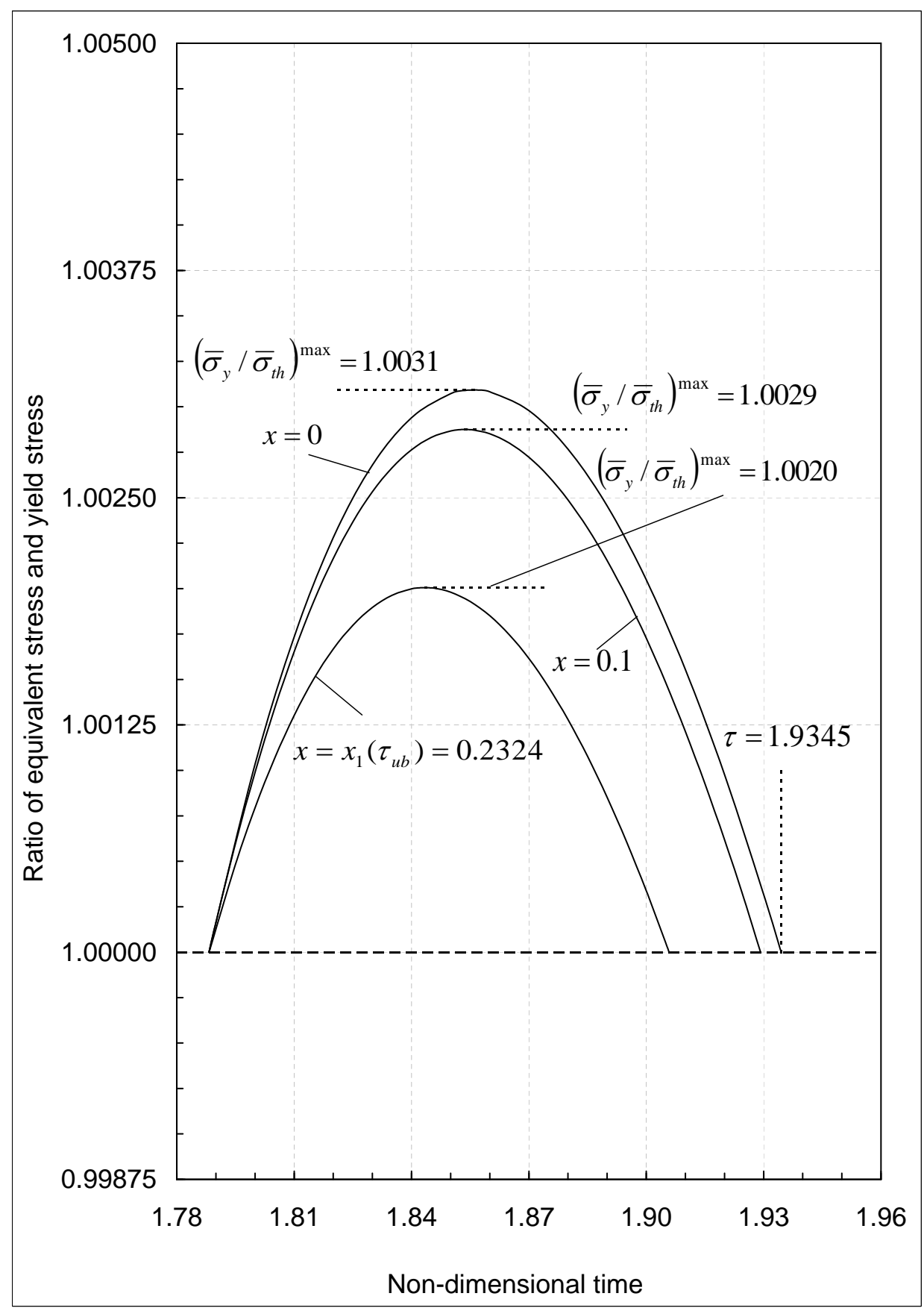

Figure 6.36: Evolution of the ratio of equivalent and yield stresses with time for three different radii after assumed sudden unloading 
To observe stresses and displacement in unloaded state at $1.7882<\tau<2.7$, Figures from 6.37 to 6.42 are plotted. Response variables are calculated at the upper time limit of elastic-plastic state and at the beginning time of the unloaded state, $\tau=$ $\tau_{u b}=1.7882$, and drawn in Figure 6.37. In the figure, dots represents the results of the elastic-plastic state, and solid lines are those of unloaded state. As seen in the figure, fairly good agreement between two results is obtained. This verifies that the formulations of the both states are correct. Moreover, in Figure 6.38, time is selected as $\tau=1.9$ to present corresponding distributions of stresses and displacement. Between Figures 6.39 and 6.42, 0.2 time increments are used to plot distributions of the response variables. In the last figure, which is plotted at time instant $\tau=2.7$, the temperature cycle ends and the surface temperature returns to reference temperature. In this cooling time interval, it is visible from the figures that stresses and especially displacement decrease dramatically with time after unloading starts. Additionally, it should be remained that plastic strains for these time instants are the same as those given in Figure 6.34. For these figures, the non-dimensional unknown constants $\bar{C}_{2}^{*}$ and $\bar{\epsilon}_{0}$ are calculated with help of Eqs. $(5.24-5.25)$ and the results are presented in Table 6.4 .

Table 6.4: Calculated constants in unloaded state at different time values until the end of the temperature cycle

\begin{tabular}{|c|c|c|}
\hline Time $(\tau)$ & $\bar{C}_{2}^{*}$ & $\bar{\epsilon}_{0}$ \\
\hline $1.7882\left(\tau_{u b}\right)$ & 0.304070 & 0.355186 \\
\hline 1.9 & 0.300530 & 0.305625 \\
\hline 2.1 & 0.293728 & 0.210395 \\
\hline 2.3 & 0.286692 & 0.111895 \\
\hline 2.5 & 0.279583 & $1.236726 \times 10^{-2}$ \\
\hline 2.7 & 0.272450 & $-8.748429 \times 10^{-2}$ \\
\hline
\end{tabular}

It certainly takes time to reach homogeneous temperature distribution in the whole shaft after reaching reference temperature of the outer surface as followed in Figure 6.6. Hence, until isothermal case is obtained, stresses and displacement in the shaft can vary with time at any point. These distributions are plotted for following time values: $\tau=3.0$ in Figure 6.43, $\tau=3.6$ in Figure 6.44, $\tau=4.0$ in Figure 6.45, $\tau=10.0$ in Figure 6.46, and $\tau=20.0$ in Figure 6.47. As seen, there are not any differences 
between Figure 6.46 and Figure 6.47. This shows that when time reaches to $\tau=20.0$, the shaft behaves isothermal. Then thermal load is removed totally from the shaft. Integration constants that are obtained to plot Figures from 6.43 to 6.47 are presented in Table 6.5.

Table 6.5: Calculated constants in unloaded state at different time values after the temperature cycle

\begin{tabular}{|c|c|c|}
\hline Time $(\tau)$ & $\bar{C}_{2}^{*}$ & $\bar{\epsilon}_{0}$ \\
\hline 3.0 & 0.268744 & -0.139379 \\
\hline 3.6 & 0.268014 & -0.149588 \\
\hline 4.0 & 0.267993 & -0.149884 \\
\hline 10.0 & 0.267991 & -0.149916 \\
\hline 20.0 & 0.267991 & -0.149916 \\
\hline
\end{tabular}

An interesting result is observed on the evolution of stresses and radial displacement with time at some critical locations, i.e., the center $(x=0)$ and the outer surface $(x=1)$ of the shaft. In Figure 6.48, the evolution of the radial stress at the center with time is presented. In the figure, the critical time values, i.e., the end of the heating time $\tau_{t}$, the beginning of the cooling time $\tau_{t}+\tau_{c}$, the end of the cooling time $2 \tau_{t}+\tau_{c}$, the time when plastic flow starts $\tau_{p}$ and the time when unloaded state starts $\tau_{u b}$, separate the time intervals. As seen in the figure, the stress tends to vary at each time interval in different manner. The radial stress at the center initially increases during the surface heating process $\left(\tau \leq \tau_{t}\right)$. On the other hand, it dramatically decreases with different slopes at the time interval when the surface temperature remains constant and in the cooling time interval $\left(\tau_{t} \leq \tau \leq 2 \tau_{t}+\tau_{c}\right)$. When the outer surface temperature reaches back to the reference temperature at $\tau=2 \tau_{t}+\tau_{c}$, the radial stress starts to increase again. However, the stress tends to a certain value, which is $\bar{\sigma}_{r}=1.1043$, with increasing time since the rotation speed is constant and the isothermal case is approaching. This value is higher than the initial one (at $\tau=0)$ and this proves that some residual stresses remain in the shaft because of the temperature field. It should also be noted that this evolution is the same as the evolution of circumferential stress at the center since $\sigma_{r}=\sigma_{\theta}$ at this location. 


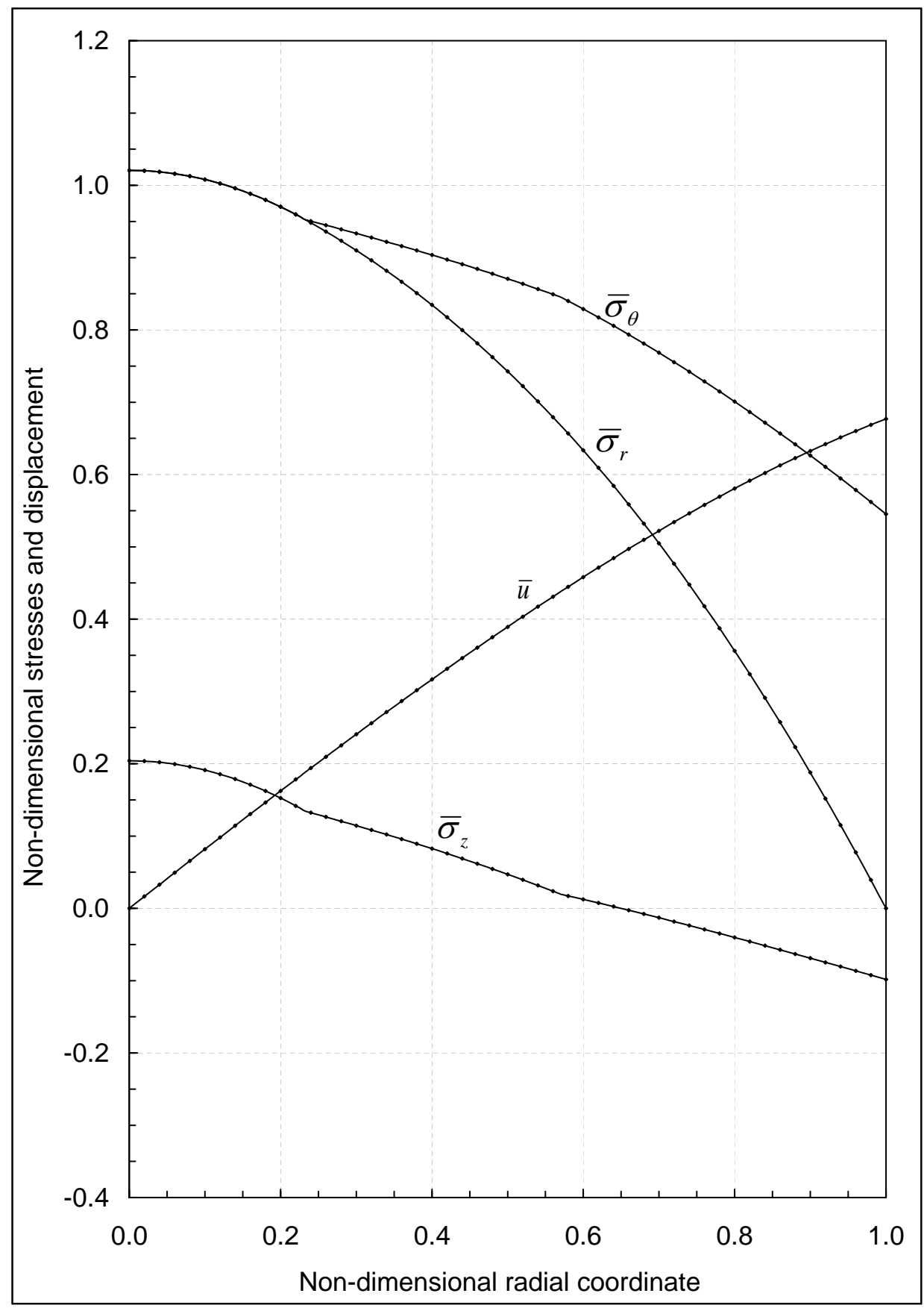

Figure 6.37: Stresses and radial displacement distributions in unloaded state at $\tau=$ $\tau_{u b}=1.7882$ 


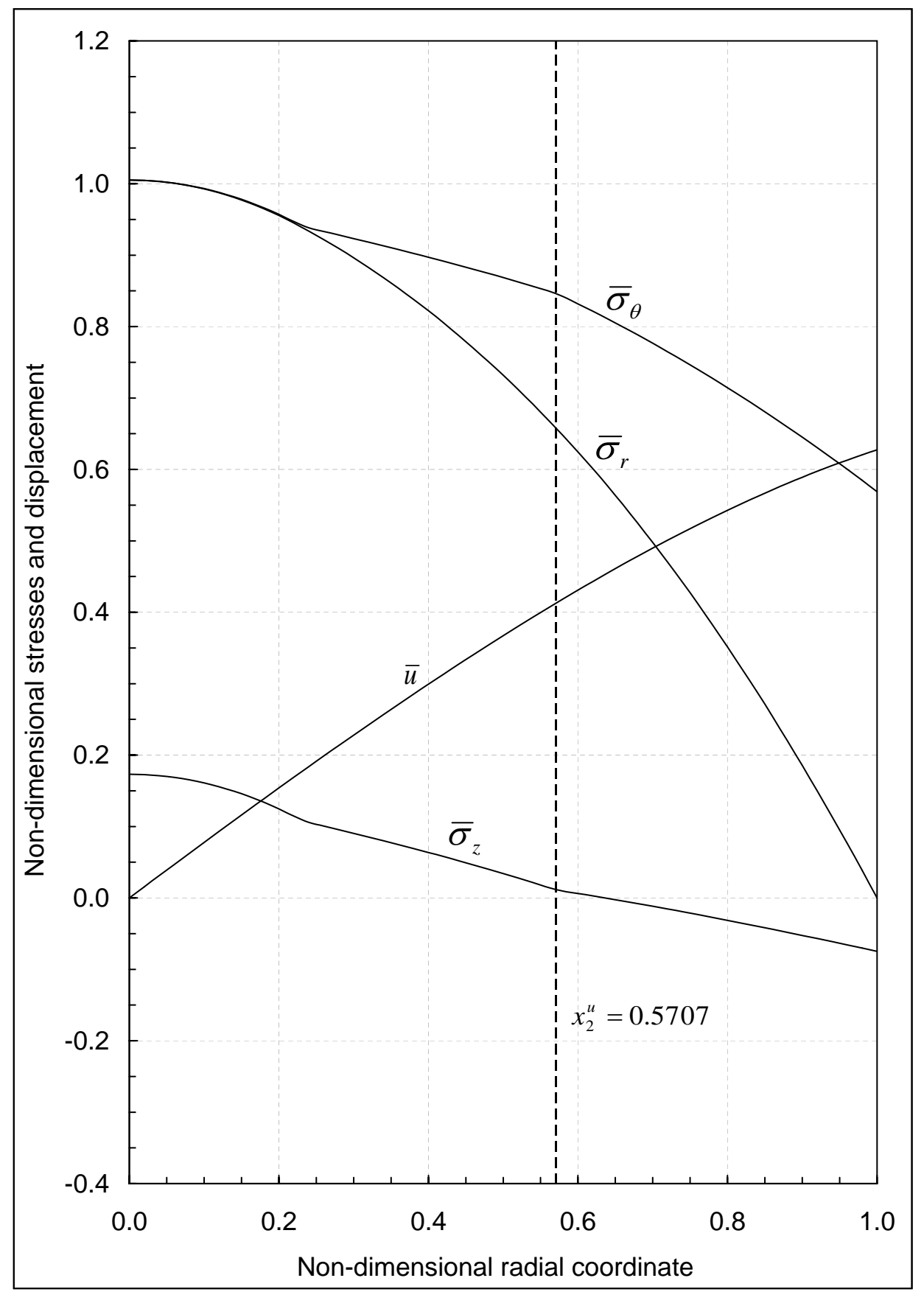

Figure 6.38: Stresses and radial displacement distributions in unloaded state at $\tau=1.9$ 


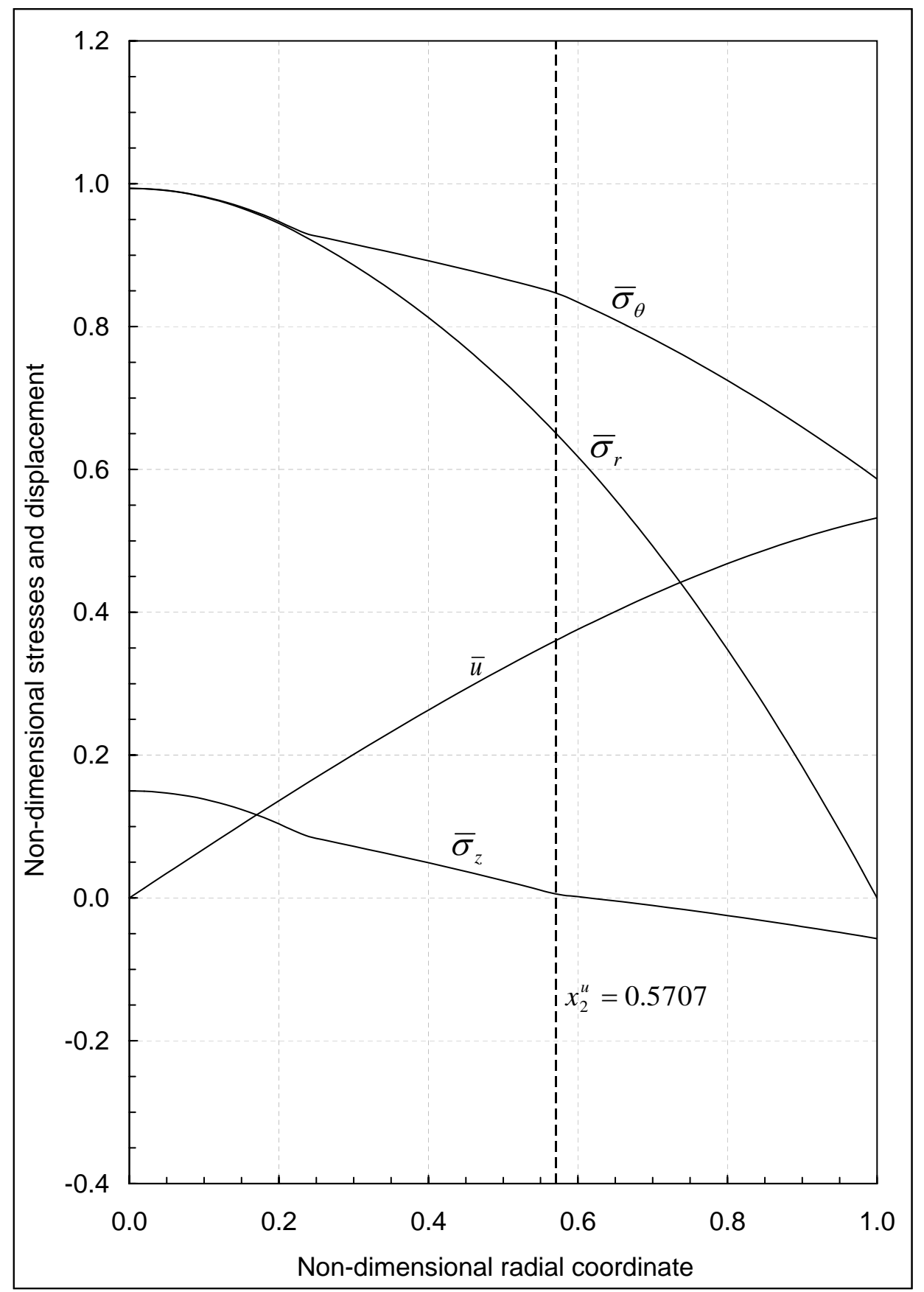

Figure 6.39: Stresses and radial displacement distributions in unloaded state at $\tau=2.1$ 


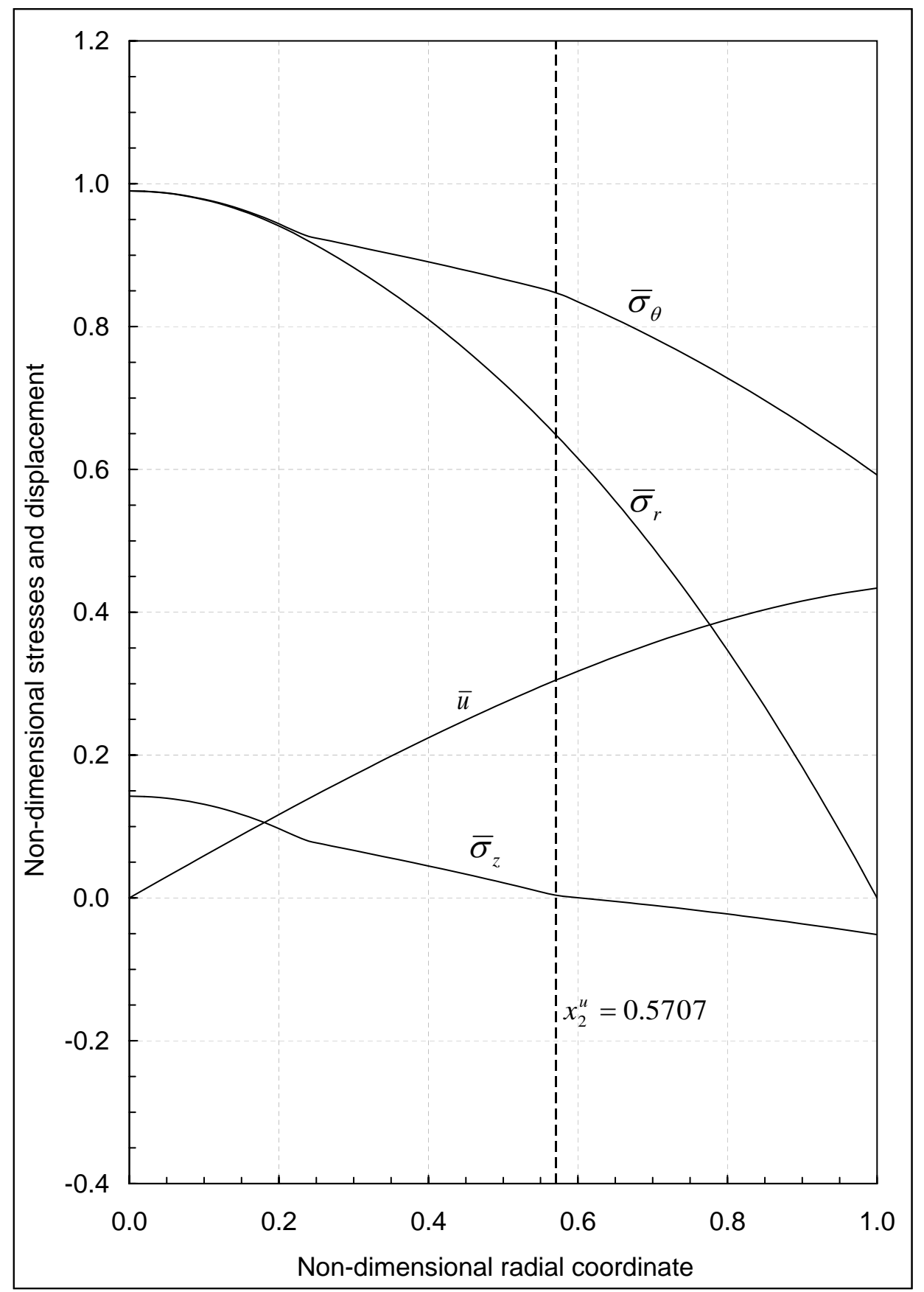

Figure 6.40: Stresses and radial displacement distributions in unloaded state at $\tau=2.3$ 


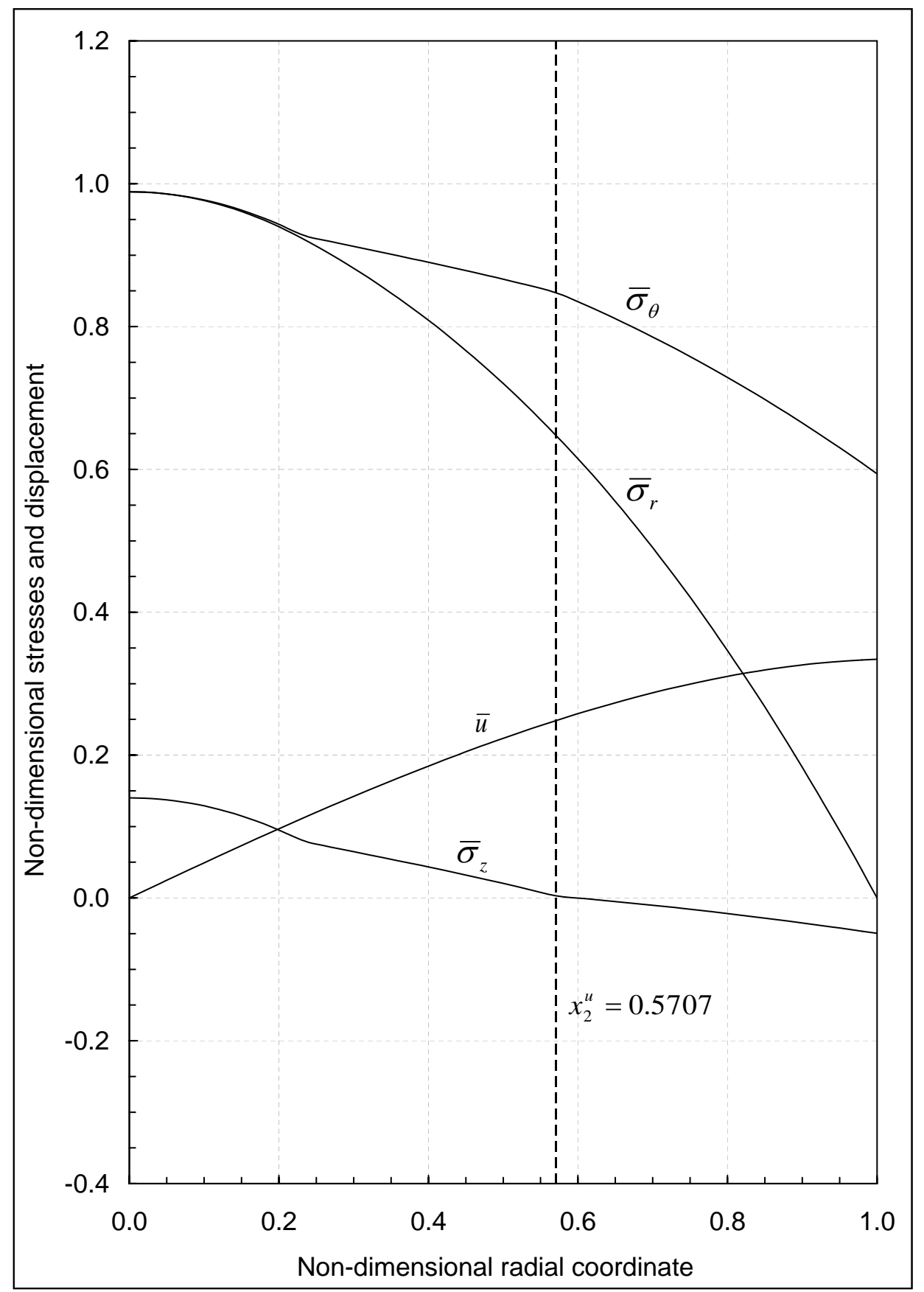

Figure 6.41: Stresses and radial displacement distributions in unloaded state at $\tau=2.5$ 


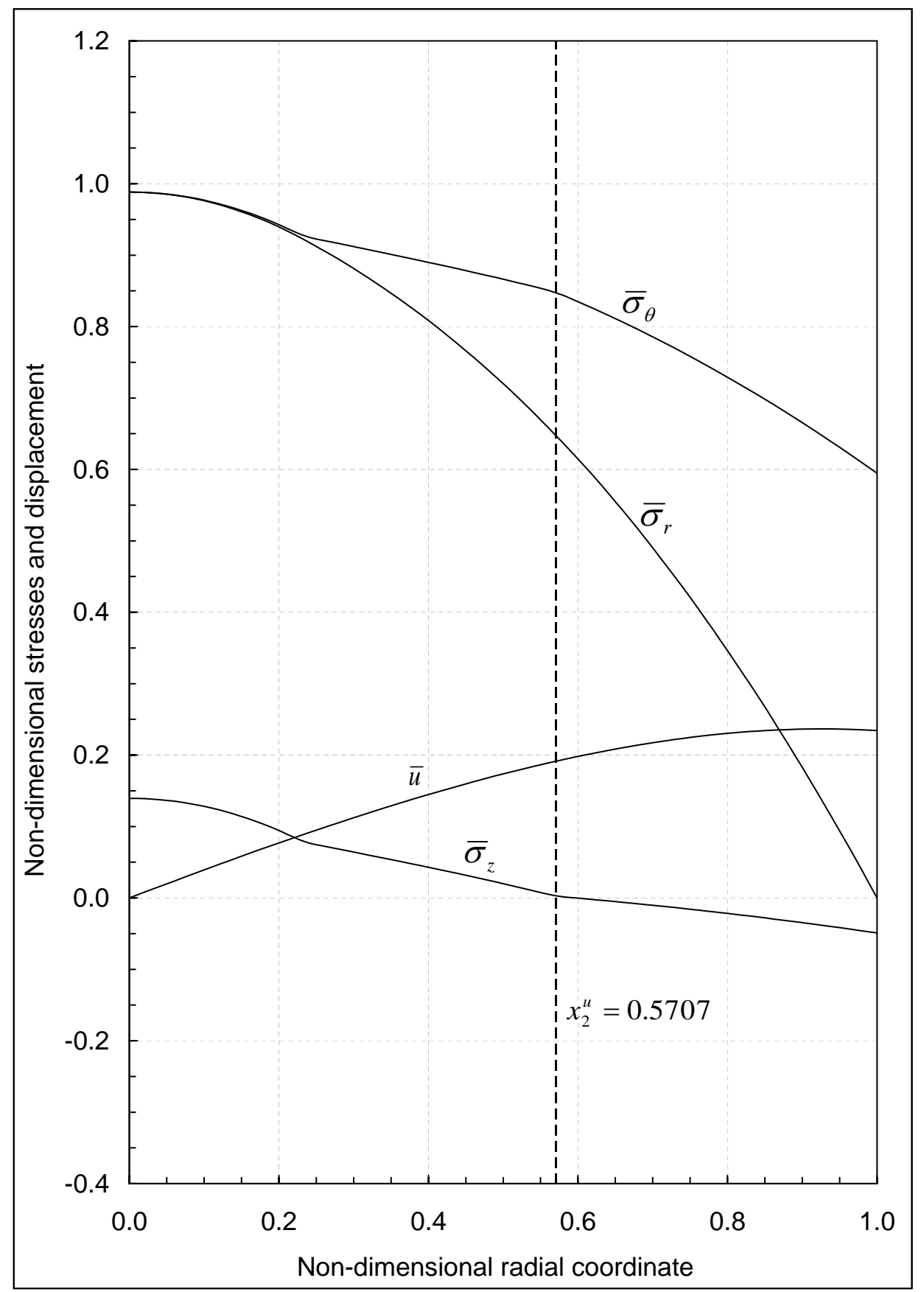

Figure 6.42: Stresses and radial displacement distributions in unloaded state at $\tau=2.7$ 


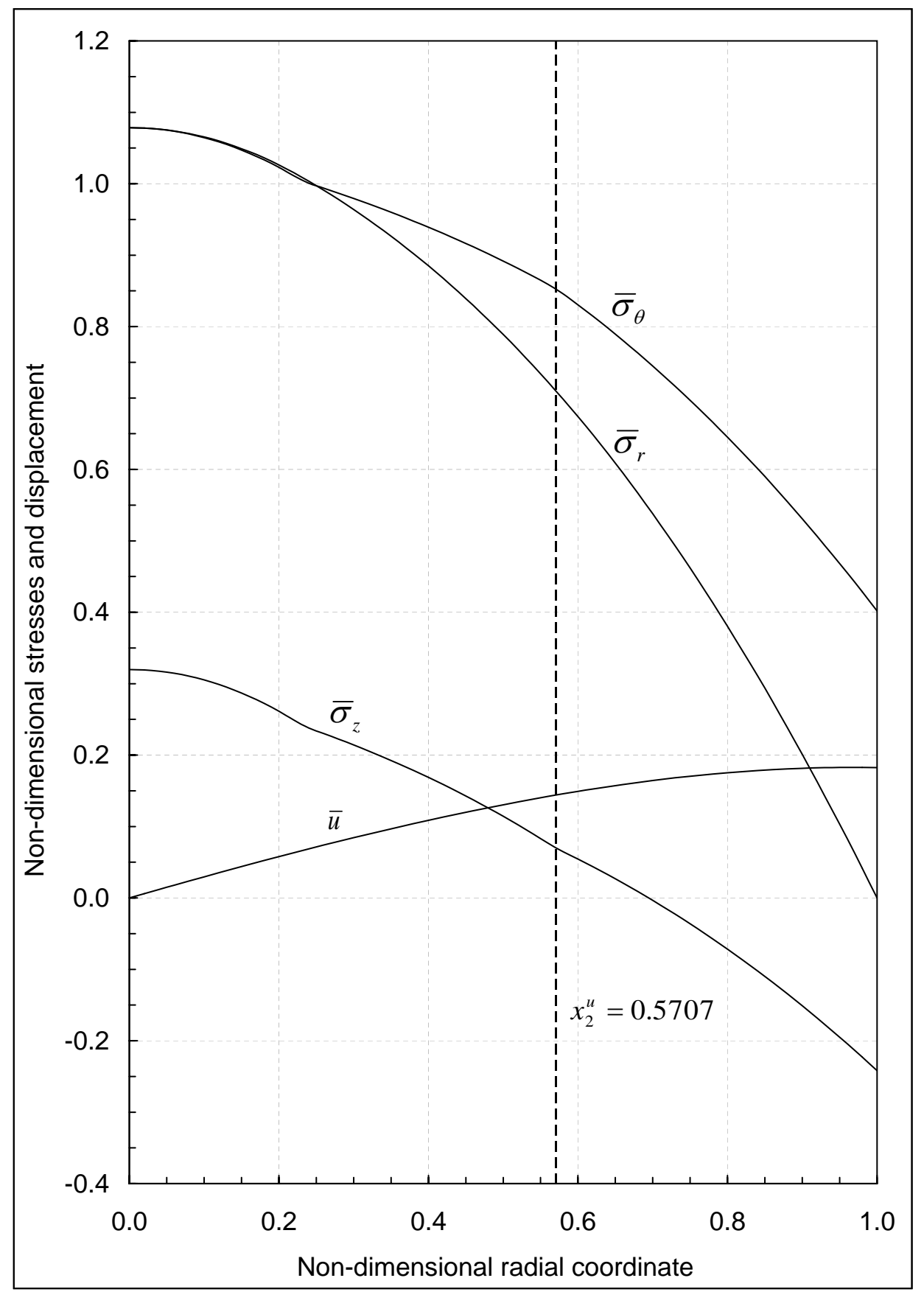

Figure 6.43: Stresses and radial displacement distributions in unloaded state at $\tau=3.0$ 


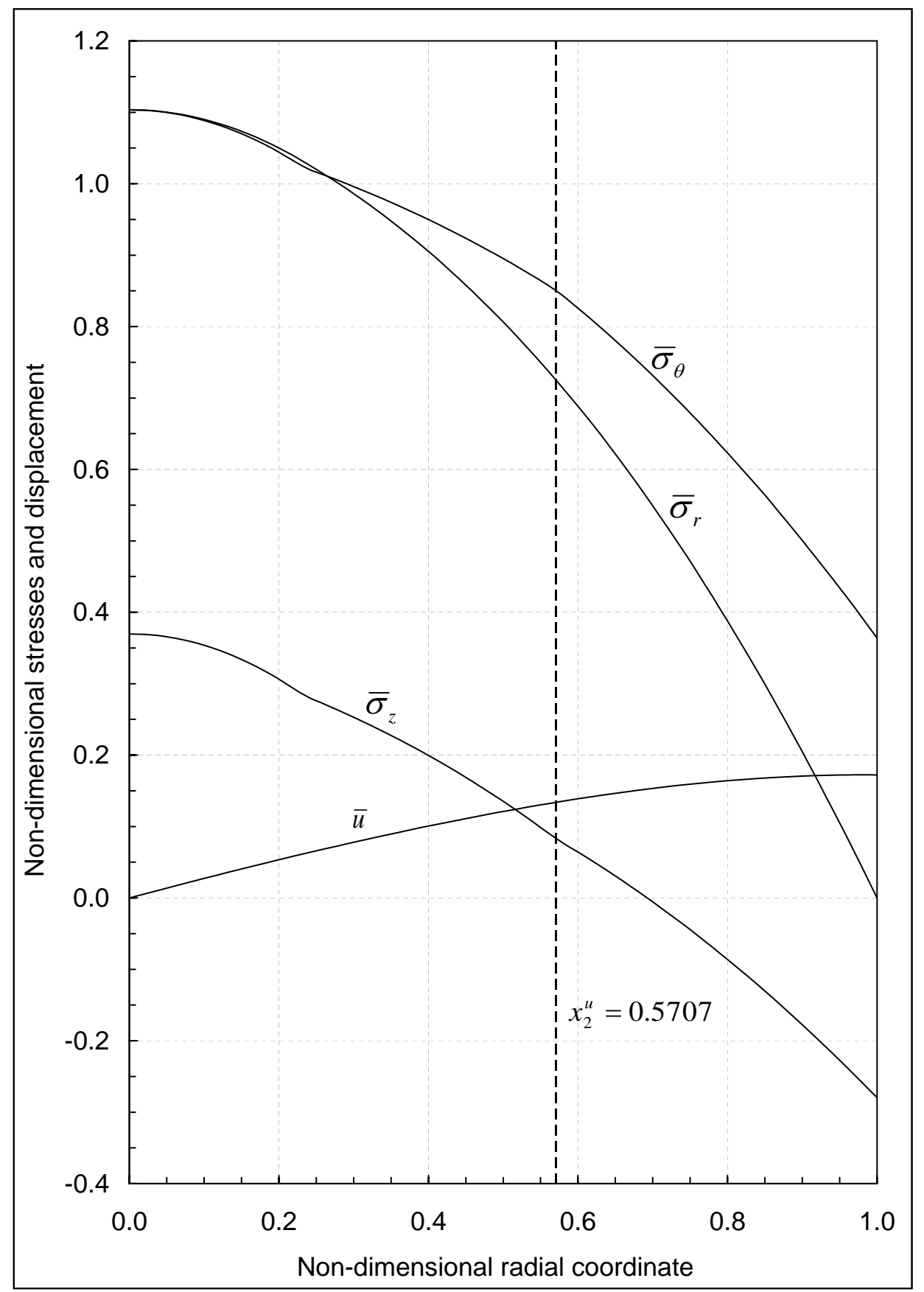

Figure 6.44: Stresses and radial displacement distributions in unloaded state at $\tau=3.6$ 


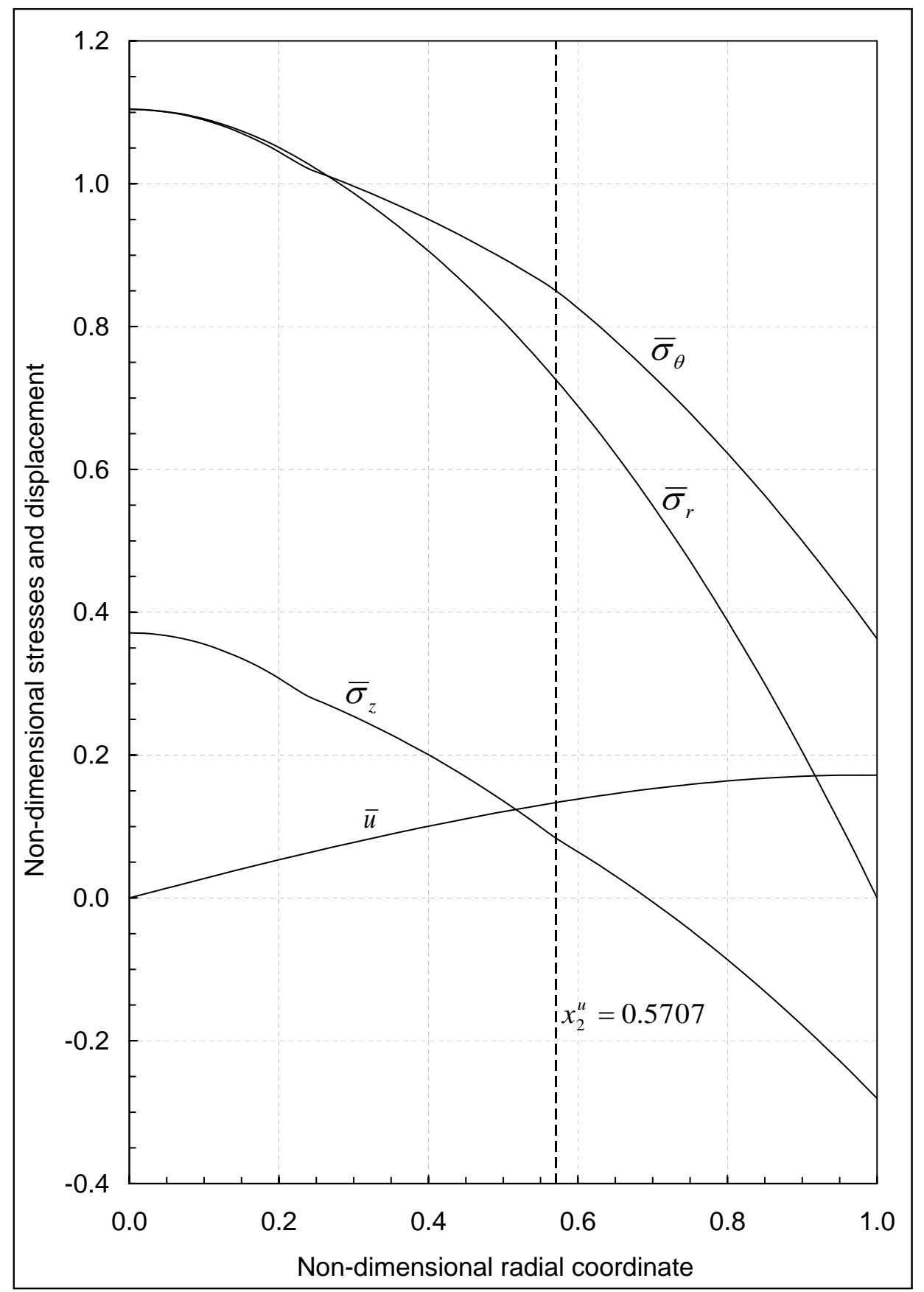

Figure 6.45: Stresses and radial displacement distributions in unloaded state at $\tau=4.0$ 


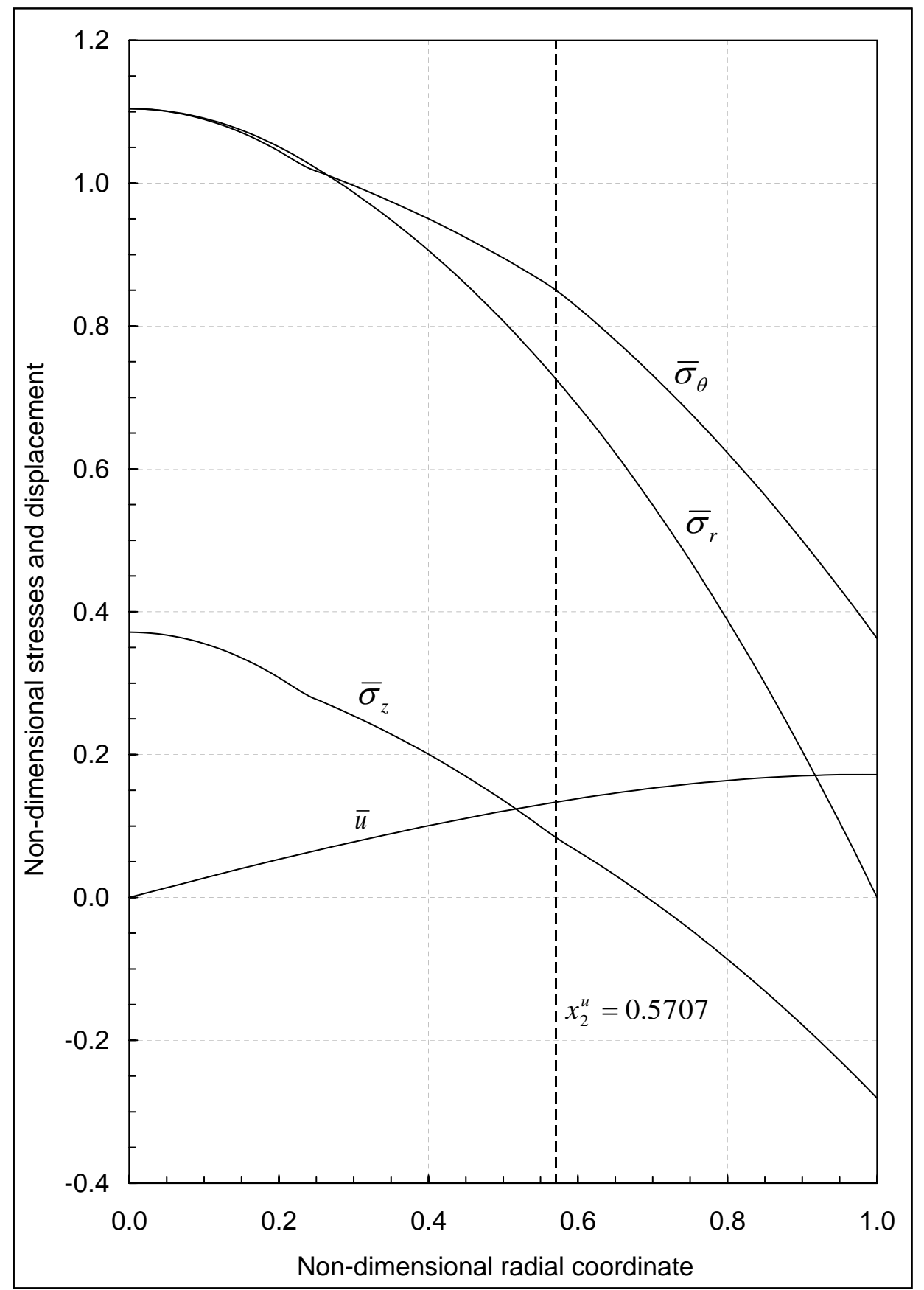

Figure 6.46: Stresses and radial displacement distributions in unloaded state at $\tau=$ 10.0 


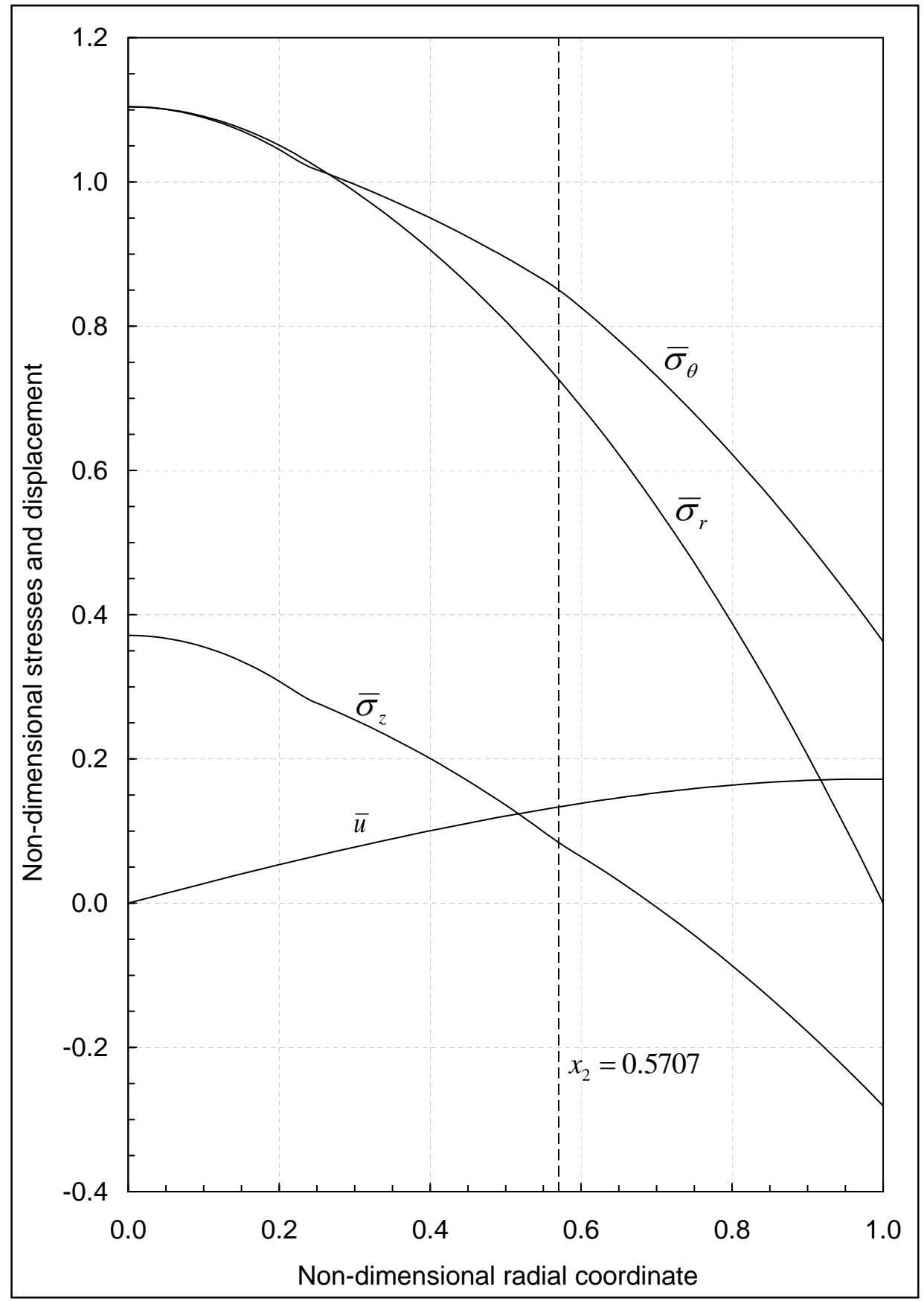

Figure 6.47: Stresses and radial displacement distributions in unloaded state at $\tau=$ 20.0 


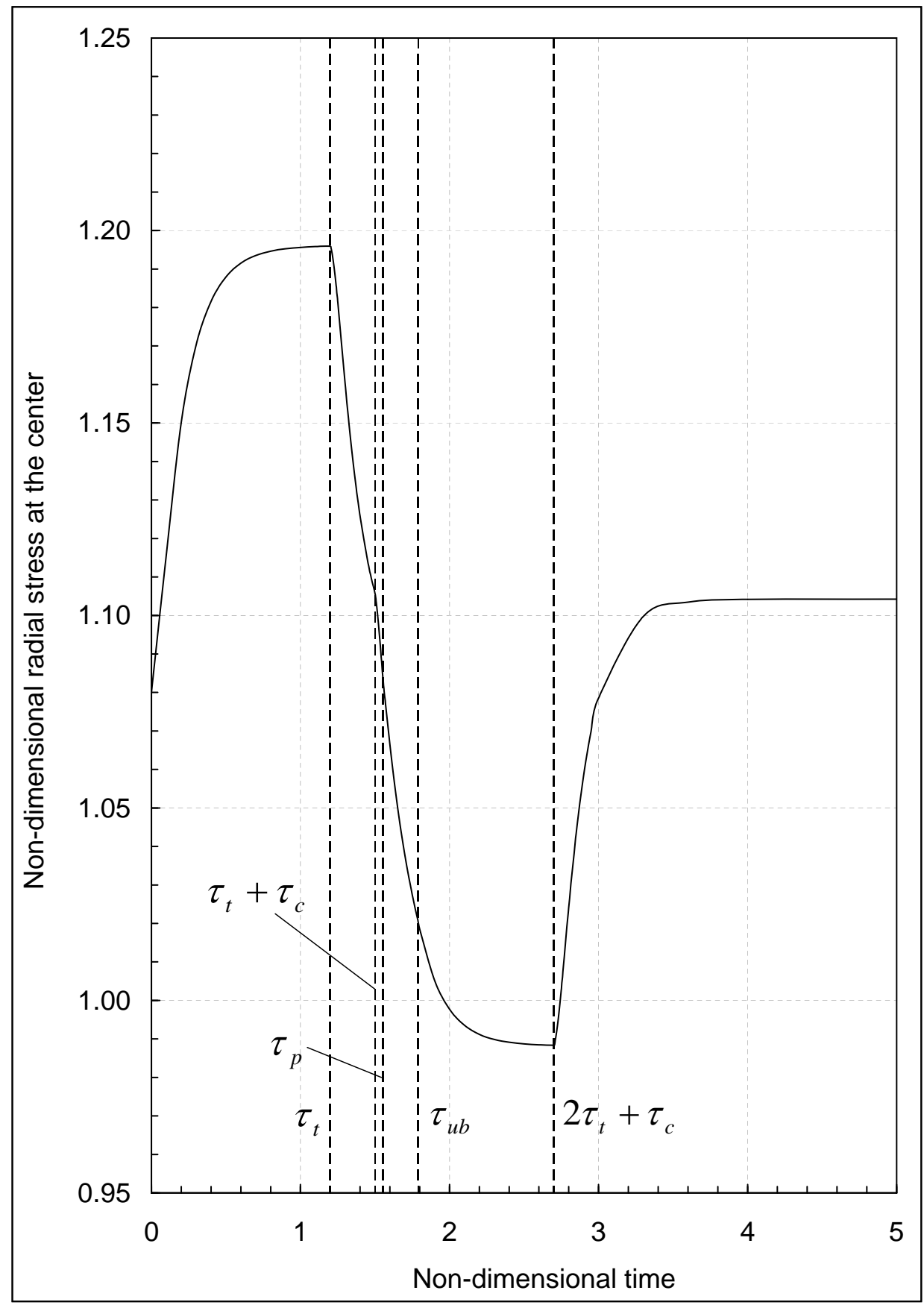

Figure 6.48: Evolution of the radial stress at the center of the shaft 
In Figure 6.49, the evolution of the circumferential stress at the surface of the shaft is presented. The behavior of the circumferential stress at $x=1$ is the opposite of that at $x=0$. In Figures 6.50 and 6.51 , the evolution of axial stresses at the center and the outer surface are plotted, respectively. These two figures show that adverse behavior is observed at the center and the outer surface for the axial stress. Lastly, the evolution of the radial displacement component at the outer surface of the shaft is presented in Figure 6.52. The displacement increases with the superposition of the rotation and the surface heating until $\tau=\tau_{t}+\tau_{c}$. However, it decreases during the cooling of the outer surface and becomes constant at $\bar{u}=0.1719$.

As seen in Figures from 6.48 to 6.52 , some differences occur between the beginning and the end of the thermal process for stresses $\left(\left.\bar{\sigma}_{i}\right|_{\tau=5}-\left.\bar{\sigma}_{i}\right|_{\tau=0}\right)$ and radial displacement $\left(\left.\bar{u}\right|_{\tau=5}-\left.\bar{u}\right|_{\tau=0}\right)$ because of the residual effects. These differences are calculated and presented in Table 6.6. As seen in the table, the maximum difference is observed in the axial stress at the center of the shaft. However, differences in the other stresses and radial displacement are very small.

Table 6.6: Differences in response variables between the beginning and the end of the thermal process

\begin{tabular}{|ccc|}
\hline$\left.\bar{\sigma}_{r}(0)\right|_{\tau=5}-\left.\bar{\sigma}_{r}(0)\right|_{\tau=0}$ & $=0.024259$, \\
\hline$\left.\bar{\sigma}_{\theta}(1)\right|_{\tau=5}-\left.\bar{\sigma}_{\theta}(1)\right|_{\tau=0}$ & $=0.002590$, \\
\hline$\left.\bar{\sigma}_{z}(0)\right|_{\tau=5}-\left.\bar{\sigma}_{z}(0)\right|_{\tau=0}$ & $=0.101247$, \\
\hline$\left.\bar{\sigma}_{z}(1)\right|_{\tau=5}-\left.\bar{\sigma}_{z}(1)\right|_{\tau=0}$ & $=$ & -0.011005, \\
\hline$\left.\bar{u}(1)\right|_{\tau=5}-\left.\bar{u}(1)\right|_{\tau=0}$ & $=0.002266$. \\
\hline
\end{tabular}

During the unloaded state, the ratio of the equivalent and the yielding stresses should be less than 1. To observe this, the distribution of $\bar{\sigma}_{y} / \bar{\sigma}_{t h}$ on radial direction for different times is presented in Figure 6.53. This ratio decreases with time since the thermal effect slowly disappears and thus the isothermal case is obtained. Finally, when the time approaches to nearly or higher value than $\tau=5.0$, the ratio of $\bar{\sigma}_{y} / \bar{\sigma}_{t h}$ remains constant in the whole shaft. Furthermore, Figure 6.54 shows the evolution of ratio of equivalent and yield stresses with increasing time at the center of the shaft. It should be noted that at $\tau \approx 1.9$ the ratio of $\bar{\sigma}_{y} / \bar{\sigma}_{t h}$ is higher than 1 . The reason for this overlap is the approximated unloading and is described in Figure 6.36. 
For completeness, the stresses after stand-still are shown on Figure 6.55. The distributions of stresses are plotted at $\tau=20.0$ and for $\Omega=0$. In other words, the thermal effect is far away and the rotation is stopped. Hence, these stresses are called residual stresses that remain in the shaft because of the thermal and the mechanical loading. As can be seen from the figure, secondary plastic flow does not occur.

In Figure 6.56, Tresca's yield conditions are presented in the usual way as Tresca's hexagon in the deviatoric plane of the three-dimensional stress space. These figures show four phases of the development of the plastic flow occurring in a rotating solid shaft under unsteady thermal load. Figure 6.56.a is sketched at $\tau=\tau_{p}$. As seen, yielding occurs when the stress image point at $x=0$ reaches an edge regime of the Tresca's hexagon in principal stress space. Additionally, $x=x_{1}$ and $x=x_{2}$ are also seem at the same point at the onset of the yielding. At this time, outer part of the shaft is still elastic then remaining part of the stress space is on the inside of the hexagon. With increasing time, for which $\tau_{p}<\tau<\tau_{u b}, x_{2}$ moves on the one side of Tresca's hexagon according to yield condition (see also Figure 2.2) as seen in Figure 6.56.b. Stress field onto deviatoric plane of the principal stress space at $\tau=\tau_{u b}$ and for $\tau>\tau_{u b}$ are given in Figures 6.56.c and 6.56.d, respectively. As seen in Figure 6.56.d, the stress space is on the inside of the hexagon since the secondary yielding does not occur during unloading.

In Figure 6.57, the evolution of the elastic and the plastic regions are summarized by sketching them at the cross-section of the shaft. The evolution of the regions at different times are plotted respectively. The evolution starts with the purely elastic state at $\tau=\tau_{p}=1.5519$ and for $\Omega=0.9 \times \Omega_{e}^{i}=1.5875$ as seen in Figure 6.57.a. Only elastic region appears in the figure. Additionally, at this time, plastic flow starts, too and moves to the outer zone of the shaft with the increasing time as seen in the Figures from 6.57.b to 6.57.l. In these figures, all regions are drawn with different shapes to make a distinction among the evolution of them. At $\tau=\tau_{u b}=1.7882$, the unloading starts and then the predeformed elastic region remains on the inner zone of the shaft as seen in Figures from 6.57.m to Figure 6.57.o. In the last one, all loads have been removed, i.e., rotation is stopped in the isothermal shaft. 


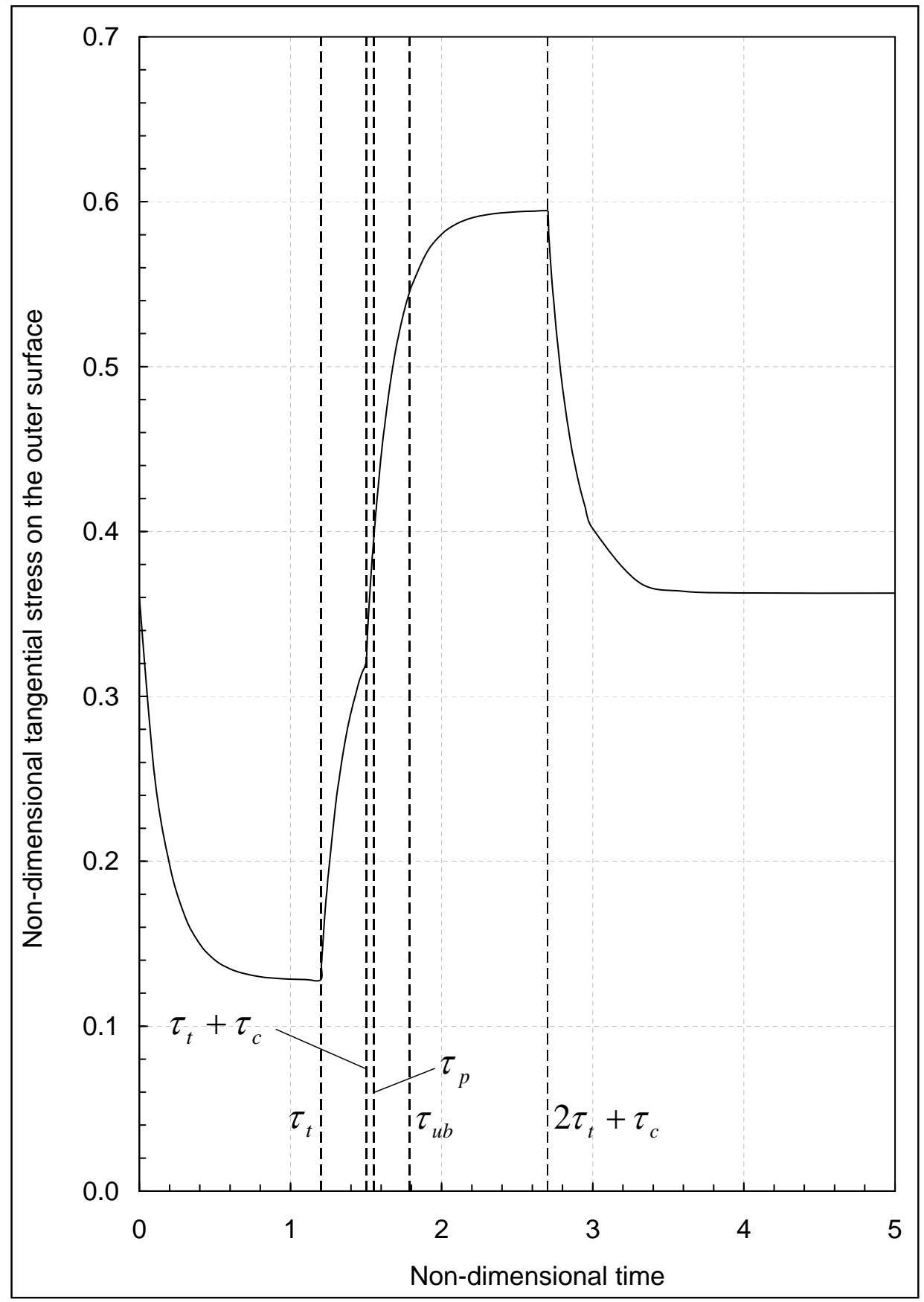

Figure 6.49: Evolution of the tangential stress on the outer surface of the shaft 


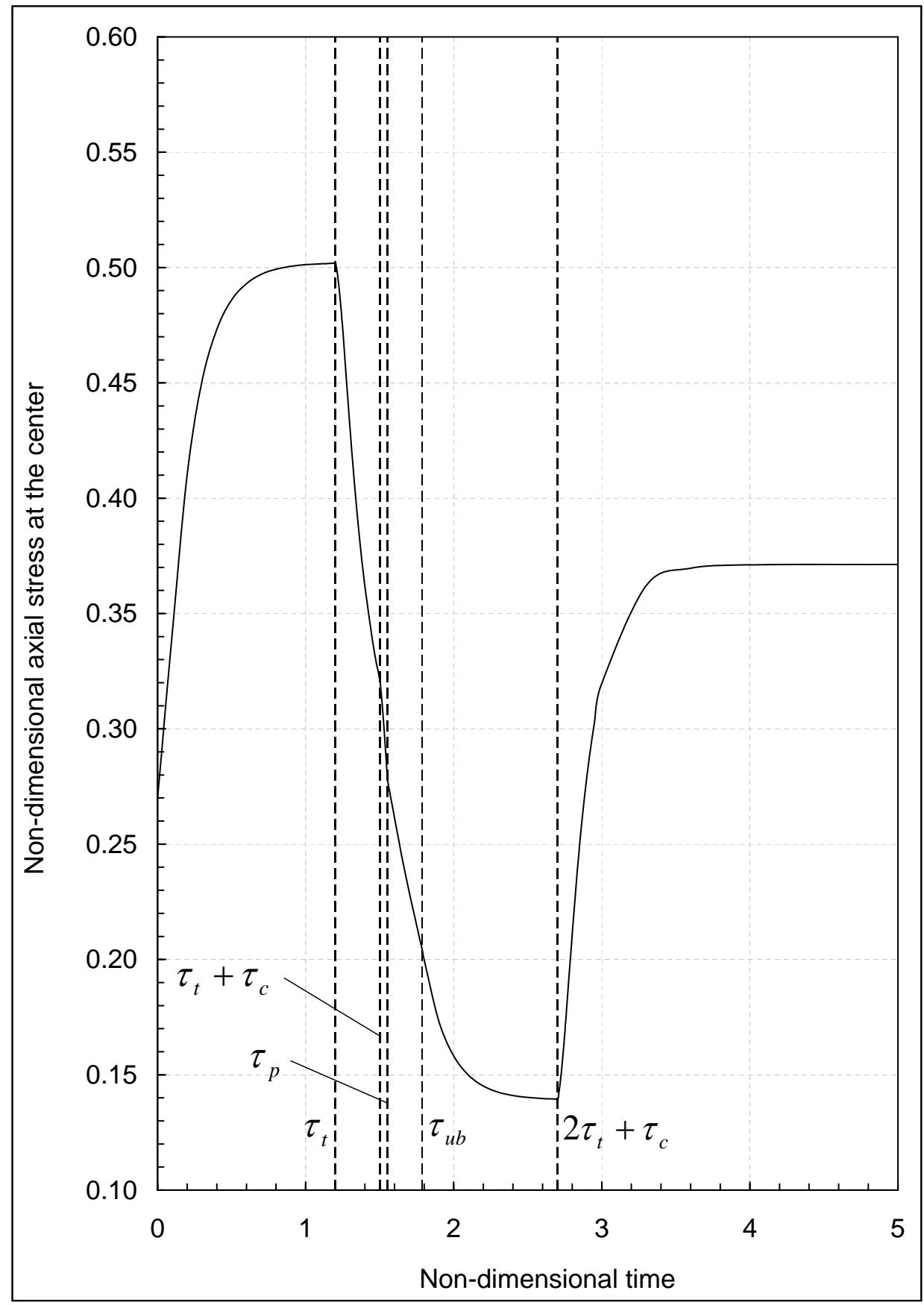

Figure 6.50: Evolution of the axial stress at the center of the shaft 


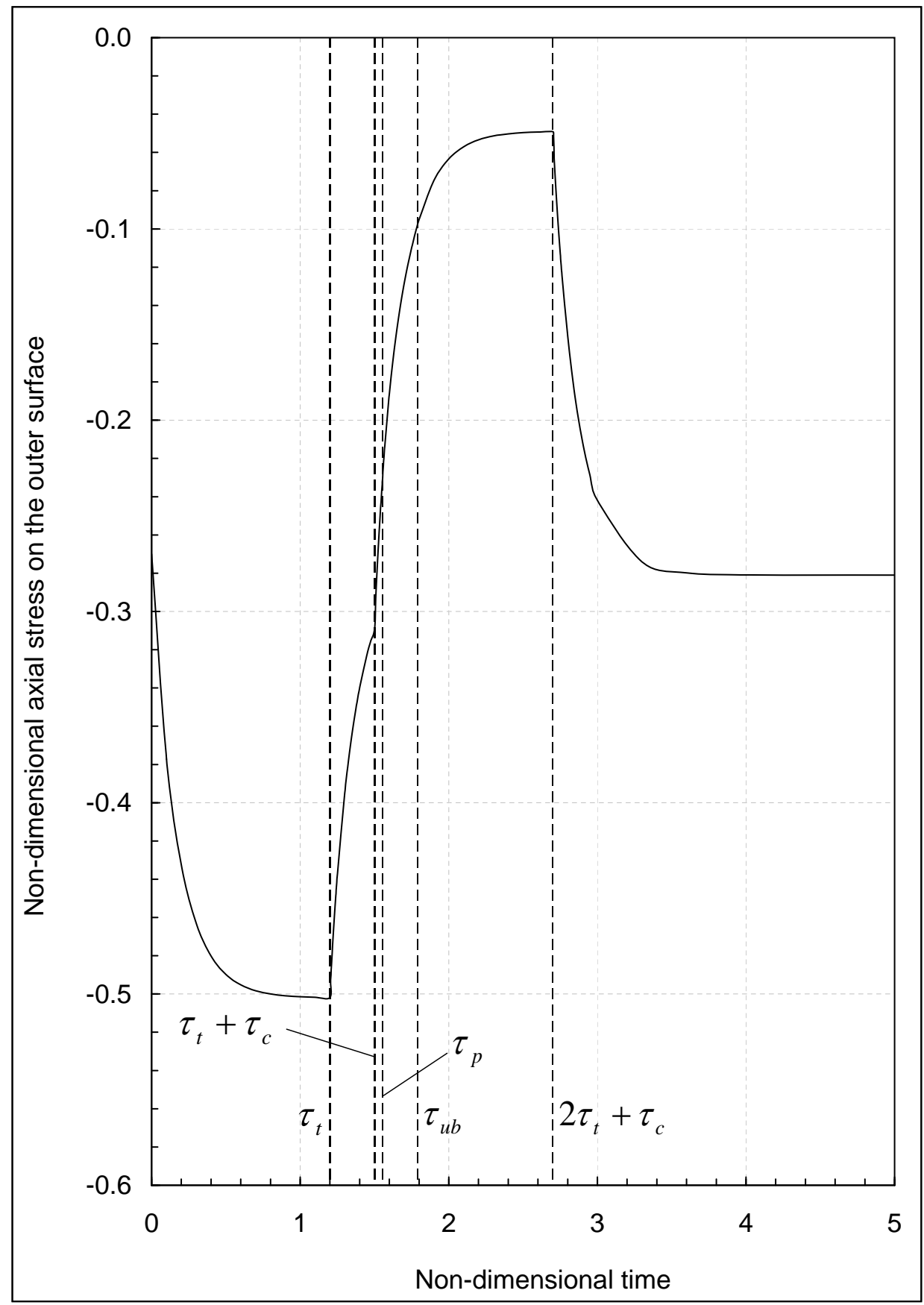

Figure 6.51: Evolution of the axial stress on the outer surface of the shaft 


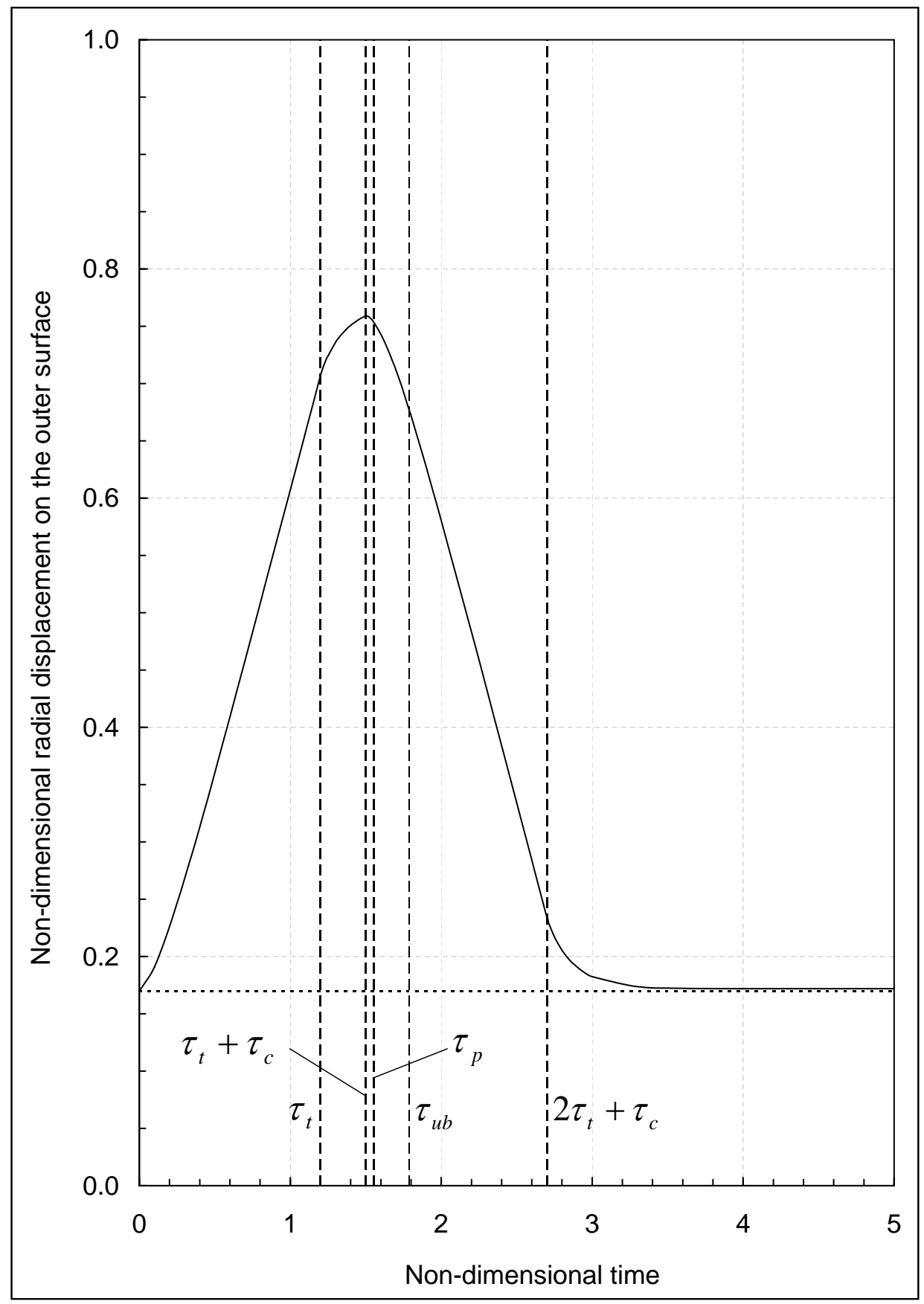

Figure 6.52: Evolution of the radial displacement on the outer surface of the shaft 


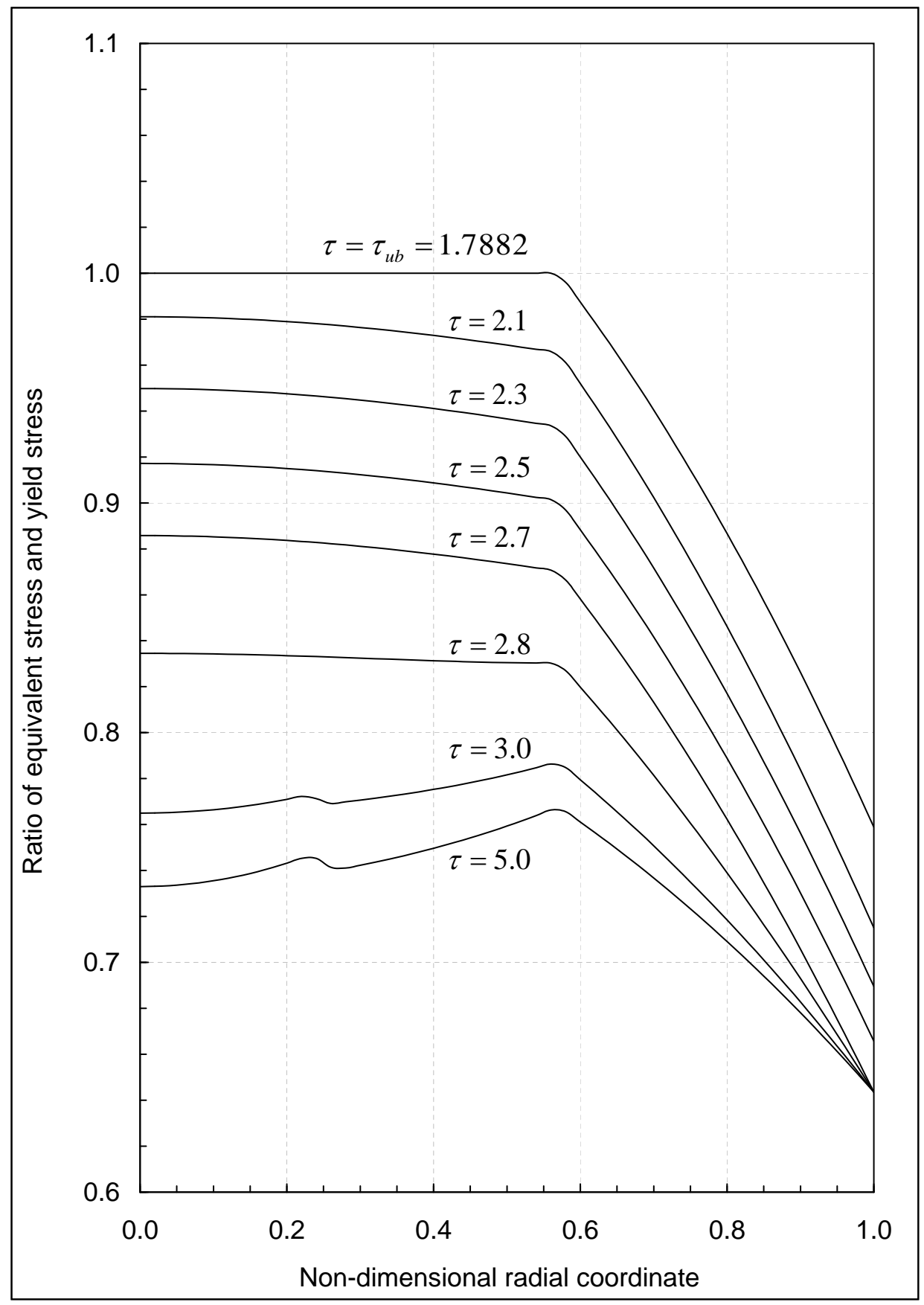

Figure 6.53: Ratio of equivalent and yield stresses at different time in the unloaded state 


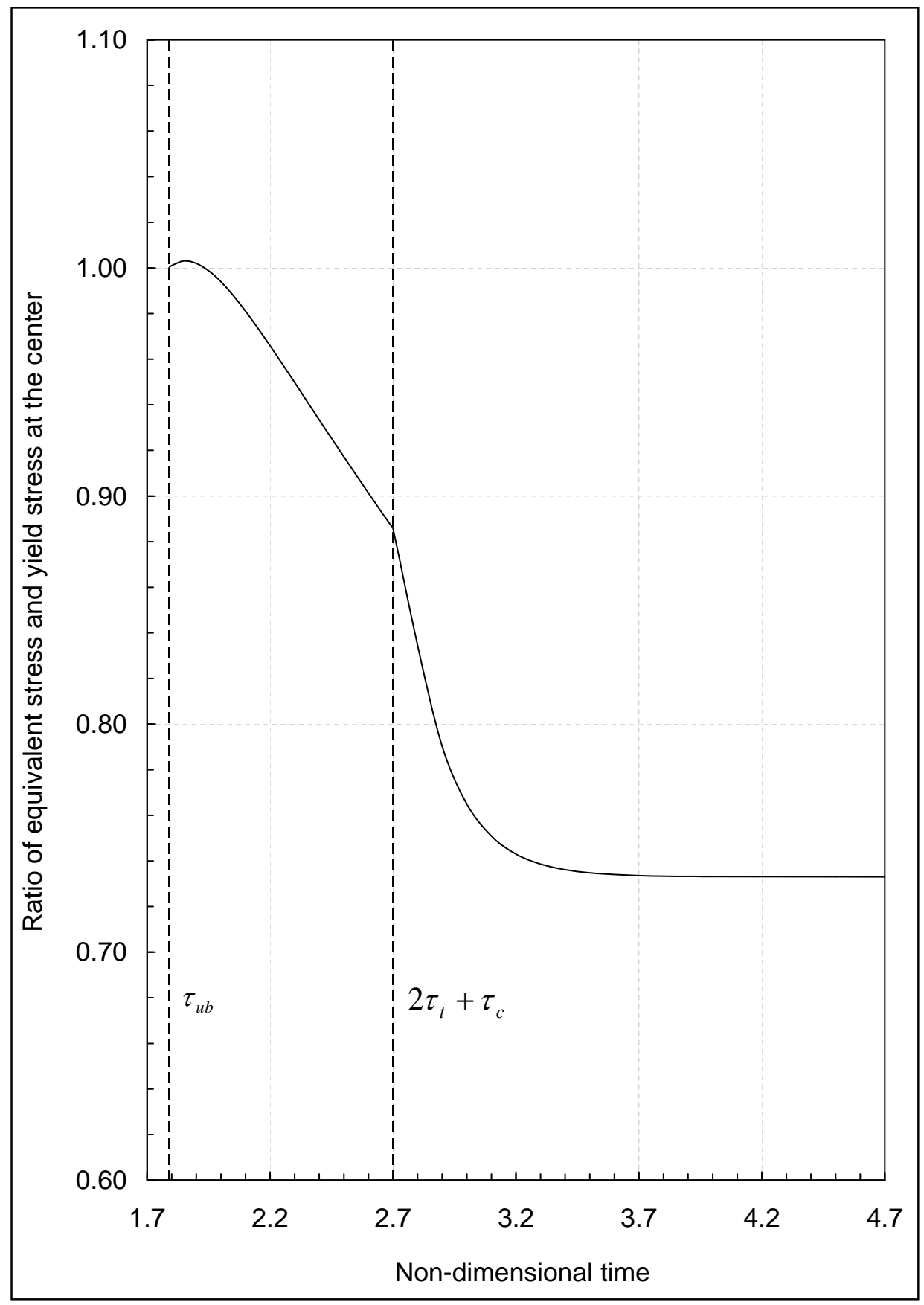

Figure 6.54: Change of ratio of equivalent and yield stresses at the center with time in the unloaded state 


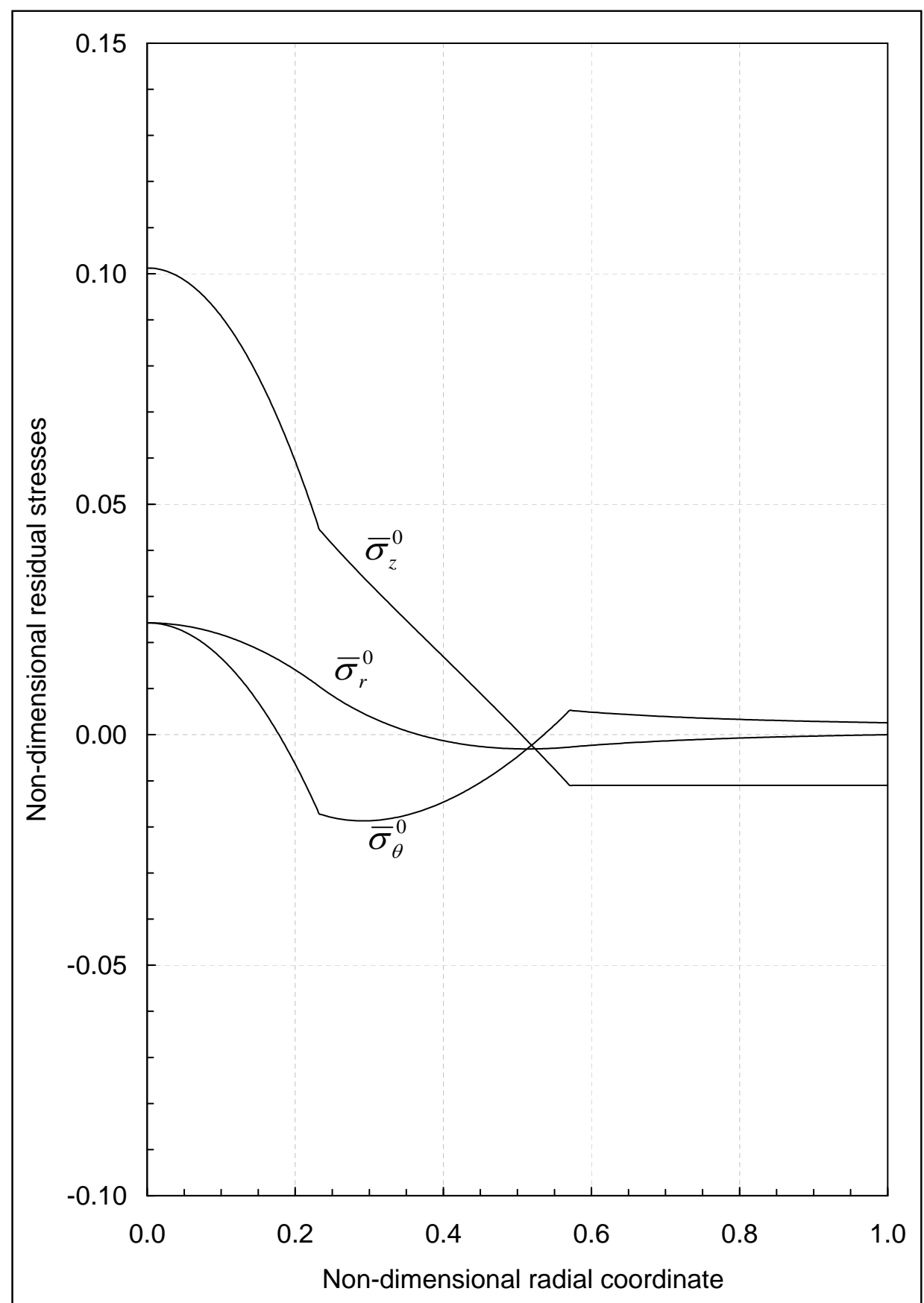

Figure 6.55: Approximate residual stress distribution at stand-still $(\Omega=0)$ after cooling 


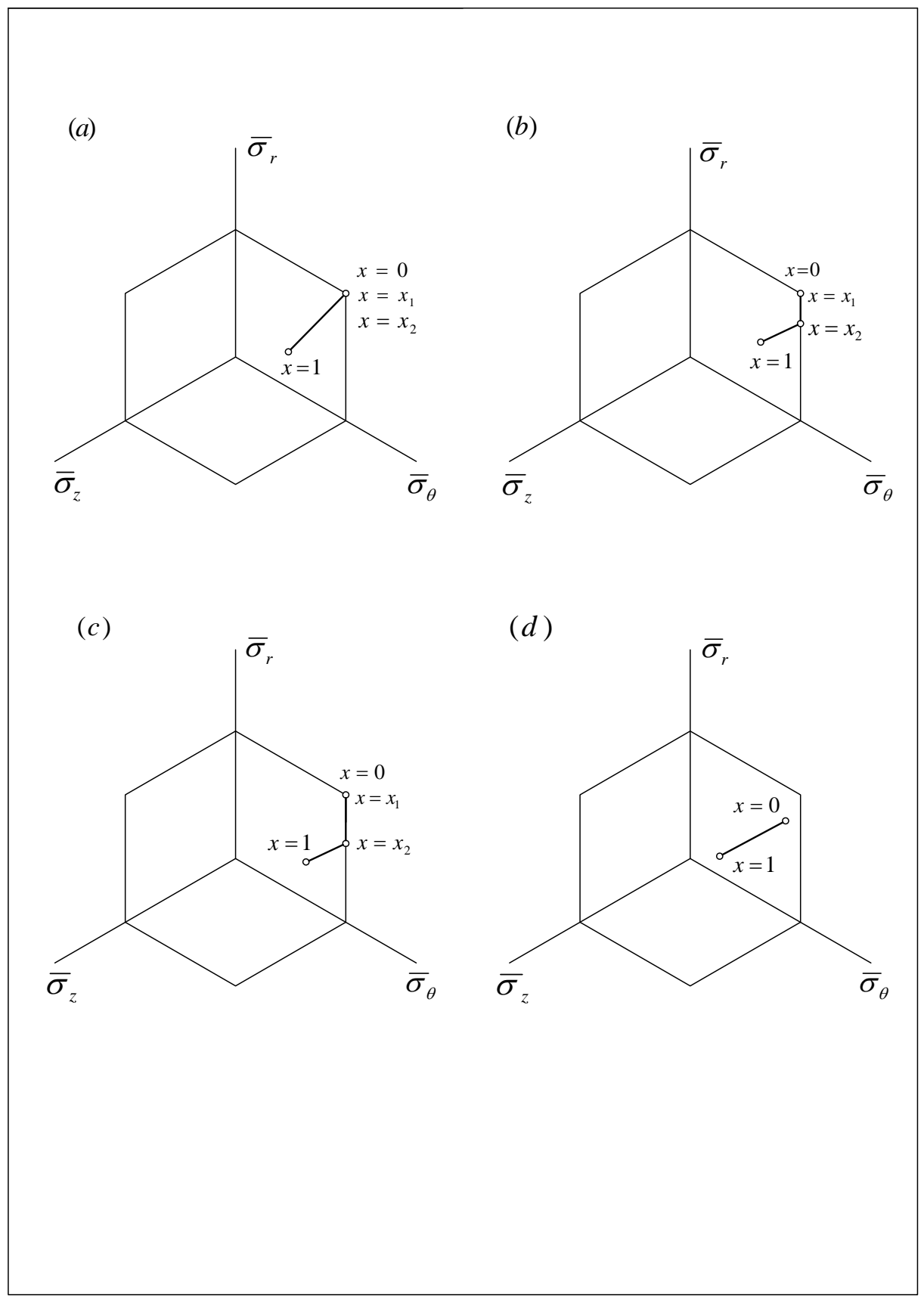

Figure 6.56: Stress field in the rotating shaft mapped onto the deviatoric plane of the principal stress space (sketch) at $(a) \tau=\tau_{p},(b) \tau_{p}<\tau<\tau_{u b},(c) \tau=\tau_{u b},(d) \tau>\tau_{u b}$ 
a)
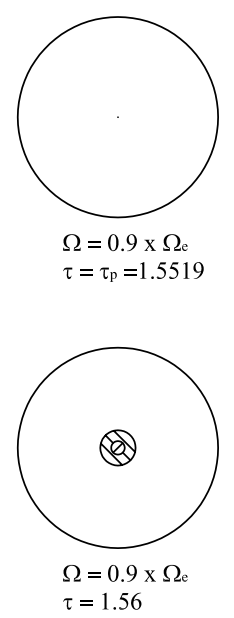

g)
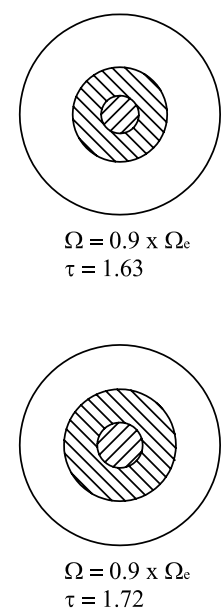

m)

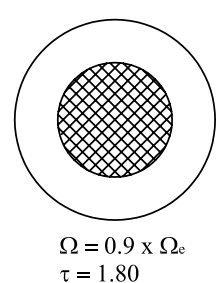

b)
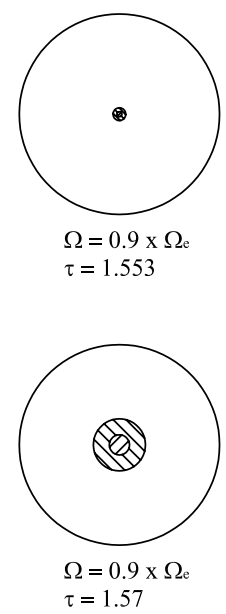

h)

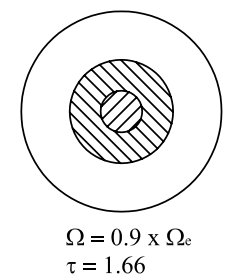

k)
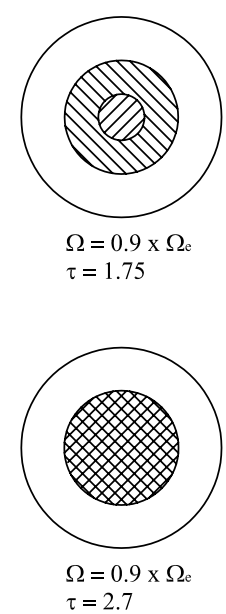
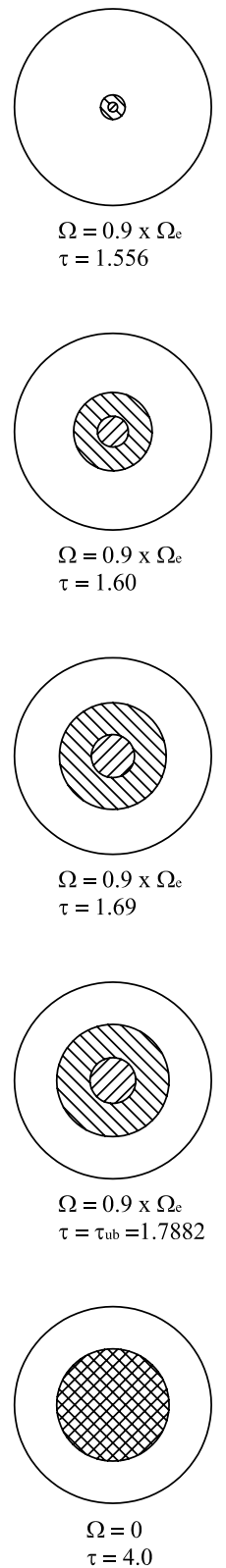

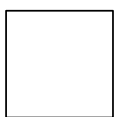

Elastic Region

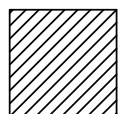

Plastic Region I

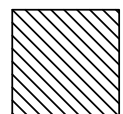

Plastic Region II

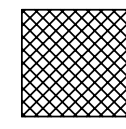

Predeformed Elastic Region

Figure 6.57: Evolution of elastic, plastic and predeformed elastic regions on the cross section of the shaft at different times 


\subsection{Summary and Discussion}

The closed form solution to a rotating solid shaft with the temperature dependent yield stress under a temperature cycle is presented. The shaft is subjected to a centrifugal force due to the rotation and an unsteady-state thermal load due to temperature cycle, i.e., the temperature of its surface is increased slowly and linearly with time, held constant for some time, and then decreased linearly with time to its reference temperature. Thermally induced wave phenomena is vanished since the thermal load is applied slowly. Elastic-plastic state of stress is presumed to obey Tresca's yield criterion and the associated flow rule with it. Furthermore, state of generalized plane strain and circular symmetry are considered.

The earlier studies, which are related to the present thesis, are separated into three categories. In the first category, the investigations which include elastic or elastic-plastic solutions of the cylindrical machine elements that are subjected to solely rotation are presented. The second category consists of the analysis for the non-rotating cylindrical elements under only thermal load. Investigation of the deformation due to superposition of these two loads on a disk or shaft are presented under title of the third category. The literature review shows the requirement of the theoretical investigation for the problem of an elastic-plastic rotating solid shaft, which is one of the most wide-spread machine parts, under unsteady thermal load, in which interesting and unpredictable results may be expected.

Initially, the entire shaft is presumed to be in a purely elastic state. As soon as the yielding condition is satisfied, two different plastic regions emerge at the center of the shaft, simultaneously. They expand into the elastic region in time until an elastic unloading occurs at the plastic-elastic interface radius. Next, plastic regions do not move into elastic region anymore. On the other hand, the predeformed elastic region spreads rapidly into the plastic zone. For the mathematical model of this elastic-plastic behavior, the governing equations and their analytical solutions for these regions are obtained with the help of the basic equations. These solutions may include unknown integration constants, axial strain and the interface radii. To evaluate each unknown value in the purely elastic state, elastic-plastic state and approximated unloaded state, boundary and interface conditions are used. The analytical expressions 
for the calculation of integration constants are also derived. The rest of the unknowns are calculated numerically. Finally, numerical results of the problem for the chosen parameters are presented. 


\section{CHAPTER 7}

\section{CONCLUSION}

First, for certain combinations of the parameter values a qualitatively different behavior, such as partial or full plasticization, may occur by depending on the loading conditions. Nevertheless, the results which are presented in Section 6.2 may be considered characteristic for a wide class of the shafts under similar conditions.

Secondly, starting at the center, the plasticization may occur even in the shafts which have been designed purely elastic. Remarkably, at least if pronounced temperature gradients occur, this happens only after the temperature of the surface has started to decrease again. The delay in the beginning of the plasticization and hence also in the beginning of the unloading may be attributed to the inhomogeneity of the temperature field.

Additionally, from the engineering point of view, the stress distribution after complete cooling and stand-still is of particular interest. It can be concluded that, all of these residual stresses are small as compared to yield limit. Remarkably, the residual stresses, after stand-still, with any smaller angular speed remain far beyond the secondary yield limit. As a further interesting result, the axial stress in the centre is found to be dominating one.

Finally, it should be pointed out that prior to unloading the numerical effort essentially is restricted to the solution of an algebraic system of equations; if the proposed approximate calculation of the stresses after unloading is applied, in the later stages only numerical integrations must be added. As the error introduced by the approximation is very small, significant benefits by applying much more complex purely numerical methods like FE-codes are hardly to be expected. 


\section{REFERENCES}

[1] Timoshenko S., Goodier J.N.: Theory of Elasticity, 3rd ed., New York: McGrawHill (1970).

[2] Rees D.W.A.: The Mechanics of Solids and Structures, New York: McGraw Hill (1990).

[3] Ugural A.C., Fenster S.K.: Advanced Strength and Applied Elasticity, 2nd ed., Amsterdam: Elsevier (1975).

[4] Boley B.A, Weiner J.H.: Theory of Thermal Stresses, 1st ed., p. 246. New York: Wiley Press (1960).

[5] Faupel J.H., Fisher F.E.: Engineering Design, 2nd ed., pp. 29-30. New York: Wiley (1981).

[6] Nadai A.: Theory of Flow and Fracture of Solids vol.1, 2nd ed., New York: McGraw Hill (1950).

[7] Davis E.A., Conelly F.M.: Stress distribution and plastic deformation in rotating cylinders of strain-hardening material. Journal of Applied Mechanics of the ASME 26, 25-30 (1959).

[8] Hodge Jr.P.G., Balaban M.: Elastic-plastic analysis of a rotating cylinder. International Journal of Mechanical Science 4, 465-476 (1962).

[9] Lenard J., Haddow J.B.: Plastic collapse speeds for rotating cylinders. International Journal of Mechanical Sciences 14, 285-292 (1972).

[10] Gamer U., Sayir M.: Elastic-plastic stress distribution in a rotating solid shaft. Journal of Applied Mathematics and Physics (ZAMP) 35, 601-617 (1984).

[11] Gamer U., Mack W., Varga I.: Rotating elastic-plastic solid shaft with fixed ends. International Journal of Engineering Science 35, 253-267 (1997).

[12] Mack W.: The rotating elastic-plastic solid shaft with free ends. Technische Mechanik 12, 119-124 (1991).

[13] Lindner T., Mack W.: Residual stresses in an elastic-plastic shaft with fixed ends after previous rotation. The Journal of Applied Mathematics and Mechanics (ZAMM) 78, 75-86 (1998).

[14] Gamer U., Lance R.H.: Stress distribution in a rotating elastic-plastic tube. Acta Mechanica 50, 1-8 (1983).

[15] Mack W.: Rotating elastic-plastic tube with free ends. International Journal of Solids and Structures 27, 1461-1476 (1991). 
[16] Mack W.: Entlastung und sekundäres Fließen in rotierenden elastisch-plastischen Hohlzylindern. The Journal of Applied Mathematics and Mechanics (ZAMM) 72, 65-68 (1992).

[17] Guven U.: Elastic-plastic stress distribution in a rotating hyperbolic disk with rigid inclusion. International Journal of Mechanical Sciences 40, 97-109 (1998).

[18] Eraslan A.N., Orcan Y.: On the rotating elastic-plastic solid disks of variable thickness having concave profiles. International Journal of Mechanical Sciences 44, 1445-1466 (2002).

[19] Eraslan A.N., Argeso H.: Limit angular velocities of variable thickness rotating disks. International Journal of Solids and Structures 39, 3109-3130 (2002).

[20] Eraslan A.N., Stress distributions in elastic-plastic rotating disks with elliptical thickness profiles using Tresca and Von Mises criteria. The Journal of Applied Mathematics and Mechanics (ZAMM) 85, 1-15 (2005).

[21] Eraslan A.N.: On the linearly hardening rotating solid shaft. European Journal of Mechanics A/Solids 22, 295-307 (2003).

[22] Eraslan A.N.: Von Mises' yield criterion and nonlinearly hardening rotating shafts. Acta Mechanica 168, 129-144 (2004).

[23] Eraslan A.N., Mack W.: A computational procedure for estimating residual stresses and secondary plastic flow limits in nonlinearly strain hardening rotating shafts. Forschung Im Ingenieurwesen/Engineering Research 69, 65-75 (2005).

[24] Horgan C.O., Chan A.M.: The stress response of functionally graded isotropic linearly elastic rotating disks. Journal of Elasticity 55, 219-230 (1999).

[25] Eraslan A.N., Akis T.: On the plane strain and plane stress solutions of functionally graded rotating solid shaft and solid disk problems. Acta Mechanica 181, 43-63 (2006).

[26] Akis T., Eraslan A.N.: The stress response and onset of yield of rotating FGM hollow shafts. Acta Mechanica 187, 169-187 (2006).

[27] Eraslan A.N., Akis, T.: The stress response of partially plastic rotating FGM hollow shafts: analytical treatment for axially constrained ends. Mechanics Based Design of Structures and Machines 34, 241-260 (2006).

[28] Eraslan A.N., Arslan E.: Plane strain analytical solutions to rotating partially plastic graded hollow shafts. Turkish Journal of Engineering and Environmental Sciences 31, 273-287 (2007).

[29] Akis T., Eraslan A.N.: Exact solution of rotating FGM shaft problem in the elastoplastic state of stress. Archive of Applied Mechanics 77, 745-765 (2007).

[30] Dahl O.G.C.: Temperature and stress distribution in hollow cylinders. American Society of Mechanical Engineering Transactions 46, 161-208 (1924).

[31] Weiner J.H., Huddleston J.V.: Transient and residual stresses in heat-treated cylinders. Journal of Applied Mechanics of the ASME 26, 31-39 (1959). 
[32] Johnson W., Mellor P.B.: Plasticity for Mechanical Engineers, Great Britain: D. Van Nostrand Comp. (1970).

[33] Landau H.G., Zwicky E.E.Jr.: Transient and residual thermal stresses in an elastic-plastic cylinder. Journal of Applied Mechanics of the ASME 27, 481-488 (1960).

[34] Mendelson A.: Plasticity: Theory and Application, 1st ed., New York: Mscmillan Comp. (1968).

[35] Chu S.C.: A numerical thermoelastic solution of a thick-walled tube. American Institute of Aeronautics and Astronautics (AIAA) Journal 12, 176-179 (1974).

[36] Perzyna P., Sawczuk A.: Problems of Thermoplasticity. Nuclear Engineering and Design 24, 1-55 (1973).

[37] Ishikawa H.: A thermoelastoplastic solution for a circular solid cylinder subjected to heating and cooling. Journal of Thermal Stresses 1, 211-222 (1978).

[38] Mack W., Gamer U.: Zur Berechnung der Restspannungen beim Abkühlen thermisch beanspruchter elastisch-plastischer Bauteile. Forschung im Ingenieurwesen/Engineering Research 54, 48-52 (1988).

[39] Jahanian S., Sabbaghian M.: Thermoelastoplastic and residual stresses in a hollow cylinder with temperature-dependent properties. Journal of Pressure Vessel Technology 112, 85-91 (1990).

[40] Valentin R.A., Carey J.J: Thermal stresses and displacements in finite, heatgenerating circular cylinders. Nuclear Engineering and Design 12, 277-290 (1970).

[41] Citakoglu E.: Thermal stresses in a finite rod with uniform energy generation under special BCs. METU Journal of Pure and Applied Sciences 9, 167-187 (1976).

[42] Citakoglu E., Eren N.: Thermal stresses in a finite composite cylinder with uniform energy generation under special boundary conditions. METU Journal of Pure and Applied Sciences 12, 91-125 (1979).

[43] Orcan Y., Gamer U.: Elastic-plastic deformation of a centrally heated cylinder. Acta Mechanica 90, 61-80 (1991).

[44] Orcan Y.: Thermal stresses in a heat generating elastic-plastic cylinder with free ends. International Journal of Engineering Science 32, 883-898 (1994).

[45] Gulgec M., Orcan Y.: Elastic-plastic deformation of a heat generating tube with temperature-dependent yield stress. International Journal of Engineering Science 38, 89-106 (2000).

[46] Orcan Y., Gulgec M.: Elastic-plastic deformation of a tube with free ends subjected to internal energy generation. Turkish Journal of Engineering and Environmental Sciences 25, 601-610 (2001).

[47] Orcan Y., Eraslan A.N.: Thermal stresses in elastic-plastic tubes with temperature-dependent mechanical and thermal properties. Journal of Thermal Stresses 24, 1097-1113 (2001). 
[48] Eraslan A.N.: Thermally induced deformations of composite tubes subjected to a nonuniform heat source. Journal of Thermal Stresses 26, 167-193 (2003).

[49] Eraslan A.N., Orcan Y.: Thermoplastic response of a linearly hardening cylinder subjected to nonuniform heat source and convective boundary condition. Mechanics Based Design of Structures and Machines 32, 133-164 (2004).

[50] Eraslan A.N., Argeso H.: Computer solutions of plane strain axisymmetric thermomechanical problems. Turkish Journal of Engineering and Environmental Sciences 29, 369-381 (2005).

[51] Argeso H., Eraslan A.N.: On the use of temperature-dependent physical properties in thermomechanical calculations for solid and hollow cylinders. International Journal of Thermal Sciences 47, 136-146 (2008).

[52] Alujevic A., Legat J., Zupec J.: Thermal yield of a rotating hyperbolic disk. The Journal of Applied Mathematics and Mechanics (ZAMM) 73, T283-T287 (1993).

[53] Alujevic A., Les P., Zupec J.: Plasticity of a thermally loaded rotating hyperbolic disk. The Journal of Applied Mathematics and Mechanics (ZAMM) 73, T287T290 (1993).

[54] Parmaksizoglu C., Guven U.: Plastic stress distribution in a rotating disk with rigid inclusion under a radial temperature gradient. Mechanical Structures and Machines 26, 9-20 (1998).

[55] Tarn J.Q.: Exact solutions for functionally graded anisotropic cylinders subjected to thermal and mechanical loads. International Journal of Solids and Structures $38,8189-8206$ (2001).

[56] Mack W., Plöchl M.: Transient heating of a rotating elastic-plastic shrink fit. International Journal of Engineering Science 38, 921-938 (2000).

[57] Mack W., Plöchl M., Gamer U.: Auswirkungen eines Temperaturzyklus auf einen rotierenden elastisch-plastischen Querpreßverband mit vollem Einschluß. The Journal of Applied Mathematics and Mechanics (ZAMM) 81, S351-S352 (2001).

[58] Eraslan A.N., Akis T.: On the elastic-plastic deformation of a rotating disk subjected to a radial temperature gradient. Mechanics Based Design of Structures and Machines 31, 529-561 (2003).

[59] Eraslan A.N., Arslan E., Mack W.: The strain hardening rotating hollow shaft subject to a positive temperature gradient. Acta Mechanica 194, 191-211 (2007).

[60] Arslan E., Mack W., Eraslan A.N.: The rotating elastic-plastic hollow shaft conveying a hot medium. Forschung im Ingenieurwesen/Engineering Research (to appear).

[61] Beer F.P., Johnston E.R., DeWolf J.T.: Mechanics of Materials, 3rd ed., New York: McGraw Hill (1943).

[62] Hill R.: The Mathematical Theory of Plasticity, London: Oxford University Press (1950). 
[63] Von Mises R.: Mechanik der festen Koerper in Plastisch deformablem Zustand, Göttinger Nachrichten Math. Phys. Klasse 1, 582-592 (1913).

[64] Tresca H.: Memoire sur I'ecoulement des Corps Solides. Mem. Sci. Savants Acad. Sci. 18, 733-799 (1868).

[65] Chen W.F., Han D.J.: Plasticity for Structural Engineers. New York: Springer (1988).

[66] Saint-Venant B.: Memoire sur I'etablissement des equations differentielles des mouvements interieurs operes dans les corpse solides ductiles au dela des limites ou I'elasticite pourrait les ramener a leur premier etat. Comptes Rendus 70, 473480 (1870).

[67] Levy M.: Memoire sur les equations generales des mouvements interieurs des corps solides ductile au dela limites ou I'elasticite purrait les ramener a leur premier etat. Comptes Rendus 70, 1323-1325 (1870).

[68] Prandtl L.: Spannungsverteilung in plastischen Koerpern. 1st International Congress on Applied Mechanics, Delft, 43-54 (1925).

[69] Reuss E.: Berueckesichtigung der elastischen Formaenderungen in der Plastizitaetstheorie. The Journal of Applied Mathematics and Mechanics (ZAMM) 10, 266-274 (1930).

[70] Melan E.: Zur Plastizitat des raumlichen Kontinuus. Ingenieur-Archiv 9, 116(1938).

[71] Carslaw H.S., Jaeger J.C.: Conduction of Heat in Solids, 2nd ed., pp. 201. Oxford: Clarendon Press (1959).

[72] Kreyszig E.: Advanced Engineering Mathematics, 8th ed., New York: Wiley Press (1999).

[73] Ziegler F.: Technische Mechanik der festen und flüssigen Körper. Dritte, verb. Aufl., Ch. 4.3. Wien: Springer (1998).

[74] Mack W.: Spannungen im thermisch gefügten elastisch-plastischen Querpreßverband mit elastischer Entlastung. Ingenieur-Archiv 56, 301-313 (1986).

[75] More J.J., Garbow B.S., Hillstrom K.E.: Testing unconstrained optimization software. ACM Transactions on Mathematical Software 7, 17-41 (1981).

[76] Davis J.D., Rabinowitz P.: Numerical Integration, 1st ed., Massachusetts: Blaisdell (1967). 


\section{APPENDIX A \\ DESCRIPTION OF FORTRAN CODES}

Integration constants, axial strain, interface radii, analytical and numerical integrals, and Bessel and hypergeometric functions are calculated by using Fortran 77 codes. In the codes, non-dimensional and normalized variables and equations are used. The codes are divided into three categories since three states of stress, which are purely elastic state, elastic-plastic state and unloaded state, are examined in the study.

The first category includes Fortran codes for the purely elastic state (see Appendix B). All codes in Appendix B (Appendices B1-B6) are compiled and run in the same project since the main program is connected to the other subroutines and functions by common block or dummy arguments. The main program in the first category is called Purely Elastic State (see Appendix B.1). In this program, after the introduction of the input parameters, unknown non-zero constants are calculated (with the help of Eqs. (5.2) and (5.3) in dimensional form) and substituted into analytical expressions of response variables (Eqs. (4.22)-(4.25)) at different radial coordinates. By manipulating the non-dimensional time value, different distribution of the response variables are obtained. During all these calculations, temperature distribution and a temperature integral are calculated for each time and radial coordinate by using the subroutine called Temperature Distribution (See Appendix B.2). In the subroutine, the temperature and some integrals are superposed according to time interval by using Eqs. (3.11). This subroutine takes the temperature and its integral by the connections to the Fortran functions called Temperature (Appendix B.3) and Temperature Integral 1 (Appendix B.4). The first function calculates the non-dimensional temperature distribution given Eq. (3.9) and the second one calculates an exact temperature integral, which is given in Eq. (4.20). Furthermore, the summation of the series in these tem- 
perature equations are computed by using Fortran functions Series 1 (Appendix B.5) and Series 2 (Appendix B.6). The Bessel functions and roots that appear in these series may be computed by any Fortran subroutine. This subroutine calculates roots of the zeroth order Bessel functions of the first kind $\gamma_{n}$ according to Eq. (3.10) and, the zeroth and the first order Bessel functions of the first kind $J_{0}$ and $J_{1}$. However, this subroutine is not presented here. Finally, by executing the main program and the connected five Fortran subroutines and functions, the response variables on the purely elastic state are calculated and written into an output data file. For continuity of the process, the instant time value is increased slowly by hand. However, the usage of these subroutines are valid until a time value when the yielding conditions are satisfied (Eq. (4.29)). After this certain time value, this codes become out of use since plastic flow starts. For the following time values, the codes, which are written for the second category, should be executed.

In the second category, Fortran codes for the numerical results of the elastic-plastic state are considered. To calculate the results in this state, beside the codes presented in Appendix C, those in Appendices B2-B6 are performed simultaneously. The main program in this category is called Elastic Plastic state (Appendix C.1). This program is designed to initially calculate six integration constants $\left(C_{1}-C_{6}\right)$ analytically; then, to compute three unknowns $\left(\epsilon_{0}, r_{1}\right.$ and $\left.r_{2}\right)$ numerically (since a non-linear equation system is obtained for the border radii) and lastly, to figure out the response variables in the elastic-plastic state. Analytical expressions for six integration constants are placed into subroutine $N L N E Q N$ (Appendix C.2). Moreover, this subroutine includes interface and boundary conditions (Eqs. (5.9), (5.10) and (5.14)) to compute the remaining unknowns. To compute these unknowns, subroutine HYBRD1, which is implemented in the program called MINPACK is performed. The Fortran program MINPACK is a non-linear equation system solver which uses the Powell Hybrid Method (see [75]). The connection between the main program and Minpack is provided by $N L N E Q N$. After the calculation of the all unknowns, the response variables are obtained by making use of the subroutines Plastic Region I, Plastic Region II and Elastic Region (Appendices C.3-C.5). These subroutines include analytical expressions for three regions. The main program executes these subroutines for different radial coordinates and writes the results in an output data file. Similar to first codes 
category, the temperature distribution, the first temperature integral and summation of the first two series are calculated by using the codes given in Appendices B2-B6 in this codes category, too. Additionally, Fortran function Temperature Integral 2 (Appendix C.6) is performed to calculate temperature integrals in Eqs. (4.76) and (4.82). The summation of the series in these equations are calculated with the help of function Series 3 (Appendix C.7). Unlike others, these integral equations include hypergeometric functions and these functions are calculated by using the Fortran codes called Hypergeometric Function (Appendix C.8). The Fortran codes in the second category may be used until the time when unloading conditions (Eq. (5.21)) are observed in the results. For the following time values, the codes of third category, which are prepared for the unloaded state, should be run.

The third category of the codes is used to calculate response variables in unloaded state. The Fortran codes used in this category in addition to codes in Appendix B.2-B.6 are presented in Appendix D. The main program called Unloaded State (see Appendix D.1) is executed with codes above mentioned, namely, Temperature Distribution, Temperature, Temperature Integral 1, Series 1 and Series 2 . The main program is arranged to calculate two non-zero unknown constants $\left(C_{2}^{*}\right.$ and $\left.\epsilon_{0}\right)$ with the help of Eqs. (5.24) and (5.25) and to substitute these constants into analytical expressions of response variables. In this process, it is necessary to access the values of permanent plastic strains $\left(\epsilon_{i}^{p r}\right)$ seen in the equations in the Chapter 4.5. The permanent plastic strains are the ones which are computed in the program of Elastic-plastic state (with the second category of the codes) at a time when the unloading starts. Hence, the codes in the second category are run one more time and the calculated plastic strains are written into a data file. The tabulated form of this data file, which is called Permanent Plastic Strains, for the prescribed input parameters is given in Table D.1 in Appendix D.2. The main program calls this file as an input. In the calculations of the unlaoded state, we need to calculate some integral which include the permanent plastic strains as given below.

$$
\begin{aligned}
\text { INTEPS1 } & =\int_{0}^{r} \frac{\epsilon_{r}^{p r}-\epsilon_{\theta}^{p r}}{\xi} d \xi, \\
\text { INTEPS2 } & =\int_{0}^{r} \xi\left(\epsilon_{r}^{p r}+\epsilon_{\theta}^{p r}\right) d \xi .
\end{aligned}
$$

The numerical integrations of these discrete permanent strain values are performed by 
the Fortran program DAVINT efficiently. DAVINT, which is documented completely in SC-M-69-335, integrates a function tabulated at arbitrarily space abscissas. This Fortran program is the adapted and modified (by Rondall E. Jones) form of AVINT, which is prepared by Davis and Rabinowitz [76]. Finally, all of these codes with the input data file are executed for different time values and the response variables are written into output data file for the unloaded state. 


\section{APPENDIX B}

\section{FORTRAN CODES OF PURELY ELASTIC STATE}

\section{B.1 MAIN PROGRAM: PURELY ELASTIC STATE}

PROGRAM PURELY ELASTIC STATE

\section{PURPOSE :}

This program calculates the non-dimensional response variables in the purely elastic state for the problem of rotating solid shaft subjected to temperature cycle. All calculations are done for non-dimensional parameters. Input parameters, which are described below, are initially introduced. Then non-zero integration constant $\mathrm{C} 2$ and axial strain EPSO are calculated by using the analytical expressions. Substituting the parameters and constants into the response variable leads to obtain output values at N1 radial points in the shaft. Results are printed to the output file, which is titled 'A-ELAST.DAT'.

The program is connected to subroutine 'DISTRIBUTION' to call TBAR and INT1. Subroutine 'DISTRIBUTION' is used to calculate some integrals which include temperature terms. By substituting variable $\mathrm{R}$ and the upper limits of the integral, INT1 is calculated analytically by using this subroutine. Additionally, this subroutine is also used to get TBAR which is non-dimensional temperature distribution.

\section{CONNECTED SUBROUTINES}

1) DISTRIBUTION ( $R$, TBAR, ULIM, INT1, POW, INT2E).

\section{DESCRIPTION OF PARAMETERS:}

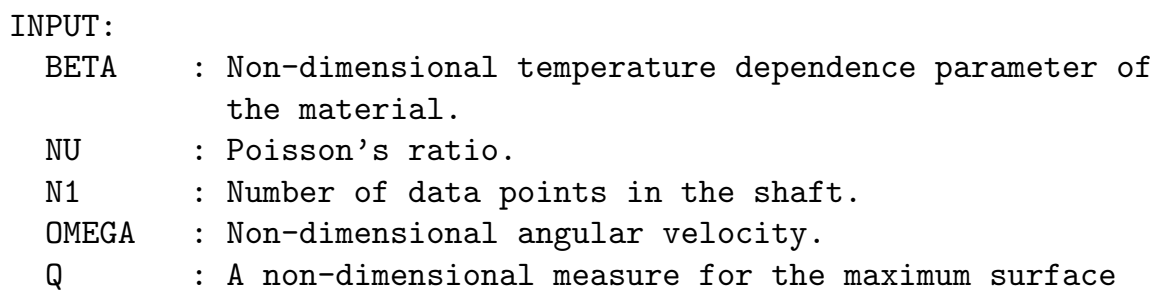




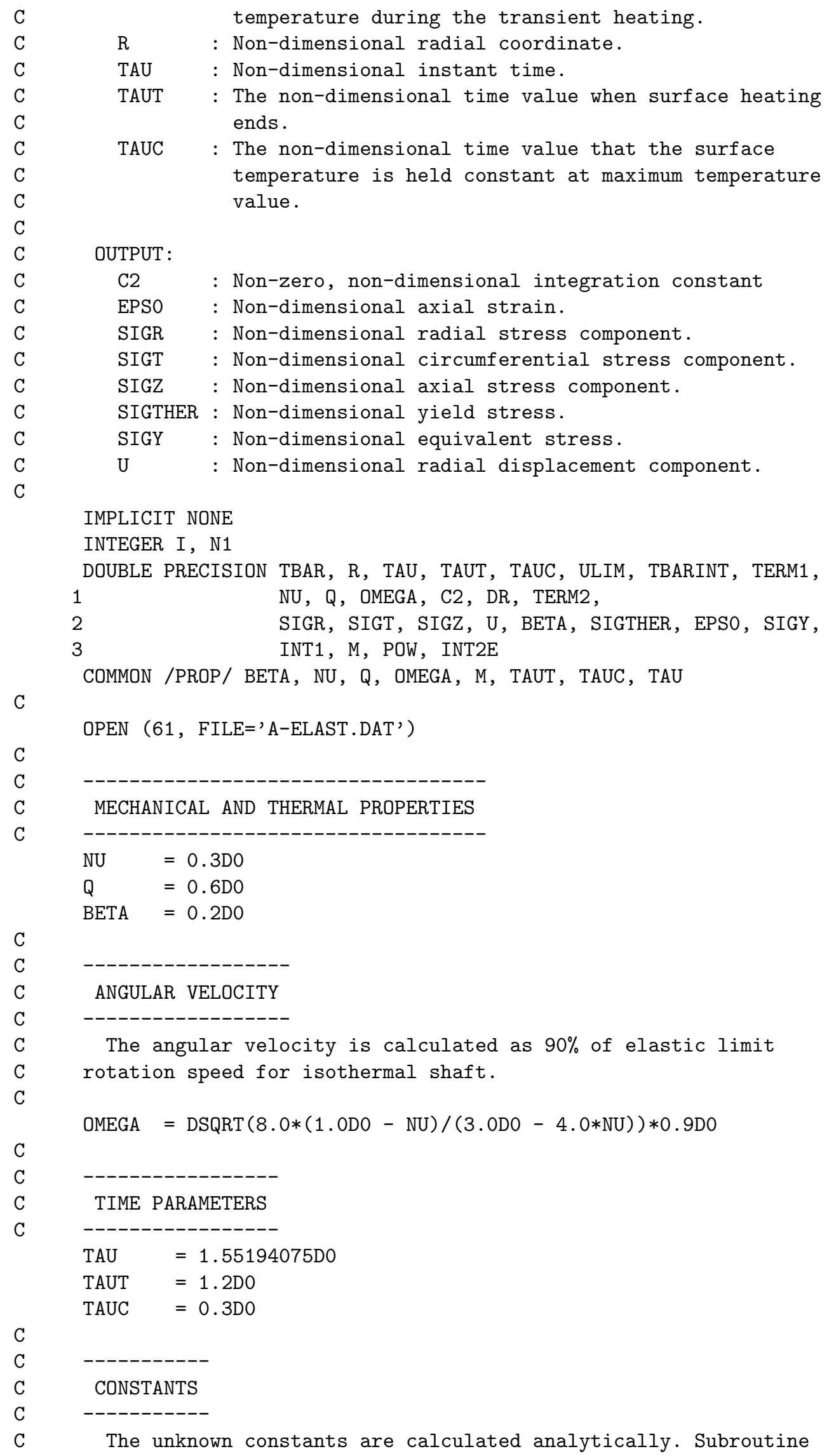




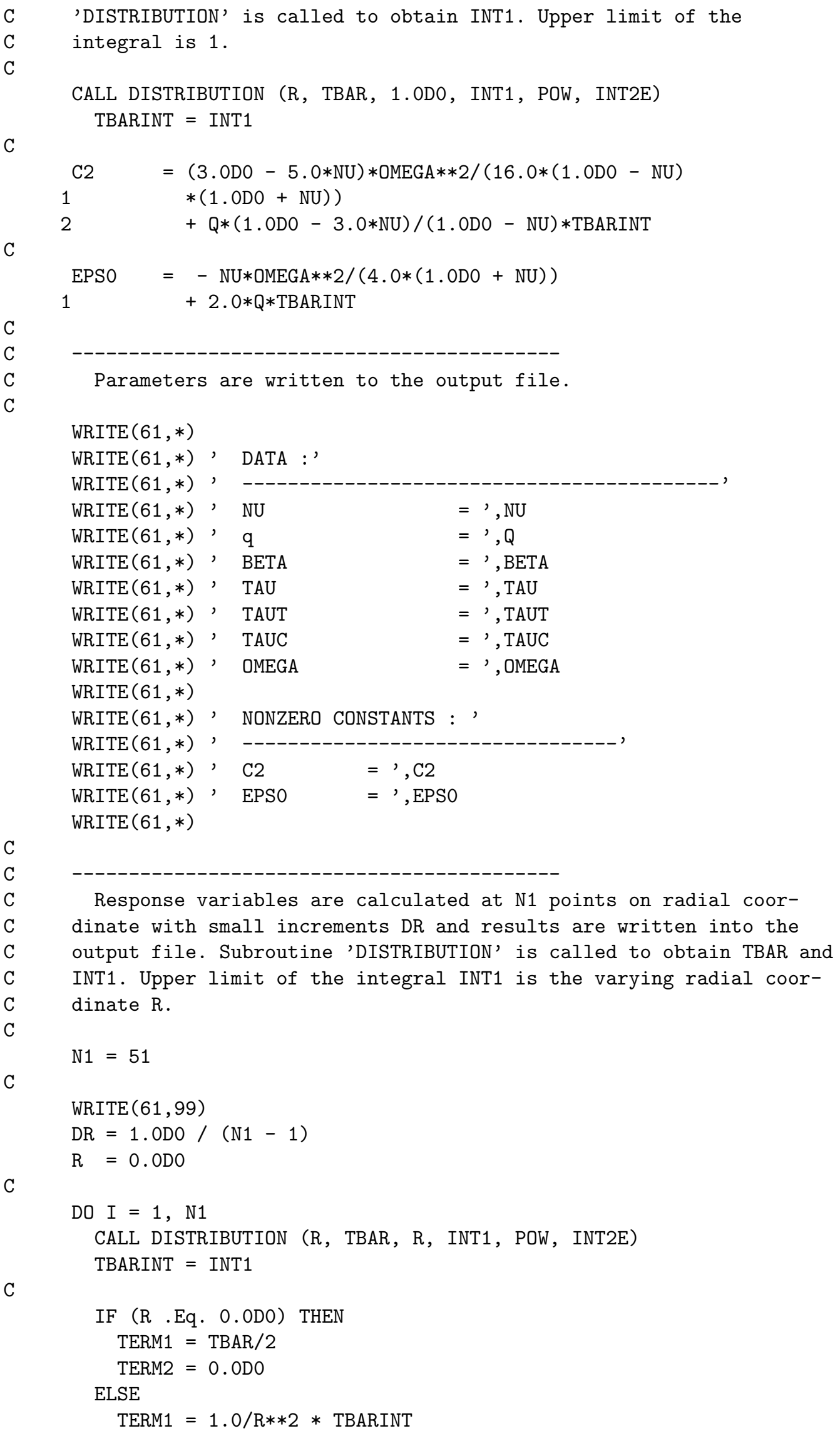




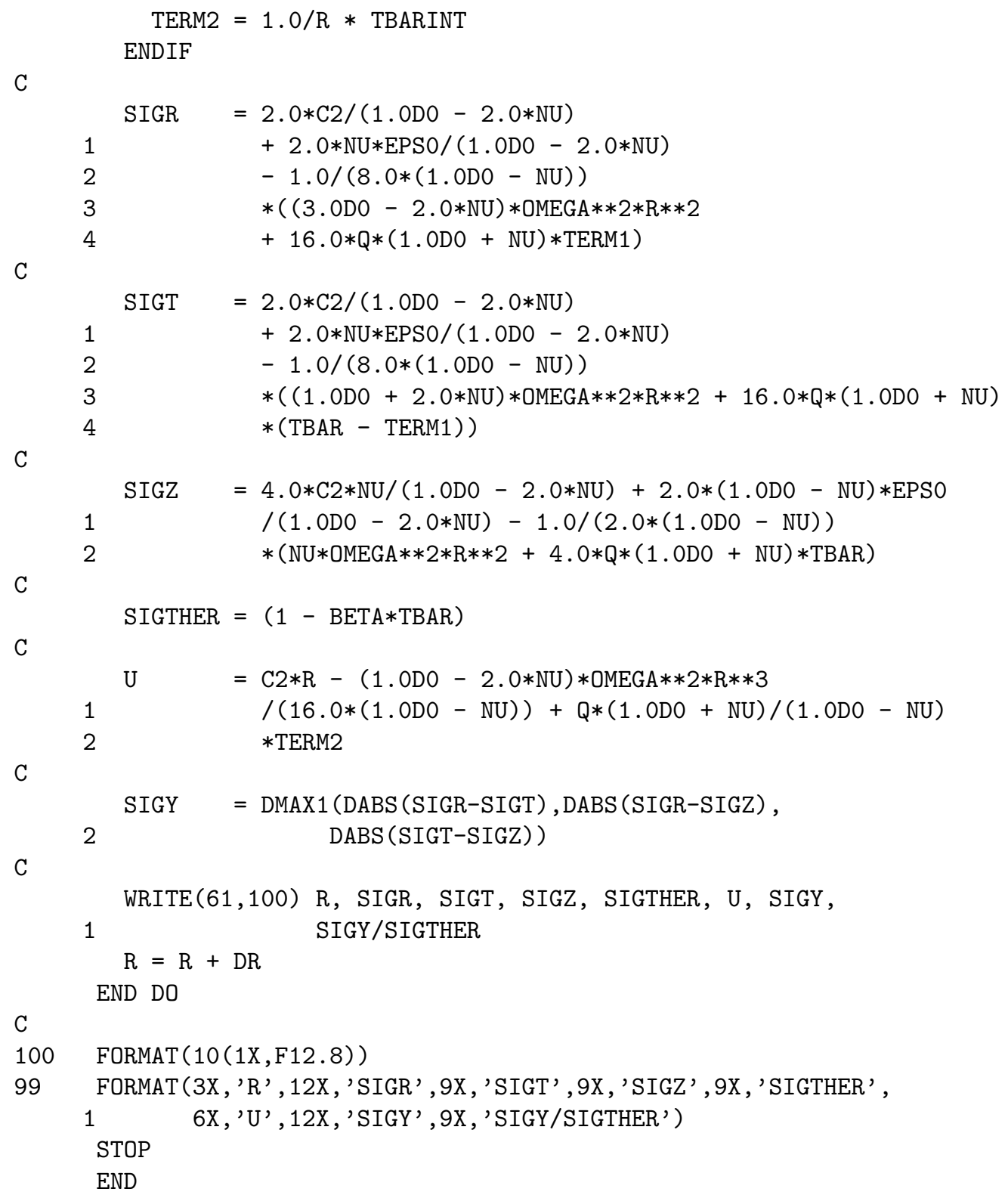

\section{B.2 SUBROUTINE: TEMPERATURE DISTRIBUTION}

SUBROUTINE DISTRIBUTION ( $R$, TBAR, ULIM, INT1, POW, INT2E)

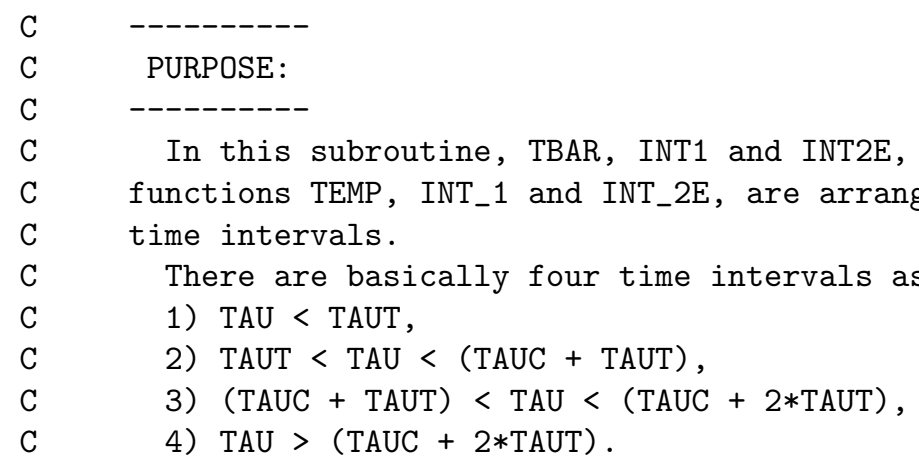




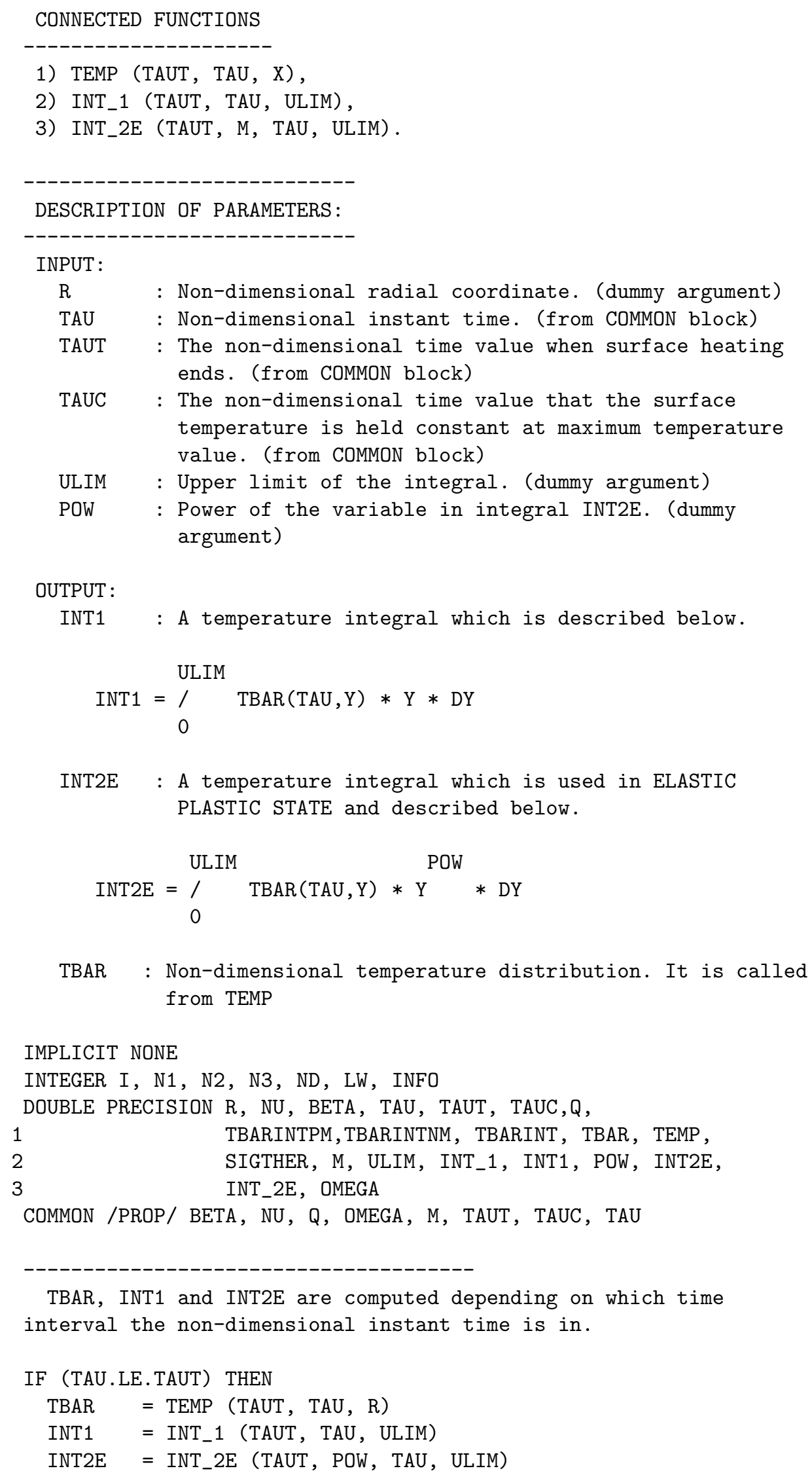

TBAR, INT1 and INT2E are computed depending on which time interval the non-dimensional instant time is in.

IF (TAU.LE.TAUT) THEN

TBAR = TEMP (TAUT, TAU, R)

INT1 = INT_1 (TAUT, TAU, ULIM)

INT2E = INT_2E (TAUT, POW, TAU, ULIM) 


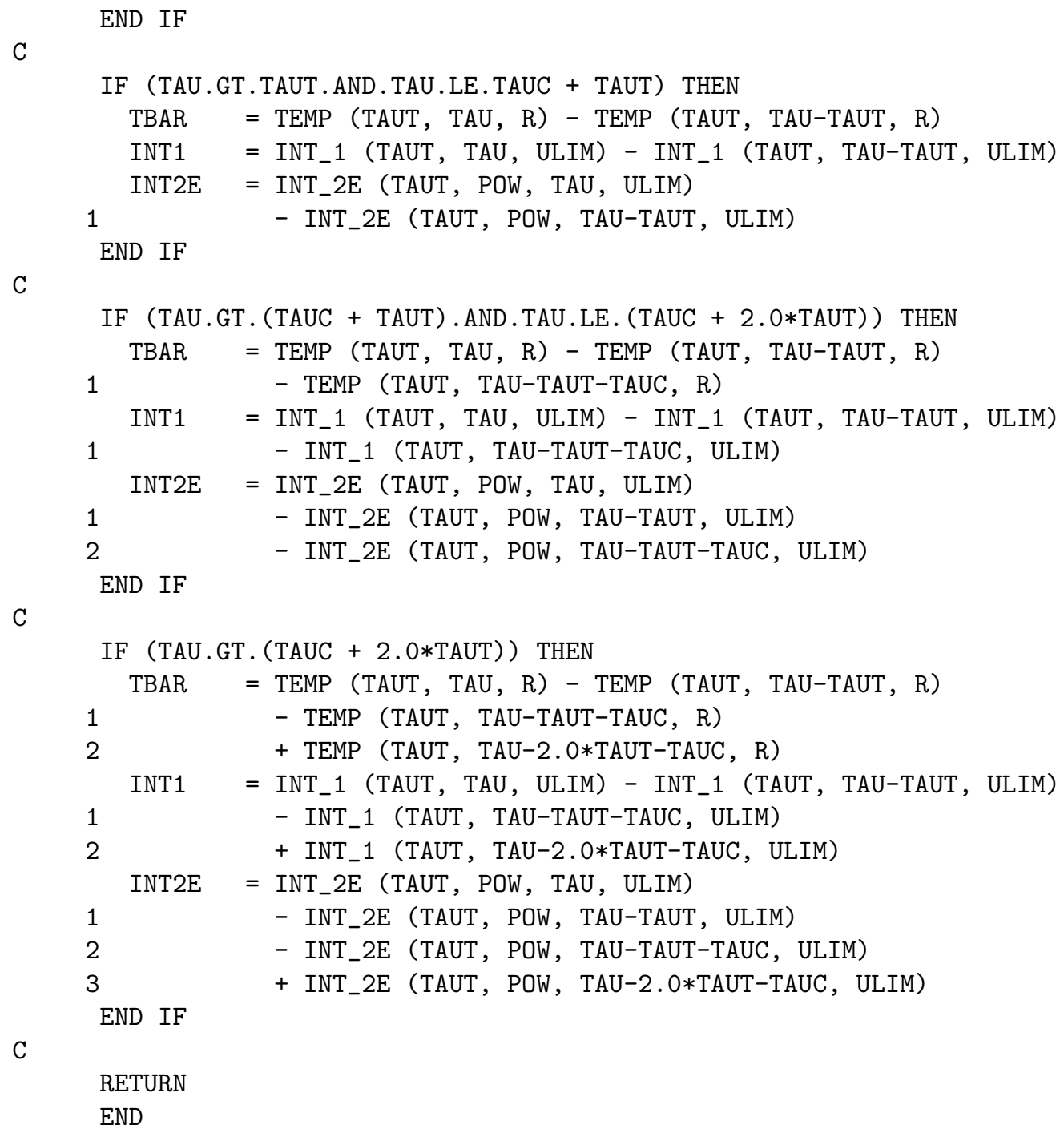

\section{B.3 FUNCTION: TEMPERATURE}

DOUBLE PRECISION FUNCTION TEMP (TAUT, TAU, X)

\section{PURPOSE :}

This function calculates analytically the non-dimensional temperature distribution TEMP (it is called TBAR in the other programs). All calculations are done for non-dimensional parameters. In the analytical expression, the term titled SER is a summation of series and it is called from function SER_1 (TAU, X). This summation includes Bessel functions and roots.

CONNECTED FUNCTIONS

1) SER_1 (TAU, X) . 


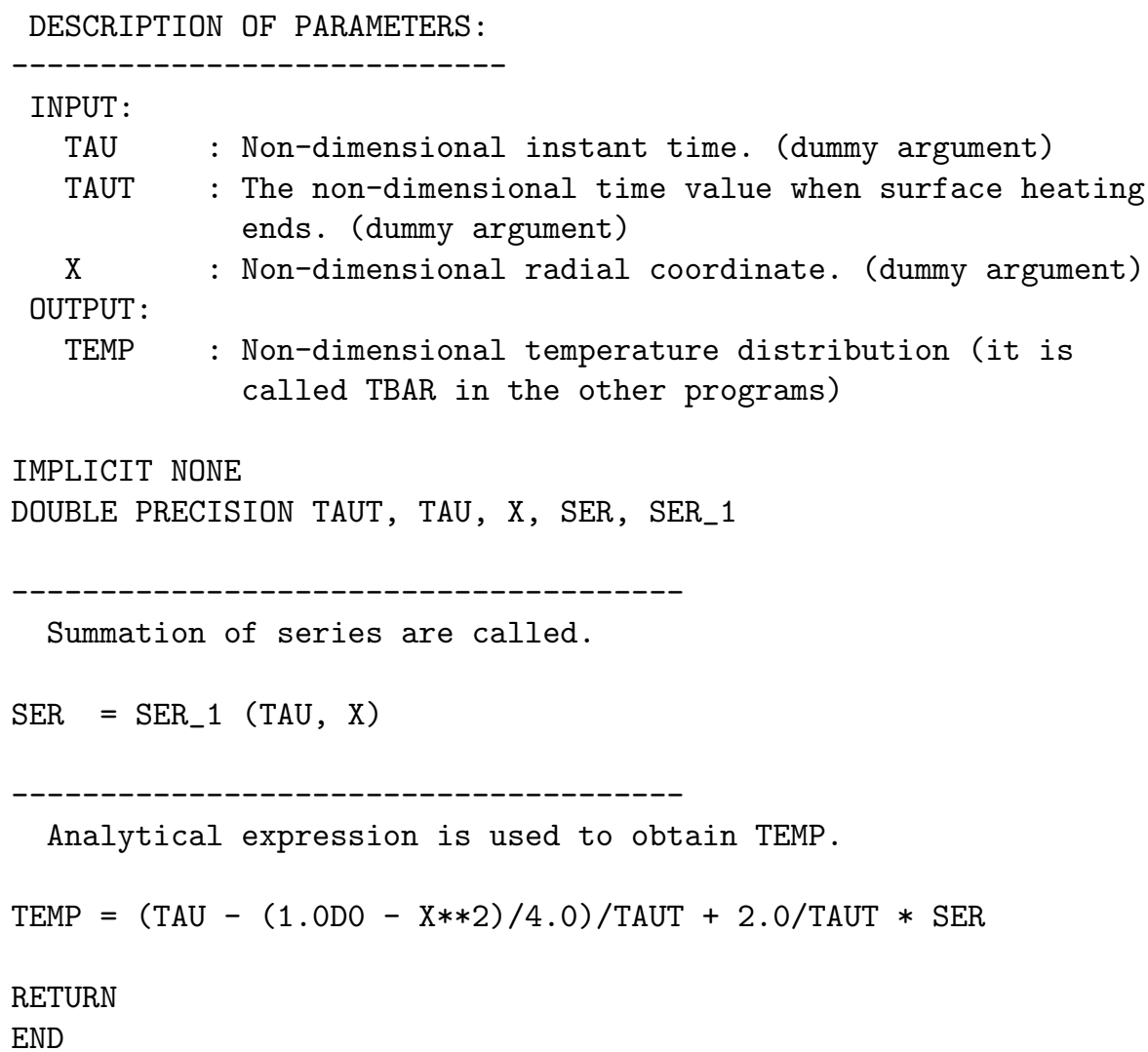

\section{B.4 FUNCTION: TEMPERATURE INTEGRAL 1}

DOUBLE PRECISION FUNCTION INT_1 (TAUT, TAU, ULIM)

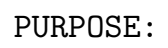




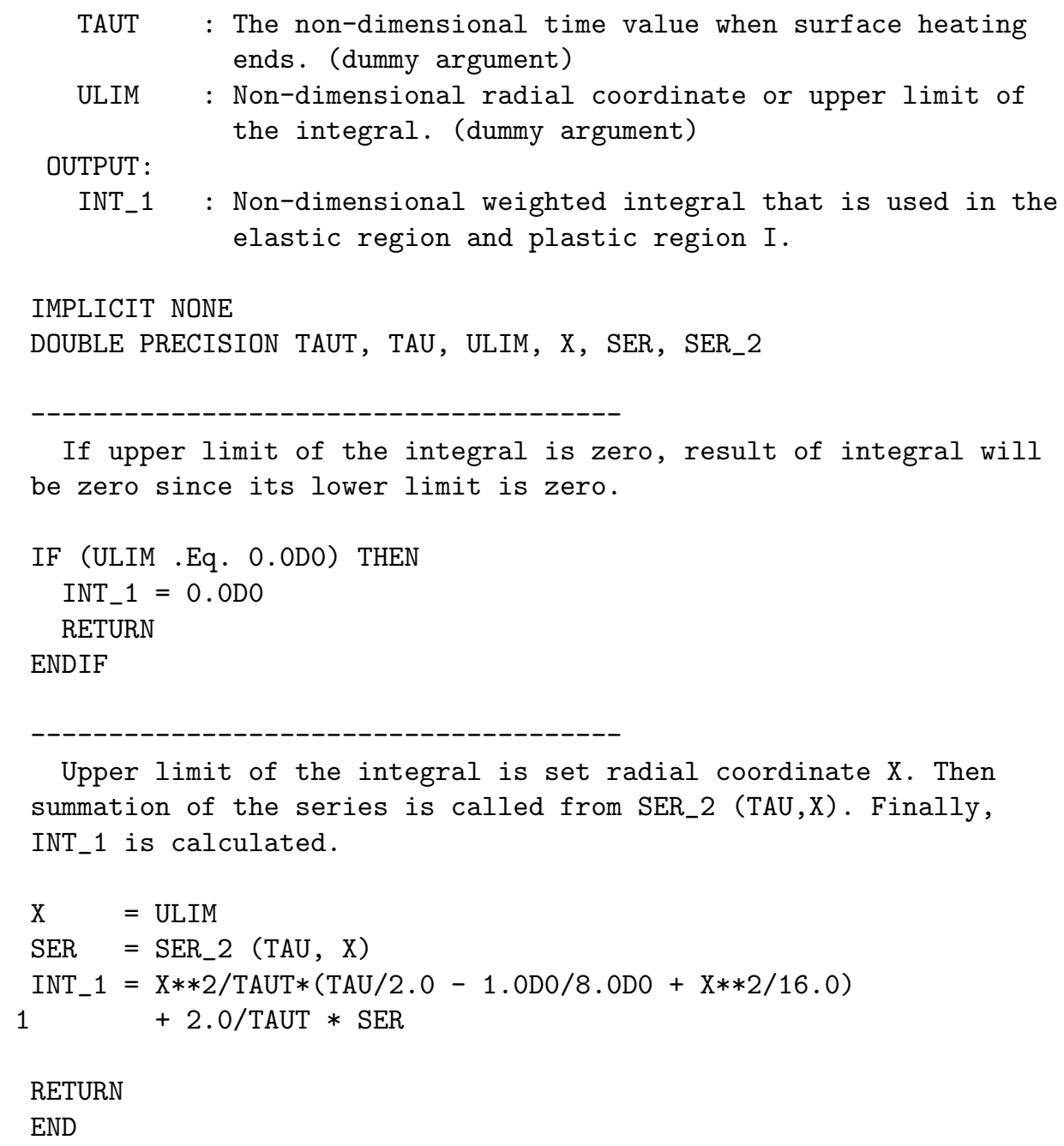

If upper limit of the integral is zero, result of integral will be zero since its lower limit is zero.

Upper limit of the integral is set radial coordinate $X$. Then summation of the series is called from SER_2 (TAU,X). Finally, INT_1 is calculated.

\section{B.5 FUNCTION: SERIES 1}

DOUBLE PRECISION FUNCTION SER_1 (TAU, X)

C
C
C
C
C
C
C
C
C
C
C
C
C
C
C
C
C
C

\section{PURPOSE :}

SER_1 is the summation of the series which is used in TEMP. These series include Bessel roots ( $R$ ) and two Bessel functions (zeroth and first order Bessel functions of the first kind). Initially, first 1250 roots of zeroth order Bessel functions of the first kind $(R)$ is found (it is possible to use any subroutine to find root of Bessel functions but it is not given here). Then zeroth order Bessel functions of the first kind DBESJO(R) and first order Bessel functions of the first kind DBESJ1(R) are computed for each $R$ (The algorithm of these Bessel functions are not either given here). Lastly, by substituting these Bessel functions into the equation of $T$ and adding for each $R$, SER_1 is calculated. All calculations are done for non-dimensional parameters. 


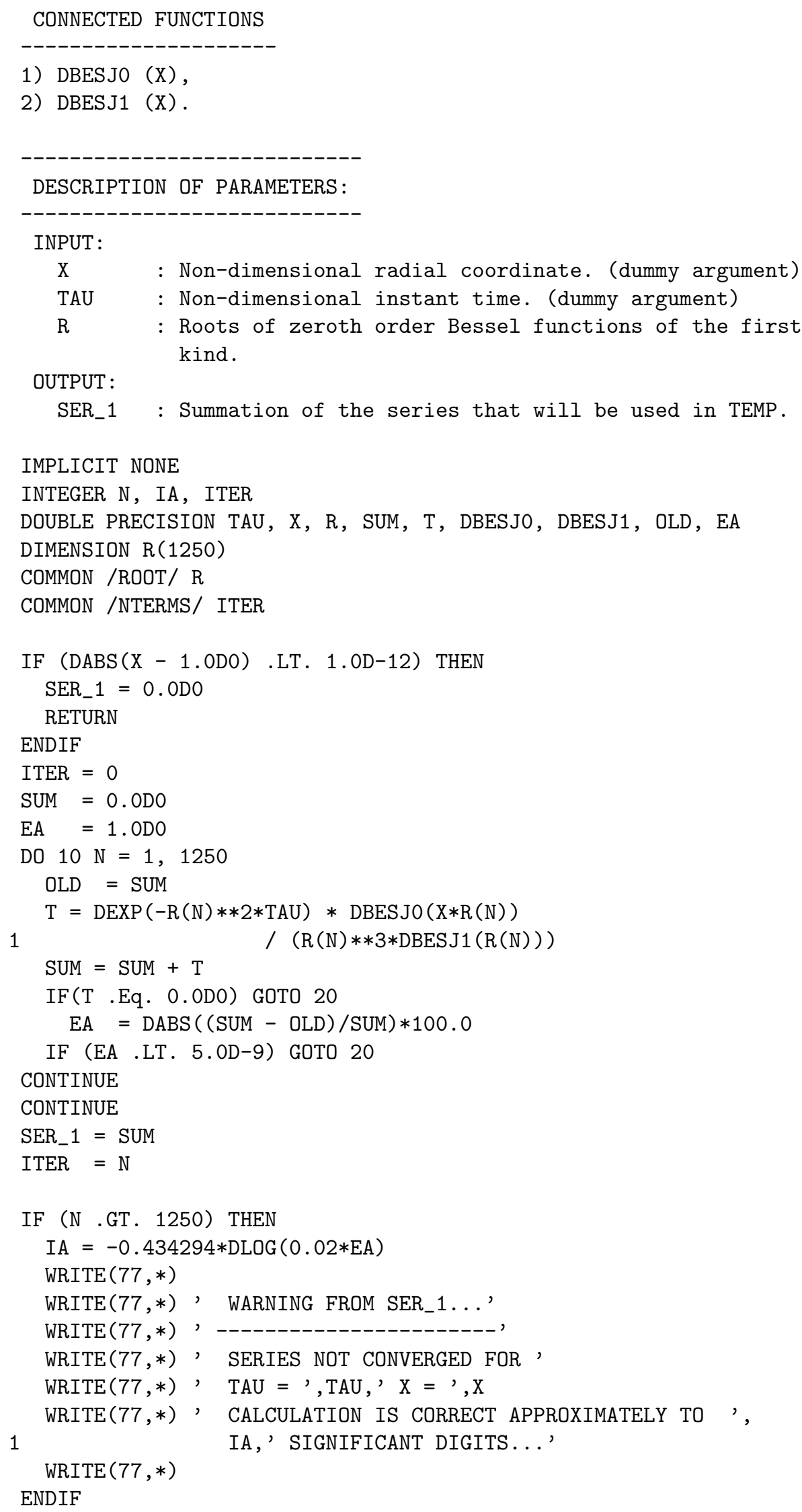


RETURN

END

\section{B.6 FUNCTION: SERIES 2}

DOUBLE PRECISION FUNCTION SER_2 (TAU, X)

C
C
C
C
C
C
C
C
C
C
C
C
C
C
C
C
C
C
C
C
C
C
C
C
C
C
C
C
C
C
C

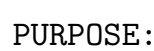

SER_2 is the summation of the series which is used in INT_1. These series include Bessel roots ( $R$ ) and one Bessel function (first order Bessel functions of the first kind). Initially, first 1250 roots of zeroth order Bessel functions of the first kind ( $R$ ) is found (it is possible to use any subroutine to find root of Bessel functions but it is not given here). Then first order Bessel functions of the first kind DBESJ1(R) are computed for each $R$ (The algorithm of this Bessel function is not either given here). Lastly, by substituting these Bessel function into the equation of $\mathrm{T}$ and adding for each $\mathrm{R}, \mathrm{SER} 2 \mathrm{is}$ calculated. All calculations are done for non-dimensional parameters.

CONNECTED FUNCTIONS

1) $\operatorname{DBESJ} 1(\mathrm{X})$

DESCRIPTION OF PARAMETERS:

INPUT :

R : Roots of zeroth order Bessel functions of the first kind.

X : Non-dimensional radial coordinate. (dummy argument)

TAU : Non-dimensional instant time. (dummy argument)

OUTPUT :

SER_2 : Summation of the series that will be used in INT_1.

IMPLICIT NONE

INTEGER N, IA, ITER

DOUBLE PRECISION TAU, $X, R$, SUM, T, DBESJ1, OLD, EA

DIMENSION R(1250)

COMMON /ROOT/ R

COMMON /NTERMS/ ITER

IF (X .Eq. 0.0D0) THEN

SER_2 $=0.0 \mathrm{DO}$

RETURN

ENDIF

ITER $=0$

$\mathrm{SUM}=0.0 \mathrm{DO}$

$\mathrm{EA}=1.0 \mathrm{DO}$

DO $10 \mathrm{~N}=1,1250$

$\mathrm{OLD}=\mathrm{SUM}$ 


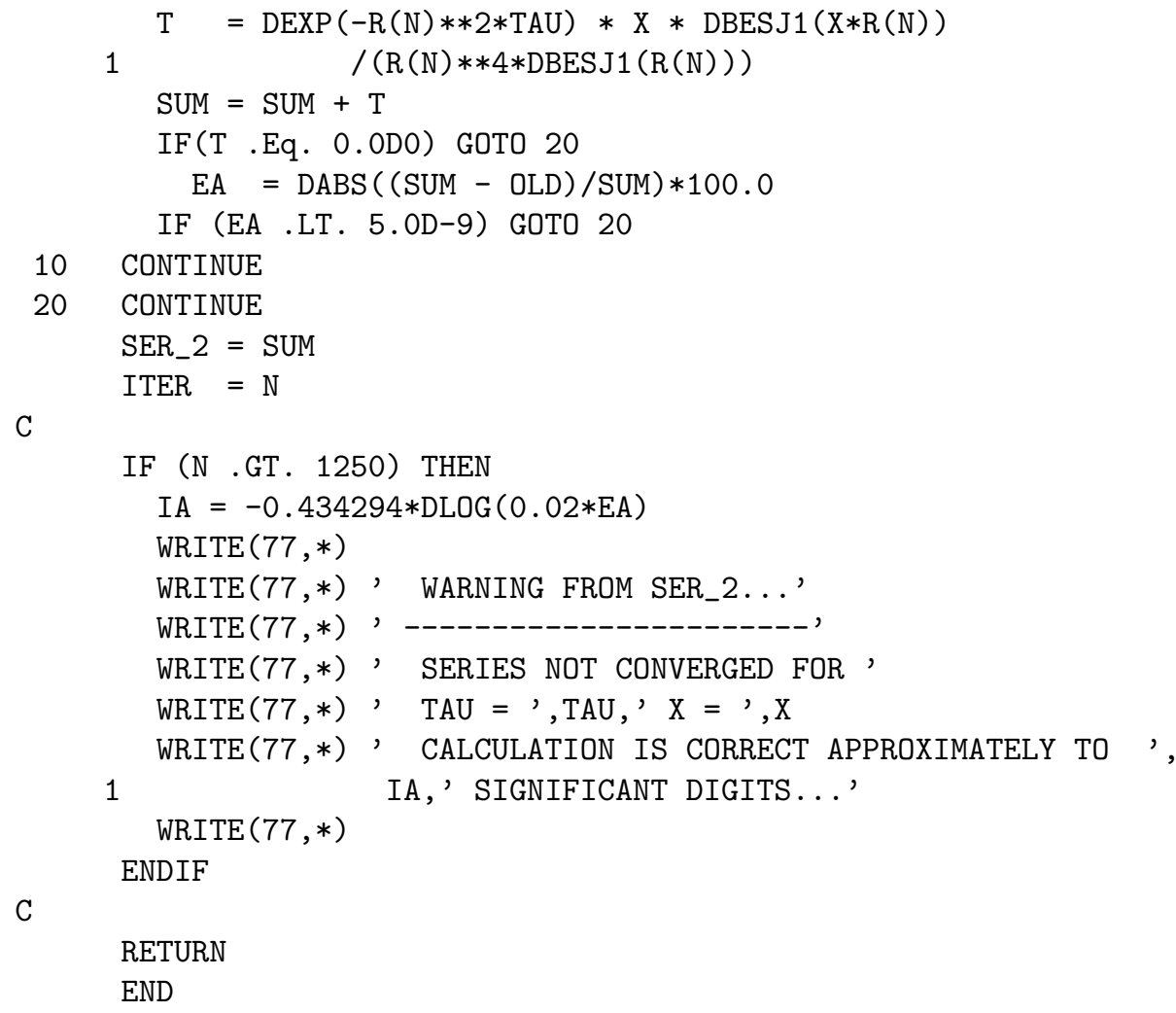




\title{
APPENDIX C
}

FORTRAN CODES OF ELASTIC-PLASTIC STATE

\section{C.1 MAIN PROGRAM: ELASTIC-PLASTIC STATE}

\author{
PROGRAM ELASTIC PLASTIC STATE
}

PURPOSE :

This program is used to calculate the non-dimensional response variables in the elastic-plastic state for the problem of rotating solid shaft subjected to temperature cycle. All calculations are done for non-dimensional parameters. In this state, six integration constants, 2 interface radius and the axial strain is need to be computed. The integration constants are already calculated analytically in subroutine NLNEQN, which is externally called by the present program, and they are moved to the current program by COMMON command. However, resulting system of equations are non-linear in the border radii. Hence, remaining three unknowns are needed to be computed numerically. This is done by the Powell Hybrid Method implemented in the program Minpack.for. Therefore, HYBRD1 is called to solve three unknowns numerically. For the present algorithm, input and output parameters are given below.

Furthermore, Subroutine 'DISTRIBUTION' is used to calculate some integrals which include temperature terms. By substituting variable $R$, power $M$ and the upper limits of the integral, INT1 and INT2E are calculated analytically by this subroutine. Additionally, this subroutine is also used to get TBAR which is non-dimensional temperature distribution.

The problem is formulated for solid shaft. Hence, there is not an inner radius. However, for numerical calculation, an inner surface radius is needed to be defined. Therefore, a sufficiently small inner radius $\mathrm{A}$ is defined as $0.1 \mathrm{D}-10$.

After the definition of input parameters (NU,Q,BETA,OMEGA,TAU, TAUT, TAUC), initial estimates are done for EPSO, R1 and R2. These estimations are sent to HYBRD1 with system of equations defined in NLNEQN. If program converges perfectly with the tolerance defined, input and output parameters are written into A-FIRST-STAGE.DAT. Response variables are calculated for each regions at N1, N2 and N3 points and results are printed to the same output file.

CONNECTED SUBROUTINES 


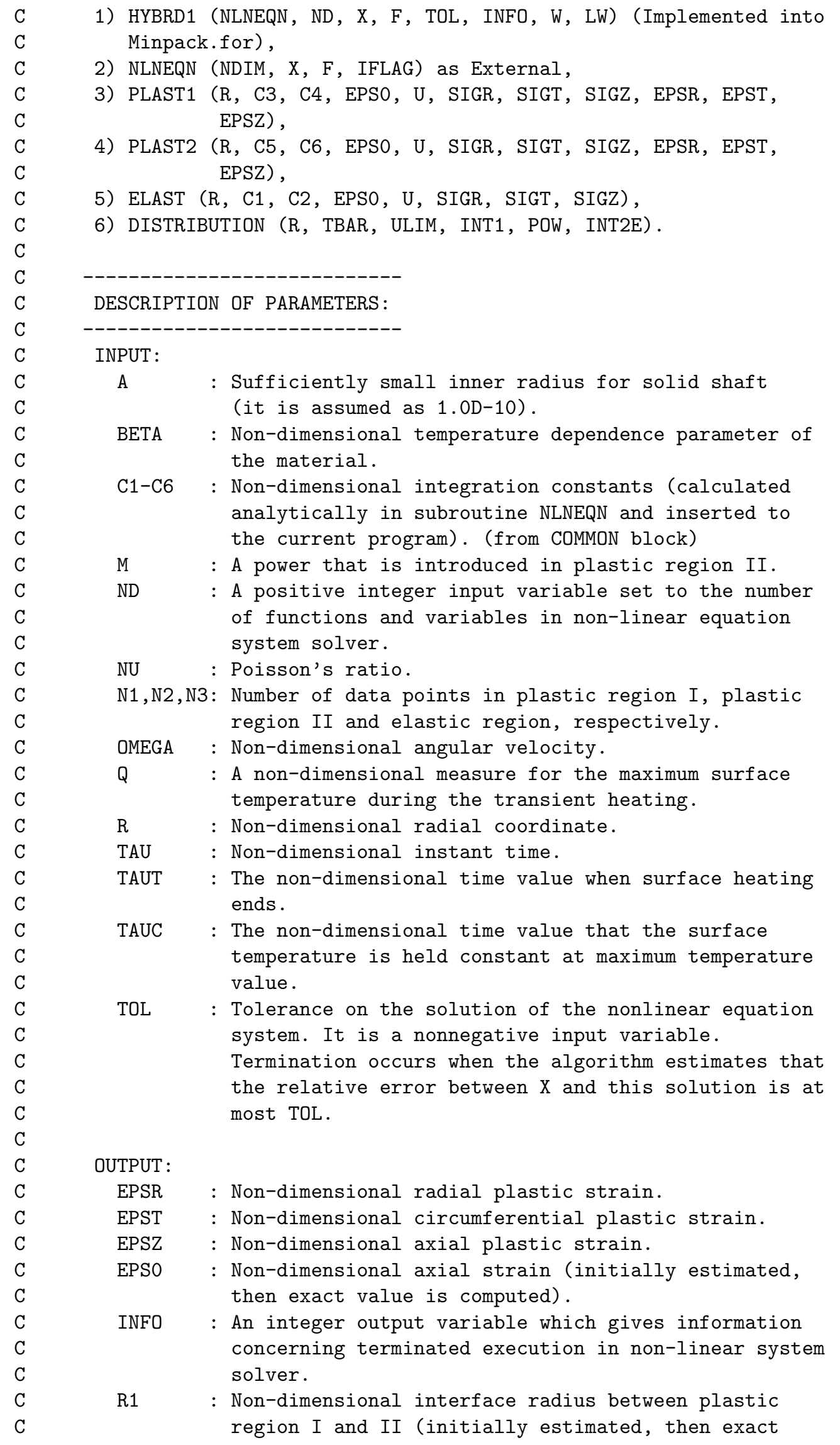




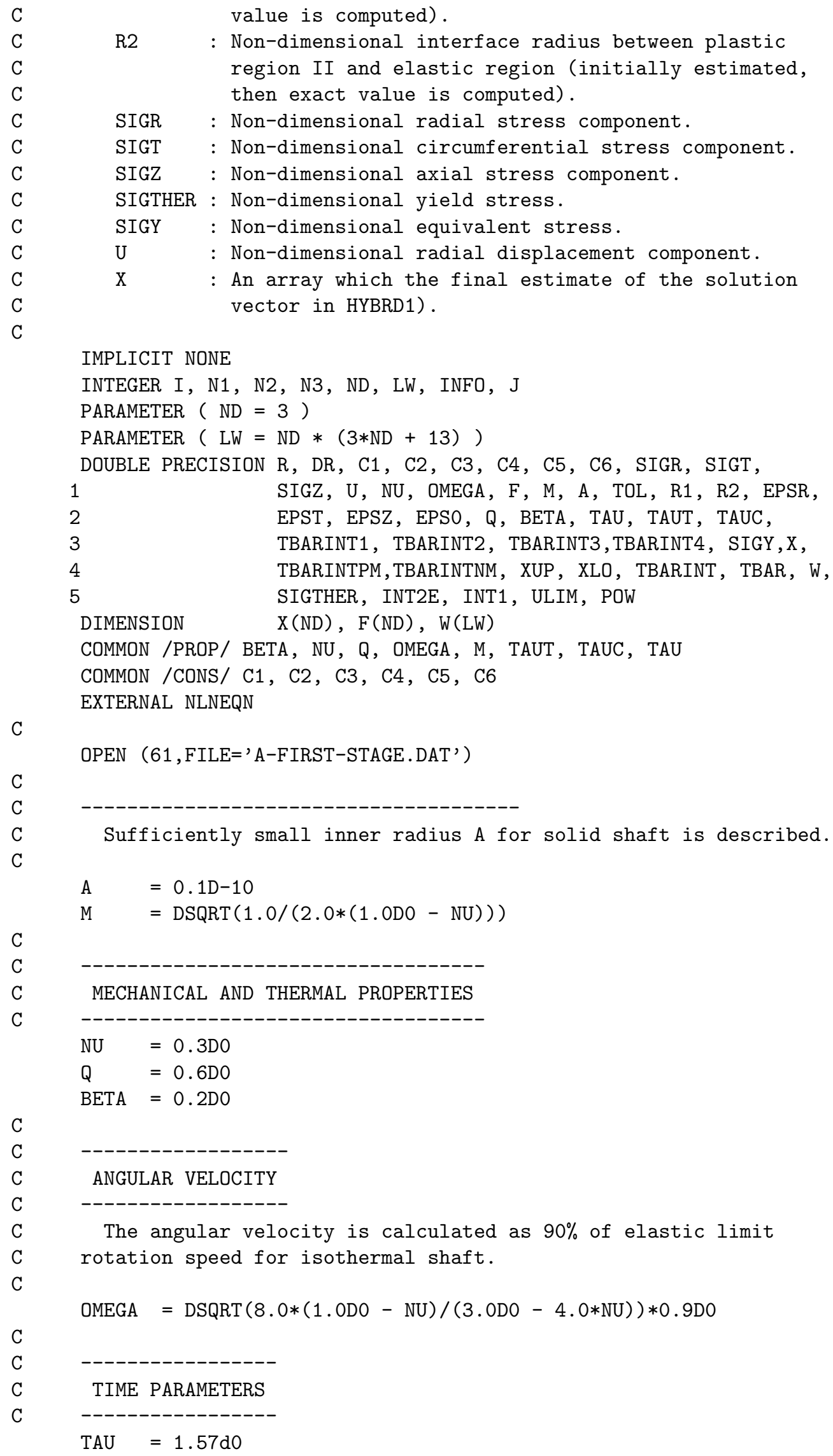


TAUT $=1.2 \mathrm{DO}$

TAUC $=0.3 \mathrm{D} 0$

\section{TOLERANCE}

Tolerance, which is used on the solution of the non-linear equation system, is defined.

$\mathrm{TOL}=1.0 \mathrm{D}-10$

\section{INITIAL ESTIMATES}

Initial estimations for EPSO, R1 and R2 are presumed to be used in non-linear equation system solver.

EPSO $=0.434827 \mathrm{DO}$

$\mathrm{R} 1=0.100458 \mathrm{D} 0$

$\mathrm{R} 2=0.260047 \mathrm{DO}$

Argument $\mathrm{X}$ is described before it enters to the nonlinear equation system solver.

$\mathrm{X}(1) \quad=$ EPSO

$\mathrm{X}(2) \quad=\mathrm{R} 1$

$\mathrm{X}(3) \quad=\mathrm{R} 2$

Non-linear equation system solver (HYBRD1) is called. During calling the solver, the subroutine NLNEQN is called as well.

CALL HYBRD1 (NLNEQN, ND, X, F, TOL, INFO, W, LW)

The computed argument $\mathrm{X}$ in non-linear equation system solver is equalized to the unknowns EPSO, R1 and R2.
EPSO $=\mathrm{X}(1)$
$\mathrm{R} 1=\mathrm{X}(2)$
$\mathrm{R} 2=\mathrm{X}(3)$

Convergence information of the results that are computed by the non-linear equation system solver is screened.

IF (INFO .Eq. 1) THEN

$\operatorname{WRITE}(6, *)$

$\operatorname{WRITE}(6, *)$,

$\operatorname{WRITE}(6, *)$, FROM HYBRID: INFO $=$, , INFO

$\operatorname{WRITE}(6, *)$ ' ITERATIONS CONVERGED PERFECTLY...'

$\operatorname{WRITE}(6, *)$ ' RESIDUALS ARE:'

$\operatorname{WRITE}(6, *)$,

$\mathrm{DO} I=1, \mathrm{ND}$

$\operatorname{WRITE}(6, *) \mathrm{I}, \mathrm{X}(\mathrm{I}), \mathrm{F}(\mathrm{I})$

END DO

$\operatorname{WRITE}(6, *)$

ELSE 
$\operatorname{WRITE}(6, *)$, FROM HYBRID: INFO $=$, , INFO

$\operatorname{WRITE}(6, *)$, ITERATIONS DIVERGE !!!!'

WRITE $(6, *)$ ' EXECUTION IS TERMINATED.'

STOP

END IF

Input parameters and calculated unknowns are written to the output file.

WRITE $(61, *)$ 'CONSTANTS ARE CALCULATED ANALYTICALLY'

$\operatorname{WRITE}(61, *)$

$\operatorname{WRITE}(61, *)$ ' MATERIAL PROPERTIES:'

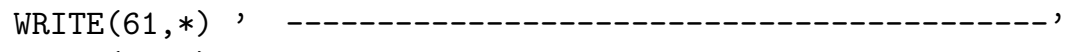

$\operatorname{WRITE}(61, *), \quad \mathrm{NU} \quad=, \mathrm{NU}$

$\operatorname{WRITE}(61, *), \quad \mathrm{Q} \quad=, \mathrm{Q}$

$\operatorname{WRITE}(61, *)$, BETA = , BETA

WRITE $(61, *)$ ' TEMPERATURE PROPERTIES:'

$\operatorname{WRITE}(61, *), \quad------1,-$

$\operatorname{WRITE}(61, *), \quad$ TAU $\quad$, , TAU

$\operatorname{WRITE}(61, *)$, TAUT $\quad=$, TAUT

$\operatorname{WRITE}(61, *), \operatorname{TAUC}=$,, $\mathrm{TAUC}$

C

$\operatorname{WRITE}(61, *)$

$\operatorname{WRITE}(61, *)$, LOAD PARAMETER (ANGULAR SPEED) :'

$\operatorname{WRITE}(61, *)$,

$\operatorname{WRITE}(61, *)$,

$\operatorname{WRITE}(61, *)$

$\operatorname{WRITE}(61, *)$,

$\operatorname{WRITE}(61, *)$,

$\operatorname{WRITE}(61, *)$

$\operatorname{WRITE}(61, *)$

$\operatorname{WRITE}(61, *)$,

$\operatorname{WRITE}(61, *)$

$\operatorname{WRITE}(61, *)$

$\operatorname{WRITE}(61, *)$,

$\operatorname{WRITE}(61, *)$,

$\operatorname{WRITE}(61, *)$,

OMEGA $=$, OMEGA

$\operatorname{WRITE}(61, *)$,

COMPUTING : '

$\operatorname{WRITE}(61, *)$,

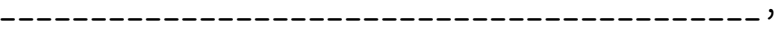

TOLERANCE $=$, TOL

INTEGRATION CONSTANTS AND INT. RADIUS: ,

$\operatorname{WRITE}(61, *)$,

------------------------------------------',

$\operatorname{WRITE}(61, *)$,

$\operatorname{WRITE}(61, *)$,

EPSO $=$, EPSO

$\mathrm{R} 1={ }^{\prime}, \mathrm{R} 1$

R2 $=$, , R2

$\mathrm{C} 1=$, $\mathrm{C} 1$

$\mathrm{C} 2=, \mathrm{C} 2$

$\mathrm{C} 3=$, $\mathrm{C} 3$

$\mathrm{C} 4=$,, $\mathrm{C} 4$

C5 $=$, , C5

C6 $=$,, $\mathrm{C} 6$

$\operatorname{WRITE}(61, *)$

Number of data points in plastic region I, plastic region II and elastic region are defined.

WRITE $(6, *)$ ' NUMBER OF DATA PTS. IN FIRST PLASTIC ?' $\operatorname{READ}(5, *) \mathrm{N} 1$

WRITE $(6, *)$ ' NUMBER OF DATA PTS. IN SECOND PLASTIC ?' $\operatorname{READ}(5, *)$ N2

WRITE $(6, *)$ ' NUMBER OF DATA PTS. IN ELASTIC ?'

$\operatorname{READ}(5, *) \mathrm{N} 3$ 


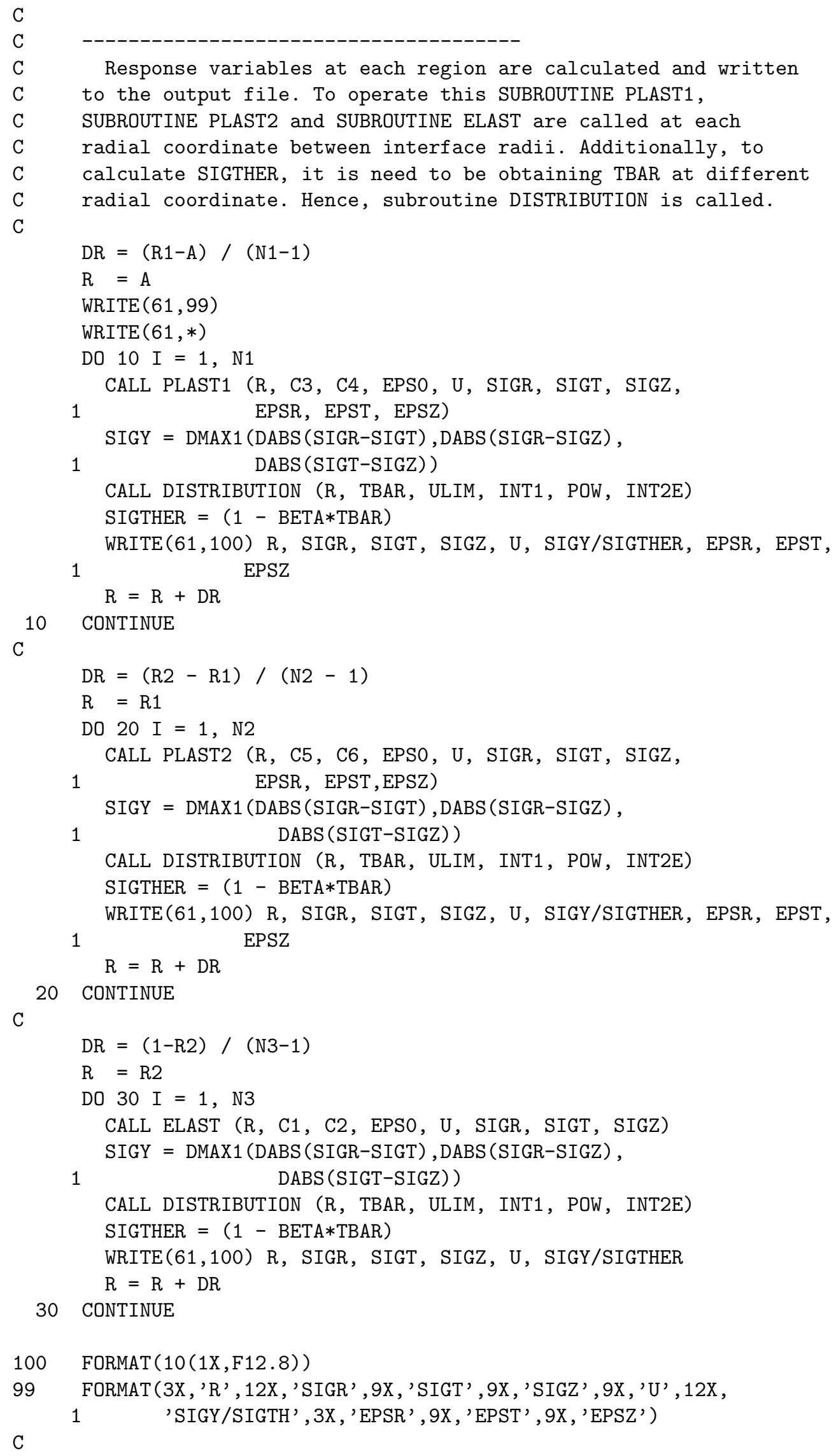


END

\title{
C.2 SUBROUTINE: NLNEQN
}

\author{
SUBROUTINE NLNEQN (NDIM, X, F, IFLAG)
}

\section{PURPOSE :}

This subroutine is used to introduce functions $F$ which describe interface and boundary conditions. The array $\mathrm{F}$ is obtained and sent to iterations in HYBRD1.

In each loop, estimated EPSO, R1 and R2 are taken from HYBRD1 and substituted into analytical expressions being for six integration constants. Then new $\mathrm{F}$ are computed by using interface and boundary conditions and sent back to HYBRD1. These loops are proceeding until the tolerance condition is satisfied in HYBRD1.

All expressions are in non-dimensional form.

\section{CONNECTED SUBROUTINES}

1) DISTRIBUTION (R, TBAR, ULIM, INT1, POW, INT2E).

\section{DESCRIPTION OF PARAMETERS:}

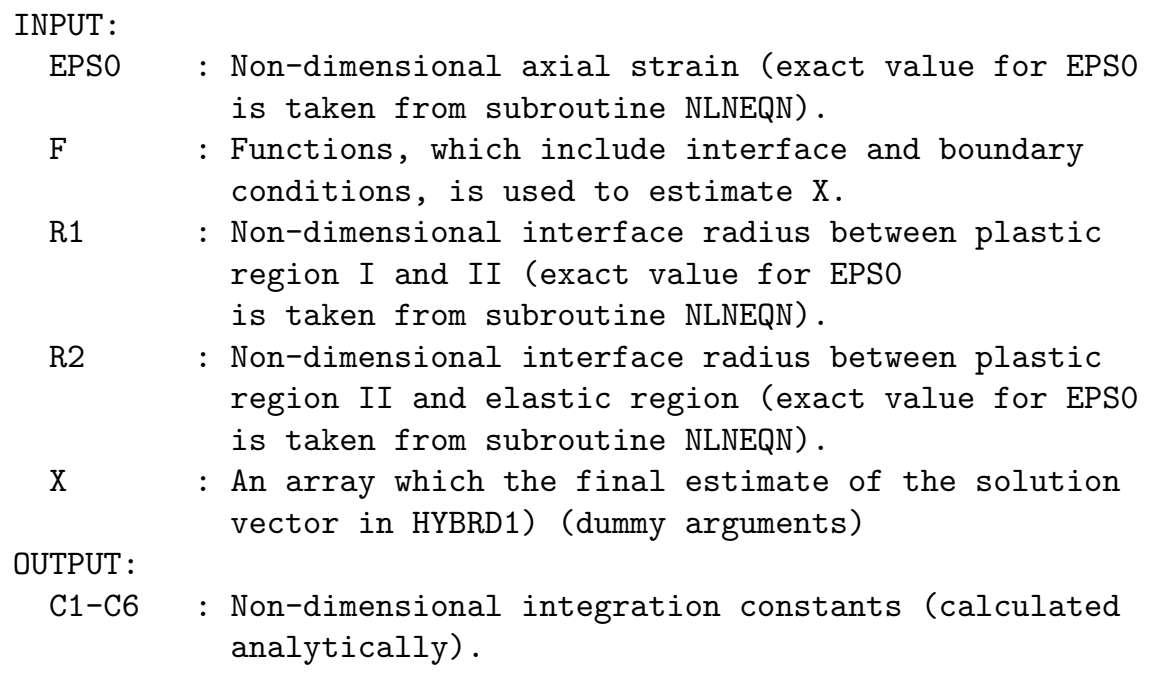

\section{IMPLICIT NONE}

INTEGER NDIM, IFLAG, ICALL

DOUBLE PRECISION R, DR, C1, C2, C3, C4, C5, C6, SIGR, SIGT, SIGZ, U, NU, OMEGA, F, M, A, TOL, R1, R2, EPSR, EPST, EPSZ, EPSO, Q, BETA, TAU, TAUT, TAUC, T1, TBARINT, TBAR, SIGR1, SIGR2, SIGT1, SIGT2, U1, U2, SIGZ1, SIGZ2, EPSR2, EPST2,EPSZ2, EPSR1, EPST1, EPSZ1, U3, SIGR3, SIGT3, SIGZ3, $\mathrm{T} 2$, T3, T4, T5 , T6, T7 , K1 , K2, K3, INT , X, XLO, XUP, TBARINTPM, TBARINTNM, TBARINT4, TBARINT3, TBARINT2, TBARINT1, TBARINT5, TBARINT6, POW, 
9

INT2E, INT1, ULIM

COMMON /PROP/ BETA, NU, Q, OMEGA, M, TAUT, TAUC, TAU

COMMON /CONS/ C1, C2, C3, C4, C5, C6

DIMENSION X(NDIM), F(NDIM)

C

DATA ICALL / 0 /

$\mathrm{C}$

Numerically estimated parameters EPSO, R1 and R2 in HYBRD1 are written by using variable $\mathrm{X}$.

EPSO $=X(1)$

$\mathrm{R} 1=\mathrm{X}(2)$

$\mathrm{R} 2 \quad=\mathrm{X}(3)$

IFLAG $\quad$ IFLAG

C

$\mathrm{C}$

INTEGRATION CONSTANTS

Analytical expressions of the integration constants includes EPS0, R1, R2, temperature terms and their integrals are written. Different temperature integrals are called from subroutine DISTRIBUTION to be inserted into the integration constants.

$\mathrm{M}=\operatorname{DSQRT}(1.0 /(2.0 *(1.0 \mathrm{DO}-\mathrm{NU})))$

$\mathrm{POW} \quad=-\mathrm{M}$

CALL DISTRIBUTION ( $R$, TBAR, 1.0D0, INT1, POW, INT2E) TBARINT1 $=$ INT1

C

CALL DISTRIBUTION ( $R$, TBAR, R2, INT1, POW, INT2E) TBARINT2 = INT1

C

CALL DISTRIBUTION ( $R$, TBAR, R1, INT1, POW, INT2E) TBARINT3 $=$ INT2E

CALL DISTRIBUTION ( $R$, TBAR, R1, INT1, M, INT2E) TBARINT4 $=$ INT2E

C

CALL DISTRIBUTION ( $R$, TBAR, R2, INT1, POW, INT2E) TBARINT5 $=$ INT2E

CALL DISTRIBUTION ( $R$, TBAR, R2, INT1, M, INT2E) TBARINT6 $=$ INT2E

C

CALL DISTRIBUTION (R2, TBAR, ULIM, INT1, POW, INT2E)

C

$\mathrm{C} 1=\mathrm{R} 2 * * 2 /(2.0 *(1.0 \mathrm{D} 0+(1.0 \mathrm{D} 0-2.0 * \mathrm{NU}) * \mathrm{R} 2 * * 2))$

$1 \quad *((1.0 \mathrm{DO}-2.0 * \mathrm{NU}) *(\mathrm{R} 2 * * 2-3.0 \mathrm{DO}+2.0 * \mathrm{NU}) * \mathrm{OMEGA} * * 2$

$2 /(8.0 \mathrm{DO} *(1.0 \mathrm{DO}-\mathrm{NU}))+2.0 *(1.0 \mathrm{DO}+\mathrm{NU}) * \mathrm{EPSO}+1.0 \mathrm{DO}$

$3-\mathrm{BETA} * \mathrm{TBAR}-2.0 * \mathrm{Q} *(1.0 \mathrm{DO}+\mathrm{NU}) /(1.0 \mathrm{DO}-\mathrm{NU})$

$4 \quad *((1.0 \mathrm{DO}-2.0 * \mathrm{NU}) *$ TBARINT1 $+1.0 /(\mathrm{R} 2 * * 2) *$ TBARINT2 $))$

C

$\mathrm{C} 2=(1.0 \mathrm{DO}-2.0 * \mathrm{NU}) /(2.0 *(1.0 \mathrm{DO}+(1.0 \mathrm{DO}-2.0 * \mathrm{NU}) * \mathrm{R} 2 * * 2))$

$1 \quad *(((1.0 \mathrm{DO}-2.0 * \mathrm{NU}) * \mathrm{R} 2 * * 4+3.0 \mathrm{DO}-2.0 * \mathrm{NU}) * \mathrm{OMEGA} * * 2$ 


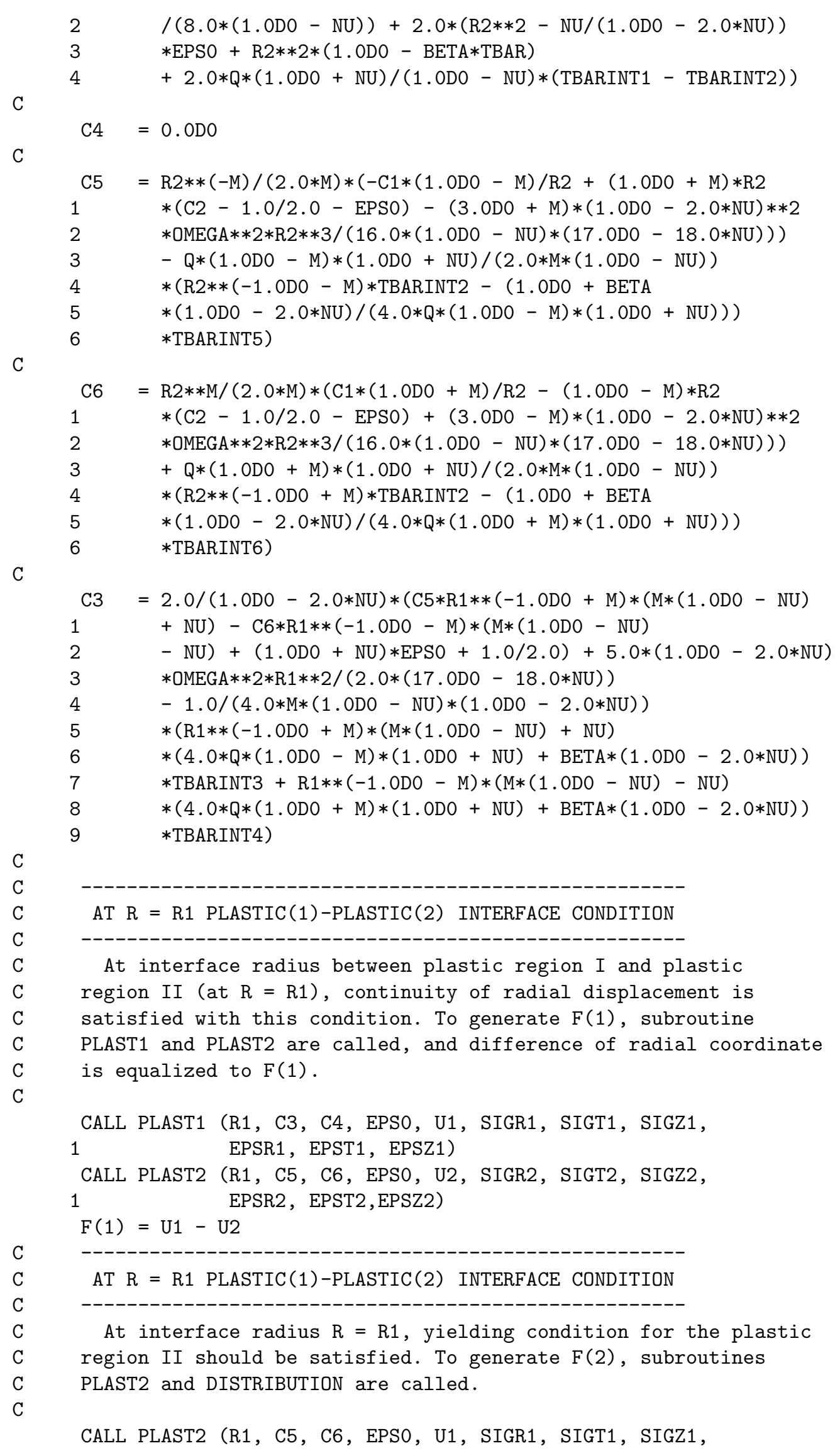


CALL DISTRIBUTION (R1, TBAR, ULIM, INT1, POW, INT2E)

$F(2)=$ SIGR1 - SIGZ1 - 1.ODO + BETA*TBAR

\section{FORCE INTEGRAL BOUNDARY CONDITION}

This condition constitutes the total axial force on any section that vanishes because of free ends of the shaft. For different temperature integrals, subroutine DISTRIBUTION is called and F(3) is formed.

CALL DISTRIBUTION ( $R$, TBAR, 1.0D0, INT1, POW, INT2E)

$\mathrm{T} 1=$ INT1

CALL DISTRIBUTION ( $R$, TBAR, R2, INT1, POW, INT2E)

$\mathrm{T} 2=$ INT1

CALL DISTRIBUTION ( $R$, TBAR, R1, INT1, POW, INT2E)

$\mathrm{T} 3=$ INT2E

CALL DISTRIBUTION ( $R$, TBAR, R2, INT1, POW, INT2E)

$\mathrm{T} 4=$ INT2E

CALL DISTRIBUTION ( $R$, TBAR, R1, INT1, M, INT2E)

$\mathrm{T} 5=$ INT2E

CALL DISTRIBUTION ( $R$, TBAR, R2, INT1, M, INT2E)

$\mathrm{T} 6=$ INT2E

CALL DISTRIBUTION ( $R$, TBAR, R1, INT1, POW, INT2E)

$\mathrm{T} 7=\mathrm{INT} 1$

C

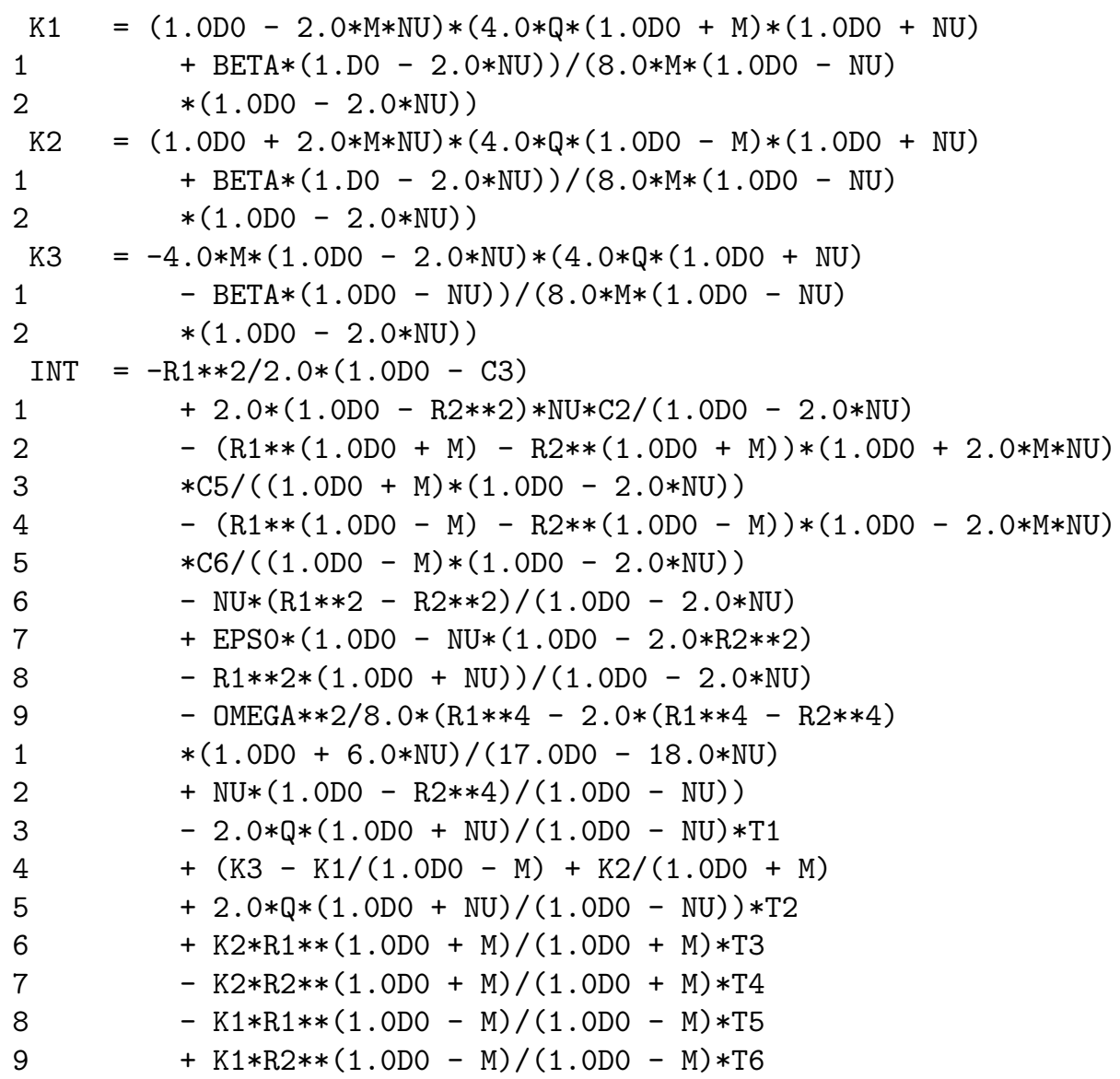


C

$\mathrm{F}(3)=$ INT

ICALL $=$ ICALL +1

$\operatorname{WRITE}(6, *), * * *$ NUMBER OF ITERATIONS $=$, ICALL

C

RETURN

END

\section{C.3 SUBROUTINE: PLASTIC REGION I}

SUBROUTINE PLAST1 (R, C3, C4, EPSO, U, SIGR, SIGT, SIGZ, 1 EPSR, EPST, EPSZ)

C

C

\section{PURPOSE}

Response variables in Plastic region I are computed at specified radial coordinate $R$. The necessary input parameters are taken by dummy arguments or by COMMON comment. All expressions are in non-dimensional form.

CONNECTED SUBROUTINES :

1) DISTRIBUTION ( $R$, TBAR, ULIM, INT1, POW, INT2E).

DESCRIPTION OF PARAMETERS:

INPUT :

BETA : Non-dimensional temperature dependence parameter of the material. (from COMMON block)

C3, C4 : Two integration constants. (dummy arguments)

EPSO : Non-dimensional axial strain. (dummy argument)

NU : Poisson's ratio. (from COMMON block)

Q : A non-dimensional measure for the maximum surface temperature during the transient heating. (from COMMON block)

$\mathrm{R}$ : Non-dimensional radial coordinate. (dummy arguments)

TAU : Non-dimensional instant time. (from COMMON block)

TAUT : The non-dimensional time value when surface heating ends. (from COMMON block)

TAUC : The non-dimensional time value that the surface temperature is held constant at maximum temperature value. (from COMMON block)

OUTPUT :

EPSR : Non-dimensional radial plastic strain.

EPST : Non-dimensional circumferential plastic strain.

EPSZ : Non-dimensional axial plastic strain.

SIGR : Non-dimensional radial stress component.

SIGT : Non-dimensional circumferential stress component.

SIGZ : Non-dimensional axial stress component.

U : Non-dimensional radial displacement component. 
C

IMPLICIT NONE

DOUBLE PRECISION R, C3, C4, EPSO, NU, OMEGA, BETA, TAU, TAUT, 1 TAUC, U, SIGR, SIGT, SIGZ, EPSR, EPST, EPSZ, TBARINT, TBAR, Q, M, TEMP, INT1, POW, INT2E, ULIM

3

COMMON /PROP/ BETA, NU, Q, OMEGA, M, TAUT, TAUC, TAU

$\mathrm{C}$

C$$
\mathrm{C}
$$

C

C

C

$\mathrm{U}=\mathrm{C} 4 / \mathrm{R}-\mathrm{EPS} 0 * \mathrm{R} / 2.0+1.0 /(4.0 *(1.0 \mathrm{DO}+\mathrm{NU}) * \mathrm{R})$

$1 \quad *((1.0 \mathrm{DO}-2.0 * \mathrm{NU}) * \mathrm{R} * * 2 / 4.0 *(12.0 * \mathrm{C} 3-4.0 \mathrm{DO}-3.0$

$2 \quad * \mathrm{OMEGA} * * 2 * \mathrm{R} * * 2)+2.0 *(6.0 * \mathrm{Q} *(1.0 \mathrm{DO}+\mathrm{NU})$

3

C

C

C

$$
\mathrm{SIGZ}=\mathrm{C} 3-\mathrm{OMEGA} * * 2 * \mathrm{R} * * 2 / 2.0-(1.0 \mathrm{DO}-\mathrm{BETA} * \mathrm{TBAR})
$$

$\mathrm{EPSR}=-\mathrm{C} 4 / \mathrm{R} * * 2-\mathrm{EPSO} / 2.0+1.0 /(16.0 *(1.0 \mathrm{DO}+\mathrm{NU}))$

$1 \quad *((1.0 \mathrm{DO}-2.0 * \mathrm{NU}) *(4.0 * \mathrm{C} 3-5.0 * 0 \mathrm{MEGA} * * 2 * \mathrm{R} * * 2)-4.0 \mathrm{DO}$

$2-8.0 *(6.0 * \mathrm{Q} *(1.0 \mathrm{DO}+\mathrm{NU})+\mathrm{BETA} *(1.0 \mathrm{DO}-2.0 * \mathrm{NU})) / \mathrm{R} * * 2$

$3 \quad *$ TBARINT $+8.0 *(4.0 * \mathrm{Q} *(1.0 \mathrm{DO}+\mathrm{NU})+\operatorname{BETA} *(1.0 \mathrm{DO}-\mathrm{NU}))$

$4 \quad *$ TBAR)

C

$$
\mathrm{EPST}=\mathrm{C} 4 / \mathrm{R} * * 2-\mathrm{EPS} 0 / 2.0+1.0 /(16.0 *(1.0 \mathrm{DO}+\mathrm{NU}))
$$

$1 \quad *((1.0 \mathrm{DO}-2.0 * \mathrm{NU}) *(4.0 * \mathrm{C} 3+0 \mathrm{OMEGA} * * 2 * \mathrm{R} * * 2)-4.0 \mathrm{DO}$

$2+8.0 *(6.0 * \mathrm{Q} *(1.0 \mathrm{DO}+\mathrm{NU})+\mathrm{BETA} *(1.0 \mathrm{DO}-2.0 * \mathrm{NU})) / \mathrm{R} * * 2$

$3 \quad *$ TBARINT $-8.0 *(2.0 * \mathrm{Q} *(1.0 \mathrm{DO}+\mathrm{NU})-\mathrm{BETA} * \mathrm{NU}) * \mathrm{TBAR})$

C

$\mathrm{EPSZ}=-(\mathrm{EPSR}+\mathrm{EPST})$

RETURN

END

\section{C.4 SUBROUTINE: PLASTIC REGION II}

\section{SUBROUTINE PLAST2 (R, C5, C6, EPSO, U, SIGR, SIGT, SIGZ,} 1 EPSR, EPST,EPSZ)

\footnotetext{
C
}

C

C

C

PURPOSE :

Response variables in Plastic region II are calculated at the specified radial coordinates $R$. The necessary input parameters are 


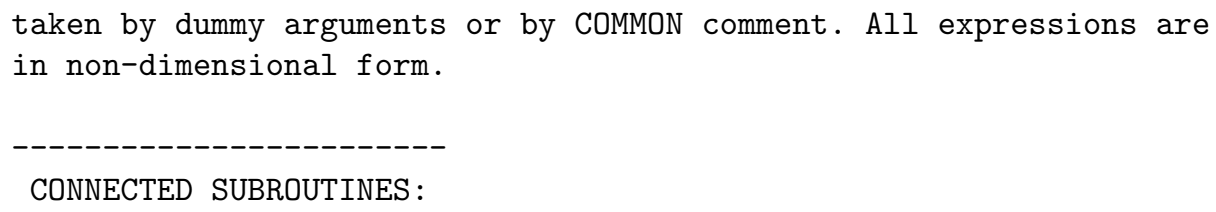

Subroutine 'DISTRIBUTION' is called to obtain INT2E with different powers ( $M$ and $-M$ ). Upper limits of the integrals are $R$.

POW $\quad=-\mathrm{M}$

CALL DISTRIBUTION ( $R$, TBAR, $R$, INT1, $M$, INT2E)

TBARINTPM $=$ INT2E

CALL DISTRIBUTION ( $R$, TBAR, $R$, INT1, POW, INT2E) 


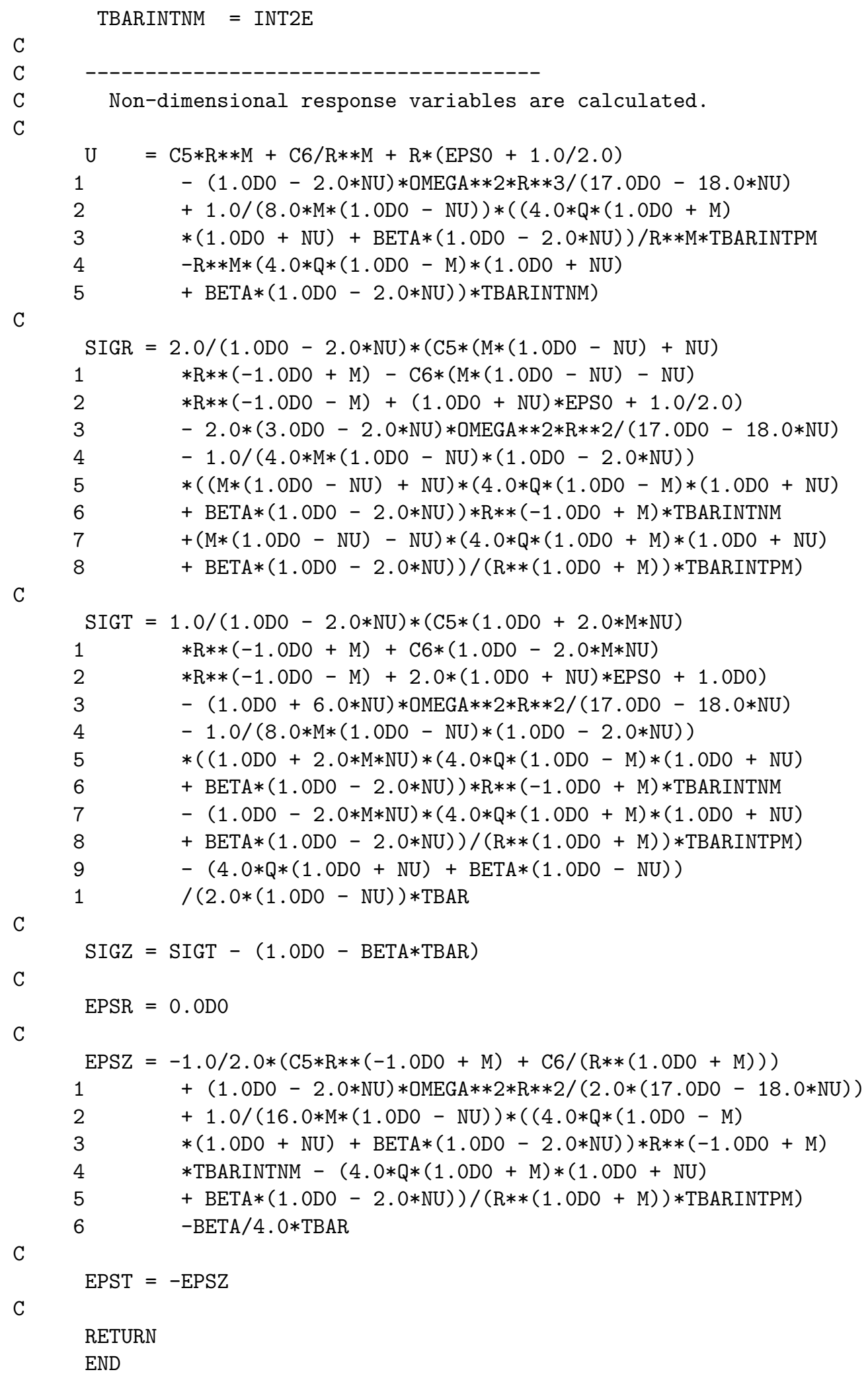

\section{C.5 SUBROUTINE: ELASTIC REGION}

SUBROUTINE ELAST ( $R, C 1, \mathrm{C} 2$, EPSO, U, SIGR, SIGT, SIGZ) 


\section{PURPOSE :}

Response variables in Elastic region are calculated at specified radial coordinate $R$. The necessary input parameters are taken by dummy arguments or by COMMON comment. All expressions are in non-dimensional form.

CONNECTED SUBROUTINES :

1) DISTRIBUTION ( $R$, TBAR, ULIM, INT1, POW, INT2E).

DESCRIPTION OF PARAMETERS:

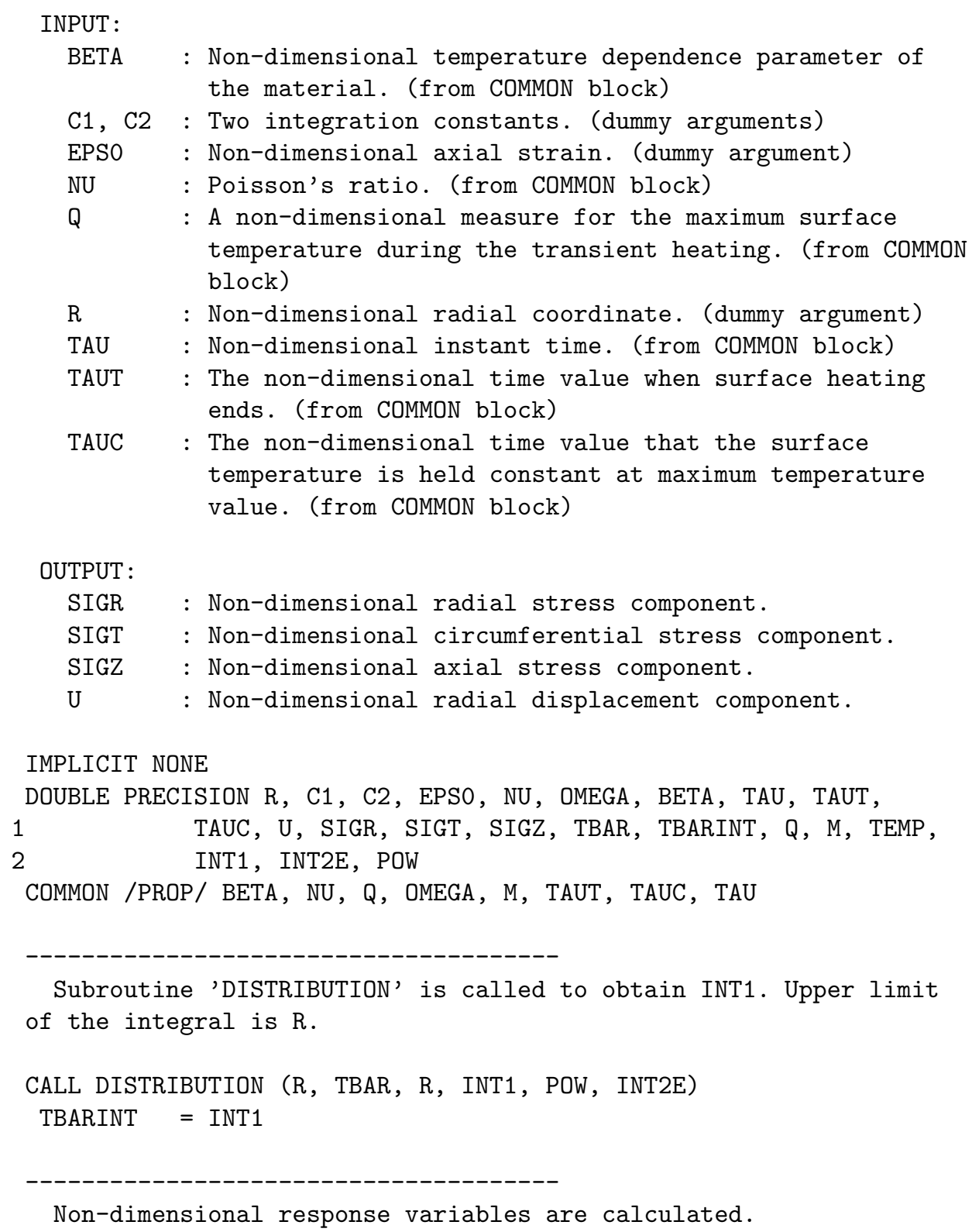

Non-dimensional response variables are calculated. 


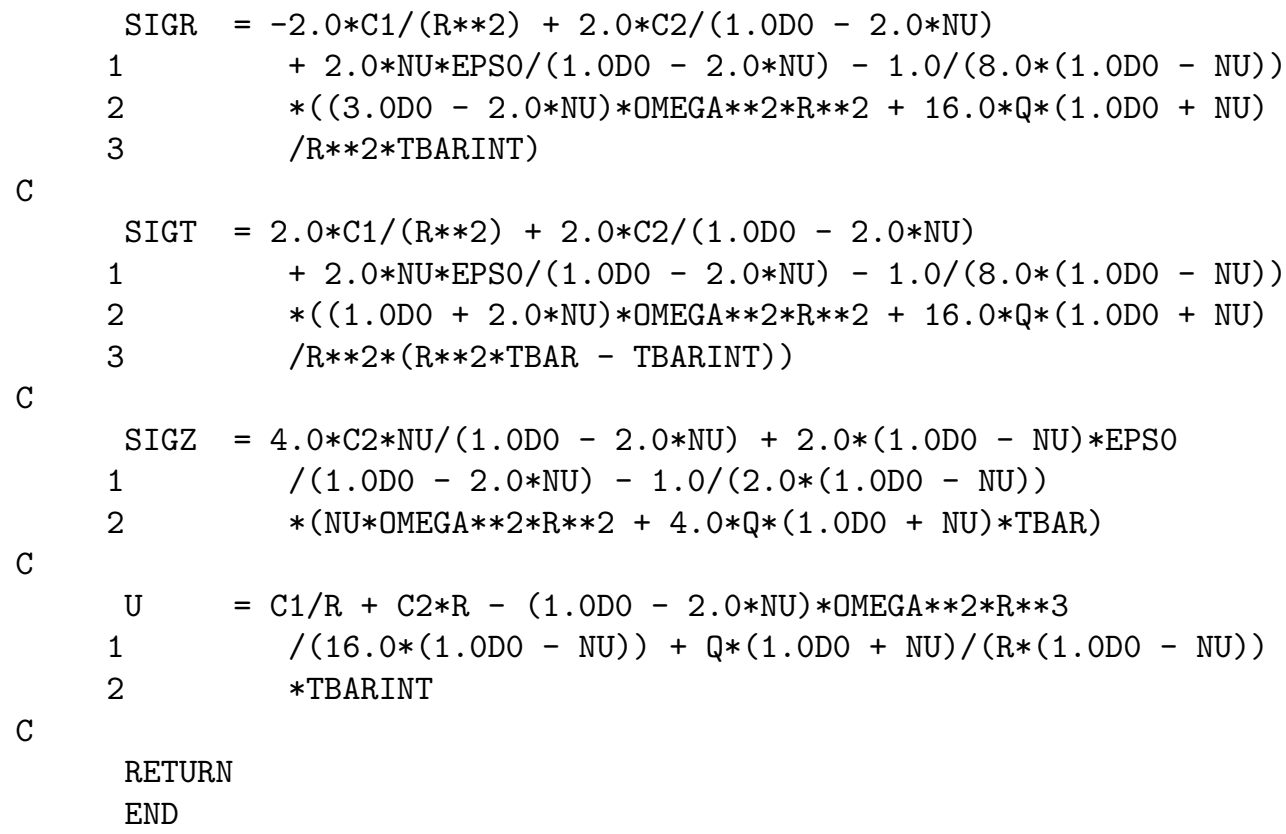

\section{C.6 FUNCTION: TEMPERATURE INTEGRAL 2}

DOUBLE PRECISION FUNCTION INT_2E (TAUT, M, TAU, ULIM)

C
C
$C$
$C$
$C$
$C$
$C$
$C$
$C$
$C$
$C$
$C$
$C$
$C$
$C$
$C$
$C$
$C$
$C$
$C$
$C$
$C$
$C$
$C$
$C$
$C$
$C$
$C$
$C$
$C$
$C$
$C$
$C$
$C$

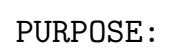






If upper limit of the integral is zero, result of integral will be zero since its lower limit is zero.

Upper limit of the integral is set radial coordinate $X$. Then summation of the series is called from SER_3 (M, TAU, X). Finally, INT_2E is calculated.

\section{C.7 FUNCTION: SERIES 3}

DOUBLE PRECISION FUNCTION SER_3 (M, TAU, X)

PURPOSE :

SER_3 is the summation of the series which is used in INT_2E. These series include Bessel roots ( $R$ ) and one Bessel function (first order Bessel functions of the first kind). Initially, first 1250 roots of zeroth order Bessel functions of the first kind ( $R$ ) is found (it is possible to use any subroutine to find root of Bessel functions but it is not given here). Then first order Bessel functions of the first kind DBESJ1(R) are computed for each $R$ (The algorithm of this Bessel function is not either given here). Furthermore, HYPPFQ(A1, A2, A3, Z) being a hypergeometric function is called. Finally, SER_3 is calculated by substituting Bessel functions for each root $R$ and hypergeometric function into $T$. All calculations are done for non-dimensional parameters. 


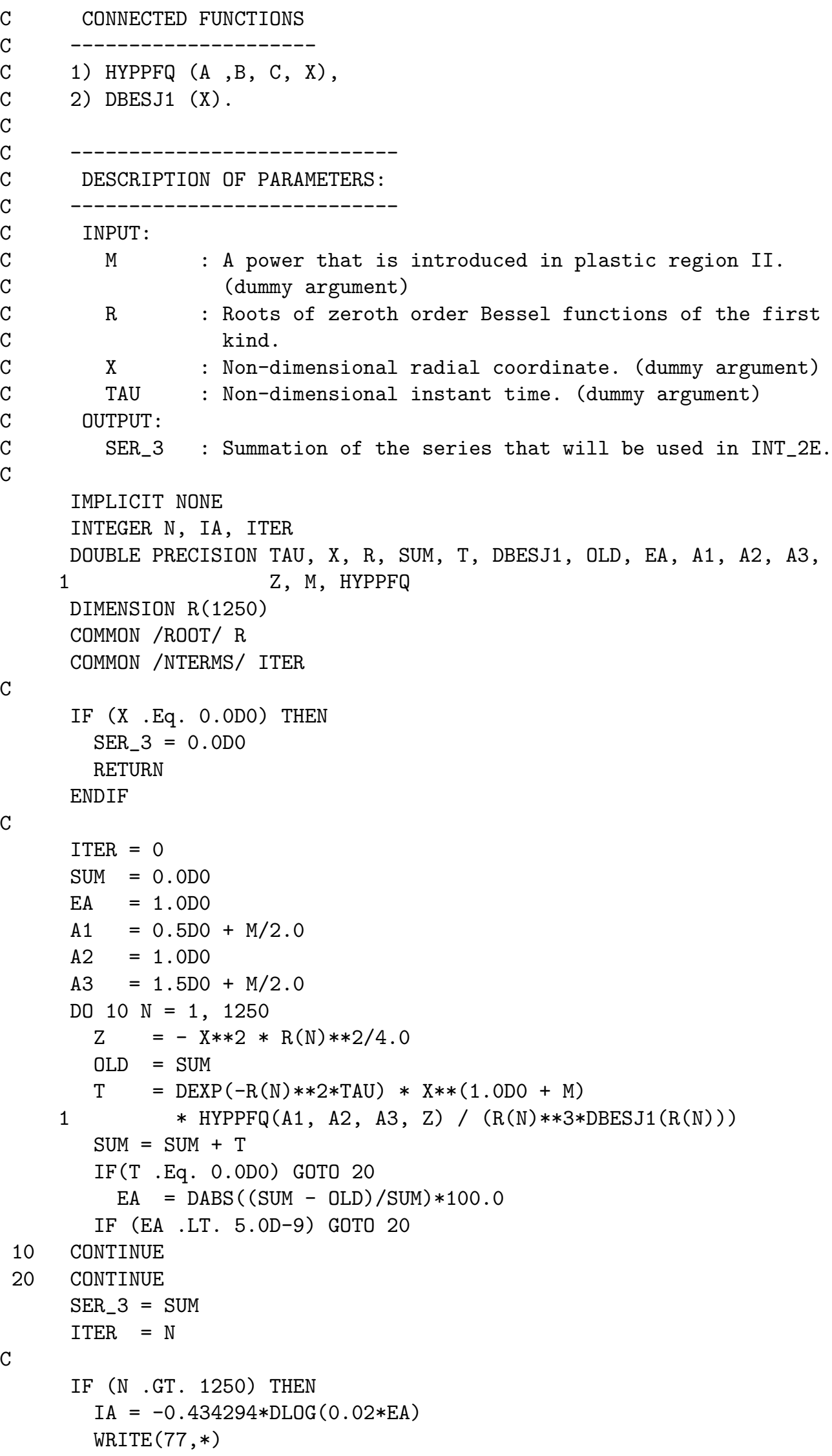




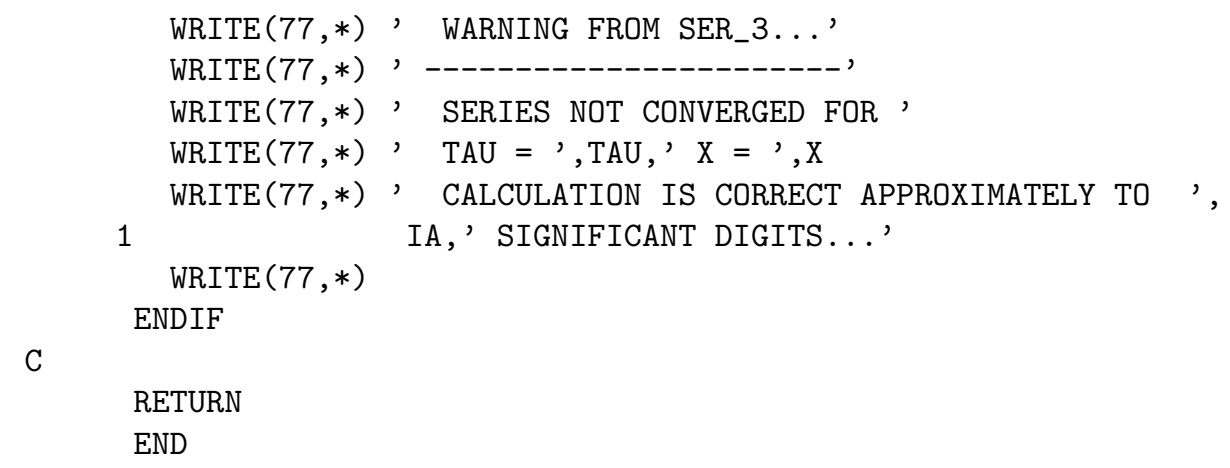

\section{C.8 FUNCTION: HYPERGEOMETRIC FUNCTION}

DOUBLE PRECISION FUNCTION HYPPFQ (A , B, C, X)

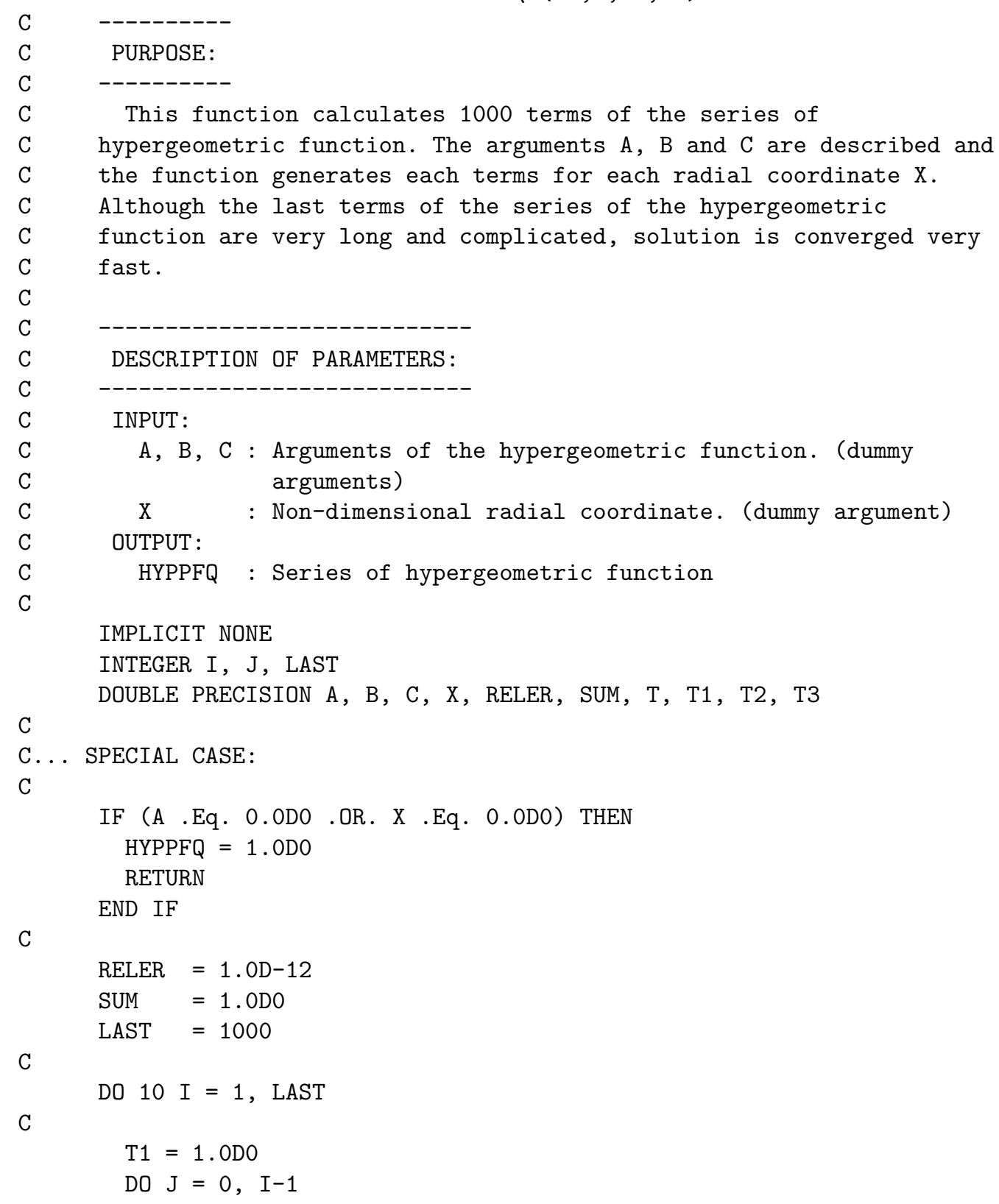


$\mathrm{T} 1=\mathrm{T} 1 *(\mathrm{~A}+1.0 \mathrm{D} 0 * \mathrm{~J}) /(\mathrm{J}+1)$

END DO

C

$\mathrm{T} 2=1.0 \mathrm{D} 0$

DO $\mathrm{J}=0, \mathrm{I}-1$

$\mathrm{T} 2=\mathrm{T} 2 *(\mathrm{~B}+1.0 \mathrm{D} 0 * \mathrm{~J})$

END DO

C

$\mathrm{T} 3=1.0 \mathrm{D} 0$

$\mathrm{DO} \mathrm{J}=0, \mathrm{I}-1$

$\mathrm{T} 3=\mathrm{T} 3 *(\mathrm{C}+1.0 \mathrm{D} 0 * \mathrm{~J})$

END DO

C

$\mathrm{T}=\mathrm{X} * * \mathrm{I} * \mathrm{~T} 1 /(\mathrm{T} 2 * \mathrm{~T} 3)$

$\mathrm{SUM}=\mathrm{SUM}+\mathrm{T}$

IF (DABS (T) .LT. RELER) GOTO 20

C

10 CONTINUE

20 CONTINUE

HYPPFQ $=$ SUM

IF (I . GT. LAST)

$1 \operatorname{WRITE}(*, *)$ ' FROM HYPPFQ: SERIES DOES NOT CONVERGE...'

C

RETURN

END 


\title{
APPENDIX D
}

\section{FORTRAN CODES OF UNLOADED STATE}

\section{D.1 MAIN PROGRAM: UNLOADED STATE}

\author{
PROGRAM UNLOADED STATE
}

PURPOSE :

This program is used to calculate the non-dimensional response variables in the unloaded state for the problem of rotating solid shaft subjected to temperature cycle. The input parameters radial coordinate and permanent plastic strains are read from an input file 'A-PERSTRAIN.DAT'. This file includes radial coordinate and permanent plastic strains at NTOT data points. Permanent plastic strains at NTOT data point are the plastic strains which are computed in the program ELASTIC PLASTIC STATE at time when the unloading state starts. After reading these parameters from the input file unknown constants $\mathrm{C} 1, \mathrm{C} 2$ and EPSO are calculated analytically. During this calculation, subroutines 'DAVINT' and 'DISTRIBUTION' are called.

Subroutine 'DAVINT' is used to compute some integral numerically which include permanent plastic strains. During calling DAVINT, argument $X$, integral function $F$, lower and upper limits of the integrals are prescribed. Numerical result of the integral is ANS.

Subroutine 'DISTRIBUTION' is used to calculate some integrals which include temperature terms. By substituting variable $\mathrm{X}$ and the upper limits of the integral, INT1 is calculated analytically by this subroutine. Additionally, this subroutine is also used to get TBAR which is non-dimensional temperature distribution.

Then response variables are calculated by using subroutines above and analytical expressions at NTOT radial coordinates. Results are written into the file 'A-OUTPUT.DAT'.

All calculations are done for non-dimensional parameters.

\section{CONNECTED SUBROUTINES AND DATA FILES}

1) A-PERSTRAIN.DAT,

2) DAVINT (X, Y, N, XLO, XUP, ANS, IERR) (Implemented in Davint.for),

3) DISTRIBUTION ( $R$, TBAR, ULIM, INT1, POW, INT2E). 


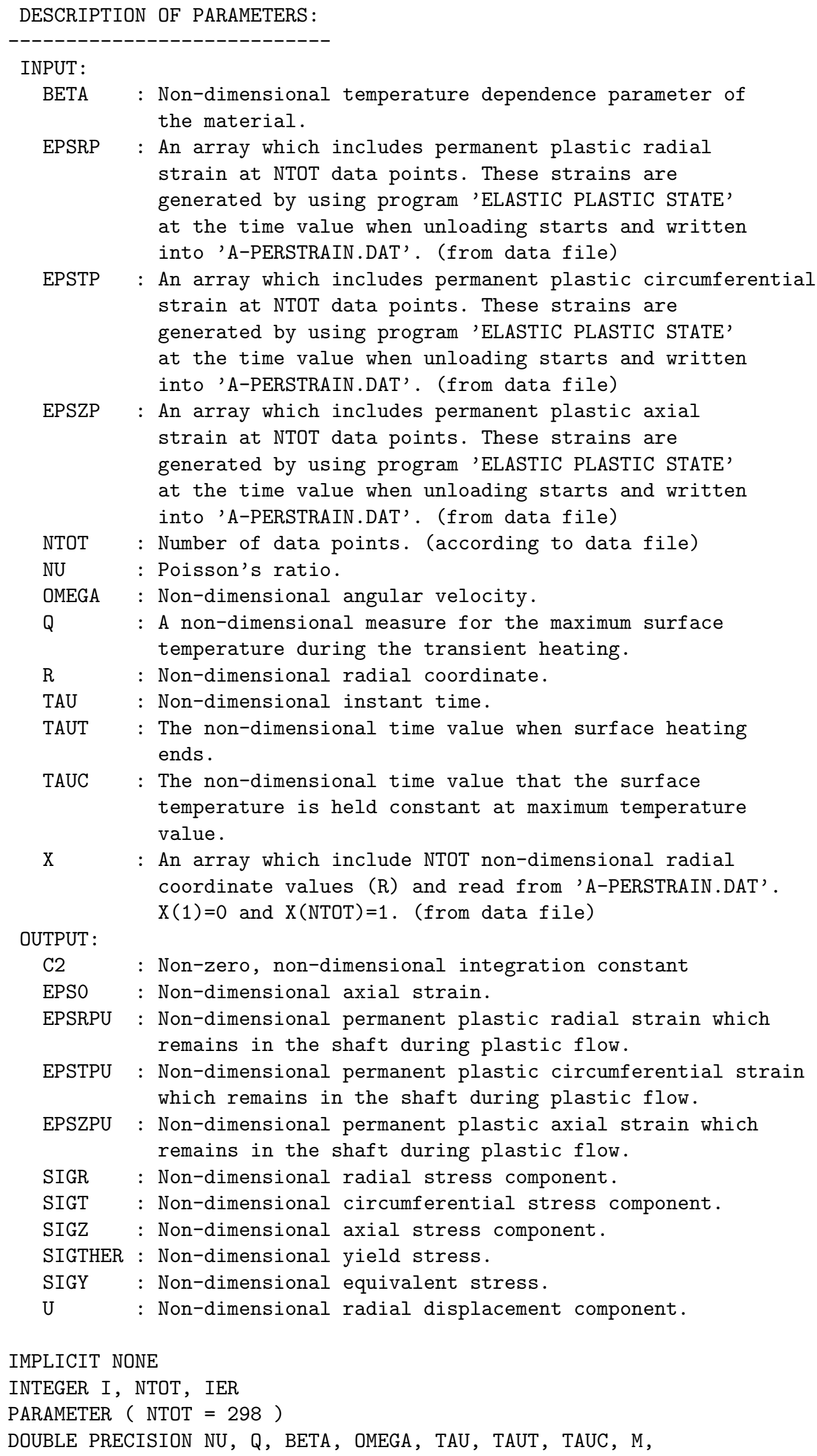

IMPLICIT NONE

INTEGER I, NTOT, IER

PARAMETER ( NTOT $=298)$

DOUBLE PRECISION NU, $Q$, BETA, OMEGA, TAU, TAUT, TAUC, M, 


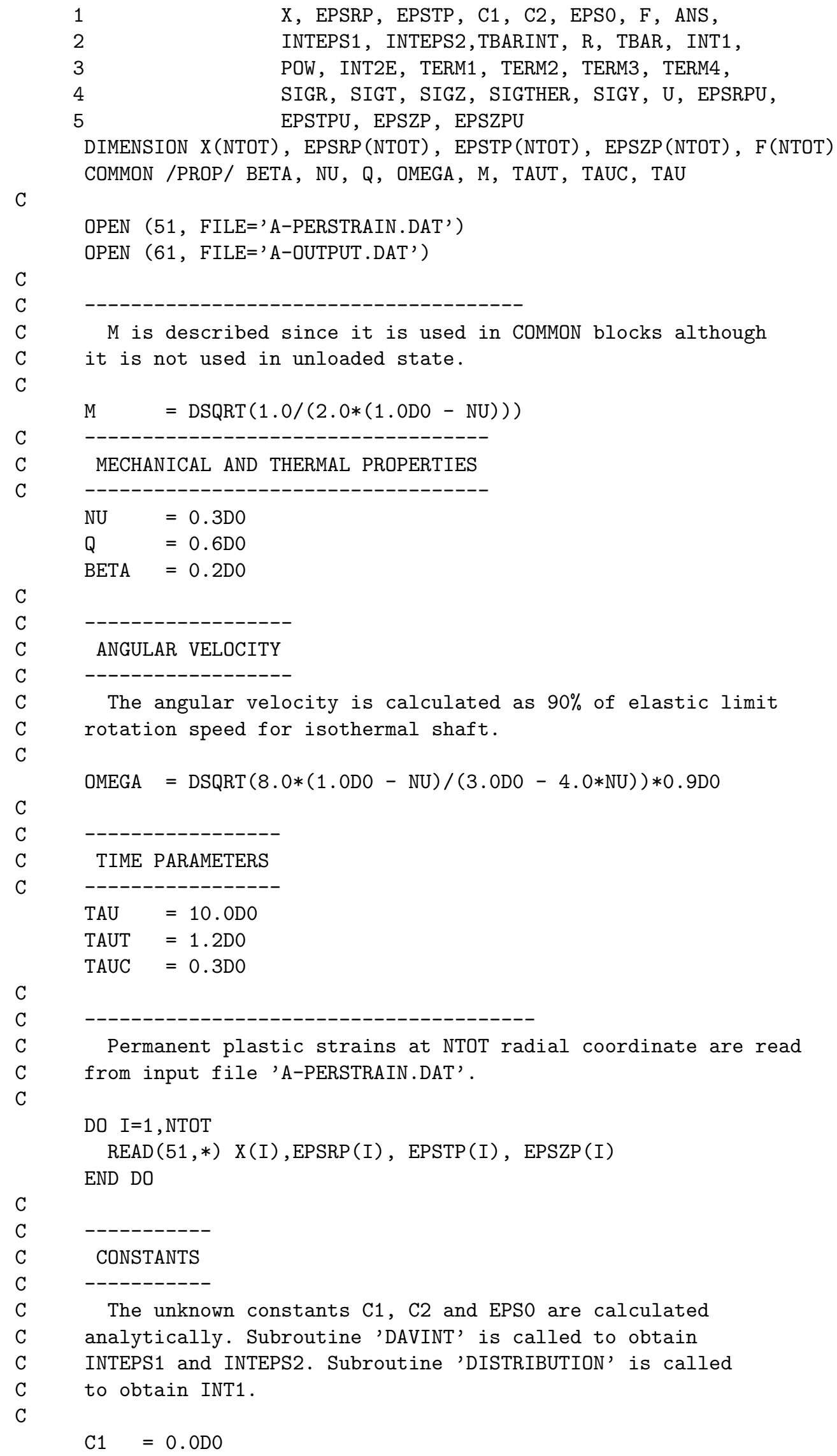


C

$\mathrm{F}=(\mathrm{EPSRP}-\mathrm{EPSTP}) / \mathrm{X}$

CALL DAVINT ( $\mathrm{X}, \mathrm{F}, \mathrm{NTOT}, \mathrm{X}(1), \mathrm{X}$ (NTOT), ANS, IER)

INTEPS1 $=$ ANS

C

$\mathrm{F} \quad=\mathrm{X} *(\mathrm{EPSRP}+\mathrm{EPSTP})$

CALL DAVINT (X, F, NTOT, $X(1), X(N T O T)$, ANS, IER)

INTEPS2 $=$ ANS

C

CALL DISTRIBUTION (X (NTOT), TBAR, X(NTOT), INT1, POW, INT2E) TBARINT $=$ INT1

C

$\mathrm{C} 2=(3.0 \mathrm{DO}-5.0 * \mathrm{NU}) * \mathrm{OMEGA} * * 2 /(16.0 *(1.0 \mathrm{DO}-\mathrm{NU} * * 2))$

$1-(1.0 \mathrm{DO}-2.0 * \mathrm{NU}) /(2.0 *(1.0 \mathrm{DO}-\mathrm{NU})) *$ INTEPS1

$2+($ INTEPS2 $/(2.0 \mathrm{DO}-2.0 * \mathrm{NU}))$

$3+\mathrm{Q} *(1.0 \mathrm{DO}-3.0 * \mathrm{NU}) /(1.0 \mathrm{DO}-\mathrm{NU}) *$ TBARINT

C

EPSO $=-\mathrm{NU} *$ OMEGA $* * 2 /(4.0 *(1.0 \mathrm{DO}+\mathrm{NU}))$

$1-2.0 *($ INTEPS2) $+2.0 * \mathrm{Q} * \mathrm{TBARINT}$

C

C

C

C

C

Input parameters and calculated unknowns are written to the output file 'A-OUTPUT.DAT'.

$\operatorname{WRITE}(61, *)$

$\operatorname{WRITE}(61, *)$ 'UNLOADING STAGE'

$\operatorname{WRITE}(61, *)$

$\operatorname{WRITE}(61, *)$, DATA :'

WRITE $(61, *)$

$\operatorname{WRITE}(61, *), \quad \mathrm{NU}$

$\operatorname{WRITE}(61, *), \mathrm{q}$

$\operatorname{WRITE}(61, *)$, $\quad$ BETA

$=, \mathrm{NU}$

$\operatorname{WRITE}(61, *) \quad, \quad$ OMEGA

$=$, , $Q$

$\operatorname{WRITE}(61, *), \quad$ TAU

$=$, BETA

$=$, , OMEGA

$\operatorname{WRITE}(61, *), \quad$ TAUT

$=$, , TAU

$\operatorname{WRITE}(61, *), \quad$ TAUC

$=$, , TAUT

$\operatorname{WRITE}(61, *)$

$\operatorname{WRITE}(61, *), \quad$ CONSTANTS : '

$\operatorname{WRITE}(61, *)$

$\operatorname{WRITE}(61, *), \mathrm{C} 1 \quad=, \mathrm{C} 1$

$\operatorname{WRITE}(61, *), \mathrm{C} 2=, \mathrm{C} 2$

$\operatorname{WRITE}(61, *), \operatorname{EPSO} \quad=, \operatorname{EPSO}$

$\operatorname{WRITE}(61, *)$

$\operatorname{WRITE}(61,99)$

A loop is generated to compute the response variables.

For the radial coordinates from $R=0$ to $R=1$, INTEPS 1 and INTEPS 2 are obtained by calling subroutine 'DAVINT', TBARINT is computed by using subroutine 'DISTRIBUTION' in NTOT data points. Limiting case for these integrals are described when $R$ approaches to 0 . Lastly, the response variables are calculated at NTOT data points and written into the output file. 
C

DO $I=1$, NTOT

$\mathrm{R}=\mathrm{X}(\mathrm{I})$

$\operatorname{EPSRPU}=\operatorname{EPSRP}(I)$

$\operatorname{EPSTPU}=\operatorname{EPSTP}(I)$

$\operatorname{EPSZPU}=\operatorname{EPSZP}(I)$

C

$\mathrm{F}=(\mathrm{EPSRP}-\mathrm{EPSTP}) / \mathrm{X}$

CALL DAVINT ( $X, F$, NTOT, $X(1), R$, ANS, IER)

INTEPS1 $=$ ANS

C

$\mathrm{F} \quad=\mathrm{X} *(\mathrm{EPSRP}+\mathrm{EPSTP})$

CALL DAVINT ( $X, F$, NTOT, $X(1), R$, ANS, IER)

INTEPS2 $=$ ANS

C

CALL DISTRIBUTION ( $R$, TBAR, $R$, INT1, POW, INT2E)

TBARINT $=$ INT1

C

IF (R.EQ.X(1)) THEN

TERM2 $=(\operatorname{EPSRP}(1)+\operatorname{EPSTP}(1)) / 2.0$

TERM1 $=0.0 \mathrm{DO}$

TERM3 $=0.0 \mathrm{DO}$

TERM4 $=\mathrm{TBAR} / 2$

ELSE

TERM2 $=$ INTEPS2 $/ \mathrm{R} * * 2$

TERM1 $=$ INTEPS2 $/ R$

TERM3 $=$ TBARINT $/ \mathrm{R}$

TERM4 $=1.0 / \mathrm{R} * * 2 *$ TBARINT

END IF

C

$\mathrm{SIGR}=2.0 * \mathrm{C} 2 /(1.0 \mathrm{DO}-2.0 * \mathrm{NU})$

$\mathrm{SIGT}=2.0 * \mathrm{C} 2 /(1.0 \mathrm{DO}-2.0 * \mathrm{NU})$

$+2.0 * \mathrm{NU} * \mathrm{EPSO} /(1.0 \mathrm{DO}-2.0 * \mathrm{NU})-1.0 /(8.0 *(1.0 \mathrm{DO}-\mathrm{NU}))$

$*((3.0 \mathrm{DO}-2.0 * \mathrm{NU}) * \mathrm{OMEGA} * * 2 * \mathrm{R} * * 2$

- 8.0*(INTEPS1 - (1.0DO - 2.0*NU)*TERM2)

$+16.0 * \mathrm{Q} *(1.0 \mathrm{DO}+\mathrm{NU}) * \mathrm{TERM} 4)$

$+2.0 * \mathrm{NU} * \mathrm{EPSO} /(1.0 \mathrm{DO}-2.0 * \mathrm{NU})-1.0 /(8.0 *(1.0 \mathrm{DO}-\mathrm{NU}))$

$*((1.0 \mathrm{DO}+2.0 * \mathrm{NU}) * \mathrm{OMEGA} * * 2 * \mathrm{R} * * 2$

$+8.0 \mathrm{D} 0 *(-2.0 * \mathrm{NU} * \mathrm{EPSRPU}+2.0 *(1.0 \mathrm{DO}-\mathrm{NU}) * \mathrm{EPSTPU}$

- INTEPS1 - (1.0DO - 2.0*NU)*TERM2)

$+16.0 * \mathrm{Q} *(1.0 \mathrm{DO}+\mathrm{NU}) *($ TBAR - TERM4 $))$

C

$\mathrm{SIGZ}=4.0 * \mathrm{C} 2 * \mathrm{NU} /(1.0 \mathrm{DO}-2.0 * \mathrm{NU})+2.0 *(1.0 \mathrm{DO}-\mathrm{NU}) * \mathrm{EPSO}$ $/(1.0 \mathrm{DO}-2.0 * \mathrm{NU})-1.0 /(2.0 *(1.0 \mathrm{DO}-\mathrm{NU}))$

$*(\mathrm{NU} * \mathrm{OMEGA} * * 2 * \mathrm{R} * * 2+4.0 * \mathrm{Q} *(1.0 \mathrm{DO}+\mathrm{NU}) * \mathrm{TBAR})$

$+2.0 /(1.0 \mathrm{DO}-\mathrm{NU}) *(\mathrm{EPSRPU}+(1.0 \mathrm{DO}-\mathrm{NU}) * \mathrm{EPSTPU}$

+ NU*INTEPS1)

C

$\mathrm{U}=\mathrm{C} 2 * \mathrm{R}-(1.0 \mathrm{D} 0-2.0 * \mathrm{NU}) * \mathrm{OMEGA} * * 2 * \mathrm{R} * * 3$

$/(16.0 *(1.0 \mathrm{DO}-\mathrm{NU}))+(1.0 \mathrm{DO}-2.0 * \mathrm{NU})$

$/(2.0 *(1.0 \mathrm{DO}-\mathrm{NU})) *(\mathrm{R} *$ INTEPS $1+$ TERM 1$)$

$+\mathrm{Q} *(1.0 \mathrm{DO}+\mathrm{NU}) /(1.0 \mathrm{DO}-\mathrm{NU}) *$ TERM 3

C

SIGTHER $=(1-$ BETA $*$ TBAR $)$ 
C

SIGY = DMAX1 (DABS (SIGR-SIGT), DABS (SIGR-SIGZ),

DABS (SIGT-SIGZ))

1

WRITE $(61,100)$ R, SIGR, SIGT, SIGZ, SIGY/SIGTHER, U, EPSRPU,

END DO

EPSTPU, EPSZPU

C

100 FORMAT (10 (1X,F12.8))

99 FORMAT(3X, 'R' , 12X, 'SIGR', 9X , 'SIGT' , 9X , 'SIGZ', 8X , 'SIGY/SIGTHER' , 1 $2 \mathrm{X}$, ' U', $12 \mathrm{X}$, 'EPSR', $9 \mathrm{X}$, 'EPST', $9 \mathrm{X}$, 'EPSZ')

STOP

END

\section{D.2 DATA FILE: PERMANENT PLASTIC STRAINS}

Table D.1: Permanent plastic strains at $\tau \geq 1.7882$

\begin{tabular}{|r|r|r|r|r|r|r|r|}
\hline $\mathrm{R}$ & EPSRP & EPSTP & EPSZP & $\mathrm{R}$ & EPSRP & EPSTP & EPSZP \\
\hline $1 \mathrm{E}-07$ & 0.01894 & 0.01894 & -0.0379 & 0.23584 & 0 & 0.02226 & -0.0223 \\
\hline 0.00235 & 0.01894 & 0.01894 & -0.0379 & 0.23926 & 0 & 0.02209 & -0.0221 \\
\hline 0.0047 & 0.01893 & 0.01894 & -0.0379 & 0.24268 & 0 & 0.02191 & -0.0219 \\
\hline 0.00704 & 0.01892 & 0.01894 & -0.0379 & 0.24609 & 0 & 0.02174 & -0.0217 \\
\hline 0.00939 & 0.01891 & 0.01894 & -0.0378 & 0.24951 & 0 & 0.02156 & -0.0216 \\
\hline 0.01174 & 0.01889 & 0.01895 & -0.0378 & 0.25293 & 0 & 0.02138 & -0.0214 \\
\hline 0.01409 & 0.01887 & 0.01895 & -0.0378 & 0.25634 & 0 & 0.0212 & -0.0212 \\
\hline 0.01643 & 0.01884 & 0.01895 & -0.0378 & 0.25976 & 0 & 0.02102 & -0.021 \\
\hline 0.01878 & 0.01881 & 0.01896 & -0.0378 & 0.26318 & 0 & 0.02084 & -0.0208 \\
\hline 0.02113 & 0.01878 & 0.01897 & -0.0377 & 0.26659 & 0 & 0.02066 & -0.0207 \\
\hline 0.02348 & 0.01874 & 0.01897 & -0.0377 & 0.27001 & 0 & 0.02048 & -0.0205 \\
\hline 0.02583 & 0.0187 & 0.01898 & -0.0377 & 0.27342 & 0 & 0.0203 & -0.0203 \\
\hline 0.02817 & 0.01866 & 0.01899 & -0.0376 & 0.27684 & 0 & 0.02012 & -0.0201 \\
\hline 0.03052 & 0.01861 & 0.019 & -0.0376 & 0.28026 & 0 & 0.01993 & -0.0199 \\
\hline 0.03287 & 0.01856 & 0.01901 & -0.0376 & 0.28367 & 0 & 0.01975 & -0.0197 \\
\hline 0.03522 & 0.0185 & 0.01902 & -0.0375 & 0.28709 & 0 & 0.01956 & -0.0196 \\
\hline 0.03756 & 0.01844 & 0.01903 & -0.0375 & 0.29051 & 0 & 0.01938 & -0.0194 \\
\hline 0.03991 & 0.01838 & 0.01904 & -0.0374 & 0.29392 & 0 & 0.01919 & -0.0192 \\
\hline 0.04226 & 0.01831 & 0.01905 & -0.0374 & 0.29734 & 0 & 0.01901 & -0.019 \\
\hline 0.04461 & 0.01824 & 0.01907 & -0.0373 & 0.30076 & 0 & 0.01882 & -0.0188 \\
\hline 0.04696 & 0.01817 & 0.01908 & -0.0372 & 0.30417 & 0 & 0.01863 & -0.0186 \\
\hline 0.0493 & 0.01809 & 0.01909 & -0.0372 & 0.30759 & 0 & 0.01844 & -0.0184 \\
\hline 0.05165 & 0.01801 & 0.01911 & -0.0371 & 0.311 & 0 & 0.01825 & -0.0182 \\
\hline 0.054 & 0.01792 & 0.01913 & -0.037 & 0.31442 & 0 & 0.01805 & -0.0181 \\
\hline 0.05635 & 0.01783 & 0.01914 & -0.037 & 0.31784 & 0 & 0.01786 & -0.0179 \\
\hline 0.05869 & 0.01773 & 0.01916 & -0.0369 & 0.32125 & 0 & 0.01767 & -0.0177 \\
\hline & & & & & & & \\
\hline
\end{tabular}


Table D.1 (cont'd)

\begin{tabular}{|c|c|c|c|c|c|c|c|}
\hline $\mathrm{R}$ & EPSRP & EPSTP & EPSZP & $\mathrm{R}$ & EPSRP & EPSTP & EPSZP \\
\hline 0.06104 & 0.01764 & 0.01918 & -0.0368 & 0.32467 & 0 & 0.01747 & -0.0175 \\
\hline 0.06339 & .01753 & 0.0192 & -0.0367 & 0.32809 & 0 & 0.01728 & 0.0173 \\
\hline 0.06574 & 0.01743 & 0.01922 & -0.0366 & 0.3315 & 0 & 0.01708 & -0.0171 \\
\hline 0.06809 & 0.01732 & 0.01924 & -0.0366 & 0.33492 & 0 & 0.01688 & -0.0169 \\
\hline 0.07043 & 0.0172 & 0.01926 & -0.0365 & 0.33834 & 0 & 0.01668 & -0.0167 \\
\hline 0.07278 & 0.01709 & 0.01928 & -0.0364 & 0.34175 & 0 & 0.01648 & -0.0165 \\
\hline 0.07513 & 0.01697 & 0.0193 & -0.0363 & 0.34517 & 0 & 0.01628 & -0.0163 \\
\hline 0.07748 & 0.01684 & 0.01932 & -0.0362 & 0.34858 & 0 & 0.01607 & -0.0161 \\
\hline 0.07982 & 0.01671 & .01935 & -0.0361 & 0.352 & 0 & 0.01587 & -0.0159 \\
\hline 0.08217 & 0.01658 & 0.01937 & -0.036 & 0.35542 & 0 & 0.01567 & -0.0157 \\
\hline 0.08452 & 0.01644 & 0 & -0.0358 & 35883 & 0 & 0.01546 & -0.0155 \\
\hline 0.08687 & 63 & 0.0 & -0.0357 & 36225 & 0 & 25 & -0.0153 \\
\hline 9922 & 1616 & 45 & -0.0 & 36567 & 0 & 04 & -0.015 \\
\hline 0.09156 & 501 & 0 & -0.0355 & 0.36908 & 0 & 83 & .0148 \\
\hline 0.09391 & 586 & 1 & -0.0354 & 0.3725 & 0 & 462 & 0.0146 \\
\hline 0.09626 & 0157 & 0.01954 & -0.0352 & .37592 & 0 & 0.01441 & -0.0144 \\
\hline 0.09861 & 0.01554 & 0.01956 & -0.0351 & 37933 & 0 & 01419 & -0.0142 \\
\hline 0.10095 & 0.01538 & 0.01959 & -0.035 & 0.38275 & 0 & 0.01398 & -0.014 \\
\hline 0.1033 & 0.01521 & 0.01963 & -0.0348 & 0.38616 & 0 & 0.01376 & -0.0138 \\
\hline 0.10565 & 0.01504 & 0.01966 & -0.0347 & 0.38958 & 0 & 0.01355 & -0.0135 \\
\hline 0.108 & 0.01486 & 69 & -0.0346 & 0.393 & 0 & 0.01333 & -0.0133 \\
\hline 0.11034 & 68 & & -0.0 & 39641 & 0 & 0.0 & -0.0131 \\
\hline 0.11269 & 45 & 76 & -0.0343 & .39983 & 0 & 0.0 & -0.0129 \\
\hline 0.11504 & 431 & 79 & -0.0341 & .40325 & 0 & 0.0 & -0.0127 \\
\hline 739 & 12 & 33 & -0.0339 & 0.40666 & 0 & 0.0 & -0.0124 \\
\hline 974 & 93 & 0.0 & -0.0338 & 08 & 0 & & -0.0122 \\
\hline 0.12208 & 73 & 99 & -0.0336 & 41349 & 0 & 0.0 & -0.012 \\
\hline 0.12443 & 352 & 94 & -0.0335 & 41691 & 0 & 176 & -0.0118 \\
\hline 0.12678 & 332 & 998 & -0.0333 & 42033 & 0 & 0.01153 & -0.0115 \\
\hline 0.12913 & 0.01311 & 0.02001 & -0.0331 & 42374 & 0 & 0.0113 & -0.0113 \\
\hline 0.13147 & 0.01289 & 0.02005 & -0.0329 & 0.42716 & 0 & 0.01107 & -0.0111 \\
\hline 0.13382 & 0.01268 & 0.02009 & -0.0328 & 0.43058 & 0 & 0.01083 & -0.0108 \\
\hline 0.13617 & 0.01245 & 0.02014 & -0.0326 & 0.43399 & 0 & 0.0106 & -0.0106 \\
\hline 0.13852 & 0.01223 & 02018 & -0.0324 & 0.43741 & 0 & 0.01036 & -0.0104 \\
\hline 0.14087 & 012 & 2022 & -0.0322 & 44083 & 0 & 0.01012 & 0.0101 \\
\hline 0.14321 & 1176 & 26 & 032 & 44424 & 0 & 88 & -0.0099 \\
\hline 0.14556 & 0.01153 & 0.02031 & -0.0318 & 0.44766 & 0 & 0.00964 & -0.0096 \\
\hline 791 & & 0.0 & & & 0 & 094 & -0.0094 \\
\hline 0.15026 & & & & 0.45449 & 0 & & -0.0092 \\
\hline 0.1526 & 0.0 & 0.02044 & -0.0312 & 0.45791 & 0 & 91 & -0.0089 \\
\hline 0.15495 & 0.01054 & 0.02049 & -0.031 & 0.46132 & 0 & 0.00867 & -0.0087 \\
\hline 0.1573 & 0.01028 & 0.0 & -0.0308 & 0.46474 & 0 & 0.00842 & -0.0084 \\
\hline 0.15965 & 0.01002 & 0.02059 & -0.0306 & 0.46816 & 0 & 0.00817 & -0.0082 \\
\hline 162 & 976 & 2063 & -0.0304 & 0.47157 & 0 & 0.00792 & -0.0079 \\
\hline 0.16434 & & & -0.0302 & 0.47499 & 0 & 0.00767 & -0.0077 \\
\hline 0.16669 & 0.00922 & 0.02073 & -0.0299 & 0.47841 & 0 & 0.00741 & -0.0074 \\
\hline
\end{tabular}


Table D.1 (cont'd)

\begin{tabular}{|r|r|r|r|r|r|r|r|}
\hline $\mathrm{R}$ & EPSRP & EPSTP & EPSZP & $\mathrm{R}$ & EPSRP & EPSTP & EPSZP \\
\hline 0.16904 & 0.00894 & 0.02079 & -0.0297 & 0.48182 & 0 & 0.00716 & -0.0072 \\
\hline 0.17139 & 0.00866 & 0.02084 & -0.0295 & 0.48524 & 0 & 0.0069 & -0.0069 \\
\hline 0.17373 & 0.00837 & 0.02089 & -0.0293 & 0.48865 & 0 & 0.00664 & -0.0066 \\
\hline 0.17608 & 0.00809 & 0.02094 & -0.029 & 0.49207 & 0 & 0.00639 & -0.0064 \\
\hline 0.17843 & 0.00779 & 0.021 & -0.0288 & 0.49549 & 0 & 0.00612 & -0.0061 \\
\hline 0.18078 & 0.0075 & 0.02105 & -0.0286 & 0.4989 & 0 & 0.00586 & -0.0059 \\
\hline 0.18313 & 0.0072 & 0.02111 & -0.0283 & 0.50232 & 0 & 0.0056 & -0.0056 \\
\hline 0.18547 & 0.0069 & 0.02116 & -0.0281 & 0.50574 & 0 & 0.00533 & -0.0053 \\
\hline 0.18782 & 0.00659 & 0.02122 & -0.0278 & 0.50915 & 0 & 0.00507 & -0.0051 \\
\hline 0.19017 & 0.00628 & 0.02128 & -0.0276 & 0.51257 & 0 & 0.0048 & -0.0048 \\
\hline 0.19252 & 0.00596 & 0.02134 & -0.0273 & 0.51599 & 0 & 0.00453 & -0.0045 \\
\hline 0.19486 & 0.00564 & 0.0214 & -0.027 & 0.5194 & 0 & 0.00426 & -0.0043 \\
\hline 0.19721 & 0.00532 & 0.02146 & -0.0268 & 0.52282 & 0 & 0.00398 & -0.004 \\
\hline 0.19956 & 0.00499 & 0.02152 & -0.0265 & 0.52623 & 0 & 0.00371 & -0.0037 \\
\hline 0.20191 & 0.00466 & 0.02158 & -0.0262 & 0.52965 & 0 & 0.00343 & -0.0034 \\
\hline 0.20426 & 0.00433 & 0.02164 & -0.026 & 0.53307 & 0 & 0.00316 & -0.0032 \\
\hline 0.2066 & 0.00399 & 0.0217 & -0.0257 & 0.53648 & 0 & 0.00288 & -0.0029 \\
\hline 0.20895 & 0.00364 & 0.02177 & -0.0254 & 0.5399 & 0 & 0.0026 & -0.0026 \\
\hline 0.2113 & 0.0033 & 0.02183 & -0.0251 & 0.54332 & 0 & 0.00231 & -0.0023 \\
\hline 0.21365 & 0.00295 & 0.02189 & -0.0248 & 0.54673 & 0 & 0.00203 & -0.002 \\
\hline 0.21599 & 0.00259 & 0.02196 & -0.0246 & 0.55015 & 0 & 0.00174 & -0.0017 \\
\hline 0.21834 & 0.00223 & 0.02203 & -0.0243 & 0.55357 & 0 & 0.00146 & -0.0015 \\
\hline 0.22069 & 0.00187 & 0.02209 & -0.024 & 0.55698 & 0 & 0.00117 & -0.0012 \\
\hline 0.22304 & 0.0015 & 0.02216 & -0.0237 & 0.5604 & 0 & 0.00088 & -0.0009 \\
\hline 0.22539 & 0.00113 & 0.02223 & -0.0234 & 0.56381 & 0 & 0.00059 & -0.0006 \\
\hline 0.22773 & 0.00076 & 0.0223 & -0.0231 & 0.56723 & 0 & 0.00029 & -0.0003 \\
\hline 0.23008 & 0.00038 & 0.02237 & -0.0228 & 0.57065 & 0 & 0 & 0 \\
\hline 0.23243 & 0 & 0.02244 & -0.0224 & 1 & 0 & 0 & 0 \\
\hline
\end{tabular}




\section{CURRICULUM VITAE}

\section{PERSONEL INFORMATION}

$\begin{array}{ll}\text { Surname, Name } & \text { : Arslan, Eray } \\ \text { Nationality } & \text { : Turkish (TC) } \\ \text { Date and Place of Birth } & : \text { 1 July 1981, Adana } \\ \text { Marital Status } & \text { : Single } \\ \text { Email } & \text { : erarslan@metu.edu.tr }\end{array}$

\section{EDUCATION}

$\begin{array}{lll}\text { Degree } & \text { Institution } & \text { Year of Graduation } \\ \text { BS } & \text { Çukurova University Mechanical Eng. } & 2003 \\ \text { High School } & \text { Halide Edip Lisesi, Ankara } & 1998\end{array}$

\section{WORK EXPERIENCE}

$\begin{array}{ll}\text { Year } & \text { Place } \\ \text { 2004-Present } & \text { METU Department of Engineering Sciences }\end{array}$

\section{Enrollment}

Research Assistant

\section{FOREIGN LANGUAGES}

Advanced English, Basic German

\section{PUBLICATIONS}

1) Arslan E., Mack W., Eraslan, A.N.: The rotating elastic-plastic hollow shaft conveying a hot medium. Forschung im Ingenieurwesen / Engineering Research. (to appear).

2) Arslan E., Eraslan, A.N.: Analytical solution to the bending of a nonlinearly hardening wide curved bar. Acta Mechanica 210, 71-84 (2010).

3) Eraslan, A.N., Arslan E.: A Computational Study on the Nonlinear Hardening Curved Beam Problem. International Journal of Pure and Applied Mathematics 43, 129-143 (2008).

4) Eraslan, A.N., Arslan E.: A Concise Analytical Treatment of Elastic-plastic Bending of a Strain Hardening Curved Beam. Zeitschrift für Angewandte Mathematik und Mechanik (ZAMM) 88 No. 8, 600-616 (2008).

5) Arslan E., Mack W., Eraslan, A.N.: Effect of a temperature cycle on a rotating elasticplastic shaft. Acta Mechanica 195, 129-140 (2008). 
6) Eraslan, A.N., Arslan E.: Plane Strain Analytical Solutions to Rotating Partially Plastic Graded Hollow Shafts. Turkish Journal of Engineering and Environmental Sciences 31, 273-288 (2007).

7) Eraslan, A.N., Arslan E., Mack W.: The strain hardening rotating hollow shaft subject to positive temperature gradient. Acta Mechanica 194, 191-211 (2007).

\section{INTERNATIONAL CONFERENCE PROCEEDINGS}

1) Arslan, E., Mack, W., Eraslan, A. N., "The rotating elastic-plastic hollow shaft heated at its inner surface", 80th Annual Meeting of the International Association of Applied Mathematics and Mechanics (GAMM), Gdansk, Poland, 4-9 February 2009.

2) Arslan, E., Mack, W., Eraslan, A. N., "Transient heating of a rotating elastic-plastic solid shaft", 79th Annual Meeting of the International Association of Applied Mathematics and Mechanics (GAMM), Bremen, Germany, 31 March- 4 April 2008, (PAMM · Proc. Appl. Math. Mech. 8, 10257 - 10258 (2008) / DOI 10.1002 / pamm.200810257).

3) Arslan, E., Eraslan, A. N., Mack, W. "Elastic-plastic states of a rotating inhomogeneously heated strain hardening hollow shaft", 6th International Congress on Industrial and Applied Mathematics GA/CT1952/004, Zurich, Switzerland, 16-20 July 2007, (PAMM Proc. Appl. Math. Mech. 7, 4040051 - 4040052 (2007) / DOI 10.1002 / pamm.200701082)

4) Eraslan, A. N., Arslan, E., "Numerical Solution of Partially Plastic Curved Beam Problem", III European Conference on Computational Mechanics Solids, Structures and Coupled Problems in Engineering, Lisbon, Portugal, 5-8 June 2006, proceeding no: 1232.

\section{NATIONAL CONFERENCE PROCEEDINGS}

1) Arslan E., Eraslan, A. N. "Doğrusal Olmayan Pekleşme Davranışı Gösteren Eğri Eksenli Kirişin Basit Eğilme Altında Analitik Çözümü: Kısmen Plastik ve Artık Gerilme Halleri", 16. Ulusal Mekanik Kongresi, Kayseri, Nisan 2009.

2) Arslan E., Eraslan, A. N. "Kısmen Plastik Eğri Eksenli Kiriş Probleminin Basit Eğilme için Analitik Çözümü", 15. Ulusal Mekanik Kongresi, Isparta, Eylül 2007, pp. 117-124.

3) Eraslan, A. N., Arslan E. "Fonksiyonel Derecelendirilmiş Dönen Milin Elastoplastik Analitik Çözümü", 14. Ulusal Mekanik Kongresi, Antakya, Eylül 2005, pp. 389-395. 